UNIVERSIDAD NACIONAL DE LA PLATA

Facultad de Ciencias Naturales y Museo
M A C N

CON I C E

\title{
El Pérmico de la Cuenca La Golondrina: paleobotánica, bioestratigrafía y consideraciones paleoecológicas.
}

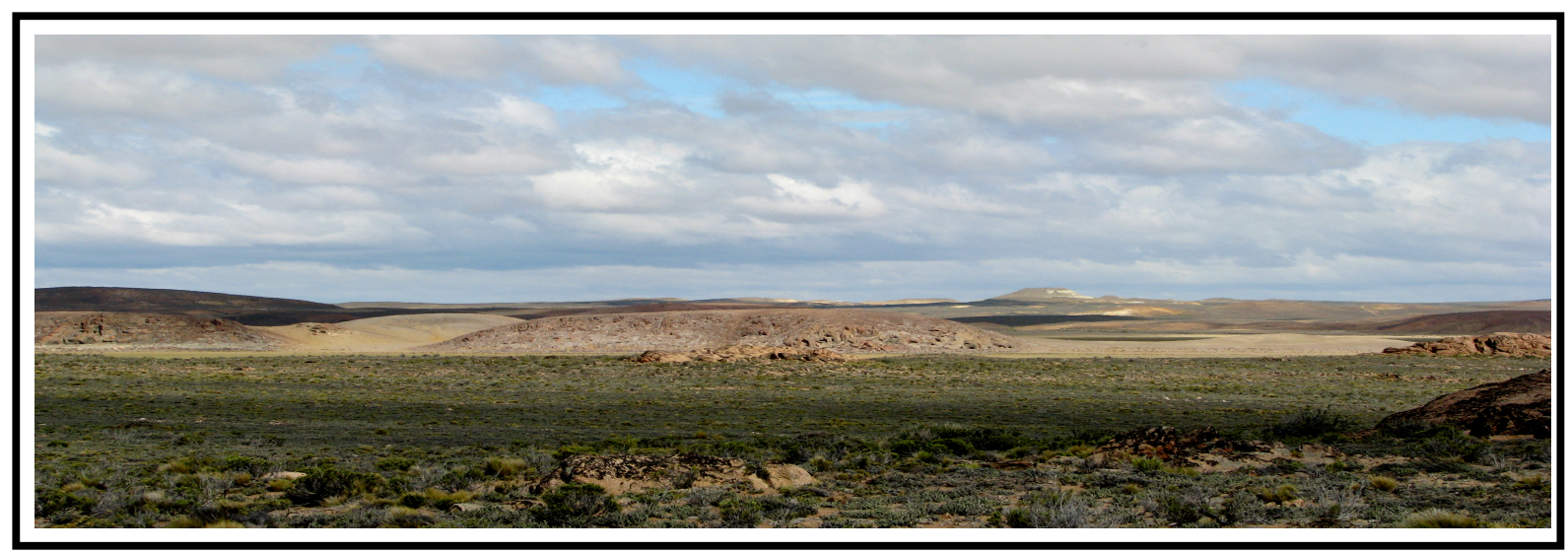

Tesis presentada para optar al título de Doctor en Ciencias Naturales otorgado por la Facultad de Ciencias Naturales y Museo, U.N.L.P.

Licenciada Bárbara Cariglino

Director: Dr. Pedro R. Gutiérrez

Co-director: Dr. Marcelo Manassero

La Plata - 2011 


\section{AGRADECIMIENTOS}

Esta etapa que culmina pudo realizarse gracias al apoyo de muchísima gente que me rodeó a lo largo de todos estos años. Es por ello que quiero expresar mi profundo agradecimiento:

A mi director de tesis, Dr. Pedro R. Gutiérrez, por creer y confiar en mí, dándome la oportunidad de pertenecer a su grupo de trabajo. Por acompañarme y apoyarme a lo largo de toda la tesis, y siempre responder pacientemente a cada una de mis dudas.

A mi codirector de tesis, Dr. Marcelo Manassero, por su ayuda en el campo y laboratorio, y su contínuo apoyo y presencia para evacuar cada interrogante planteado.

A los integrantes del jurado de esta tesis, Dr. S. Archangelsky, Dr. R. Herbst, y Dr. E. Morel, por las correcciones y sugerencias que mejoraron el manuscrito final de esta tesis.

Al Dr. Sergio Archangelsky por su constante buena predisposición, brindándome su tiempo para interesantes discusiones, y ayudándome con la bibliografía de difícil acceso.

A mis amigos y compañeros de laboratorio, Lucía Balarino, Gustavo Correa, y Eliana Coturel, por la ayuda en el campo y laboratorio, por las prolíficas discusiones, y los buenos momentos que hacen del día a día en el gabinete tan llevadero.

A los curadores H. Carrizo y E. Fernández (Instituto Miguel Lillo), L. Lezama (MACN), R. Melchor (UNLPam), M. Tánuz (FCEyN, UBA), y A. Zuñiga (Museo de La Plata), por permitir el acceso a las colecciones a su cargo.

A los técnicos del MACN, M. Iberlucea y F. Tricárico, por su desinteresada ayuda en la confección de moldes sintéticos de material y fotografiado en el microscopio electrónico de barrido respectivamente.

A la Sra. Mariel Fjell, los cuidadores de su campo, Félix y Pablo, y la Sra. Beatriz San Juan por permitir el acceso a las Ea. La Golondrina y Ea. Leonardo respectivamente.

A toda mi amada familia, especialmente mi madre y padre, quienes desde muy pequeña me fomentaron mi pasión por la paleontología, y me dieron incondicionalmente todo el apoyo necesario para hacer de mi sueño una meta. No puedo dejar de mencionar las 
tartas hechas por mi madre, que me alimentaron incesantemente a lo largo de estos 4 años de estudio! :)

A Cecilia por estar siempre a mi lado, acompañándome.

A mis amigas de siempre, Ale, Car, Chechu, Chí, Lau, Leco, y Maia, quienes estuvieron y siguen estando en las buenas y las malas.

A mis amigas y colegas: Josefina Bodnar, Ana Carignano, Lydia Calvo Marcilese, Florencia Gordón, Natalia Mego, y Juliana Sterli, quienes me acompañaron todo a lo largo de mis estudios, y lo siguen haciendo el día de hoy compartiendo consejos y buenos momentos juntas.

A todos mis compañeros y amigos durante mis años en la UNLP, PSU, y MACN, años en los cuales aprendí no solamente acerca de esta profesión, sino también acerca de la vida y amistad.

A la Negra, Fernanda Franco, porque sé que nunca te fuiste, siempre estás.

La asistencia económica fue brindada por la Agencia de Promoción Científica y Tecnológica de Argentina (PICT 32693/05), y el Consejo Nacional de Investigaciones Científicas y Técnicas (CONICET-PIP 2007-5723, 2009-0705). Este estudio fue llevado a cabo en el Museo Argentino de Ciencias Naturales "Bernardino Rivadavia".

La música de Kevin Johansen + The Nada y la tira diaria de Liniers proveyeron de apoyo espiritual para el desarrollo de esta tesis.

A todos, y por todo, MUCHAS GRACIAS!!! 


\section{ÍNDICE}

AGRADECIMIENTOS $\quad$ i

RESUMEN $\quad$ V

ABSTRACT viii

1.0 - INTRODUCCIÓN

1.1 - Reseña histórica 1

1.2 - Marco Geológico 2

$\begin{array}{lr}1.3 \text { - Objetivos e hipótesis de trabajo } & 8\end{array}$

2.0 - MATERIALES Y MÉTODOS

2.1 - Análisis de nuevo material traído del campo 11

2.2 - Análisis y revisión de material de colección 11

2.3 - Cortes de muestras petrográficas. Muestreo y análisis bajo el microscopio 13

2.4 - Herramientas utilizadas 14

3.0 - ESTRATIGRAFÍA

3.1 - Antecedentes

3.2 - Prospección de la zona, relevamiento y descripción de perfiles de la Fm La

Golondrina. Colección de nuevo material 16

3.3 - Discusión general

4.0 - DESCRIPCIÓN SISTEMÁTICA

4.1 - Antecedentes

4.2 - Pteridophyta

4.3 - Sphenophyta

4.4 - Lycophyta

4.5 - Pteridospermophyta

4.6 - Gymnospermophyta

4.7 - Incertae Sedis

104 


\section{0 - BIOESTRATIGRAFÍA Y EDAD}

5.1 - Antecedentes 204

5.2 - Comparación bioestratigráfica con otras floras Pérmicas 206

5.3 - Distribución estratigráfica de las especies presentes en la Formación La $\begin{array}{ll}\text { Golondrina } & 212\end{array}$

5.4 - Potencial como indicadores bioestratigráficos de los géneros y especies presentes en la Formación La Golondrina 215

5.5 - Discusión general. Propuesta bioestratigráfica para la Formación La Golondrina. Edad para la Formación La Golondrina 225

5.6 - ¿Flora de Glossopteris, flora mixta, o flora de La Golondrina? 233

6.0 - PALEOECOLOGÍA e INFERENCIAS PALEOAMBIENTALES

6.1 - Antecedentes

6.2 - Análisis petrográfico de areniscas

6.3 - Inferencias paleoambientales

252

6.4 - Discusión general

7.0 - CONCLUSIONES

7.1 - Conclusiones generales 261

7.2 - Líneas de investigación

\section{ANEXOS}




\section{RESUMEN}

El presente estudio ("El Pérmico de la Cuenca La Golondrina: paleobotánica, bioestratigrafía y consideraciones paleoecológicas"), tiene como principal objetivo profundizar la comprensión de la megaflora fósil de la Formación La Golondrina, a través de la revisión sistemática de material, su correlación bioestratigráfica con otras floras provenientes de cuencas pérmicas de Argentina y del resto del Gondwana, y la interpretación de las condiciones paleoambientales en los cuales esta flora se habría desarrollado, aplicando por primera vez el análisis petrográfico a las areniscas de la Formación La Golondrina.

Para alcanzar dichos objetivos, se prospectaron las zonas del Bajo de La Leona y Estancia La Juanita, en el NE de la provincia de Santa Cruz, donde afloran sedimentos pérmicos de la Formación La Golondrina, y se levantaron perfiles sedimentológicos en las localidades de Laguna Lillo (miembro inferior y medio), Laguna Polina (miembro medio y superior), Laguna Castellanos (miembro medio), Laguna Feruglio (miembro medio y superior), y Laguna Turbia (miembro medio). Todo el material fósil colectado ( 1100 ejemplares) y las muestras de areniscas fueron estratigráficamente ubicadas. Estos perfiles fueron correlacionados con los perfiles de referencia de la unidad, ampliando las listas florísticas conocidas para cada uno de los miembros de la formación.

El estudio del material fósil de la Formación La Golondrina (tanto el aquí colectado como el depositado en las colecciones de paleobotánica de la Fundación M. Lillo (Tucumán), Museo de La Plata, Facultad de Ciencias Exactas y Naturales de la UBA y el Museo Argentino de Ciencias Naturales "B. Rivadavia”, permitió incrementar el número de taxones reconocidos para la flora de La Golondrina a un total de 65, destacándose como novedades: el hallazgo de fructificaciones de glossopterídeas referibles a los géneros Bifariala, Dictyopteridium, Gonophylloides, Plumsteadia, Ottokaria, Scutum, Senotheca, Lidgettonia y ?Arberia, con la propuesta de una nueva especie (Plumsteadia pedicellata) y una nueva combinación (Gonophylloides semnes); el hallazgo, por primera vez para el Gondwana, de Lilpopia sp. (fructificación de esfenófita); la presencia de 3 nuevas especies 
(referidas al género Asterotheca) entre los helechos; el hallazgo novedoso para La Golondrina de tallos referidos a Caulopteris sp.; la descripción de una nueva especie de licófita (Cyclodendron golondrinensis) y la propuesta de una nueva combinación (Bumbudendron patagonicum); el primer hallazgo de coniferofitas en la flora de La Golondrina; y el primer hallazgo de flora fósil en sedimentitas referibles al miembro inferior (Laguna Lillo) de la Formación La Golondrina.

La comparación del contenido paleoflorístico de la Formación La Golondrina con el de otras floras de edad pérmica de Argentina, Sudamérica y del resto del Gondwana, permitió sugerir para la unidad una edad Cisuraliana tardía-Lopingiana. Sobre la base de la distribución de integrantes de la flora de la Formación La Golondrina se propone modificar el esquema bioestratigráfico de la Cuenca. Dicho esquema informal incluye, de base a techo a las: Biozona 1, reconocida por el predomino de Gangamopteris por sobre Glossopteris, la aparición de Megistophyllum leanzai Archangelsky, y la presencia de helechos pecopterídeos de pínnulas pequeñas (ej., Asterotheca sp. 3), caracteriza al miembro inferior (Laguna Lillo); Biozona 2 (equivalente a la biozona de Dizeugotheca waltonii Archangelsky y de La Sota), reconocida por la presencia exclusiva de Annularia kurtzii Archangelsky, Dichotomopteris hirundinis Archangelsky y de La Sota, D. ovata Maithy, Glossopteris stricta Bunbury, y Eremopteris golondrinensis Archangelsky, por la aparición de Dizeugotheca waltonii, por la abundancia de las fructificaciones de glossopterídeas y por el reemplazo de las especies de Gangamopteris por las de Glossopteris, y que caracteriza al miembro medio (Laguna Polina); Biozona 3 (equivalente a la biozona de Asterotheca singeri Archangelsky), reconocida por un claro empobrecimiento de la flora (respecto a la Biozona 2), por la presencia dominante de Glossopteris damudica Feistmantel, G. retifera Feistmantel y Asterotheca golondrinensis Herbst, la ausencia de Gangamopteris spp. y de Asterotheca anderssonii Archangelsky y de La Sota, que se halla documentada en el miembro superior (Dos Hermanos) de la unidad.

El estudio petrográfico de las areniscas de los diferentes miembros de la Formación La Golondrina realizado para analizar la procedencia de sus componentes permitió inferir las condiciones ambientales que predominaron durante la depositación de la cuenca: el área 
de aporte de las areniscas del miembro inferior difiere del resto, presentando una elevada participación de rocas originadas en el arco magmático gondwánico, el cual habría estado activo durante la depositación del Miembro Laguna Lillo, mientras que su actividad e influencia habrían cesado durante la sedimentación del Miembro Laguna Polina.

La flora de la Formación La Golondrina presenta una riqueza florística mayor a la previamente conocida, acercándose en diversidad a aquellas conocidas para Sudáfrica, Australia y la India, y diferenciándose de sus coetáneas sudamericanas. A través de la comparación con otras floras pérmicas, se logró acotar las posibles edades para cada uno de los miembros que la componen (Laguna Lillo, Laguna Polina, y Dos Hermanos). Finalmente, la evidencia aportada a través del análisis de cortes delgados de areniscas no solamente permitió realizar inferencias ambientales para los distintos miembros de la formación, sino que además, aportó de más evidencia (además de la ya provista por la megaflora) para asignar una edad Cisuraliano Tardío-Lopingiano a la Formación La Golondrina.

Palabras clave: Argentina, bioestratigrafía, Formación La Golondrina, glossopterídeas, megaflora, Pérmico, Santa Cruz. 


\begin{abstract}
The present study's ("The Permian of the La Golondrina Basin: paleobotany, biostratigraphy and paleoecological considerations") main goal is to improve the knowledge and understanding of the La Golondrina Formation fossil megaflora through a systematic revision of the fossil material, its biostratigraphic correlation with other Permian floras from Argentina and rest of Gondwana, and the interpretation of environmental conditions in which this flora developed, applying the methodology of petrographic analysis for the first time at the La Golondrina.
\end{abstract}

In order to accomplish these objectives, two field trips were conducted to the areas of Bajo de La Leona and Estancia La Juanita, NE of Santa Cruz province, where Permian sediments from the La Golondrina Formation outcrop, and geological sequences were measured at the localities of Laguna Lillo (lower and middle members), Laguna Polina (middle and upper members), Laguna Castellanos (middle member), Laguna Feruglio (middle and upper members) and Laguna Turbia (middle member). All the collected fossils ( 1100 pieces) as well as fresh pieces of sandstones were stratigraphycally located. The geological sequences were correlated with the reference sequences for each of the units, and paleofloristic lists were augmented for the three members of the formation.

The revision of fossils from the La Golondrina Formation included both the recently collected and the ones deposited at the paleobotany collections from Fundación M. Lillo (Tucumán), Museo de La Plata (La Plata), Facultad de Ciencias Exactas y Naturales (University of Buenos Aires) and the Museo Argentino de Ciencias Naturales "B. Rivadavia" (Buenos Aires). Following this revision, a total of 65 taxa were recognized, among which stand out: the discovery of various genera of glossopterid fructifications (Bifariala, Dictyopteridium, Gonophylloides, Plumsteadia, Ottokaria, Scutum, Senotheca, Lidgettonia and ?Arberia), the proposal of a new species (Plumsteadia pedicellata) and a new combination (Gonophylloides semnes); the first record of Lilpopia sp. (spehnophyte fructification) in Gondwana; the presence of at least 3 new taxa of ferns (Asterotheca sp.); the discovery of fern stems assignable to Caulopteris sp.; the description of a new species of lycopsid (Cyclodendron golondrinensis), and a new combination (Bumbudendron viii 
patagonicum); the first record of coniferophytes for the La Golondrina Formation; and the first findings and description of paleoflora for the lower member (Laguna Lillo) of the formation.

The comparison of La Golondrina's paleofloristic list with other permian floras from Argentina, South America and rest of Gondwana allowed to infer a late CisuralianLopingian age for the formation. Based on the stratigraphic distribution of the taxa analyzed, a new biostratigraphic scheme is proposed, with the following biozones (base to top): Biozone 1 characterizes the lower member (Laguna Lillo), and is recognized by the predominance of Gangamopteris over Glossopteris, the appearance of Megistophyllum leanzai Archangelsky, and the presence of small pinnule pecopterid ferns (e.g., Asterotheca sp. 3); Biozone 2 (equivalent to the Dizeugotheca waltonii Archangelsky and de La Sota biozone) characterizes the middle member (Laguna Polina), and is recognized by the exclusive presence of Annularia kurtzii Archangelsky, Dichotomopteris hirundinis Archangelsky and de La Sota, D. ovata Maithy, Glossopteris stricta Bunbury, and Eremopteris golondrinensis Archangelsky, the appearance of Dizeugotheca waltonii, the abundance of glossopterid fructifications, and the replacement of Gangamopteris for Glossopteris; Biozone 3 (equivalent to the Asterotheca singeri Archangelsky biozone) characterizes the upper member (Dos Hermanos) and is recognized by a general impoverishment of the flora (compared to biozone 2), the dominant presence of Glossopteris damudica Feistmantel, G. retifera Feistmantel and Asterotheca golondrinensis Herbst, and the absence of Gangamopteris spp. and Asterotheca anderssonii Archangelsky y de La Sota.

A petrographic analysis of sandstones from the different members of the La Golondrina Formation was executed to determine the rock sources and to infer the paleoenvironmental conditions that prevailed during the deposition of the basin. Results concluded that the source from the lower member differs from the rest, presenting a high participation of rocks originated from the gondwanic arc, which was apparently active during the deposition of the Laguna Lillo member, while its activity would have decreased by the time the middle member (Laguna Polina) deposited. 
This study revealed an even richer floristic assemblage for the La Golondrina Formation than the previously known, closer in diversity to those floras in South Africa, Australia and India, and differing from the ones in South America. Through the comparison with other Permian floras, it was possible to narrow the ages of each of the members from the formation (Laguna Lillo, Laguna Polina and Dos Hermanos). Finally, the petrographic analysis of sandstones allowed to infer paleoenvironmental conditions during the deposition of the basin, as well as provided of further evidence (besides megaflora) to assign a late Cisuralian-Lopingian age to the La Golondrina Formation.

Key words: Argentina, biostratigraphy, glossopterids, La Golondrina Formation, megaflora, Permian, Santa Cruz. 


$$
\begin{aligned}
& \text {-CAPÍTULO } 1 \text { - } \\
& \text { INTRODUCCIÓN }
\end{aligned}
$$




\section{0 - INTRODUCCION}

\section{1 - Reseña histórica}

Fue a partir de trabajos regionales de geología superficial llevados a cabo por personal de Yacimientos Petrolíferos Fiscales (Y.P.F), cuando a mediados del siglo pasado se identificaron varias unidades litoestratigráficas portadoras de una abundante y variada flora del Paleozoico Superior en el noreste de la Provincia de Santa Cruz, Argentina, en terrenos caracterizados dentro de la Cuenca La Golondrina (Fig. 1b). Los primeros reconocimientos del área y sus nuevas unidades fueron realizados por Criado Roque (1953), De Giusto (1954), Suero y Criado Roque (1955) y Di Persia (1955, 1956), entre otros. A partir de allí, varios aportes significativos referidos a la geología y paleontología del área se han producido.

Hacia fines de 1950, Archangelsky (1959a) publicó un estudio detallado de la geología y paleontología de afloramientos en la zona sur del Bajo de La Leona, dentro de la Cuenca La Golondrina, iniciando una de las colecciones más importante de flora de Glossopteris conocida para Argentina, y una serie de publicaciones con descripciones e ilustraciones de los elementos que componen esta flora (Archangelsky 1957a, 1957b, 1959a, 1959b, 1960a, 1960b, Archangelsky y de La Sota, 1960, Archangelsky y Bonetti, 1963). Posteriormente, Arrondo (1969-tesis inédita, 1972), publicó un estudio de la misma índole para la zona de la Estancia La Juanita y sus alrededores, ampliando el conocimiento de esta paleoflora pérmica. Estudios paleontológicos en el área se realizaron esporádicamente durante las siguientes décadas, entre los cuales se destacan los aportes de Archangelsky (1992), Archangelsky y Cúneo (1984, 2002) y Archangelsky et al. (1999, 2000, 2004).

Distintos trabajos se realizaron sobre la geología de la Cuenca La Golondrina, entre ellos, se destacan las contribuciones de Chebli et al. (1976: descripciones de las secuencias permo-triásicas que incluyen las Formaciones La Golondrina, La Juanita, y El Tranquilo), Pezzuchi (1978-tesis inédita: completo estudio geológico en la zona de la Estancia Dos 
Hermanos y sus adyacencias), y Jalfin (1987-tesis inédita: detallado análisis sedimentológico de la zona).

\section{2 - Marco geológico}

La Cuenca La Golondrina se encuentra ubicada en la región nor-oriental de la Provincia de Santa Cruz, comprende unos $1500 \mathrm{~km}^{2}$ de afloramientos neopaleozoicos localizados en el Macizo del Deseado (Fig. 1a). Está limitada hacia el NNE por el Río Deseado, hacia el SSE por la Dorsal Río Chico, mientras que el límite occidental es desconocido (Jalfin, 1987; Andreis, 2002). Según Jalfin (1987), la Cuenca La Golondrina (Fig. 1b) se habría desarrollado en el interior de un arco magmático paleozoico, tomando una forma de herradura elongada, abierta hacia el sudeste y con un eje axial orientado NNO-SSE (Fig. 1a). La visión de una cuenca de intra - arco es aceptada por Archangelsky et al. (1996a), Buatois et al. (1997) y Andreis y Archangelsky (1996); mientras que otros autores han sugerido que esta cuenca sería del tipo "supracontinental asociada a la evolución de un rift incipiente" debido al sustrato siálico subyacente (Palma y Ubaldón, 1988). Esta visión fue también apoyada por Ramos y Palma (1996), quienes interpretaron a la cuenca como de rift, consistente con la información brindadad a partir de datos sísmicos presentados por Homovc y Constantini (2001, en Ramos, 2008). Por su parte, Limarino y Spalletti (2006) mencionan a la Cuenca La Golondrina como una cuenca infracratónica. De todas estas visiones, aquella que considera a la Cuenca La Golondrina como una cuenca de intra - arco es la aceptada en este trabajo.

Considerada por décadas como parte de la gran "Cuenca Central Patagónica", la cual abarcaba junto a las cuencas Tepuel Genoa e Islas Malvinas (Fig. 1a) una extensa faja de orientación NNO-SSE (Suero y Criado, 1955; Archangelsky y Cúneo, 1984; Archangelsky et al., 1985), la Cuenca La Golondrina es actualmente reconocida como una entidad estratigráfica separada de éstas (Jalfin y Bellosi, 1984; Azcuy y Caminos, 1987; 
Andreis et al., 1987; Jalfin, 1987), basado en evidencias sedimentológicas y paleobiológicas.

En la Cuenca La Golondrina, las principales zonas de afloramientos pérmicos principales incluyen (Fig. 1b) el Bajo de la Leona, Estancia La Juanita - Cerro Chato, Estancia Dos Hermanos, y Laguna Dulce (Vieira y Pezzuchi, 1976; Jalfin, 1987; Bellosi y Jalfin, 1990; Panza, 1994; Archangelsky et al., 1996a; Guido y de Barrio, 2004). En la cuenca se depositaron sedimentitas neopaleozoicas de origen continental incluidas en el Grupo Tres Cerros (Archangelsky et al., 1996a); esta secuencia incluye de base a techo a las Formaciones La Golondrina, y apoyando en aparente concordancia sobre ésta, La Juanita (véase Jalfin, 1990; Archangelsky et al., 1996a). El Grupo Tres Cerros incluye aproximadamente 2600 metros de sedimentitas (compilación de perfiles sensu Andreis, 2002), y estaría limitado por discordancias tanto en la base como en el techo. Guido y de Barrio (2004) sugieren, a partir de sus observaciones en la zona de Laguna Dulce, que la Formación La Golondrina apoyaría discordantemente sobre leucogranitos del Complejo Río Deseado (Proterozoico a Paleozoico Inferior; Vieira y Pezzuchi, 1976). Por otra parte, el techo del Grupo Tres Cerros está cubierto por sedimentos triásicos tardíos de la Formación El Tranquilo (Herbst, 1965).

La Formación La Golondrina (denominación formal propuesta por Lesta y Ferrello, 1972) se halla mayormente constituída por areniscas de color gris verdoso, con intercalaciones escasas de limolitas y lutitas. Niveles de conglomerados polimícticos con clastos bien redondeados predominan en la base y en la parte superior de la Formación (Fig. 2). Esta Formación fue subdividida en tres Miembros, de base a techo: Laguna Lillo, Laguna Polina, y Dos Hermanos (Jalfin y Bellosi, 1984; Archangelsky et al., 1996a; Gutiérrez et al., 2006). En aparente concordancia, apoya la Formación La Juanita, integrada por areniscas de grano mediano a grueso e intercalaciones de conglomerados cuarcíticos oligomícticos (Chebli et al., 1976), sin contenido fósil, y de origen fluvial (Jalfin, 1987), aunque se ha sugerido un posible origen marino también (Archangelsky et al., 1996a). Esta secuencia pérmica es considerada en su totalidad por la mayoría de los autores como de 
origen continental, sin presencia de niveles marinos, como sí ocurre por ejemplo, en la Cuenca de Tepuel-Genoa, también pérmica (Andreis y Archangelsky, 1996).

Debido a la ausencia de una secuencia contínua completa en las zonas donde aflora el pérmico, Jalfin (1987) sugirió la designación del Perfil I (orilla Norte de la Laguna Polina) de Archangelsky (1959a) como holoestratotipo de la Formación La Golondrina, que incluye los miembros medio y superior únicamente. Asimismo, propuso como secuencias complementarias (paraestratotipos) a los perfiles realizados en la localidad de Laguna Lillo (miembros inferior y medio) para el miembro Laguna Lillo, y en la localidad de Dos Hermanos (miembro superior) para el miembro Dos Hermanos (Jalfin, 1987; Jalfin, 1990). 

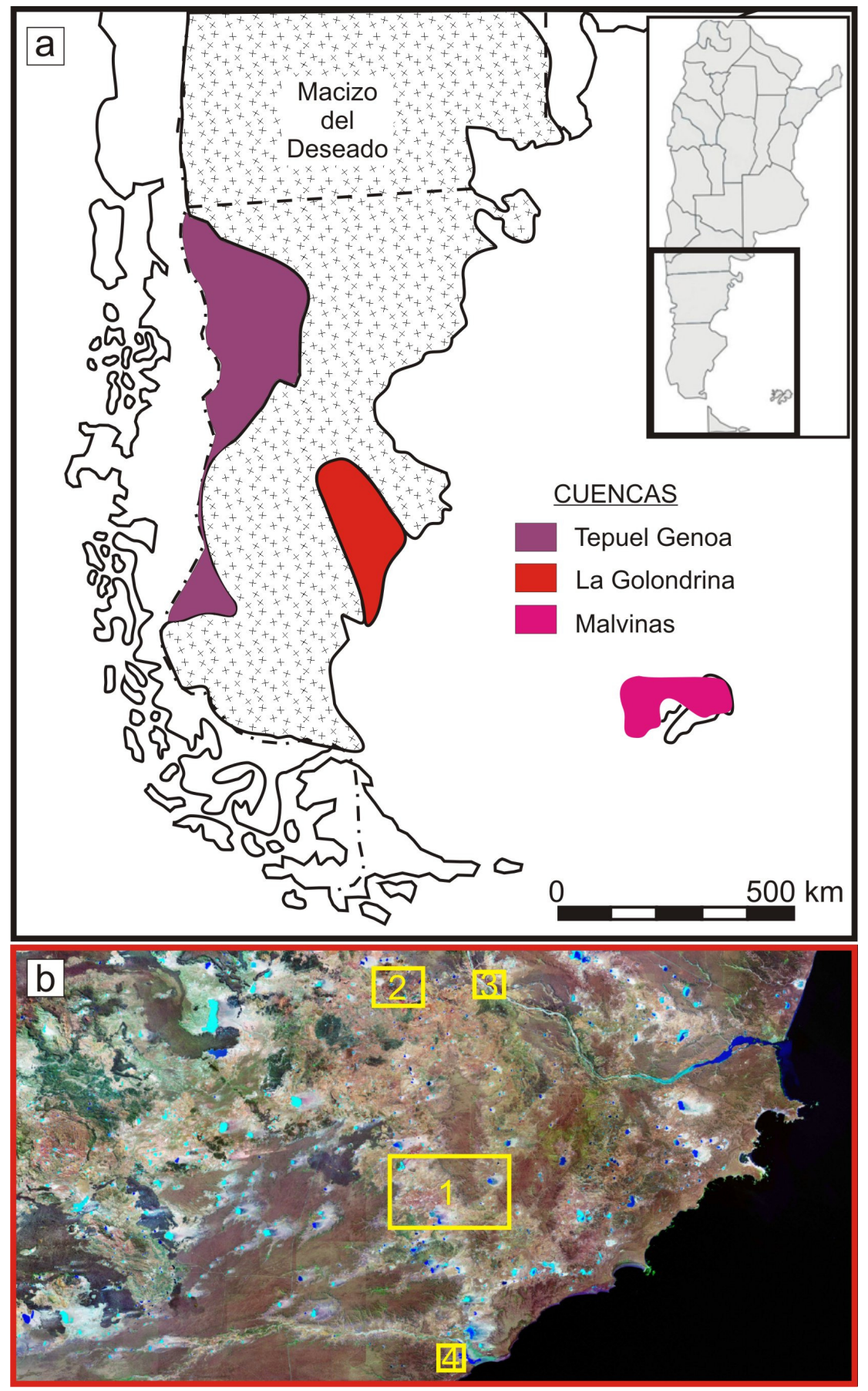

Figura 1 - a) Ubicación de las cuencas Tepuel Genoa, La Golondrina y Malvinas. b) Imagen satelital del NE de la Provincia de Santa Cruz, mostrando zonas con afloramientos Pérmicos. 1) Bajo de La Leona, 2) Estancia La Juanita - Cerro Chato, 3) Estancia Dos Hermanos, 4) Laguna Dulce. Escala 1:14000. 


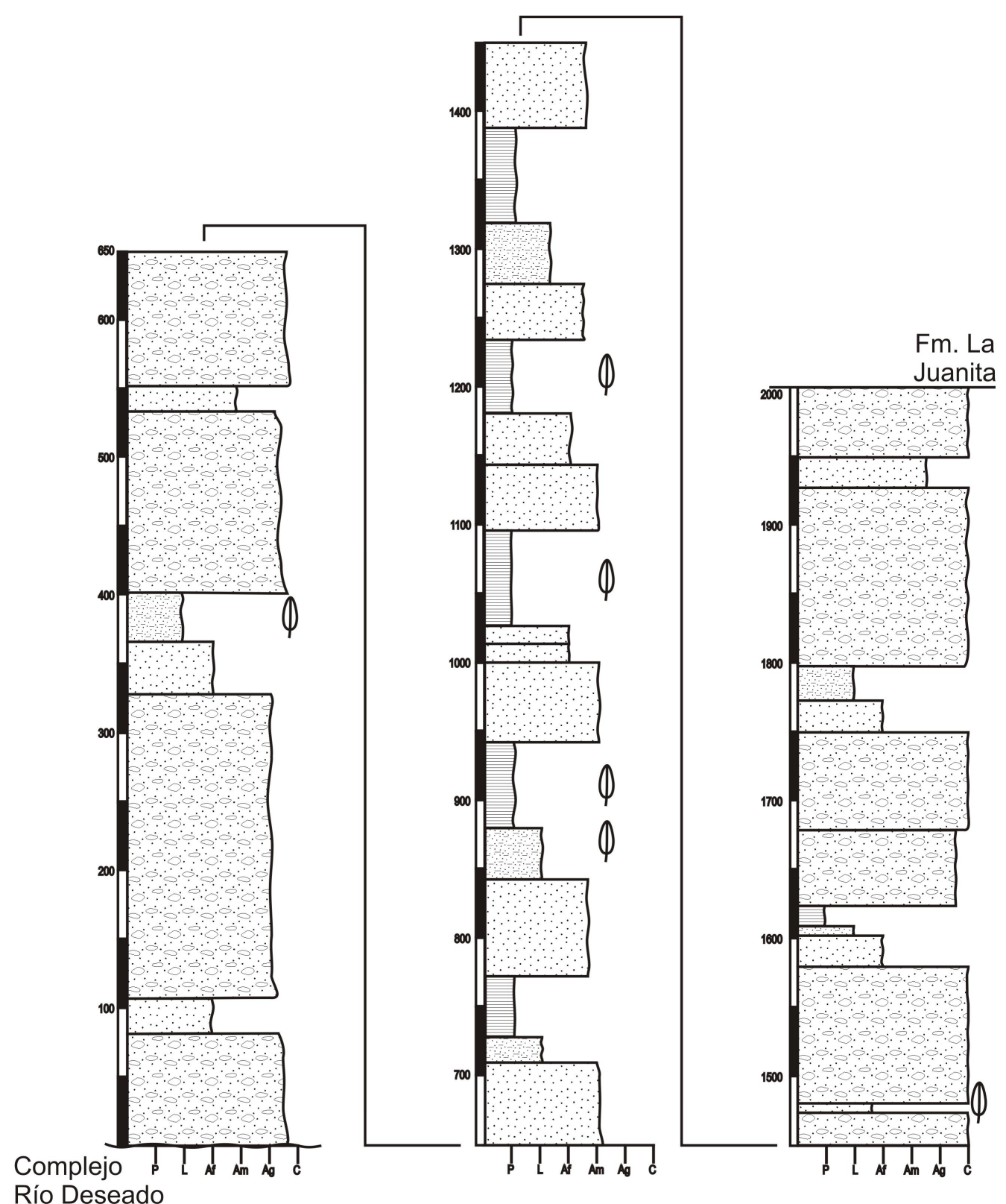

Figura 2 - Perfil generalizado para la Formación La Golondrina representando los tres miembros: Laguna Lillo (izquierda), Laguna Polina (medio), Dos Hermanos (derecha), y los niveles donde se hallaron fósiles. Escala vertical en metros. 
El miembro inferior - Laguna Lillo - aflora en la parte más austral del Bajo de La Leona, y presenta un espesor total de 650 metros (Jalfin, 1987). Las facies conglomerádicas son predominantes, así como las areniscas medianas a gruesas. Ocasionalmente, se encuentran niveles finos, pelíticos, portadores de flora fósil (Fig. 2). La localidad tipo para este miembro se halla en la Laguna Lillo.

El miembro medio - Laguna Polina - está ampliamente extendido tanto en el Bajo de La Leona, como en las proximidades de la Ea. La Juanita, y Leonardo (Gutiérrez et al., 2006) (Fig. 1). El espesor máximo medido alcanza los 800 metros en la Ea. La Juanita. Se caracteriza por la desaparición de los conglomerados del miembro inferior, y la predominancia de areniscas medianas a finas, con alternancia de niveles pelíticos portadores de una rica flora (Fig. 2). La localidad tipo para este miembro se halla en la Laguna Polina.

El miembro superior - Dos Hermanos - también aflora en la zona de las Ea. La Juanita y Dos Hermanos, y en menor medida, en el Bajo de La Leona y la localidad de Laguna Dulce (Panza, 1994; Gutiérrez et al., 2006). En este miembro, de $900 \mathrm{~m}$ de espesor máximo, vuelven a predominar los conglomerados con intercalaciones de areniscas gruesas y medianas, con presencia en menor medida de niveles finos portadores de flora fósil (Achangelsky et al., 1996a) (Fig. 2). La localidad tipo para este miembro se halla en la localidad de Dos Hermanos, a orillas del Río Deseado.

En total, la Formación La Golondrina tendría un espesor máximo de $2350 \mathrm{~m}$ aproximadamente (Jalfin, 1987), los cuales sumados a los $200 \mathrm{~m}$ de la Formación La Juanita, darían un total de 2550 m de espesor para el Grupo Tres Cerros.

En base a la abundancia de hojas de Glossopteris sp. que fueron halladas desde un principio, se consideró que la edad de la Formación La Golondrina era pérmica (Archangelsky, 1959), más precisamente, “desde Asseliana a Artisnkiana” (Archangelsky, 1959a: 120). El posterior hallazgo de la fructificación de glossopteridal Dictyopteridium cf. D. sporiferum (Archangelsky, 1992), permitió ajustar su edad a un pérmico más alto, entre 253-263 Ma. (Archangelsky, 1992: 22). 
De esta forma, la Formación La Golondrina sería la única reconocida hasta el momento para el Pérmico Superior de Argentina, comparable con algunas floras de Brasil, Sudáfrica, India y Australia (Cúneo, 1996). A su vez, la abundante y diversa flora que presenta en comparación con otras megafloras del Pérmico Inferior de Argentina (Sierras Australes, Paganzo, etc; ver Archangelsky et al., 1996b), contrasta en la tendencia generalizada de un empobrecimiento florístico a medida que transcurre el Pérmico. Es por ello que esta tesis propone el estudio de la megaflora de La Golondrina a través de la revisión de colecciones y colecta de nuevo material en el campo, para intentar lograr un mayor grado de conocimiento de la composición de esta flora, delimitar sus tendencias evolutivas, y compararla con otras floras coetáneas y previas en un contexto paleoclimático y paleogeográfico local, regional, y global, de lo que se espera reconocer y definir esquemas de biozonación, correlacionarla con otras unidades de las diferentes cuencas de Gondwana, y en lo posible, acotar con mayor precisión su edad.

\section{3 - Objetivos de trabajo}

Los objetivos generales de trabajo de esta tesis son los siguientes:

- Caracterización de la megaflora fósil de la Formación La Golondrina, a partir de la revisión sistemática de material depositado en las distintas colecciones del país y de nuevas colecciones realizadas para tal objetivo.

- Correlación bioestratigráfica con cuencas Pérmicas de Argentina, Sudamérica, y resto de Gondwana.

- Análisis petrográfico y caracterización paleoambiental de la Formación La Golondrina.

Los objetivos particulares de trabajo de esta tesis son los siguientes: 
- Identificación, descripción, y asignación sistemática del material fósil recientemente colectado, y del proveniente de las colecciones revisadas.

- Descripción de nuevos perfiles estratigráficos en la zona del Bajo de La Leona y Estancia La Juanita, abarcando los tres miembros que componen la Formación La Golondrina, ubicando los niveles fosilíferos identificados y de los que provienen el material aquí analizado.

- Ajustar la edad reconocida para la Formación La Golondrina (Pérmico Tempranotardío a Pérmico Tardío) en base a su contenido paleoflorístico, a través de la comparación con distintas cuencas del Pérmico de Gondwana, y aportando otras evidencias.

Las hipótesis de trabajo para esta tesis son:

- La flora fósil de la Formación La Golondrina posee una diversidad mucho mayor a la previamente reconocida, acercándose en diversidad a aquellas conocidas para Sudáfrica, Australia y la India, y alejándose de sus afines sudamericanas, como ser Tepuel Genoa (Chubut, Argentina) y Paraná (Brasil).

- La mayor afinidad con floras de cuencas extra-sudamericanas estaría más relacionada a un sesgo de colección en las floras pérmicas sudamericanas (en comparación con las de cuencas extra-sudamericanas), que a una diferencia real en la diversidad.

- La edad de la Formación La Golondrina abarcaría desde finales del Cisuraliano (Artinskiano) al Lopingiano, de acuerdo a la evidencia paleobotánica y la aportada por el análisis de cortes delgados petrográficos. 
En los siguientes capítulos de esta tesis, se explican los materiales y métodos utilizados para la realización de este trabajo, haciendo mención de las colecciones visitadas (Capítulo 2); se describe la estratigrafía de la zona estudiada en donde fue colectado el material a través de nuevos perfiles levantados por la autora (Capítulo 3); se examinan, describen, e ilustran todos los grupos reconocidos a partir del material fósil tanto de las colecciones revisadas como del recientemente traído de las campañas llevadas a cabo al área (Capítulo 4); se analiza la distribución temporal y espacial de los taxones en los distintos miembros de la Formación, se los correlaciona con los de otras cuencas pérmicas y se discute sus afinidades, se plantea un nuevo esquema de biozonación para la Formación y se ajusta su edad (Capítulo 5); se utiliza el análisis petrográfico de cortes de areniscas para realizar inferencias paleoambientales como método novedoso aplicado en la Formación La Golondrina (Capítulo 6); y por último, se mencionan las conclusiones finales derivadas de este estudio, y se proponen nuevas líneas de investigación a futuro (Capítulo 7). 


\section{- CAPÍTULO 2 -}

\section{MATERIALES Y MÉTODOS}




\section{0 - MATERIALES Y MÉTODOS}

\section{1 - Análisis de nuevo material traído del campo}

Unas 1100 muestras de flora fósil fueron recuperadas entre las campañas del 2008 y 2010. Estas piezas fueron estratigráficamente ubicadas en cada uno de los perfiles realizados en las localidades correspondientes (ver Capítulo 3). Una vez en el gabinete, se procedió a su numeración correspondiente (asignada por el repositorio Museo Padre Jesús Molina), y su estudio bajo la lupa.

El material, perteneciente a la provincia de origen (Santa Cruz), cuyo repositorio designado es el Museo Regional Provincial Padre Jesús Molina, en Río Gallegos, será devuelto luego de finalizado su estudio bajo las siglas MPM-Pb, con los números de inventario 2497 - 2902, 4394 -- 4999, y 15103 - 15160, como parte de la Colección Cariglino, Gutiérrez, Manassero (2008) y Cariglino, Gutiérrez, Correa, Coturel (2010).

\section{2 - Análisis de material de colección}

La revisión de material se llevó a cabo en las siguientes colecciones de paleobotánica:

El material fue minuciosamente revisado y puesto bajo la lupa para su observación en detalle. Aquel material de mejor preservación y más completo, fue fotografiado para utilizar como ilustración en su descripción. No se encontraron razones para hacer enmiendas de las descripciones originales del material conocido para La Golondrina. Sin embargo, cuando el material se hallaba clasificado únicamente a nivel de género, se intentó ubicarlo específicamente. 


\begin{tabular}{lllll}
\hline \hline \multicolumn{1}{c}{ Colección } & \multicolumn{1}{c}{ Año } & \multicolumn{1}{c}{ Repositorio } & \multicolumn{1}{c}{ Acrónimo } & Publicado \\
\hline Criado Roque & 1953 & Instituto Miguel Lillo, Tucumán. & LIL & Sí \\
Archangelsky & $1956 / 7$ & Instituto Miguel Lillo, Tucumán. & LIL & Sí \\
Arrondo & $1969 / 72$ & $\begin{array}{l}\text { Museo de Cs. Naturales de La Plata, } \\
\text { La Plata. }\end{array}$ & LP-Pb & Sí \\
Archangelsky \& Cúneo & $1984 / 8$ & $\begin{array}{l}\text { Museo Argentino de Cs. Naturales } \\
\text { "B. Rivadavia", Buenos Aires. }\end{array}$ & BA-Pb & No \\
Azcuy, César, & \multirow{2}{*}{$\begin{array}{l}\text { Facultad de Ciencias Exactas y } \\
\text { Longobucco, Ottone }\end{array}$} & Naturales, UBA, Buenos Aires. & No & \\
\hline \hline
\end{tabular}

Por otra parte, a través de la revisión del material de colección, se hallaron abundantes elementos novedosos, que son descriptos, ilustrados, y asignados a una especie en otro capítulo (ver Capítulo 4) de esta tesis.

La visita a las distintas colecciones permitió una comparación de los elementos que las componen; asimismo, fueron consultadas abundantes referencias bibliográficas para comparación con aquel material perteneciente a otras cuencas gondwánicas (India, Australia, Sudáfrica, Antártida, y Madagascar), y extragondwánicas (Europa, América del Norte, Pakistán, China).

El modo de preservación de todo el material aquí descripto es en forma de impresiones. Es destacable la total ausencia de cutículas o materia orgánica, como fuera mencionado por Arrondo (1972). Asimismo, se han encontrado moldes de troncos de licófitas en la localidad de Laguna Lillo, en posición de vida, pero su anatomía interna no fue preservada. Hasta la fecha, toda preparación palinológica ha resultado infructuosa, por la intensa carbonización (producto del metamorfismo de contacto sufrido por los sedimentos Pérmicos) que impide cualquier preservación de material palinológico.

El estudio sistemático de todo el material, tanto el recientemente colectado como el de las colecciones mencionadas, se efectuó siguiendo la postura planteada por Archangelsky (1959a: 23) y continuada por Arrondo (1969: 44; 1972:35), en la que se 
intenta evitar la creación de nuevos taxones en la medida de lo posible, buscando siempre una comparación y afinidad con los géneros y especies ya descriptos para cuencas gondwánicas, y en menor medida, extra-gondwánicas. Esto se debe al reconocimiento de la flora de La Golondrina como una flora de Glossopteris con elementos de mezcla, donde se hallan elementos típicamente gondwánicos (Glossopteris y Gangamopteris, por ejemplo) y nórdicos (helechos pecopterídeos y sphenophyllales, entre otros) (véase 5.6).

Asimismo, la sistemática está basada en aquella propuesta por Archangelsky (1959, y sucesivas colaboraciones), ya que como fue mencionado previamente, las descripciones hechas por ese autor se encontraron congruentes con el material estudiado, por lo que no se necesitó enmendar las diagnosis.

\section{3 - Cortes de muestras petrográficas. Muestreo y análisis bajo el microscopio}

Para llevar a cabo el análisis paleoecológico, se muestrearon fragmentos frescos de roca provenientes de los distintos estratos medidos en las secuencias realizadas, de los miembros inferior (Laguna Lillo) y medio (Laguna Polina) tomados de los perfiles en las localidades homónimas. Las muestras se hallan designadas bajo las siglas P\#.

Las muestras de areniscas fueron recolectadas en las localidades de Laguna Lillo y Laguna Polina (Fig. 4) a medida que fueron levantados los perfiles que involucraban el miembro inferior y medio, y medio y superior respectivamente, por lo que su ubicación estratigráfica a lo largo de las secuencias analizadas puede consultarse en las Figuras 5 y 6. Las muestras fueron tomadas manteniendo un orden estratigráfico de aquellos estratos que presentaban mayor potencial para su análisis, esto es, desechando a aquellas areniscas de grano fino o limoso, ya que la identificación de fragmentos líticos se hace muy problemática dentro de este rango de granulometrías.

En el laboratorio, se hicieron 22 cortes delgados de 30 micrones de espesor (medida estándar) para su análisis bajo un microscopio petrográfico de luz polarizada Nikon Eclipse 
E200, con una cámara Leika DFC290-HD unida a éste, con el cual se fotografiaron las muestras utilizando diferentes escalas para abarcar un campo mayor (4X) y uno de mayor detalle (10X). A su vez, se procedió a fotografiar los ejemplares con y sin los nicoles cruzados, para observaciones mineralógicas a color de interferencia (nicoles cruzados) y de relaciones texturales y porosidad (nicoles sin cruzar).

El análisis de estas muestras permitirá diferenciar los estudios sedimentológicos de campo (por ejemplo, textura, estructuras, paleocorrientes, presencia de fósiles), con los de laboratorio, a través de los cuales se determinará la procedencia, modas detríticas, y análisis composicional utilizando los modelos de Dickinson (Dickinson y Suczek, 1979; Dickinson et al., 1983), para luego, comparar los datos obtenidos con los publicados de otras unidades de la misma edad (tanto de esta cuenca, como de otras coetáneas, por ejemplo, Sierras Australes). Los resultados, discusión y conclusiones de este análisis se desarrollan a lo largo del Capítulo 6 de esta tesis.

\section{4 - Herramientas utilizadas}

Tanto el material recientemente colectado, como el de las colecciones, fue fotografiado utilizando una cámara digital Canon Powershot S5IS (8.0 megapixeles). Para el análisis en detalle, el material fue observado bajo una lupa estereomicroscópica Nikon SMZ800. A esta lupa, se le conectó una cámara Nikon DS-Fi1-U2 para fotografiado de detalle bajo luz unilateral de bajo ángulo.

Cuando fue posible, se hicieron moldes sintéticos de goma y plástico rígido de algunos elementos, que luego fueron llevados para observación bajo un microscopio electrónico de barrido Phillips XL30, perteneciente al Museo Argentino de Ciencias Naturales "B. Rivadavia”. 
La medición, escalamiento, y ajuste de imágenes digitales se hizo utilizando software Adobe Photoshop 7.0. Cuando fue posible, se hicieron mediciones con el ejemplar en mano, utilizando un calibre Vernier.

Reconstrucciones e interpretaciones gráficas se efecturaron utilizando el software CorelDraw X3 y una tableta digital Wacom Bamboo. 
- CAPÍTULO 3 -

ESTRATIGRAFÍA 


\section{0 - ESTRATIGRAFÍA}

\section{$3.1-$ Antecedentes}

Varios estudios estratigráficos fueron realizados en la zona donde afloran los sedimentos pérmicos de la Formación La Golondrina, entre los que se destacan los aportes de Di Persia (1955, 1956), Herbst (1965), Arrondo (1972), Viera y Pezzuchi (1976), Chebli et al. (1976), y Jalfin (1987, 1990). En su tesis doctoral, Jalfin (1987-inédita) realizó un análisis detallado de la estratigrafía en la Cuenca La Golondrina, proponiendo el uso de Grupo Tres Cerros para definir al "conjunto de rocas pérmicas aflorantes en el sector nororiental de la provincia de Santa Cruz" (Jalfin 1987: 16). Asimismo, sugirió que la Formación La Golondrina estaría en realidad dividida en tres miembros, a los que designó Miembro Laguna Lillo (inferior), Miembro Laguna Polina (medio, análogo a la sección inferior del perfil I de Archangelsky, 1959), y Miembro Dos Hermanos (superior, análogo a la sección superior del perfil I de Archangelsky, 1959a). Tales designaciones fueron posteriormente utilizadas por distintos autores (Jalfin et al., 1990 y Bellosi y Jalfin, 1989, en Gutiérrez et al., 2006), pero recién fueron formalizadas a partir de la publicación de Archangelsky et al. (1996a: 96). Por lo tanto, en esta tesis, se sigue la estratigrafía propuesta por Jalfin (1987) y aceptada a partir de Archangelsky et al. (1996a).

3.2 - Prospección de la zona, relevamiento y descripción de perfiles de la Fm La Golondrina. Colección de nuevo material.

Como ha sido mencionado previamente, el Pérmico en la Cuenca La Golondrina aflora en 4 localidades, siendo las dos más reconocidas y estudiadas por distintos autores, la Estancia La Juanita (Fig. 3), y el Bajo de La Leona (Fig. 4). El trabajo de campo llevado a cabo para esta tesis se desarrolló principalmente en esas dos localidades. En una primera campaña, realizada en marzo de 2008, se prospectó e hizo un reconocimiento de la zona del Bajo de La Leona, a través del acceso permitido por los 
dueños de las estancias La Golondrina y Leonardo. En una campaña posterior, llevada a cabo en noviembre de 2010, se pudo acceder a las zonas aledañas a las estancias La Leona y La Juanita.
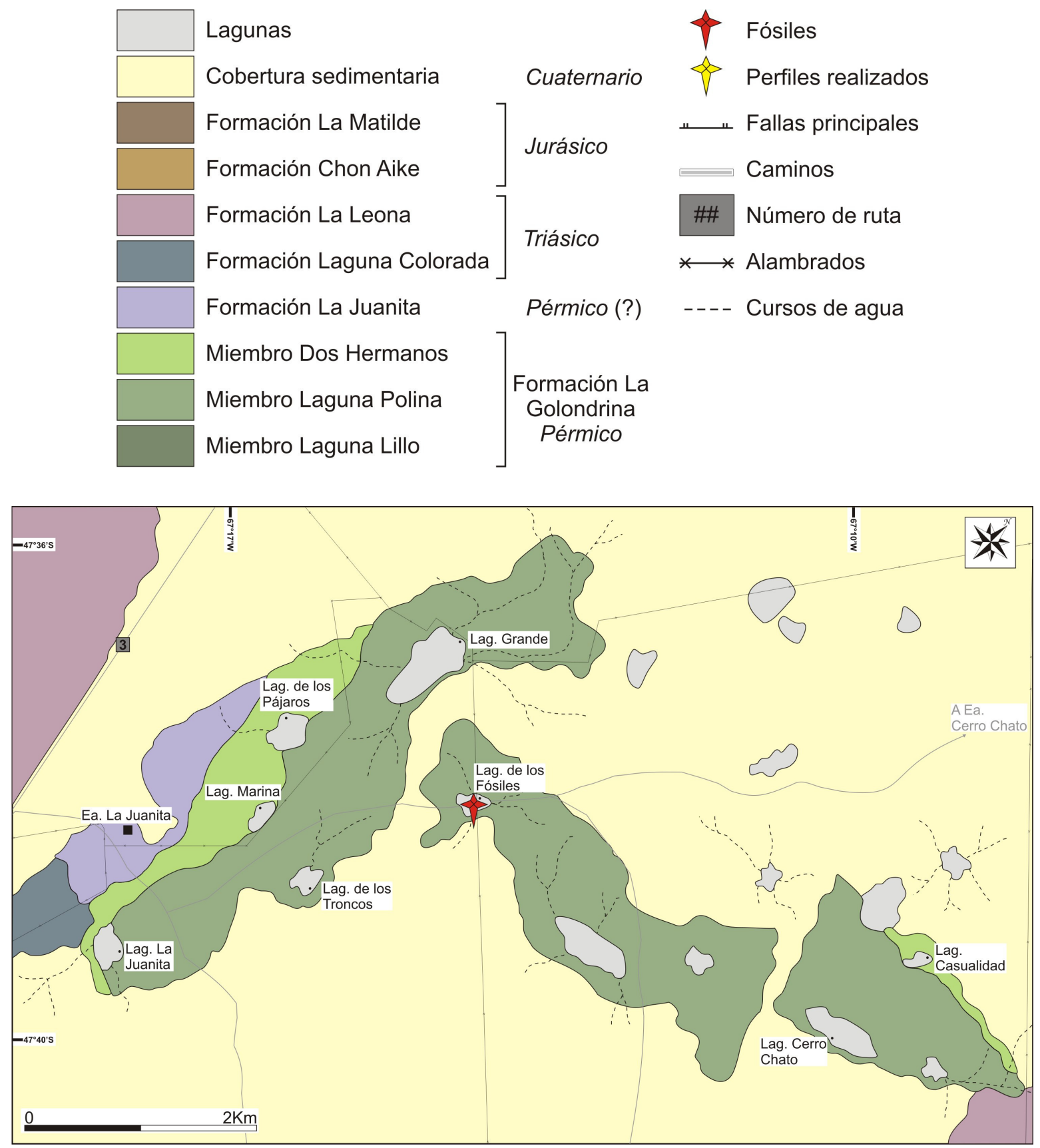

Figura 3 - Mapa geológico de la Ea. La Juanita (modificado de Panza, 1994). 


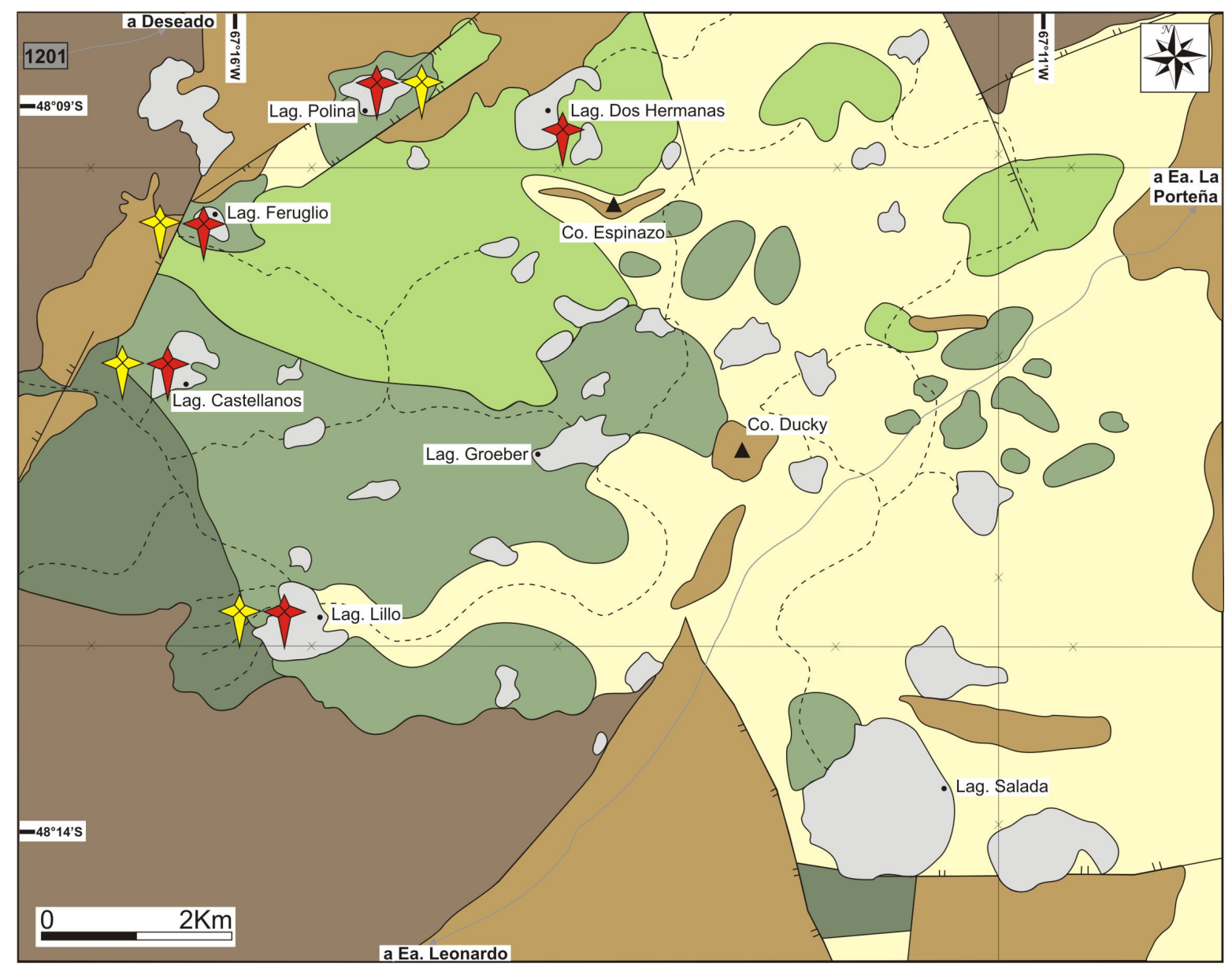

Figura 4 - Mapa geológico del Bajo de La Leona (modificado de Panza, 1994).

A partir de la prospección en estas áreas, cinco nuevos perfiles [ $\left[\mathrm{p}_{\text {] fueron }}\right.$ relevados en la zona del Bajo de La Leona, abarcando los miembros Laguna Lillo, Laguna Polina y Dos Hermanos de la Formación La Golondrina.

El miembro inferior (Laguna Lillo) fue perfilado en la laguna homónima (Lám. 1, A-D). Más de 260 ejemplares fósiles fueron recuperados y estratigráficamente ubicados, así como muestras de petrología para su posterior análisis de procedencia en el gabinete. 
El miembro medio (Laguna Polina) fue perfilado en distintas localidades, a saber, Laguna Polina, Laguna Castellanos, Laguna Feruglio (Lám. 2, A-I), y Laguna Turbia ${ }^{1}$ (Lám. 1, E), debido a que este miembro aflora con predominancia en el Bajo de La Leona. Abundante material fósil ( 760 ejemplares) fue recuperado y estratigráficamente ubicado en cada uno de los perfiles levantados. Asimismo, muestras petrográficas fueron recogidas de la localidad de Laguna Polina para su posterior análisis en el laboratorio.

El miembro superior (Dos Hermanos) fue prospectado en la zona de la Ea. La Juanita, y Laguna Dos Hermanas en la zona del Bajo de La Leona. No habiéndose hallado una localidad ideal para su perfilamiento, es únicamente mencionado en su contacto con el miembro medio en las localidades de Laguna Polina y Laguna Feruglio. Unos pocos fósiles ( 15 ejemplares) de pobre preservación fueron recuperados en Laguna Dos Hermanas, sin que se reconocieran elementos novedosos. La localidad tipo para el miembro superior se ubica en la zona de la Estancia Dos Hermanos, a la margen del Río Deseado, lugar donde aflora el miembro superior únicamente. Se planea la incorporación de datos de sectores de la cuenca aún no prospectados en campañas a realizar próximamente, donde se realizarán nuevos relevamientos de perfiles y colección de fósiles que abarquen niveles pertenecientes al Miembro Dos Hermanos.

\footnotetext{
${ }^{1}$ La Laguna Turbia si bien se ubica fuera del área mapeada, está localizada en el área del Bajo de La Leona. Es el sitio en el que Archangelsky (1960a) hizo referencia como "contacto del granito con el Paleozoico".
} 


\section{LÁMINA 1}
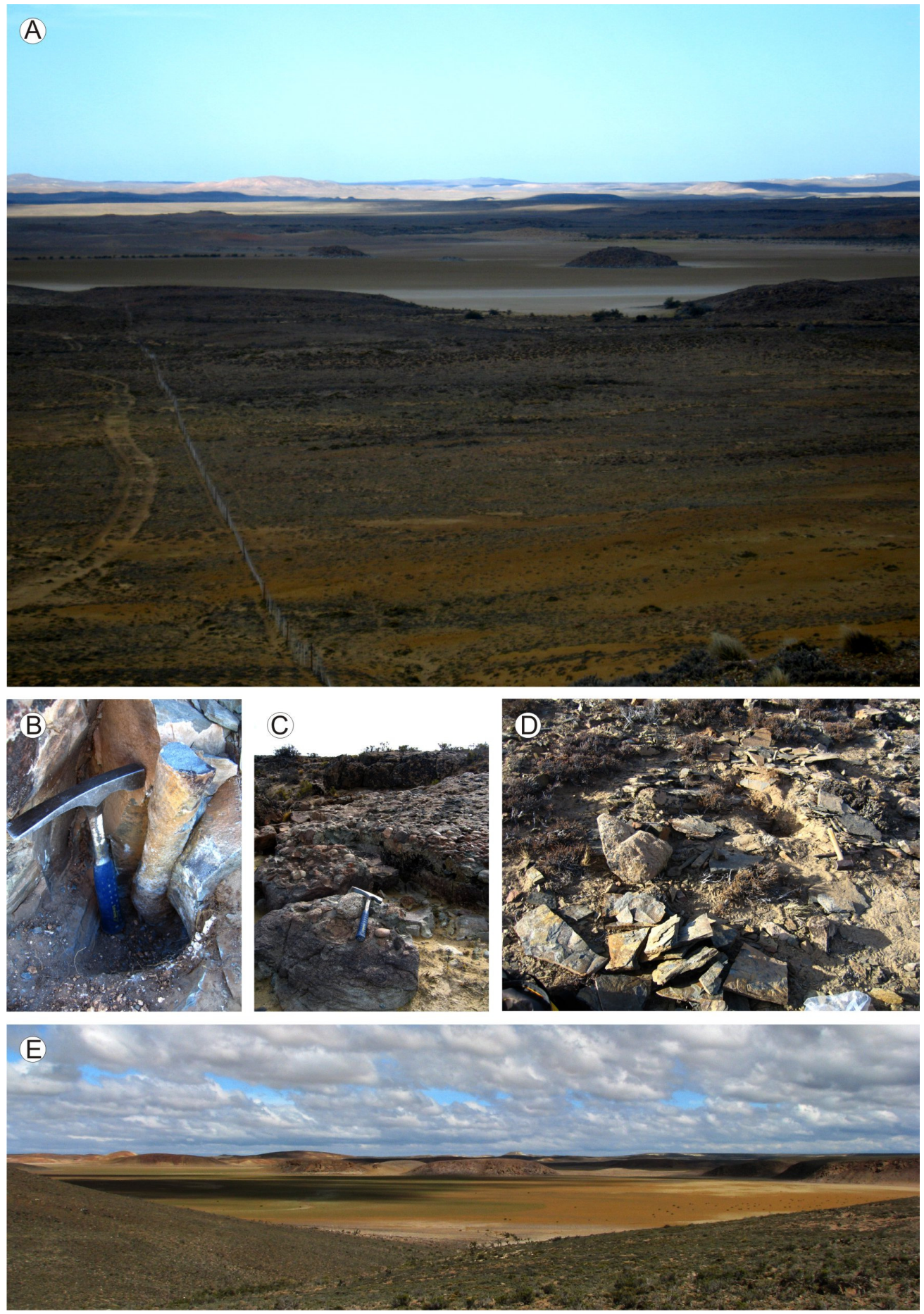

A) Vista de la Laguna Lillo desde el camino. B) Ejemplar de licofita in situ. C) Conglomerados del miembro inferior en Laguna Lillo. D) Ejemplares fósiles colectados. E) Vista de la Laguna Turbia 


\section{LÁMINA 2}
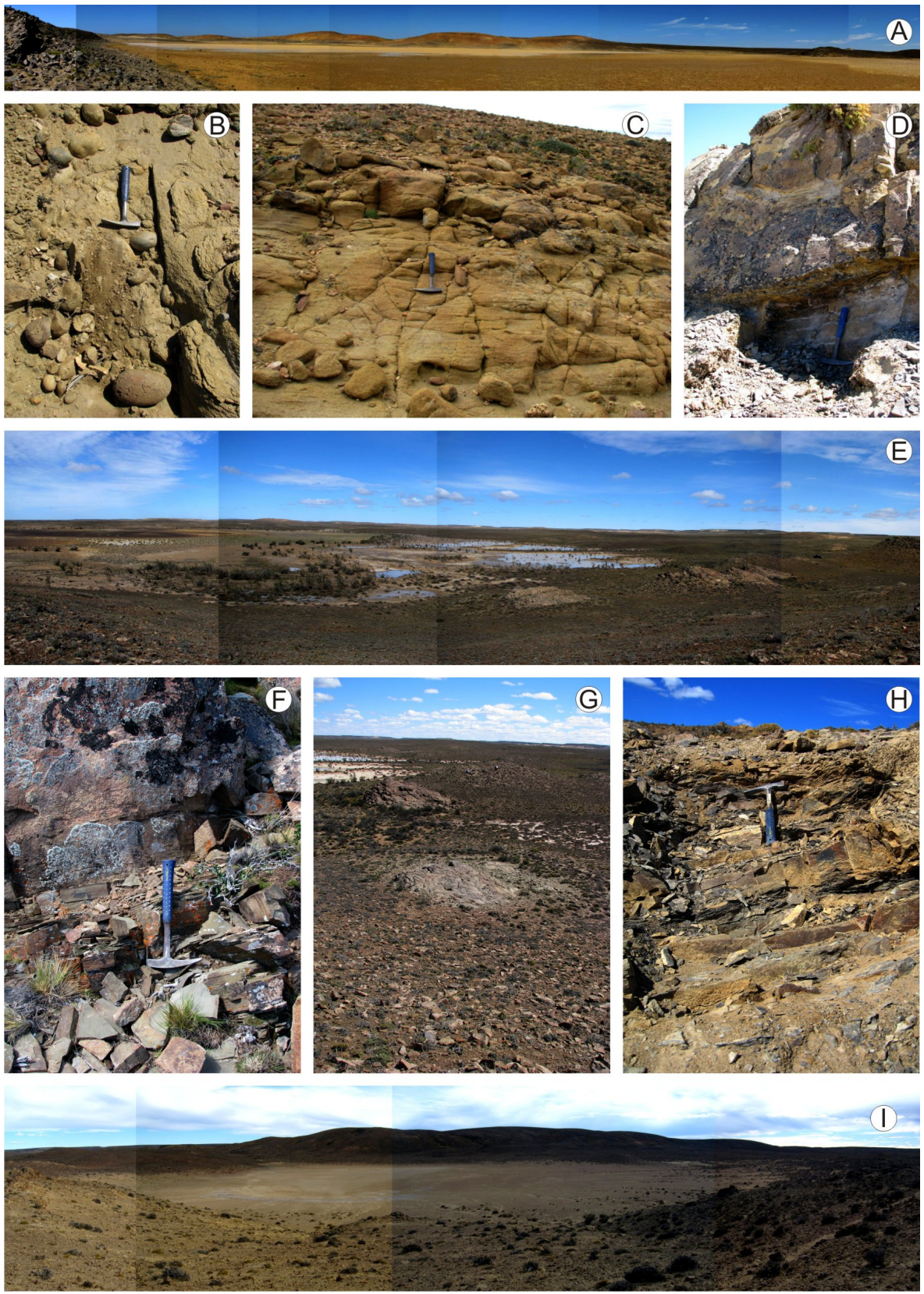

A) Vista de la Laguna Polina. B) Areniscas conglomerádicas del miembro medio en Laguna Polina.

C) Areniscas en artesas del miembro medio en Laguna Polina. D) Niveles de pelitas portadoras de fósiles en Laguna Polina. E) Vista de la Laguna Castellanos. D) Areniscas medianas en artesas en Laguna Castellanos.

G) Vista de lomadas con niveles portadores de fósiles. H) Calicata mostrando los níveles de areniscas finas y pelitas intercaladas portadoras de fósiles en Laguna Feruglio. I) Vista de la Laguna Feruglio. 
A continuación, se detallan los perfiles relevados en las localidades visitadas, donde se muestrean los niveles portadores de flora fósil. Se detallan con especial énfasis los perfiles Laguna Lillo y Laguna Polina por ser los más representativos del miembro inferior y medio, respectivamente. Las siguientes referencias aplican a las figuras 5 (perfil Laguna Lillo), 6 (perfil Laguna Polina), 7 (perfil Laguna Castellanos), 8 (perfil Laguna Feruglio) y 9 (perfil Laguna Turbia).

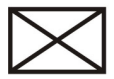

Cubierta sedimentaria

Pelita (P)

Limolita (L)

Arenisca fina (Af)

Arenisca media (Am)

Arenisca gruesa $(\mathrm{Ag})$

Conglomerado (C)

Masiva

Laminación planar

Laminación convoluta/ondulada

Estratificación entrecruzada

Estratificación entrecruzada en artesas

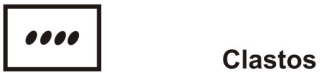

P\#

Muestra de petrología

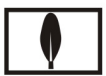

Glossopteris sp

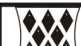

Licofitas

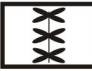

Sphenophyllum sp y afines

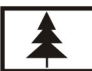

Cordaites sp y coníferas

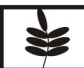

Helechos

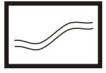

Icnitas

Muestra de palinología

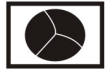

Fósiles mal preservados 
Perfil Laguna Lillo (Lám. 1, A-D; Fig. 5)

Este perfil abarca mayormente el miembro inferior (Laguna Lillo), y la parte más basal del miembro medio (Laguna Polina) de la Formación La Golondrina (Fig. 5). Posee una dirección OSO -ENE, y su base se localiza en 48¹2’4', S - 67¹6’4’' O (Fig. 4). El espesor total de la sección medida es de $\sim 84$ metros. A lo largo de la secuencia, predominan areniscas medianas a gruesas, con estratificación entrecruzada o en artesas, y conglomerados polimícticos clasto-soportados. Excepciones se encuentran a los 9-12, 23, y 79 metros de la base, donde se encuentran niveles de pelitas y areniscas finas-muy finas con laminación planar, portadoras de una rica flora fósil.

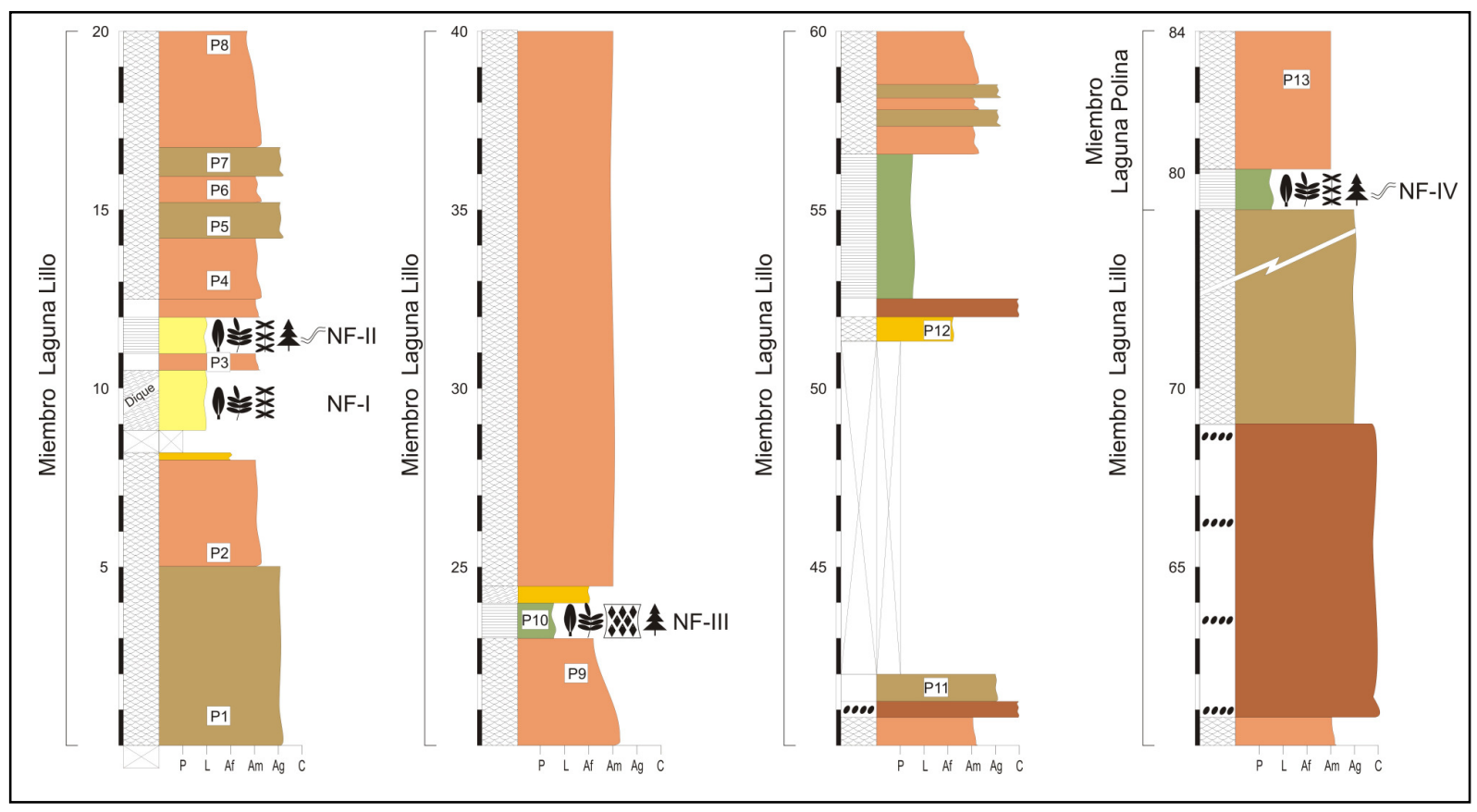

Figura 5 - Perfil realizado en la localidad de Laguna Lillo.

El perfil comienza con $8 \mathrm{~m}$ de areniscas gruesas a medianas con estratificación entrecruzada en artesas, que yacen sobre la base tapada por sedimento moderno. Le suprayace $1 \mathrm{~m}$ cubierto, y luego, afloran $\sim 2 \mathrm{~m}$ de limolitas con laminación ondulada, 
cruzada por un dique de composición subvolcánica, posiblemente de edad Jurásica. Este nivel es portador de flora fósil (Nivel fosilífero I: NFI), donde se registraron glossopterídeas estériles y helechos pecopterídeos mayormente, de buena preservación. Un estrato de aproximadamente $0,5 \mathrm{~m}$ de areniscas medianas subyace el siguiente nivel de limolitas fosilíferas (Nivel fosilífero II: NFII), con la misma flora encontrada en el nivel fosilífero anterior. A $12 \mathrm{~m}$ sobre la base, le siguen $\sim 10 \mathrm{~m}$ de areniscas medianas alternando con areniscas muy gruesas con entrecruzamientos en artesa, sin fósiles. A $23 \mathrm{~m}$ sobre la base, se encuentra $1 \mathrm{~m}$ de pelitas con estratificación laminar portadora de abundante flora (Nivel fosilífero III: NFIII), donde se hallaron glossopterídeas estériles, helechos pecopterídeos fértiles y estériles, y un nivel de troncos de licófitas in situ. Suprayacente sobre este nivel, hay unos $0,5 \mathrm{~m}$ de areniscas medianas con laminación ondulada. A continuación, siguen $\sim 16$ m de areniscas medianas con estratificación en artesa. Un nivel de conglomerados de aproximadamente medio metro aflora a $40 \mathrm{~m}$ sobre la base, y por encima de éste, hay casi $1 \mathrm{~m}$ de areniscas muy gruesas. Sedimentos modernos cubren aproximadamente $9 \mathrm{~m}$ del perfil. A $\sim 51 \mathrm{~m}$ desde la base, vuelven a aflorar unas areniscas medianas con capas entrecruzadas en artesas, y un nivel de conglomerados por encima de éstas, ambos niveles abarcando $1 \mathrm{~m}$ en total. Continúan $4 \mathrm{~m}$ de sedimento pelítico, con estratificación laminar, estéril. Una alternancia de areniscas medianas y gruesas con estratificación entrecruzada en artesas afloran en los $4 \mathrm{~m}$ siguientes. A $61 \mathrm{~m}$ sobre la base, se midió un nivel de $8 \mathrm{~m}$ de un conglomerado clasto-soportado, polimíctico, que presentaba una composición variada de granito, vulcanita, cuarcita, metamorfita y cuarzo (en orden decreciente) en sus clastos, reflejando variadas fuentes de procedencia. Los clastos eran de formas suavemente redondeadas, elongados y levemente aplanados, con una orientación preferencial hacia el N-S, lo que sugiere un potencial aporte desde la Cuenca de Tepuel Genoa, en Chubut, en acuerdo a lo propuesto por Jalfin (1987: 29). El perfil continúa con 9 $\mathrm{m}$ de areniscas gruesas con estratificación entrecruzada en artesas, que marcan el tope del miembro inferior, y se halla en contacto con un nivel de $1 \mathrm{~m}$ de pelitas con estratificación laminar, portador de flora fósil (Nivel fosilífero IV: NFIV), que marca la parte más basal del miembro medio. Por encima de este nivel, hay una arenisca de grano mediano, estéril. 
En este nivel se determinó arbitrariamente la finalización del levantamiento de la columna, por estar representado ya el miembro inferior, de interés en esta localidad.

El listado de las especies encontradas en los niveles fosilíferos (NF) marcados en el perfil Laguna Lillo (Fig. 5), se detalla a continuación:

Nivel fosilífero I (Miembro inferior)

Gangamopteris angustifolia McCoy, 1860

Gangamopteris mosesii Dolianiti, 1954

Gangamopteris sp.

Pecopteris sp. 3

Sphenophyllum sp.

Helecho indet.

Nivel fosilífero II (Miembro inferior)

Gangamopteris angustifolia McCoy, 1860

Gangamopteris sp. cf. G. castellanosii Archangelsky, 1957a

Gangamopteris mosesii Dolianiti, 1954a

Gangamopteris sp.

Pecoteris sp. 3

Asterotheca singeri Archangelsky, 1959a

Asterotheca sp.

Sphenophyllum sp.

Cordaites (Noeggerathiopsis) hislopi Seward y Leslie, 1908

Nivel fosilífero III (Miembro inferior) 
Bumbudendron patagonicum nov. sp.

Cyclodendron golondrinensis nov. sp.

Gangamopteris angustifolia McCoy, 1860

Gangamopteris mosessii Dolianiti, 1954

Gangamopteris obovata White, 1908

Gangamopteris sp.

Glossopteris sp. cf. G. ampla Dana, 1849

Glossopteris stipanicicii Archangelsky, 1957a

Glossopteris sp.

Megistophyllum leanzai Archangelsky, 1959a

Cordaites (Noeggerathiopsis) hislopi Seward y Leslie, 1908

Pecopteris sp. 3

Helecho indet.

Nivel fosilífero IV (Miembro medio)

Gangamopteris sp. cf. G. mosesii Dolianiti, 1954

Glossopteris ampla Dana, 1849

Glossopteris sp. cf. G. brownianaBrongniart, 1828

Glossopteris conspicua var. patagonica Archangelsky, 1957a

Glossopteris sp.

Vertebraria sp.

Sphenophyllum thonii Mahr, 1868

Sphenophyllum sp.

Lilpopia sp.

Asterotheca singeri Archangelsky, 1959a

Asterotheca sp. 
Pecopteris sp. 3

Cordaites (Noeggerathiopsis) hislopi Seward y Leslie, 1908

Perfil Laguna Polina (Lám. 2, A-D; Fig. 6)

Este perfil (Fig. 6) abarca el miembro medio (Laguna Polina) de la Formación La Golondrina, y la secuencia medida finaliza en el primer conglomerado (Conglomerados I de Archangelsky, 1959a) perteneciente al miembro superior (Dos Hermanos), según la estratigrafía propuesta por Jalfin (1987) y Archangelsky et al. (1996a). Posee una dirección predominantemente SSO-NNE, y su comienzo se localiza arbitrariamente en $48^{\circ} 09^{\prime} 41.6^{\prime}$ ' S - 67 15'09.9" O, dado que la base se encuentra tapada por vulcanitas Jurásicas (Fig. 4). El espesor total medido para esta sección es de 185 metros. En la primera mitad de la secuencia, predominan areniscas finas a medianas con estratificación en artesas, intercaladas con niveles más finos de pelitas y limolitas con laminación planar portadores de una abundante flora fósil. En la segunda mitad, predominan areniscas más gruesas, con un único nivel de pelitas portador de fósiles a $146 \mathrm{~m}$ desde la base. La secuencia termina en un conglomerado polimíctico (Conglomerado I), perteneciente al miembro superior (Dos Hermanos). 

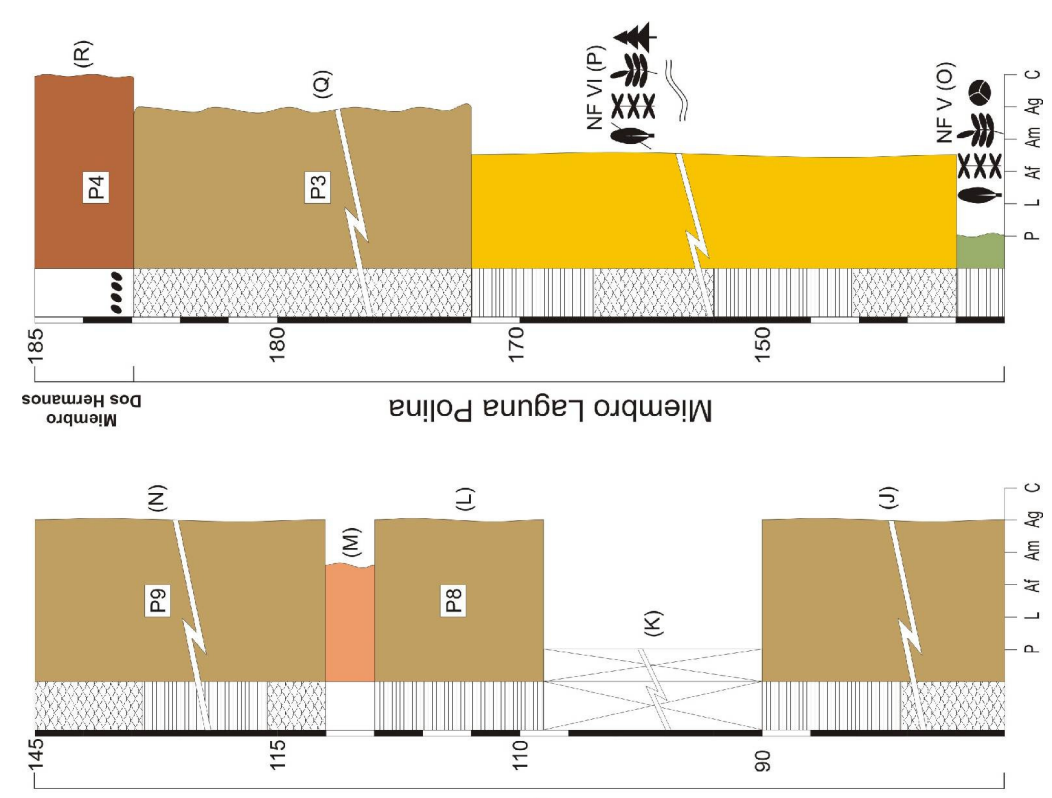

eu!|od eun6eך oıquə!W
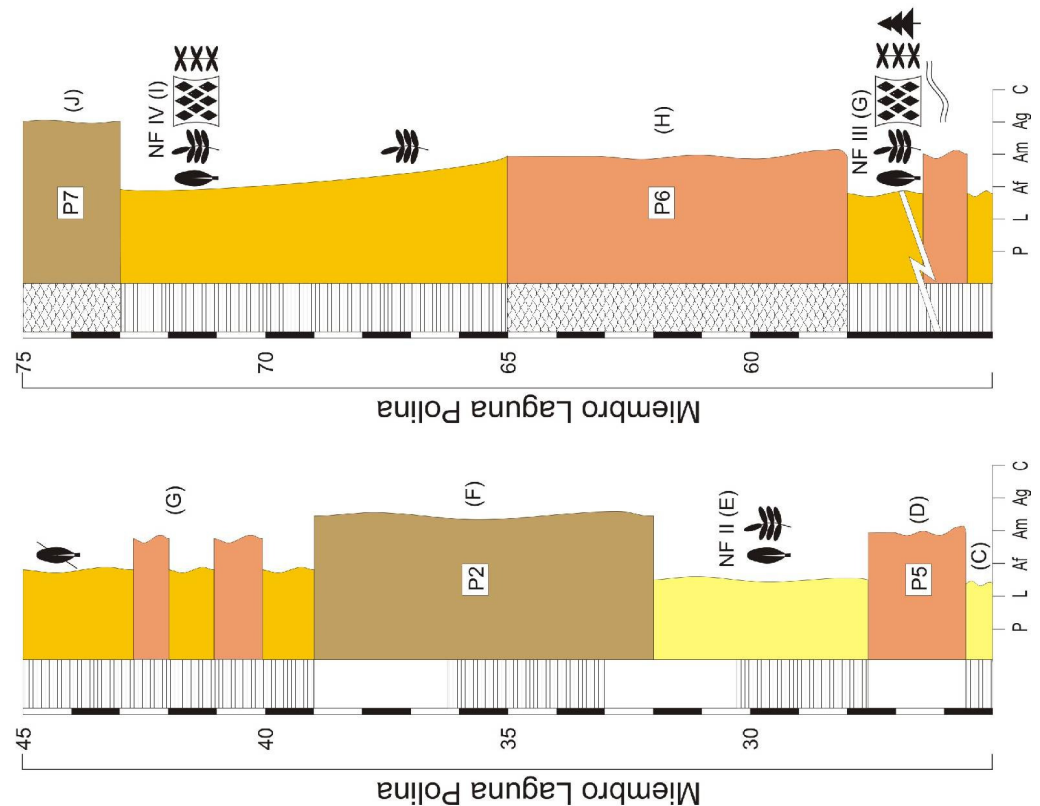

$\widehat{\underline{m}}$

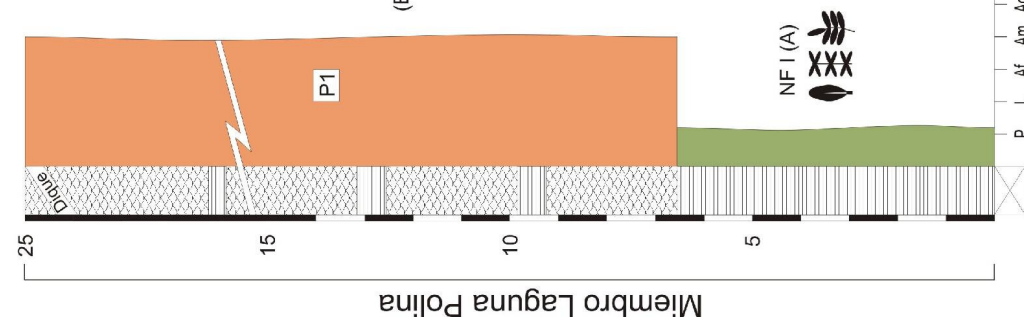

Figura 6 - Perfil realizado en la localidad de Laguna Polina. 
El perfil se comenzó arbitrariamente en el punto GPS mencionado previamente, en la margen S de la Laguna, a $135 \mathrm{~m}$ hacia el NO del Cerro Polina, donde aflora un nivel de sedimentitas Pérmicas. El primer estrato medido tiene un espesor de $7 \mathrm{~m}$, y está compuesto de pelitas con laminación planar, donde se hallaron restos de fósiles de glossopterídeas, helechos y sphenophyllales de regular preservación (A; Nivel fosilífero I: NFI). A continuación, alternan areniscas de grano mediano con estratificación entrecruzada en artesas y laminación planar, carentes de elementos fósiles (estériles), que alcanzan hasta los $25 \mathrm{~m}$ sobre la base (B). Le siguen aproximadamente $0,5 \mathrm{~m}$ de una limolita fina con laminación planar, estéril (C). Por encima, yace una arenisca de grano mediano, masiva (D). A 28 m sobre la base, aflora un estrato de limolitas con laminación planar en la base que pasa a masiva en su parte superior; glossopterídeas y helechos fueron hallados en este nivel (E; Nivel fosilífero II: NFII). A $32 \mathrm{~m}$ sobre la base, continúa un estrato de $7 \mathrm{~m}$ de espesor de areniscas gruesas, sabulíticas, con niveles alternantes de laminación planar y masivos (F). Sobre este estrato, yace una sucesión de areniscas finas a medianas con estratificación planar, que alcanzan los $58 \mathrm{~m}$ sobre la base $(\mathrm{G})$. Fósiles mal preservados fueron hallados a los 44-45 m sobre la base, mientras que glossopterídeas, helechos y licófitas de mejor preservación fueron recuperados de los niveles superiores (Nivel fosilífero III: NFIII). A continuación, sigue un estrato estéril de areniscas medianas con estratificación entrecruzada en artesas $(\mathrm{H})$, y por sobre éste, un estrato de areniscas más finas con laminación planar, con abundante presencia de fósiles muy bien preservados de glossopterídeas, helechos, licófitas y sphenophyllales mayormente (I; Nivel fosilífero IV: NFIV). A $73 \mathrm{~m}$ sobre la base, afloran $17 \mathrm{~m}$ de una arenisca muy gruesa, sabulítica, con estratificación entrecruzada en artesas en su parte basal, y luego, laminación planar (J). Aproximadamente $20 \mathrm{~m}$ de sedimento moderno cubren los niveles pérmicos, por lo que se infiere la presencia de una zona de falla en el área (K). A casi $110 \mathrm{~m}$ sobre la base, afloran $\sim 3,5 \mathrm{~m}$ de una arenisca gruesa con laminación planar (L), y por encima de este estrato, $1 \mathrm{~m}$ de arenisca mediana, masiva (M). La arenisca gruesa, sabulítica, vuelve a aflorar en los 31 $\mathrm{m}$ siguientes, alternando niveles laminares con estratificación entrecruzada en artesas $(\mathrm{N}) .1$ m de pelita laminar yace por encima de estas areniscas gruesas, portando flora fósil de muy buena preservación (O; Nivel fosilífero V: NFV). A $146 \mathrm{~m}$ sobre la base, y hasta los $171 \mathrm{~m}$ 
sobre ésta, yacen areniscas finas con estratificación entrecruzada en artesas alternando con niveles laminares, en los cuales se hallaron fósiles de relativamente buena preservación, y donde se registraron las primeras coníferas para la Formación La Golondrina (P; Nivel fosilífero VI: NFVI). Por encima de estas areniscas, afloran $12 \mathrm{~m}$ de areniscas muy gruesas, casi conglomerádicas, con capas entrecruzadas en artesa $(\mathrm{Q})$, que presentan dispersamente clastos subesféricos a prolados de aproximadamente $2-3 \mathrm{~cm}$ de diámetro promedio, de composición ígnea y arcósica, sin una orientación preferencial. Este nivel marca el tope del miembro medio (Laguna Polina). Finalmente, en concordancia, suprayace un nivel de ortoconglomerado, matriz-sostén $(\mathrm{R})$, con clastos bien redondeados, que marca el comienzo del miembro superior (Dos Hermanos).

Utilizando como referencia el perfil tipo (perfil I: 1959a) para el miembro medio Laguna Polina de Archangelsky (1959a), posteriormente mejorado por Jalfin (1987 y sucesivas publicaciones), el perfil aquí descripto se correlaciona en los siguientes niveles:

\begin{tabular}{||lll|}
\hline \multicolumn{1}{|c}{ Perfil Cariglino 2010 } & & \multicolumn{1}{c|}{ Perfil Archangelsky 1959 } \\
\hline A & $\rightarrow$ & - \\
B - E & $\rightarrow$ & P5 (NF II - III) \\
F & $\rightarrow$ & P6 \\
G & $\rightarrow$ & P7 (NF IV - V) \\
H - J & $\rightarrow$ & P8 - 10 (NF VI - NF VII) \\
K & $\rightarrow$ & - \\
L - Q & $\rightarrow$ & P11 (NF VIII - NF IX) \\
R & $\rightarrow$ & Conglomerado I \\
\hline
\end{tabular}

La flora fósil colectada incluye las siguientes especies:

\section{Nivel fosilífero I (A)}

Glossopteris argentina Archangelsky, 1957a

Glossopteris indica Schimper, 1869 
Glossopteris sp.

Gangamopteris mosesii Dolianiti, 1954

Gangamopteris sp.

Escamas de glossopterídeas

Pecopteris (Asterotheca) sp. 3

Pecopteris sp.

Sphenophyllum sp.

Helecho indet.

Semillas

Nivel fosilífero II (E)

(?) Glossopteris retifera Feistmantel, 1881

Glossopteris sp.

Pecopteris sp.

\section{Nivel fosilífero III (G)}

Asterotheca golondrinensis Herbst, 1978

Asterotheca sp. 3

Pecopteris sp.

Glossopteris conspicua var. patagonica Archangelsky, 1957a

Glossopteris sp.

Gangamopteris castellanosii Archangelsky, 1957a

Gangamopteris sp.

Sphenophyllum speciosum McClelland, 1850

Sphenophyllum thonii Mahr, 1868 
Sphenophyllum sp.

Caulopteris sp.

Samaropsis golodnrinensis A. Archangelsky, 2000

Licófita (?)

Coniferofitas

Tallos indet.

\section{Nivel fosilífero IV (I)}

Asterotheca golondrinensis Herbst, 1978

(?) Asterotheca piatnitzkyi Frenguelli, 1953

Asterotheca sp.

Pecopteris (Asterotheca) singeri Archangelsky, 1959a

Pecopteris (Asterotheca) sp. 3

Pecopteris sp.

Glossopteris argentina Archangelsky, 1957a

Glossopteris browniana Brongniart, 1828

Glossopteris conspicua var. patagónica Archangelsky, 1957a

Glossopteris damudica Feistmantel, 1881

Glossopteris indica Schimper, 1869

Glossopteris retifera Feistmantel, 1881

Glossopteris stipanicicii Archangelsky, 1957a

Glossopteris stricta Bunbury, 1861

Glossopteris sp.

Gangamopteris angustifolia McCoy, 1860

Gangamopteris mosesii Dolianiti, 1954

Gangamopteris obovata White, 1908 
Gangamopteris sp.

(?) Palaeovittaria kurtzi Feistmantel, 1876

Dictyopteridium spp.

Ottokaria spp.

Senotheca sp.

Arberia sp. (?)

Escamas de glossopterídeas

Annularia kurtzii Archangelsky, 1960a

Sphenophyllum speciosum McClelland, 1850

Sphenophyllum thonii Mahr, 1868

Sphenophyllum sp.

Cyclodendron golondrinensis nov. sp.

(?) Megistophyllum leanzai Archangelsky, 1959a

Samaropsis golondrinensis A. Archangelsky, 2000

Helechos indet.

Fructificaciones indet.

Nivel fosilífero $\mathrm{V}(\mathrm{O})$

(?) Pecopteris (Asterotheca) singeri Archangelsky, 1959a

Pecopteris sp.

Glossopteris conspicua var. patagonica Archangelsky, 1957a

Glossopteris sp.

Sphenophyllum sp.

Nivel fosilífero VI (P) 
Pecopteris (Asterotheca) singeri Archangelsky, 1959a

Pecopteris sp.

Glossopteris conspicua var. patagonica Archangelsky, 1957a

Glossopteris sp.

Sphenophyllum thonii Mahr, 1868

Sphenophyllum sp.

Megistophyllum leanzai Archangelsky, 1959a

Cordaites (Noeggerathiopsis) hislopi Seward y Leslie, 1908

Coniferofitas

Helechos indet.

Esfenófita indet.

Perfil Laguna Castellanos (Lám. 2, E-G; Fig. 7)

Únicamente el miembro medio (Laguna Polina) está representado en esta secuencia (Fig. 7). Fue medido siguiendo una dirección SSO - NNE, y su base se ubica en 48 11'01.6' S - 67²1'10.6' O (Fig. 4). El espesor total medido es de aproximadamente 70 metros. La primer parte de la secuencia está dominada por areniscas medianas con estratificación entrecruzada en artesas, alternando con niveles más finos de limolitas con estratificación entrecruzada, portadores de una rica flora fósil. La segunda mitad se caracteriza por un aumento en el tamaño de grano, predominando las areniscas gruesas, con estratificación entrecruzada en artesas, y algunos niveles de areniscas medianas y limolitas. 


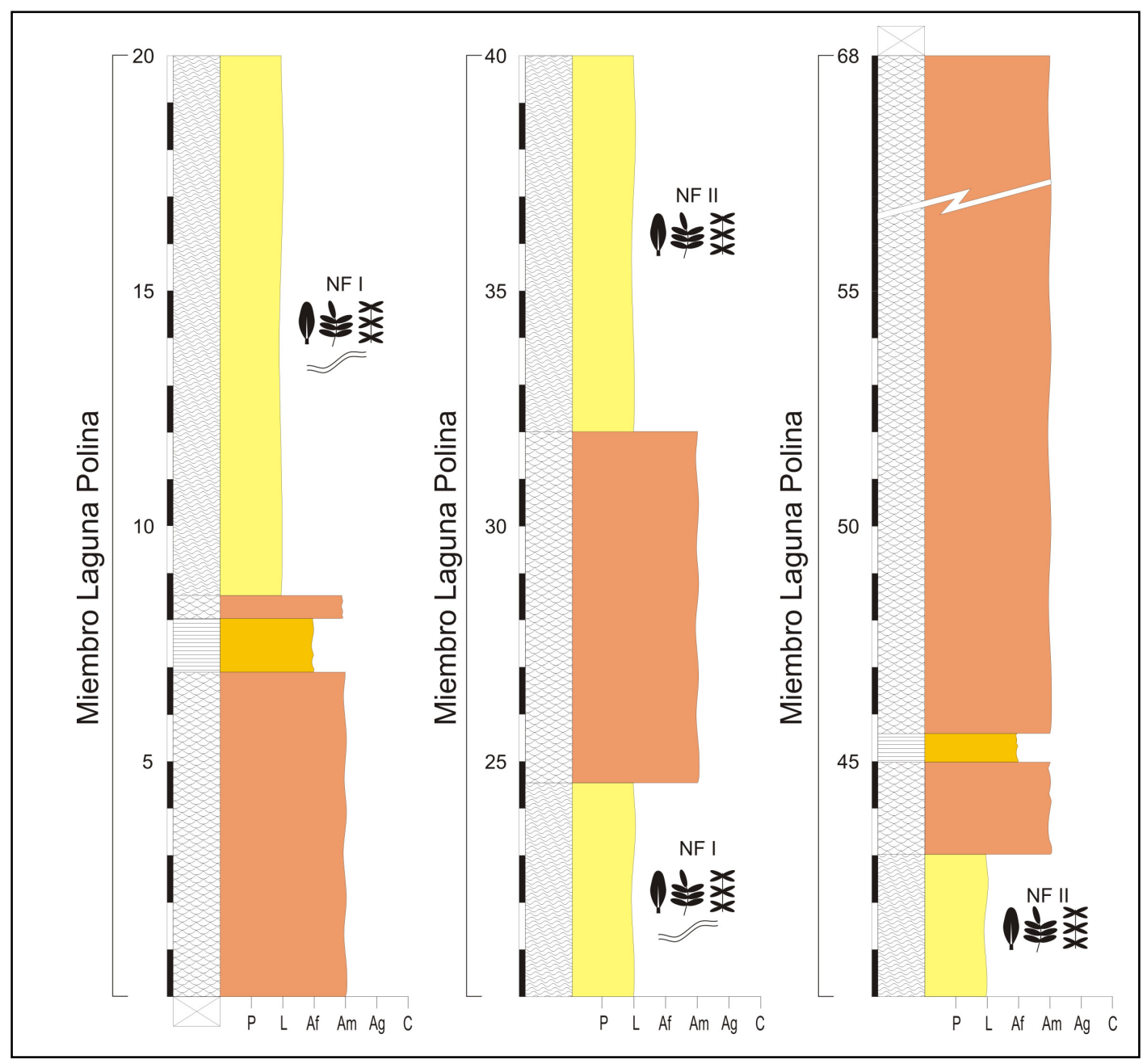

Figura 7 - Perfil realizado en la localidad de Laguna Castellanos.

El perfil comienza con $7 \mathrm{~m}$ de una arenisca mediana con estratificación entrecruzada en artesas. A continuación, le sigue $1 \mathrm{~m}$ de arenisca fina a mediana, con laminación planar. Por encima de éste nivel, yacen 0,5 m de areniscas medianas, también con estratificación entrecruzada en artesas. A 8,5 m sobre la base, continúan 16 m de limolitas con laminación ondulada portadoras de una abundante flora fósil, que incluye glossopterídeas, helechos, sphenophyllales, e icnitas (Nivel fosilífero I: NFI). Suprayaciendo estas limolitas, hay 7,5 $\mathrm{m}$ de areniscas medianas, con entrecruzamientos en artesas. Por encima, vuelven a aflorar $11 \mathrm{~m}$ de limolitas con laminación ondulada, también portadora de flora fósil (Nivel fosilífero II: NFII). A $43 \mathrm{~m}$ sobre la base, siguen aproximadamente $2 \mathrm{~m}$ de areniscas 
medianas con estratificación entrecruzada en artesas, estéril. 0,5 m de una arenisca entre fina y mediana suprayace estas areniscas, donde se encontraron algunos restos mal preservados de glossopterídeas sin detalle de venación. Por último, se midieron $\sim 23 \mathrm{~m}$ de areniscas medianas con capas entrecruzadas en artesas, estériles. Sedimento moderno cubre por encima de este nivel, por lo que se decidió finalizar con la columna en estas areniscas.

Los elementos fósiles colectados incluyen:

\section{Nivel fosilífero I}

Sphenophyllum speciosum McClelland, 1850

Sphenophyllum thonii Mahr, 1868

Pecopteris (Asterotheca) sp. 3

Pecopteris sp.

Glossopteris conspicua var. patagonica Archangelsky, 1957a

Glossopteris ampla Dana, 1849

Glossopteris sp.

Gangamopteris sp.

Eremopteris golondrinensis Archangelsky, 1959b

Samaropsis golondrinensis A. Archangelsky, 2000

Escamas tipo C

\section{Nivel fosilífero II}

(?) Chiropteris harrisii Archangelsky, 1960b

Eremopteris golondrinensis Archangelsky, 1959b

Sphenophyllum thonii Mahr, 1868

Pecopteris sp. 
Glossopteris sp.

Perfil Laguna Feruglio (Lám. 2, H-I; Fig. 8)

El perfil (Fig. 8) para esta localidad fue medido a partir desde unos $150 \mathrm{~m}$ al sur de la costa de la laguna homónima, con su base localizada en 48¹0’30.0' ' S - 67¹6'59.0', O (Fig. 4). La secuencia se midió siguiendo el margen de la laguna, manteniendo una dirección aproximada SO-NE. El total medido para la secuencia es de 60 metros. A lo largo del perfil, predominan las areniscas de grano grueso, y los niveles conglomerádicos, con algunas excepciones de niveles finos (pelíticos y limolíticos) alternando, y portadores de flora fósil, predominantemente glossopterídeas tanto fértiles como estériles, helechos pecopterídeos fructificados, y sphenophyllales. Estos niveles se presentan a los $\sim 38,41$, y 50 metros desde la base. A $55 \mathrm{~m}$ sobre la base, se encuentra el límite entre los miembros medio (Laguna Polina), y el miembro superior (Dos Hermanos), marcado por la presencia de un conglomerado polimíctico, de composiciones variadas, de mayor a menor: granitoide, arenisca, metamorfita, vulcanita, cuarcita, ortocuarcita, vaque-cuarcita, cuarzo-feldespato y filita. Los son clastos redondeados, elongados y aplanados, con imbricación que sugiere una paleocorriente N-S, apoyando la propuesta de aporte desde la Cuenca de TepuelGenoa, como lo sugirió Jalfin (1987: 29). 


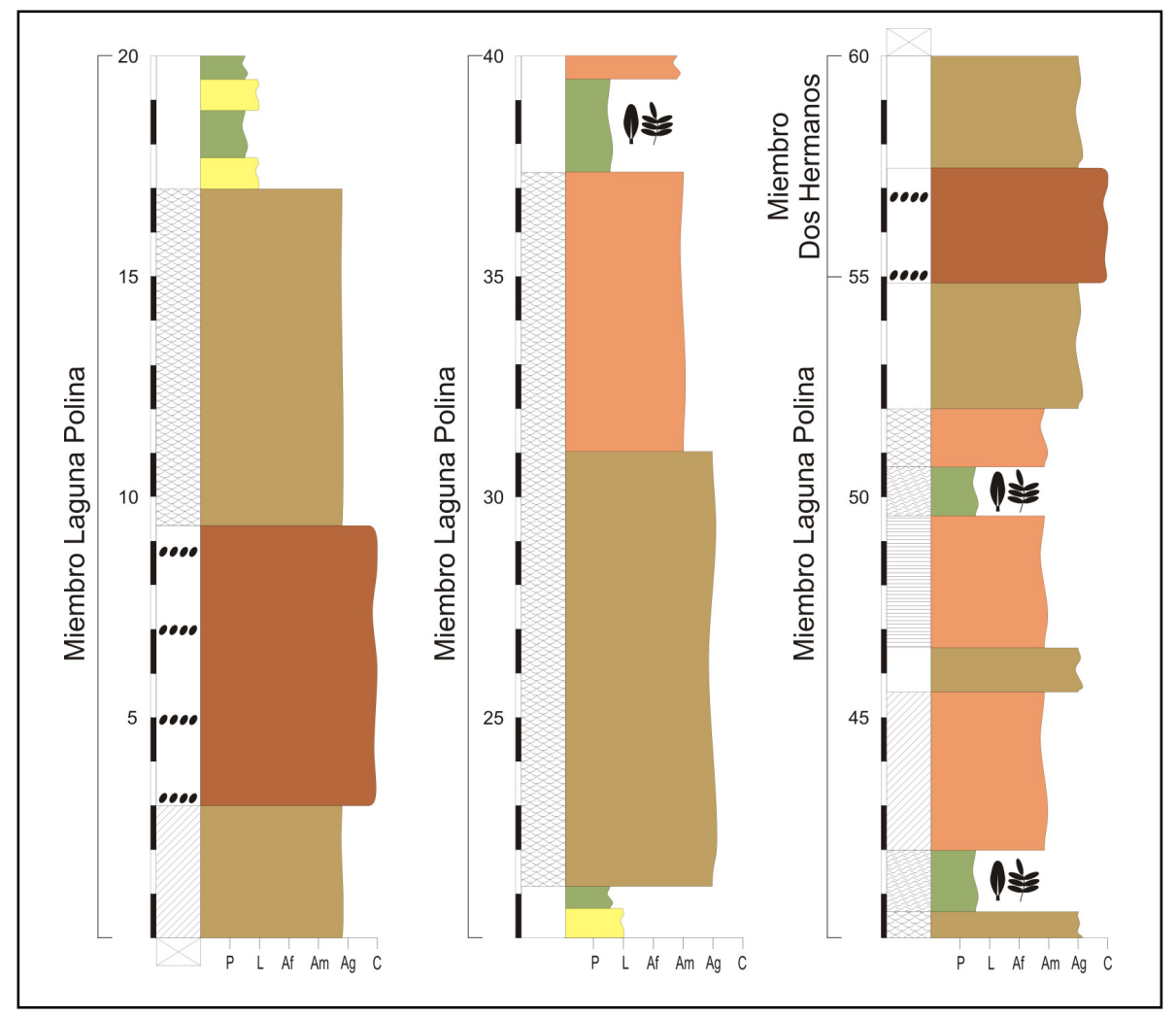

Fig. 8 - Perfil realizado en la localidad de Laguna Feruglio.

La flora fósil hallada en los niveles portadores mencionados en el perfil (Fig. 8) presentan los siguientes elementos:

Pecopteris (Asterotheca) anderssonii Archangelsky y de La Sota, 1960

Pecopteris sp.

Asterotheca singeri Archangelsky, 1959a

Asterotheca sp.

Dizeugotheca furcata Arrondo, 1972

Dizeugotheca neuburgiae Archangelsky y de La Sota, 1960

Dizeugotheca waltonii Archangelsky y de La Sota, 1960

Dizeugotheca sp. 
Gangamopteris obovata White, 1908

Glossopteris ampla Dana, 1849

Glossopteris browniana Brongniart, 1828

Glossopteris conspicua var. patagonica Archangelsky, 1957a

Glossopteris damudica Feistmantel, 1881

Glossopteris retifera Feistmantel, 1881

Glossopteris stipanicicii Archangelsky, 1957a

Glossopteris stricta Bunbury, 1861

Glossopteris sp.

Plumsteadia pedicellata Cariglino et al., 2009

Bifariala sp. cf. B. intermittens Prevec, 2008

Sphenophyllum thonii Mahr, 1868

Sphenophyllum sp.

Helecho indet.

Perfil Laguna Turbia (Lám. 1, E; Fig. 9)

La secuencia medida en Laguna Turbia (Fig. 9) se levantó con el fin de ubicar estratigráficamente las muestras de paleoflora encontradas, en su gran mayoría, licófitas. Archangelsky (1960a) describió unas licófitas provenientes del "contacto entre el granito y el Paleozoico" (1960a: 26, 28), que no figuraban dentro del área mapeada previamente por él (1959a). En una consulta al Dr. Archangelsky, él mismo me confirmó que esa zona se encontraba pasando la Ea. La Golondrina, hacia el norte, cerca de la "pista de aterrizaje". En base a imágenes satelitales actuales (Google Earth®) y ayuda del mapa geológico del Bajo de La Leona reproducido por Godeas (1985), me fue posible hallar el "contacto", el cual afloraba en la margen norte de la Laguna Turbia. Es a partir de estos datos, que en la campaña llevado a cabo en 2010, prospectamos la zona, coleccionamos más licófitas, entre otros elementos florísticos, y levantamos un perfil para ubicar estratigráficamente el 
material fósil. Este perfil abarca el miembro medio (Laguna Polina), y posee una dirección NW-SE. Su base está localizada en 48 05'31.1' S $-67^{\circ} 18^{\prime} 24.01^{\prime \prime}$ O. El espesor total medido para esta sección es de $\sim 50 \mathrm{~m}$. La secuencia en su totalidad está dominada por una arenisca mediana a gruesa, masiva, con una arenisca de grano fino con fósiles mal preservados entre los 8 y 13 metros desde la base.

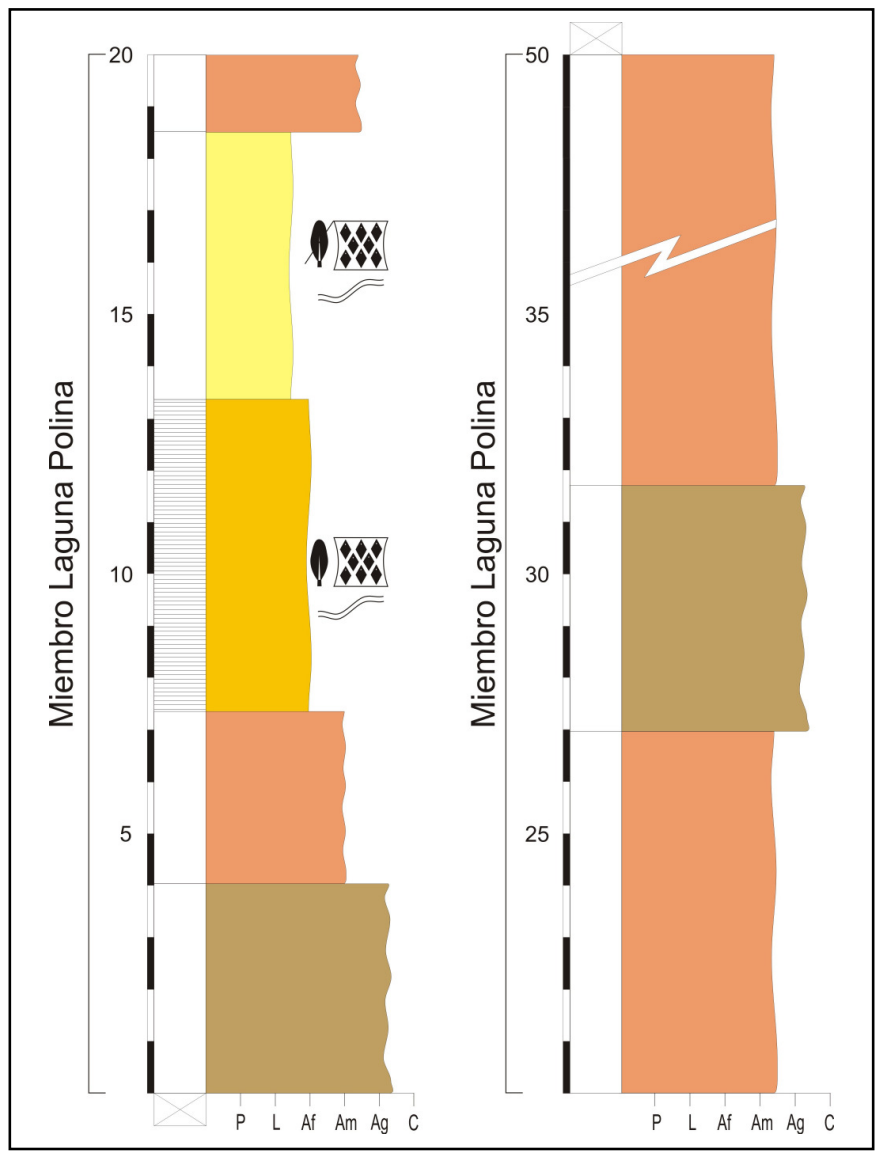

Fig. 9 - Perfil realizado en la localidad de Laguna Turbia.

Los ejemplares colectados son mayormente ejemplares de licófitas, y algunas hojas de Glossopteris sp. El material no presenta una buena preservación general. Entre los elementos hallados, se destacan: 


\section{Glossopteris sp.}

\section{Gangamopteris sp.}

Cyclodendron golondrinensis nov. sp.

Micrófilos de licófitas

\section{3 - Discusión general}

El relevamiento de los perfiles se llevó a cabo en todas las zonas prospectadas donde se recolectó material fósil, a excepción de la localidad de Dos Hermanas (miembro superior, Fig. 4) y Laguna de los Fósiles (Estancia La Juanita, Fig. 3), por haberse colectado fósiles de relativamente mala preservación. Asimismo, se realizó un perfil (Fig. 9) en la zona de Laguna Turbia (ver Godeas, 1985: fig. 2), con la intención de encontrar más ejemplares de los especímenes de licófitas colectados por el Dr. Archangelsky (1960a) y ubicarlos estratigráficamente.

Todos los taxones colectados fueron ubicados estratigráficamente en cada uno de los perfiles relevados (Figs. 5-9), y en las localidades tipo del miembro inferior (Laguna Lillo) y miembro medio (Laguna Polina), se levantaron muestras de areniscas para su posterior análisis petrográfico en el gabinete (Figs. 5, 6).

A partir de los listados de taxa para cada perfil, se observa que la Laguna Polina sigue siendo la localidad fosilífera de excelencia en la Formación La Golondrina, tanto por la abundancia como por la excelente preservación de los fósiles que allí se pueden extraer.

Por último, en este trabajo se presenta por primera vez un listado de ejemplares de flora fósil para el miembro inferior, provenientes de la localidad tipo Laguna Lillo (Fig. 5).

En el capítulo siguiente (Capítulo 4), se describen, asignan, e ilustran todos los taxa mencionados en los listados precedentes. 


$$
\begin{gathered}
\text { - CAPÍTULO } 4 \text { - } \\
\text { DESCRIPCIÓN SISTEMÁTICA }
\end{gathered}
$$




\section{0 - DESCRIPCIÓN SISTEMÁTICA.}

\section{1 - Antecedentes}

La flora de la Formación La Golondrina ha sido ampliamente estudiada en distintas contribuciones, entre las que se destacan las de Archangelsky (1957a, 1959a, 1959b; 1960a, 1960b; 1992), Archangelsky y de La Sota (1960), Archangelsky y Bonetti (1963), Arrondo (1972), Herbst (1978), Archangelsky y Cúneo (1984), Durango de Cabrera (1990), Archangelsky et al. (1996a, 1999, 2004), Archangelsky, A. (1999, 2000), y Escapa y Cúneo (2006). Hasta el momento, fueron descriptos taxones correspondientes a Glossopterídeas (18), helechos (15), y en menor medida, esfenófitas (4), licófitas (4) y cordaitales (1), y algunos morfogéneros de afinidad incierta (Megistophyllum leanzai, Chiropteris harrisii).

En esta tesis se incorporan nuevas especies de glossopterídeas (fructificaciones), helechos, y esfenófitas, mientras que unas pocas, son redescriptas y reasignadas. Algunos elementos son mantenidos con una asignación abierta a discusión. Todos los elementos aquí mencionados son descriptos e ilustrados.

A lo largo de esta sección, se listan todos los taxa conocidos para la Formación La Golondrina hasta la fecha, pero únicamente se describen aquellos que son novedosos, ya sea como especies nuevas o primer hallazgo para la Formación. Las especies previamente descriptas son ilustradas y refereridas a la publicación correspondiente. Con esto, se intenta evitar la repetición descriptiva de taxones que han sido ya ampliamente estudiados y reconocidos para la Formación La Golondrina.

El material novedoso aquí presentado es descripto en base a características cualitativas y cuantitativas. En cuanto a las medidas tomadas, están dadas en escala milimétrica, y en aquellos casos en los que se pudo realizar un set de mediciones, se consideraron los valores mínimo, media, y máximo en milímetros (\#-[\#]-\# mm). En aquellos casos en que es posible, se pone mayor énfasis en la descripción de las 
características de la parte reproductiva de los especímenes, dado que es a partir de éstas que un ejemplar puede ser asignado con mayor seguridad que si se toman únicamente en cuenta las características de la parte estéril (helechos, por ejemplo). Asimismo, bajo "material nuevo" se mencionan aquellos ejemplares hallados en las colecciones que no han sido previamente descriptos o publicados (Colecciones Lil, LP-Pb, BA-Pb, BAFC-Pb) o bien, ejemplares provenientes de las campañas llevadas a cabo recientemente, por la autora (MPM-Pb).

\subsection{PTERIDOPHYTA}

Orden MARATTIALES Link, 1833

Familia ASTEROTHECACEAE sensu Boureau y Doubinger, 1975

Género Asterotheca Pres1, 1845

Especie tipo: Asterotheca sternbergii (Goeppert) Pres1, 1845

Asterotheca sp. 1

Lám. I, Figs. 1-3

Material nuevo: $\mathrm{BA}-\mathrm{Pb} 13801$.

Descripción: Pinnas con raquis no estriado. Pínnulas (sub)opuestas a alternas, casi perpendiculares al raquis, alargadas, de margen recto y paralelos. Ápice redondeado. Base ancha y simétrica. Vena media marcada, recta, llegando hasta casi el ápice, donde se abre 
en varias venas secundarias, todas del mismo calibre. Venas secundarias rectas, saliendo en ángulo $\sim 45^{\circ}$ hacia el margen. Hay pínnulas estériles y fértiles en el mismo ejemplar (Lám. I, fig. 1), inclusive, en una misma pinna se observan las pínnulas apicales estériles y las más inferiores fértiles. Pínnulas fértiles con pequeños sinangios redondos, agrupados en dos hileras, una a cada lado de la vena media (Lám. I, fig. 2). Las hileras no son todo a lo largo de la pínnula, sino más bien en la parte media de ésta. Hasta 10 sinangios por fila.

Medidas: Largo pinnulas $=6,8-[9,7]-11,1 \mathrm{~mm}$; ancho pinnulas $=2,8-[3,2]-3,9 \mathrm{~mm} ; \mathrm{L}: \mathrm{A}=$ 3 ; ancho raquis $=0,5-[0,8]-1,2 \mathrm{~mm}$.

Discusión: A diferencia de la mayoría de las Asterothecáceaeas presentes en La Golondrina, las venas secundarias que salen de la vena media de la pínnula son rectas, y no sufren ninguna dicotomía (Lám. I, fig. 3). La vena media y un conjunto de venas apicales secundarias del mismo calibre se abren en abanico, alcanzando todo el margen apical de la pínnula. Estas características son suficientes para considerar a este ejemplar distinto de las especies registradas hasta el momento para la Formación La Golondrina. Sin embargo, la ausencia de detalle en lo que sus estructuras fértiles respecta, no permite determinar momentáneamente en cuantos esporangios estarían divididos los sinangios, un carácter que suele ser de importancia taxonómica. Debido a esto, se prefiere dejar la asignación específica abierta, hasta que la aparición de nuevo material mejor preservado permita resolver esta situación.

\section{Asterotheca sp. 2}

Lám. II, Figs. 1-9

Material nuevo: BA-Pb 13756 a-d, 13758 a-b, 13759 b, 13854, 13869. 
Descripción: Pinnas alternas (Lám. II, figs. 1,5), con aguzamiento en la parte apical. Pínnulas pequeñas, anchas, cortas, bien redondeadas en su ápice y completamente apoyadas por su base (Lám. II, fig. 3). Pínnulas subopuestas a alternas. Las estériles tienen una vena media recta, marcada, llega al ápice. Las venas II no se observan claramente, pero parecieran salir en ángulo semi-agudo desde la vena media. Son rectas y simples (no presentan dicotomías). Las pínnulas fértiles tienen entre 2 y 3 sinangios a cada lado de la vena media, aunque se han observado hasta 6 a cada lado de la vena media en pínnulas mayores (Lám. II, fig. 2). Hay 4 esporangios por sinangio (Lám. II, figs. 4, 8).

Medidas: Largo pinnulas = 2,9-[4,5]-6,4 mm; ancho pinnulas = 2,6-[3,4]-4,2 $\mathrm{mm}$; L:A = 1,32 ; ancho raquis $=1,1-[1,8]-2,2 \mathrm{~mm}$.

Discusión: Esta especie difiere de las otras conocidas para La Golondrina en el tamaño reducido de sus pínnulas, la presencia de venas secundarias que no dicotomizan, y la presencia de (más comunmente) 5 sinangios tetra-esporangiados por pínnula (aunque con excepciones, se han contabilizado hasta 6 a cada lado de la vena media). Es por ello que estos ejemplares estarían representando una especie novedosa para la Formación La Golondrina. Pese a la exhaustiva búsqueda a través de bibliografía (Archangelsky y de La Sota, 1960; Boureau, 1970, 1975; Anderson y Anderson, 1985; Rohn y Rösler, 1986; Vieira et al., 2004, 2007), tampoco se hallaron hasta el momento especies comparables, por lo que ésta podría ser además, una especie novedosa a nivel global. Sin embargo, se prefiere mantener su asignación abierta hasta certificar que todas las fuentes bibliográficas hayan sido agotadas.

Asterotheca sp. 3

Lám. III, Figs. 1-7 
Material nuevo: MPM-Pb 2631 a-b, 1632, 2637, 4417, 4421, 4422, 4432, 4439, 4441, 4530, 4536, 4537, 4560, 4566/8, 4576 a-b, 4586/91, 4587, 4591, 4592, 4600, 4605, 4627, $4767,15141 / 7$.

Descripción: Tallos al menos bi-pinnados, lisos, estriados o con puntuaciones (Lám. III, figs. 1, 3, 6). Pinnas opuestas a subopuestas. Pínnulas pecopterídeas de tamaño pequeño, opuestas, elongadas, falcadas, con ápice subagudo a redondeado, y base recta, unida en su totalidad al eje, en algunos caso levemente ensanchada (Lám. III, figs. 2, 4, 6, 7). Vena media de la pínnula recta, llega casi hasta el ápice. Las venas laterales fueron difíciles de observar, cuando se pudo, se las vió hasta una vez bifurcadas. Pínnulas fértiles con hasta 8 sinangios circulares a cada lado de la vena media cubriendo el envés de la pínnula (Lám. III, fig. 2).

Medidas: Largo pinnulas = 1,8-[4,7]-7 mm; ancho pinnulas =0,7-[1,7]-2,3 mm; L:A= 2,8; ancho raquis $=0,2-[0,7]-1,3 \mathrm{~mm}$.

Discusión: Las pínnulas de esta especie se asemejan en forma y características a Asterotheca singeri. Sin embargo, difieren en el tamaño (considerablemente menor en Asterotheca sp. 3), y la disposición apretada y opuesta de las pínnulas y pinnas en el eje. La preservación regular de los ejemplares aquí descriptos no permitió la observación detallada de los sinangios, por lo que no se puede decir cuántos esporangios los componen. Sin embargo, la forma circular de los sinangios no hace dudar de su asignación al género Asterotheca.

Si bien el material considerado es relativamente abundante, la mayoría de los ejemplares estudiados son estériles y de una preservación más bien pobre, por lo que se prefiere por el momento mantener su asignacón abierta, hasta hallar más y mejores ejemplares con frondes fértiles, que ayuden a asignar específicamente a este material. 
Asterotheca andersonii (Halle) Archangelsky y de La Sota, 1960

Lám. IV, Figs. 1-6

Referencias: Archangelsky y de La Sota (1960: 86).

Material nuevo: BA-Pb 13580, 13804, 13818, 13868, 13859, 13926, 13927, 14045, 14050, 14059; MPM-Pb 2557 a-b, 4395, 4446, 4489 a-b, 4490, 4491, 4494.

Discusión: Las características más distintivas de esta especie son la vena media decurrente que no llega al ápice, la dicotomización (hasta dos veces) de las venas secundarias, y la forma menos falcada de las pínnulas comparadas con aquellas de Asterotheca singeri(Lám. IV, figs. 1, 5, 6). Sin embargo, puede haber casos de pínnulas fértiles de A. andersonii que son fácilmente confundibles con las de A. singeri, dado que la cantidad, forma, y tipo de sinangios es similar, y éstos cubren la lámina por entero, impidiendo ver las características de la vena media de la pínnula, carácter definitorio entre una y otra especie (Lám. IV, figs, $2,3,4)$. La presencia de un raquis de pinna estriado es también una característica única de esta especie (Lám. IV, figs. 2, 3, 6).

Las pínnulas fértiles tienen aproximadamente 8 sinangios por pínnula en total, aunque este número puede variar entre 6 y 7 (Lám. IV, figs. 2, 3). Se han contabilizado hasta 6 esporangios por sinangio (Lám. IV, fig. 4). 
Asterotheca golondrinensis Herbst, 1978

Lám. V, Figs. 1-4

Referencias: Herbst (1978: 126-130); Archangelsky et al. (1999: 71-81).

Material nuevo: BA-Pb 13858 (?); MPM-Pb 4509, 4590, 15107, 15148.

Discusión: A. golondrinensis es diferente de las demás especies descriptas para La Golondrina en la presencia de pínnulas con márgenes dentados, y su venación secundaria, simple y casi recta (Lám. V, figs. 1-4).

Las pínnulas fértiles poseen entre 7 y 8 sinangios circulares con hasta 5 esporangios, dispuestos a lo largo de los márgenes, separados entre sí por una breve distancia.

Asterotheca piatnitzkyi Frenguelli, 1953

Lám. VI, Figs. 1-6

Referencias: Archangelsky y de La Sota (1960: 93).

Material nuevo: BA-Pb 13759, 13785, 13810, 13857, 14049; MPM-Pb 4438, 4510, 4602 (?), $4603(?), 4604(?)$.

Discusión: Las características más distintivas de esta especie con respecto a las demás son la ausencia de un raquis estriado en las pinnas, y la vena media de las pinnulas decurrente con venas secundarias una vez dicotomizadas en aquellas estériles (Lám. VI, fígs. 1-6). 
Pínnulas fértiles generalmente con 8-11 sinangios en total. Comúnmente, hay 6 esporangios por sinangio, aunque pueden contabilizarse también 4 o 5 (Lám. VI, figs. 2, 3, $4,6)$.

Asterotheca singeri Archangelsky, 1959a

Lám. VII, Figs. 1-7

Referencias: Archangelsky y de La Sota (1960: 97).

Material nuevo: BA-Pb 13816, 13819, 14041, 14042, 14044, 14046, 14051; MPM-Pb 2505, 2611-2612, 2617-2619 b, 2623 a-b, 2716 a-b, 2718, 2829, 2840, 2869, 4395, 4488 (?), 4512, 4700 a-b.

Discusión: A. singeri se diferencia de las otras especies por la presencia de una vena media recta que llega hasta el ápice y está bien marcada, venas secundarios una vez bifurcadas (Lám. VII, figs. 1, 2), y en aquellas pínnulas fértiles, por la cantidad de sinangios (+8 a cada lado de la vena media) ocupando toda la lámina.

Las pínnulas fértiles son iguales a las estériles, con una hilera de 8 o más sinangios formada a cada lado de la vena media. Los sinangios poseen hasta 6 esporangios, siendo 4 o 5 también comunes (Lám. VII, figs. 3-7). 
Género Dizeugotheca Archangelsky y de La Sota, 1960

Especie tipo: Dizeugotheca waltonii Archangelsky y de La Sota, 1960.

Dizeugotheca furcata Arrondo, 1972

Lám. VIII, Figs. 1-4

Referencias: Arrondo (1972: 41).

Material nuevo: BA-Pb 13793, 13799, 13838; MPM-Pb 2601 b, 2605.

Discusión: Los dos caracteres principales tenidos en cuenta para asignar a los ejemplares como D. furcata fueron la presencia de venas secundarias dicotomizadas (Lám. VIII, fig. 1), y la disposición alterna a subopuesta de las pínnulas sobre el raquis de la pinna (Lám. VIII, fig. 2). En aquellos ejemplares fértiles, las tecas ocupan todo el envés de las pínnulas, y se disponen apretadamente (Lám. VIII, figs. 3 y 4).

Dizeugotheca neuburgiae Archangelsky y de La Sota, 1960

Lám. IX, Figs. 1-4

Referencias: Archangelsky y de La Sota (1960: 104). 
Material nuevo: $\mathrm{BA}-\mathrm{Pb} 13786,13787,13788,13790,13791,13796,13798,14054$, 14055; MPM-Pb 2521, 2523, 2563, 2572, 2579, 2580, 2581, 2582, 2583, 2594 a-b, 2592, 2624 a-b, 2899.

Discusión: El carácter principal para reconocer esta especie de las otras de Dizeugotheca es la presencia de pínnulas opuestas (Lám. IX, figs. 1-4), siendo alternas en D. waltonii y D. furcata. Además, se caracteriza por la presencia de un raquis de pinna surcado (Lám. IX, figs. 2, 3). En las pínnulas estériles, la vena media es robusta y recta, y las laterales simples (Lám. IX, fig. 1). En las pínnulas fértiles, las tecas se disponen perpendicularmente a la vena media, y ocupan todo el envés de la pínnula (Lám. IX, figs. 2-4).

Dizeugotheca waltonii Archangelsky y de La Sota, 1960

Lám. VIII, Figs. 5-6

Referencias: Archangelsky y de La Sota (1960: 102); Arrondo (1969: 62, 1972: 48).

Material nuevo: MPM-Pb 2543, 2544, 2562 (?), 2615, 2622, 4482.

Discusión: Dizeugotheca waltonii se diferencia de Dizeugotheca neuburgiae en las venas secundarias (rectas en la primera, más curvadas en la segunda), y en el número de tecas en el envés de la pínnula (siendo mucho menor en $D$. waltonii), las cuales no ocupan todo el envés de la pínnula (como ocurre en D. neuburgiae) (Lám. VIII, figs. 5, 6).

Esta especie es característica del Miembro Medio de la Formación La Golondrina, por lo que le da nombre a la biozona inferior de las Superzona de Dizeugotheca. 
Familia MARATTIACEAE Berchtold y Presl, 1820

Género Pecopteris (Brongniart) Sternberg, 1825

Especie tipo: Pecopteris pennaeformis Brongniart, 1822

Pecopteris sp A Archangelsky, 1959a

Lám. X, Figs. 1-3

Referencias: Archangelsky (1959a: 43).

Material nuevo: $\mathrm{BA}-\mathrm{Pb} 13928$.

Discusión: La presencia de un fino canal longitudinal en el raquis de las pinnas (Lám. X, fig. 1), así como la inclinación que tienen las pinnulas en el raquis (menor a $80^{\circ}$, Archangelsky, 1959a: 43) (Lám. X, figs. 2, 3), diferencian esta especie de A. andersonii. Sin embargo, hasta el momento, únicamente un ejemplar estéril perteneciente a la colección $\mathrm{BA}-\mathrm{Pb}$ ha sido asignable a esta especie, sin hallarse nuevo material para mejorar su descripción, y poder así asignarle un epíteto específico adecuado.

Pecopteris sp I Archangelsky y de La Sota, 1960

Lám. X, Fig. 4

Referencias: Archangelsky y de La Sota (1960: 110). 
Material nuevo: BA-Pb 13809 (?).

Discusión: Pecopteris sp. I se asemeja a Asterotheca anderssonii en la venación secundaria hasta tres veces dicotomizada; sin embargo, se diferencia de ésta en la ausencia de una vena media decurrente, siendo recta todo a lo largo en Pecopteris sp. I.

Pecopteris sp III Archangelsky y de La Sota, 1960

Referencias: Archangelsky y de La Sota (1960: 112).

\section{Material nuevo: -}

Discusión: Archangelsky y de La Sota (1960) sugieren cierto parecido con las pínnulas de D. neuburgiae en base a las dimensiones, y a lo que pareciera ser un esbozo de "cápsulas del tipo Dizeugotheca" (1960: 112). La ausencia de venas laterales observables, sin embargo, no permitieron ubicar a este material específicamente. Tampoco se halló material como el de esta descripción en las colecciones revisadas o material recientemente colectado.

Pecopteris sp IV Archangelsky y de La Sota, 1960

Lám. X, Figs. 5-6

Referencias: Archangelsky y de La Sota (1960: 112).

Material nuevo: BA-Pb 13887, 14066. 
Discusión: Esta especie posee un raquis con numerosas puntuaciones (Lám. X, figs. 5, 6), y en algunos casos, con un surco medio bien visible. Las pínnulas se disponen de forma alterna, y presentan una vena media recta, con venas laterales una vez furcadas. En aquellos casos en que las pínnulas se encuentran más falcadas, esta especie puede ser muy semejante a aquella descripta por Arrondo (1969) para Dizeugotheca furcata; sin embargo, al no haber evidencia fértil, el material es asignado bajo el epíteto Pecopteris sp. IV.

Género Caulopteris Lindley y Hutton, 1832

Especie tipo: Caulopterys primaeva Lindley y Hutton, 1832.

\section{Caulopteris sp.}

Lám. XI - Figs. 1-7

Material nuevo: MPM-Pb 15137, 15105 (?), 15114 (?) 15124 (?).

Descripción: Tallos incompletos, fragmentados. El ancho promedio medido de los tallos es de 10,2 $\mathrm{mm}$. Cicatrices circulares de 2-3 mm de diámetro, con una marca central (¿haz vascular?) dispuestas en hileras verticales con un patrón helicoidal. Estriado longitudinal presente.

Discusión: Caulopteris se utiliza para incluir tallos generalmente asociados a frondes de tipo pecopterídeas (Boureau, 1970). El género Caulopteris se caracteriza por la presencia de estrías longitudinales marcadas, que a veces tapan la presencia de cicatrices foliares claramente definidas (Lám. XI, figs. 3-7). Estas cicatrices foliares tienen formas circulares a verticalmente elongadas (Lám. XI, fig. 2), con una marca central como un círculo 
completo o incompleto (en forma de "U"). En comparación con otros morfotaxa utilizados para referirse a las distintas compresiones-impresiones de troncos/tallos de helechos paleozoicos (ej., Megaphyton Artis, Hagiophyton Pfefferkorn, Artisophyton Pfefferkorn) (Pfefferkorn, 1976; Taylor et al., 2009), Caulopteris se diferencia por presentar las cicatrices foliares dispuestas en dos o más hileras verticales en un patrón helicoidal (Lindley y Hutton, 1831-1833) (Lám. XI, figs 1, 3, 4, 6).

Los ejemplares hallados en La Golondrina son todos provenientes de la localidad de Laguna Polina (Nivel fosilífero III, perfil Laguna Polina). De acuerdo a la preservación de los tallos, se puede asegurar con certeza que las piezas MPM-Pb 15106 (Lám. XI, figs. 1, 2) y 15137 (Lám. XI, figs. 4, 5) son asignables a éste morfogénero; sin embargo, se prefiere ser cauto respecto de las demás piezas (Lám. XI, figs. 3, 6).

\section{Orden OSMUNDALES}

Familia OSMUNDACEAE Berchtold y Presl, 1820

Género Dichotomopteris Maithy, 1974b

Especie tipo: Dichotomopteris major (Feistmantel) Maithy, 1974b.

Dichotomopteris hirundinis (Archangelsky y de La Sota) Archangelsky, Césari y Cúneo, 2004

Lám. XII, Fig. 1 
Referencias: Archangelsky y de La Sota (1960: 106); Archangelsky et al. (2004: 74); Arrondo (1969: 63).

Material nuevo: BA-Pb 13580, 13808, 13813 (?), 13815; MPM-Pb 4436 (?).

Discusión: Las principales características de esta especie que la diferencian del resto de las pecopterídeas están en sus pínnulas delicadas, y su venación fina, pero bien marcada (Lám. XII, fig. 1). Los ejemplares fértiles presentan soros terminales en las venas secundarias, dispuestos de a 4-8 esporangios (McLoughlin, 1992).

Dichotomopteris hirundinis es una combinación propuesta por Archangelsky et al. (2004) para incluir algunos de los especímenes previamente asignados a Pecopteris hirundinis por Archangelsky y de la Sota (1960) que se caracterizaban por la fusión basal de las pínnulas, el tipo de venación (delicada), y la presencia de esporangios libres en dos hileras a cada lado de la vena media de la pínnula (Archangelsky et al., 2004) (Lám. XI, fig. 1).

Dichotomopteris ovata Maithy, 1977

Lám. XII, Figs. 2-6

Referencias: Archangelsky y de La Sota (1960: 118); Archangelsky et al. (2004: 77).

Material nuevo: BA-Pb 13581, 13869, 14060.

Discusión: Los caracteres diagnósticos de esta especie son las disposición alternada de las pínnulas, la vena media decurrente que se divide en la mitad de la lamina pinnular en venas de menor espesor, y la división hasta dos veces de las venas laterales (Lám. XII, figs. 2-6). 
Los ejemplares de La Golondrina de esta especie fueron originalmente asignados por Archangelsky y de la Sota (1960: 118) como Merianopteris sp. Luego, Maithy (1977) los incluyó bajo Dichotomopteris ovata, basándose en las características de la forma redondeada de las pínnulas, con una vena media decurrente que llega a la mitad de la pínnula y se divide en varias vénulas, y las venas laterales que se dividen una vez (Archangelsky et al., 2004).

Genus Damudopteris Pant y Khare ex Chandra y Rigby, 1983

Especie tipo: Damudopteris bengalensis Chandra y Rigby, 1983

Damudopteris bengalensis Chandra y Rigby, 1983

Referencias: Archangelsky y de la Sota (1960: 114); Archangelsky et al. (2004: 80).

\section{Material nuevo: -}

Discusión: Descriptas por Archangelsky y de la Sota (1960) como Sphenopteris sp I, fue posteriormente combinado a Damudopteris bengalensis, en base a la presencia de pinnas alternas con raquis liso, que puede o no estar alado, pínnulas de base constricta y decurrente, con margen lobulado, y vena media fina, del mismo tenor que las laterales, las cuales se dicotomizan entre 1-2 veces. Las pínnulas fértiles poseen esporangios libres o en grupos de 2 en el extremo de las venas laterales, cerca del margen pinnular (Archangelsky y de la Sota, 1960; Archangelsky et al., 2004). 
Género Sphenopteris (Brongniart) Sternberg, 1825

Especie tipo: Sphenopteris elegans (Brongniart) Sternberg, 1825.

Sphenopteris sp. II Archangelsky y de La Sota, 1960

Lam. XIII, Figs. 1-4

Referencias: Archangelsky y de La Sota (1960: 116).

Material nuevo: MPM-Pb 4449, 4484.

Discusión: Archangelsky et al. (2004) discutieron acerca de la ubicación sistemática de los ejemplares asignados por Archangelsky y de la Sota (1960) como Sphenopteris sp II. Esta especie fue considerada por Maithy (1974a) como asignable a Neomariopteris hughesii Maithy a partir de la presencia de las pínnulas de tipo sphenopteroideas, con bases apoyadas de forma decurrente sobre el raquis (carácter principal que diferencia al género Neomariopteris de Sphenopteris). Sin embargo, a diferencia de Maithy (1975) - quien agrupa tanto especímenes fértiles como estériles en su género - Chandra y Rigby (1983) sugirieron la separación de unos y otros espécimenes, utilizando Neomariopteris para referirse a aquellos con frondes estériles, y Damudopteris para aquellos con frondes fértiles. El problema en entre una u otra clasificación radica en que se utilizó el mismo material tipo para ambas descripciones. Este problema de índole nomenclatural ha sido también mencionado por McLoughlin (1992), sin ofrecer una solución consensuada. Es por ello que aquí se prefiere mantener la clasificación original utilizada por Archangelsky y de la Sota (1960), como fue sugerido por Archangelsky et al. (2004), hasta tanto no se realice la revisión y estudio de los ejemplares tipo hindúes, que puedan clarificar este dilema. 


\subsection{SPHENOPHYTA}

Orden SPHENOPHYLLALES Seward, 1898

Familia SPHENOPHYLLACEAE Potonié, 1893

Género Sphenophyllum (Brongniart) Koenig, 1825

Especie tipo: Sphenophyllum emarginatum Brongniart, 1822.

Sphenophyllum speciosum (Royle) McClelland, 1850

Lám. XIV - Figs. 1-6

Referencias: Archangelsky (1959a: 27, 1960a: 30); Arrondo (1972: 38).

Material nuevo: BA-Pb 13732, 13737, 13739, 13740, 13746, 13747, 13748, 13749; MPM$\mathrm{Pb}$ 4417, 4432, 4433, 4498, 4517, 4527, 4543, 4572, 4576 a-b, 4605, 4620 a-b, 4628, 4629, 4632, 4633, 4644, 4714, 4724, 4729, 4759, 4760, 4821, 4873 a-b, 4902, 4904, 4910, 4969, 4970, 4975, 4991, 15119, 15146.

Discusión: Verticilos con 6 folíolos, en pares de distintos tamaños (par superior mayor, par inferior menor). Folíolos de formas oblongas a cuneiformes (Lám. XIV, figs. 2, 3, 5), con ápices desde subredondeados (Lám. XIV, fig. 5) a truncados (Lám. XIV, fig. 2) en algunos especímenes. La venación es abierta, y presenta escasas dicotomías y anastomosis (Lám. XIV, fig. 2, 4, 6). Archangelsky (1959a) mencionó la semejanza de esta especie con $S$. sino-coreanum Yabe, proveniente de China. Tal como lo remarcó (Archangelsky, 1959a), una diferencia clara con los ejemplares de China era la ausencia de venación que se 
insertara en los bordes laterales en los ejemplares de La Golondrina, dato que se puede reconfirmar a través del nuevo material examinado.

Sphenophyllum thonii Mahr, 1868

Lám. XV - Figs. 1-7

Referencias: Archangelsky (1959a: 29, 1960a: 29); Arrondo (1972: 36).

Material nuevo: BA-Pb 13732, 13735, 13736, 13741, 13742, 13743, 13744, 13745, 13804, 13932?; MPM-Pb 2541, 2663 c, 2683 a-b, 4498, 4524, 4629, 4637, 4679 a-b, 4733, 4841, 4843, 4844 a-b, 4851, 4871, 4872, 4873 a-b, 4922, 4945, 4971, 4989, 4995 a-b, 4999, 15117, 15138, 15158.

Discusión: Siempre se observan 6 folíolos por verticilo, los que exhiben una amplia variación de tamaño y forma, con márgenes desde lisos a crenulados o lobulados (Lám. XV, figs. 1-4). La venación se diferencia con las Sphenophyllum thonii europeas, asiáticas y africanas en que únicamente una vena entra al nudo (Archangelsky, 1959a: 30).

Género Lilpopia Conert y Schaarschmidt, 1970 emend. Lipiarsky, 1972a

Especie tipo: Lilpopia raciborskii (Conert y Schaarschmidt) Lipiarsky, 1972a.

\section{Lilpopia sp.}

Lám. XVI - Figs. 1-4 
Material nuevo: MPM-Pb 2715.

Descripción: Fructificación subesférica, de $\sim 1,3 \mathrm{~cm}$ de diámetro, compuesto por 10-14 esporangióforos, probablemente peltados (Lám. XVI, fig. 1). Cada esporangióforo se muestra como una placa de 6 lados (Lám. XVI, figs. 2-4). Corto pedicelo presente (Lám. XVI, figs. 1, 2, 4).

Discusión: Originalmente se utilizó el nombre Trystachia Lilpop para referirse a sphenophyllales con tallos hexagonales articulados con 6 hojas por verticilo estéril y 3 por verticilo fértil, con estróbilos esporangiados ubicados axilarmente sobre las hojas (Boureau, 1964; Kerp, 1984). Estos fósiles fueron posteriormente pasados al género Lilpopia por Conert y Schaarschmidt (1970) al descubrirse que el género era homónimo con un pasto sudafricano actual (Kerp, 1984). Lipiarski (1972a, b) redescribió y emendó la diagnosis genérica al demostrar que los verticilos fértiles alternaban conos y hojas en lugar de estar los conos dispuestos axilarmente sobre éstas. En total, se conocen 3 especies: L. raciborskii Conert y Schaarschmidt, L. crokensis (Remy y Remy) Lipiarski (ambas de Alemania), y L. polonica Lipiarski (de Polonia), todas del Pérmico Temprano. Éste representa el primer registro Gondwánico para el género, estirando también su rango bioestratigráfico al Pérmico Medio-Superior.

Lilpopia raciborskii presenta hojas de Sphenophyllum thonii Mahr, más específicamente de la variedad minor Sterzel. Los estróbilos en L. raciborskii poseen entre 18 y 24 esporangióforos. Lilpopia crokensis presenta hojas con polimorfismo, donde se destacan además "ganchos" que representarían una adaptación epífita. Los estróbilos poseen un diámetro de 4-5 mm, y los esporangióforos en esta especie llegan a 10. Por último, Lilpopia polonica posee hojas más pequeñas que aquellas de L. raciborskii. A diferencia de las otras dos especies, los estróbilos en esta especie alternan con 6 hojas, en vez de 3, teniendo 6 hojas en total tanto los verticilos estériles como los fértiles. Si bien no se menciona para cada una de las especies descriptas, hojas del "grupo thonii" (sensu Hetterscheid y Batenburg, 1984) fueron halladas en conexión orgánica con Lilpopia (Hetterscheid y Batenburg, 1984). 
Desafortunadamente, el único ejemplar hallado hasta el momento en la Formación La Golondrina está representado solamente por un estróbilo aislado, sin evidencia de cómo sería su conexión en el verticilo, ni de las hojas que lo acompañarían. A pesar de esto, la pieza MPM-Pb 2715 es claramente un estróbilo de Lilpopia, que se diferencia de las demás especies en tener entre 10 y 14 esporangióforos marcadamente hexagonales, dispuestos apretadamente sobre un corto pedicelo levemente ensanchado en su contacto con el estróbilo. El adelgazamiento del pedicelo al alejarse del cuerpo fructífero sería evidencia de un posible mecanismo de abscisión al madurar el cono, tal cual fue sugerido por Kerp (1984: 254). Como fue mencionado previamente, en la Formación La Golondrina se reconocen dos especies de Sphenophyllum: S. speciosum y S. thonii. Si bien este espécimen se encuentra disociado de cualquier tipo de hojas de Sphenophyllum, teniendo en cuenta las descripciones de las otras especies de Lilpopia, S. thonii sería un fuerte candidato como hojas asociadas a estos estróbilos. Sin embargo, Archangelsky (1960a: 29), describió para esta localidad un ejemplar de $S$. thonii fructificada. Dicha fructificación es claramente separable de la aquí descripta por su forma alargada, de 1,5 $\mathrm{cm}$ de largo por $0,4 \mathrm{~cm}$ de ancho, que presentaba varios esporangióforos dispuestos a lo largo, y se insertaba en la parte nodal del tallo que la portaba.

Orden EQUISETALES sensu Meyen, 1987

Familia CALAMITACEAE

Género Annularia Sternberg, 1822

Especie tipo: Annularia spinosa Sternberg, 1822. 
Annularia kurtzii Archangelsky, 1960a

Lám. XVII - Figs. 1-3

Referencias: Archangelsky (1960a: 32).

Material nuevo: MPM-Pb 4604, 4630, 4641, 4728.

Discusión: Esta especie fue creada por Archangelsky (1960a) para referirse a ejemplares de tallos articulados con hasta 15 verticilos foliares lineares (Lám. XVII, figs. 1-3), con venación subparalela, dispuestos en un anillo a la altura de los nudos, donde no se observa ninguna vaina rodeando a este anillo. Es precisamente la ausencia de esa vaina que separa a estos especímenes de un género relacionado, Phyllotheca. A partir de la ausencia de la vaina, los ejemplares de esfenófitas articuladas de la Formación La Golondrina son asignables al género Annularia, y la asignación del material de esta formación a una nueva especie se vio justificada por diferencias en el tamaño, forma, venación, y disposición de los segmentos foliares, tamaño de tallos, y relaciones nudo-entrenudo (ver Archangelsky, 1960a: 32-34).

Medidas: Largo hojas $=7,6-[16,6]-33,5 \mathrm{~mm}$; ancho hojas $=0,36-[1.57]-3,3 \mathrm{~mm}$; $\mathrm{L}: \mathrm{A}=$ 10,6 .

Familia EQUISETACEAE sensu Meyen, 1987

Género Neocalamites (Halle) Vladimirovicz, 1958

Especie tipo: Neocalamites hoerensis (Schimper) Halle, 1908. 


\section{Neocalamites sp.}

Referencias: Escapa y Cúneo (2006: 85-92).

\section{Material nuevo: -}

Discusión: Descripta recientemente por Escapa y Cúneo (2006), se caracteriza por tener hojas lineares lanceoladas, como en Annularia, pero su ancho máximo se halla en la parte más basal de éstas. El hallazgo de este género para La Golondrina se basa mayormente en el reconocimiento de estructuras reproductivas estrobilares asociadas, y su importancia radica en que a partir de su descubrimiento en estos sedimentos, el rango bioestratigráfico del género (conocido hasta el momento para el Triásico y Jurásico) se extiende ahora hasta al menos el Pérmico Superior.

Familia PHYLLOTHECACEAE sensu Boureau, 1964

Género Phyllotheca Brongniart, 1828

Especie tipo: Phyllotheca australis Brongniart, 1828.

\section{? Phyllotheca sp.}

Lám XVII - Fig. 4

Material nuevo: LIL 1140-1147. 
Descripción: Ejemplares muy incompletos y fragmentados de tallos de artrófitas. Surcos y carenas marcados, nudos y entrenudos visibles. Hojas unidas basalmente por una vaina (visible en ejemplar Lil 1145?), alargadas, lineares, de márgenes paralelos, con venación subparalela, y ápice agudo (Lám. XVII, fig. 4).

Discusión: Material colectado por Archangelsky durante una campaña en 1957, y depositado en el Instituto Lillo, no ha sido descripto ni publicado, pero sí clasificado, bajo la especie de P. australis. Dado que el material es escaso y muy fragmentario (Lám. XVII, fig. 4), no se puede confirmar que dicha asignación específica sea correcta, por lo que se sugiere dejar únicamente como ?Phyllotheca sp.

Si bien Phyllotheca y Annularia son géneros muy semejantes, la principal diferencia entre ambos es la presencia de una vaina basal en la inserción de las hojas con el tallo en la primera, mientras que las hojas se encuentran separadas en su totalidad hasta la base en la segunda. En el material de La Golondrina, las hojas de Phyllotheca son más lineares y con ápice aguzado (Lám. XVII, fig. 4), mientras que Annularia poseen hojas lineares, lanceoladas-alargadas, que pueden ensancharse levemente en su parte media o hacia el ápice, terminando en un ápice romo a agudo (Lám. XVII, figs. 1-3).

Los ejemplares LIL 1140-1147 son referidos con duda a Phyllotheca dado que no todos los ejemplares presentan los verticilos con hojas; el ejemplar 1145 (Lám. XVII, fig. 4) es el más representativo, y si bien pareciera que las hojas se encuentran unidas basalmente por una vaina, no se puede afirmar con precisión, dado el carácter fragmentario de la pieza. Se sugiere mantener a estos ejemplares como ?Phyllotheca hasta que mayor y mejor material sea encontrado.

Familia SCHIZONEURACEAE sensu Boureau, 1964

Género Paraschizoneura Radczenko, 1955 
Especie tipo: Paraschizoneura siberica (Neuberg) Radczenko, 1955.

\title{
Paraschizoneura sp.
}

\author{
Lám XVIII - Figs. 1-4
}

\section{Material nuevo: LIL 1135-1136.}

Descripción: Tallos angostos de 2,5 mm de diámetro (medidos en el nudo). Del nudo, salen hasta 7 hojas acintadas, lineares a lanceoladas, de largo aproximado $70 \mathrm{~mm}$ por $6 \mathrm{~mm}$ de ancho. Hojas con venación subparalela (Lám. XVIII, figs. 1-4).

Discusión: Material colectado por Archangelsky en una campaña al Bajo de La Leona en 1957, y depositado en el Instituto Lillo, no ha sido formalmente descripto, publicado, o clasificado. Si bien el material consiste en un único ejemplar (cara y contracara) que se encuentra levemente fragmentado, se asemeja en forma y dimensiones a Paraschizoneura czekanowskii Rasskazova, descripto para el Pérmico Superior de la Cuenca de Tunguska (Boureau, 1964: 423), y Paraschizoneura jonesii Holmes, descripto para el Triásico temprano de la Cuenca de Sydney (Holmes, 2001). Asimismo, la ilustración de Schizoneura africana Feistmantel provista por Anderson y Anderson (1985: 103), muestra un ejemplar muy semejante en forma y tamaño a los ejemplares conocidos como Paraschizoneura. El ejemplar de La Golondrina presenta 7 folíolos alargados con una venación paralela a los márgenes, pero a diferencia de estos géneros, la venación no está muy marcada (Lám. XVIII, figs. 1-4). 


\subsection{LYCOPHYTA}

Orden LEPIDODENDRALES sensu Chaloner y Boureau, 1967

Familia LYCOPODIOPSIDACEAE sensu Chaloner y Boureau, 1967

Género Bumbudendron Archangelsky et al., 1981a

Especie tipo: Bumbudendron paganzianum Archangelsky et al., 1981a

Bumbudendron patagonicum comb. nov.

Lám. XIX - Figs. 1-7

Lepidodendron patagonicum Archangelsky (1960a: 22).

Referencias: Archangelsky (1960a: 22).

Material nuevo: MPM-Pb 2802.

Diagnosis enmendada: Tallos al menos de $5 \mathrm{~cm}$ de diámetro (Lám. XIX, fig. 1). Intersección de la espiral filotáxica en ángulo agudo (Lám. XIX, figs. 3, 5). Cojinetes foliares densamente dispuestos, sin dejar interareas (Lám. XIX, figs. 3, 4, 5, 6). Cojinetes foliares romboidales, $7 \mathrm{~mm}$ de largo y $4 \mathrm{~mm}$ de ancho, con ápices superior e inferior agudos, a veces fusionados con el cojinete adyacente (Lám. XIX, figs. 1, 3, 4). Cicatriz foliar triangular a subtriangular, localizada en la parte media a superior del cojinete (Lám. XIX, figs. 1, 3). En la parte central-inferior de la cicatriz se ubica la traza vascular, redondeada. La cicatriz foliar limita dos campos: uno inferior, más elongado, y con una 
quilla longitudinal que no llega al ápice inferior (lámina infrafoliar), y uno superior, sin quilla y de menor tamaño que el anterior (Lám. XIX, figs. 1, 3).

Descripción: Cojinetes foliares pequeños, romboidales, de $7 \mathrm{~mm}$ de largo y $4 \mathrm{~mm}$ de ancho, dispuestos en filotaxis lepidodendroidea. La cicatriz foliar divide al cojinete en dos secciones, una inferior más elongada y surcada por una quilla (lámina infrafoliar), y una superior, de menor longitud. Traza vascular visible en la parte inferior de la cicatriz foliar. No se observaron marcas de paricnos, ni ligular.

Discusión: La presencia de cojinetes foliares romboidales, fusiformes, dispuestos densamente de forma lepidodendroidea en el tallo, sumado a la observación de pequeñas cicatrices a los costados de la marca del haz (paricnos?), llevaron a Archangelsky (1960a) a asignar al espécimen LIL 525 (Lám. XIX, figs. 1-3) como Lepidodendron patagonicum. Sin embargo, en su descripción, no hizo mención de marcas de lígula, o paricnos inferiores.

En la revisión del material, no se pudieron observar esas marcas de paricnos; pero así como en la descripción original (Archangelsky, 1960a), sí se pudo observar la presencia de una quilla en la parte inferior del cojinete, considerada aquí como una lámina infrafoliar (Lám. XIX, fig. 3). Es debido a este carácter en particular, que se propone el paso de Lepidodendron patagonicum a Bumbudendron patagonicum, bajo una nueva combinación.

Asimismo, se identificaron 3 estadíos de decorticación (Lám. XIX, fig. 7). En el estadío de menor decorticación (Lám. XIX, figs. 2, 7A) se observa un cojinete foliar más redondeado, con su forma menos definida, y con una cicatriz central (haz vascular). En un estadío de decorticación intermedia (Lám. XIX, figs. 3, 7B), los cojinetes foliares se hallan bien delimitados, y en aquellos ejemplares con mejor preservación, se pueden observar todas las características diagnósticas de la especie (por ejemplo, lámina infrafoliar, presencia/ausencia de paricnos, lígula, etc). Por último, en el estadío de mayor decorticación (Lám. XIX, figs. 4-6, 7C), se observan únicamente aquellos caracteres más marcados (por ejemplo, la lámina infrafoliar), perdiéndose aquellos más superficiales, observables en el estadío de decorticación B. 
Todas las especies conocidas de Bumbudendron son exclusivas de la Argentina. Éstas incluyen: B. paganzanium, B. nitidum (Archangelsky et al., 1981a), B. millani (Arrondo y Petriella, 1978, 1985), y B. versiforme (Gutiérrez et al., 1986). Bumbudendron paganzanium se diferencia de B. patagonicum en la forma de la cicatriz foliar: pentagonal en el primero, y triangular en el segundo. $B$. millanii tiene cojinetes de forma más fusiforme que B. patagonicum. Por último, B. versiforme difiere en la forma subtriangular de las cicatrices foliares, y en la presencia de interareas, característica no observada en $B$. patagonicum.

Género Cyclodendron Kräusel, 1961

Especie tipo: Cyclodendron leslii (Seward) Kräusel, 1928

Cyclodendron golondrinensis sp. nov.

Lám. XX - Figs. 1-10

Lepidodendron cf. pedroanum Archangelsky (1960a: 25).

Referencias: Archangelsky (1960a: 25).

Material nuevo: MPM-PB 2755 2756, 2757, 2758, 2759, 2760, 2761, 2762, 2765, 2766, 2767, 2774, 2775, 2776, 2777, 2801, 2803, 2804, 2805, 2806, 2807, 2808, 2809, 2810, 2811, 2812, 2813, 2815, 2819, 2820, 2821, 2874, 4398, 4403, 4408, 4474, 15152, 15153.

Diagnosis: Tallos al menos de $6 \mathrm{~cm}$ de ancho y $30 \mathrm{~cm}$ de largo, con cicatrices de bases foliares dispuestas densa a laxamente, dependiendo del nivel de decorticación (Lám. XX, 
figs. 1, 4, 5, 8, 9) . Filotaxis lepidodendroidea, ángulo entre $40^{\circ}-70^{\circ}$. Cicatrices foliares subromboidales a ovaladas, equidimensionales (Lám. XX, figs. 3, 6, 9). Haz vascular redondeado, central en la mitad o levemente más arriba en la cicatriz foliar.

Descripción: Cicatrices foliares (sub) romboidales a ovaladas, dependiendo del nivel de decorticación. Las cicatrices foliares miden 3.6 - $5 \mathrm{~mm}$ de alto y $5-6 \mathrm{~mm}$ de ancho, siendo mayormente equidimensionales. Traza vascular circular, usualmente localizada en el centro, aunque a veces, desplazada levemente hacia la parte superior de la cicatriz foliar. Filotaxis lepidodendroidea.

Discusión: Archangelsky (1960a) asignó bajo Lepidodendron cf. pedroanum a numerosos ejemplares de las cuencas La Golondrina y Tepuel Genoa (Chubut). Sin embargo, los ejemplares de La Golondrina difieren notablemente de aquellos del Chubut. Menciones posteriores referidas a este material (Archangelsky y Cúneo, 1984, 2002) cambian la nomenclatura a Brasilodendron pedroanum (Carruthers) Chaloner et al., 1979, en concordancia con una sistemática más gondwánica. Luego de un detallado análisis del material, se observaron diferencias significativas entre los "cojinetes folieares" de Brasilodendron y los de "Lepidodedron" provenientes de La Golodrina; más específicamente, la forma fusiforme con una extensión inferior y superior en el primero que no se observa en el segundo. La descripción de Archangelsky (1960a) es coincidente con la aquí expuesta en la disposición densa de las cicatrices foliares, sin dejar espacios (interareas) entre una y otra, la forma romboidal a suboval de las cicatrices, y la presencia de una traza circular central o levemente desplazada hacia arriba en la cicatriz, sin evidencia de paricnos o lígula.

Cyclodendron es el género propuesto por Kräusel (1928, 1961) para describir licópsidas arborescentes con tallos cubiertos por cicatrices foliares dispuestas densa a laxamente, en una filotaxia espiral de bajo ángulo. Ubicado centralmente, o levemente desplazado hacia la parte superior de la cicatriz, se encuentra el haz vascular. En su diagnosis, Kräusel (1928) estableció que Cyclodendron no tenía cojinetes foliares, visión apoyada por Seward (1903) y Arber (1905a). Sin embargo, en una enmienda de la diagnosis 
hecha posteriormente por el mismo Kräusel (1961), hace mención de la presencia de cojinetes foliares, visión apoyada por varios otros autores (Sommer y Trindade, 1966; Chaloner y Boureau, 1967; Lejal- Nicol y Bernardes de Oliveira, 1979; Lemoigne y Brown, 1980; Herbst, 1986; Herbst y Gutiérrez, 1995). Cuando Rayner (1985) enmienda la Especie tipo, provee a su vez una diagnosis enmendada del género Cyclodendron, donde menciona la presencia de cicatrices y trazas vasculares, pero no de cojinetes foliares. La ausencia de cojinetes foliares es el concepto aceptado en esta tesis, por lo que el material de Lepidodendron cf. pedroanum proveniente de La Golondrina es asignado a Cyclodendron, en base a los caracteres coincidentes con la descripción para este género.

Se conocen especies de Cyclodendron del Pérmico de Sudáfrica (C. leslii; Kräusel, 1928; Anderson y Anderson, 1985; Rayner, 1985), Brazil (C. brasiliensis; Lejal-Nicol y Bernardes de Oliveira, 1979), Uruguay y Paraguay (C. andreisii; Herbst, 1986, Herbst \& Gutiérrez, 1995). Cyclodendron golondrinensis difiere de C. leslii en la forma de las cicatrices foliares: rómbica a suboval, con el lado superior redondeado en el primero, y rómbica con el lado superior agudo en el segundo. También se diferencia en la forma de las cicatrices de $C$. andreisii, al ser éstas hexagonales. Por último, el material de La Golondrina difiere del de Brasil (C. brasiliensis) en las dimensiones del tallo, y la forma general de las cicatrices. Es por todo esto que se le asigna una nueva especie a los ejemplares de La Golondrina.

Herbst y Gutiérrez (1995: 147), hicieron un análisis detallado de los estadíos de decorticación (Lám. XX, fig. 10) en tallos de Cyclodendron, donde proponen una secuencia que va desde un estadío A (de menor decorticación), a un estadío C (de mayor decorticación), pasando por un estadío B intermedio. Si bien en sus descripciones utilizan el concepto de cojinetes foliares, este concepto puede ser fácilmente reemplazable por el de cicatrices foliares, sin perder su significado. De esta forma, en el estadío C (Lám. XX, figs. 9, 10C), las cicatrices foliares están claramente marcadas, mientras que en el estadío A (Lám. XX, figs. 7, 10A), los límites entre éstas son más difusos, y el espacio de interareas 
es mayor. En general, aquellos especímenes en estadío A de decorticación están cubiertos por bases foliares bien desarrolladas (Lám. XX, fig. 7).

\section{Licófita sp. A}

Lám. XXI - Figs. 1-2

Cf. Sigillaria Archangelsky (1960a: 28).

Referencias: Archangelsky (1960a: 28).

\section{Material nuevo: -}

Discusión: Archangelsky (1960a) utilizó el nombre de cf. Sigillaria para referirse a los ejemplares LIL 1014/15 (Lám. XXI, figs. 1, 2), por presentar una forma hexagonal de los cojinetes foliares (Lám. XXI, fig. 2), similares a aquellos descriptos como S. brardii Bgt. f. menardi por Hirmer (1927, fig. 331), White (1908, Lám. V, fig. 12), y Arber (1905, Lám. VIII, fig. 1). Debido a la ausencia de marcas de paricnos y/o lígula, Archangelsky (1960a) no asignó específicamente a estos ejemplares.

El género Archaeosigillaria es conocido desde el Devónico al Carbonífero inferior del Gondwana (Chaloner y Boureau, 1967; Anderson y Anderson, 1985). Este género se caracteriza por poseer cojinetes foliares alineados en series verticales, de forma hexagonal a subhexagonal (a veces, redondeados, dependiendo del nivel de decorticación), con una marca del haz vascular central, pero sin marcas de paricnos o ligular (Boureau, 1967; Gutiérrez y Arrondo, 1994). Dadas estas características, los especímenes descriptos por Archangelsky (1960a) encajarían perfectamente bajo este género. Sin embargo, el rango bioestratigráfico de Archaeosigillaria (Dv - Cb) plantearía un problema a la hora de asignar bajo ese nombre material de La Golondrina, por ser éste del Pérmico medio- 
superior. Por otra parte, Herbst (1972: 262-263) describe una licópsida con afinidades sigillarioides del Pérmico superior de Paraguay, que posee características similares al material de La Golondrina, como la forma y tamaño de los cojinetes foliares, la filotaxis sigillarioidea, la presencia de una cicatriz foliar central-superior, y la ausencia de marcas de paricnos y ligula. El material de Paraguay aportaría evidencias sobre la presencia de licópsidas del tipo sigillarioide, las cuales también habrían sido ampliamente distribuídas en el hemisferio sur durante el Pérmico.

Teniendo en cuenta que Sigillaria es un género típicamente nórdico (Boureau, 1967), y su presencia no ha sido probada en el hemisferio sur; y sumado a la ausencia de

paricnos y/o marcas de lígula en el espécimen 1014/15, se propone la reasignación de cf. Sigillaria por Licófita sp. A - dado que Archaeosigillaria no alcanza a llegar al Pérmico hasta que el hallazgo de más material permita una asignación más precisa.

\section{Licófita sp. B}

Lám. XXI - Figs. 3-4

Cf. Lepidophloios laricinus Archangelsky (1960a: 27).

Referencias: Archangelsky (1960a: 27).

\section{Material nuevo: -}

Discusión: El ejemplar LIL 1012 (Lám. XXI, figs. 3, 4) fue asignado cf. Lepidophloios laricinus por Archangelsky (1960a), basado en la forma rómbica de los cojinetes foliares, con el eje mayor horizontal. Posee una cicatriz foliar lateralmente elongada, que ocupa la base del cojinete, y de la cual irradian líneas rectas en forma de abanico (Lám. XXI, fig. 4). Cerca de la base, se observa el haz vascular central, redondeado. Archangelsky (1960a) 
menciona la presencia de dos punteaduras por encima de la traza foliar, consideradas por este autor como marcas de paricnos. Lamentablemente, en la revisión de material, no se pudo confirmar la presencia de estas marcas.

Lepidophloios es un género típico de floras carboníferas del hemisferio norte. Según Thomas (1977), la característica principal de Lepidophloios es la superposición de los cojinetes, un ancho superior al largo de éstos, y la presencia de paricnos laterales y una marca ligular por encima de la traza vascular. A excepción de la forma lateralmente elongada de los cojinetes foliares, ninguna otra de las características típicas del género pudieron ser confirmadas para el ejemplar de La Golondrina, por lo que se propone reasignar a este espécimen como Licófita sp. B hasta que más y mejor material sea hallado.

\subsection{PTERIDOSPERMOPHYTA}

Familia SPHENOPTERIDEAE Göeppert (sensu Boureau, 1975)

Género Eremopteris Schimper, 1869

Especie tipo: Eremopteris artemisiaefolia (Sternberg) Schimper, 1869

Eremopteris golondrinensis Archangelsky, 1959b

Lám. XXII - Figs. 1-4

Referencias: Archangelsky (1959b: 285-289). 
Material nuevo: MPM-Pb 4410, 4413, 4415, 4416, 4418, 4419, 4420, 4423, 4437, 4440, 441, 4442, 4443 a-b, 4444, 4445, 4447, 4448, 15155.

Discusión: Abundantes ejemplares, mayormente estériles, han sido hallados en las localidades de Laguna Polina (Archangelsky, 1959b) y Laguna Castellanos (campaña 2010) (Lám. XXII, figs. 1-4). Recientemente, frondes fértiles de esta especie fueron descriptas por Carrizo y Archangelsky (2009), pero ningún ejemplar fértil fue reconocido en el material colectado en las últimas campañas llevadas a cabo por la autora.

Esta especie fue propuesta por Archangelsky (1959b) para describir frondes hasta tri-pinnadas con raquis de los segmentos estriados longitudinalmente, portando pinnas subopuestas a alternas. Las pínnulas son alternas, decurrentes, y profundamente lobuladas, sub-rómbicas a ovaladas en contorno. La venación de las pínnulas es abierta y dicotómica, por lo que no hay una vena media marcada (Archangelsky, 1959b).

\subsection{GYMNOSPERMOPHYTA}

Orden CORDAITALES sensu McLoughlin y Drinnan, 1996

Género Cordaites Unger, 1850

Especie tipo: Cordaites borassifolius (Sternberg) Unger, 1850.

Cordaites (Noeggerathiopsis) hislopi (Bunbury) Seward y Leslie, 1908

Lám. XXIII - Figs. 1-8 
Referencias: Archangelsky (1959a: 48).

Material nuevo: MPM-Pb 2731, 2785, 2787-2788, 2843, 4542, 4607, 4736, 4737, 4745, 4842, 4867, 4868, 4998, 4542 .

Descripción: Fragmentos de hojas de tamaño mediano a grande, en general sin ápice ni bases preservados (Lám. XXIII, figs. 1, 3, 5, 7). Márgenes paralelos a levemente curvados, por lo que se intuye una forma linear-lanceolada de las hojas. Venación paralela a subparalela, bien definida, a veces con venas intersticiales o fibras de menor calibre corriendo paralelas entre las venas mayores (Lám. XXIII, figs. 2, 4, 6, 8). Las venas mantienen un grosor constante a lo largo de la hoja, y se dicotomizan en algunos casos.

Discusión: Feistmantel (1879) propuso el género Noeggerathiopsis Feistmantel para hojas semejantes a Cordaites halladas en estratos neopaleozoicos de la India (Singh et al., 2007), y proveyó de una descripción del género bastante abarcativa, con algunas inexactitudes (hábito pinnado). Posteriormente, Meyen (1964, 1969) mencionó que las diferencias morfológicas propuestas para separar a uno de otro género no eran lo suficientemente justificadas, por lo que favoreció la sinonimia de ambos, y creó el género Rufloria Meyen (Meyen, 1964), para asignar hojas semejantes a Cordaites, pero que se diferenciaban de éstas por poseer surcos en su superficie inferior (Archangelsky y Leguizamón, 1980). En un trabajo sobre la flora carbonífera de Sierra de los Llanos (provincia de La Rioja), Archangelsky y Leguizamón (1980) presentaron una detallada revisión de las aceptaciones entre Cordaites y Noeggerathiopsis de acuerdo a los distintos autores. Asimismo, y de acuerdo con lo propuesto por Meyen $(1964,1969)$, estos autores propusieron la revisión de todas las hojas cordaitales descriptas para Argentina, usualmente designadas indistintamente como "Cordaites (Noeggerathiopsis) hislopi”, para definir su pertenencia a uno u otro género. Hasta la fecha, tal revisión no ha sido realizada, por lo que las hojas de tipo cordaital suelen seguirse encontrando en la literatura como Cordaites hislopi, o Cordaites (Noeggerathiopsis) hislopi. Este último ha sido también el caso en lo que respecta al material proveniente de la Formación La Golondrina. 
La visión más aceptada actualmente es la que apoya la separación de ambos géneros, basado en criterios morfológicos externos (hojas preservadas como impresión/compresión, análisis de cutículas), así como anatómicos internos (en hojas permineralizadas) (Maithy, 1965; McLoughlin, 1992; Srivastava, 1992; McLoughlin y Drinnan, 1996; Singh et al., 2007). Entre los caracteres que justificarían la diferenciación de ambos géneros, se encuentran (1) la presencia de venas intersticiales o fibras en Cordaites, ausentes en Noeggerathiopsis (Singh et al., 2007), (2) la presencia de hileras estomáticas profundas protegidas por densos pelos epidérmicos en Noeggerathiopsis, ausentes en Cordaites (McLoughlin y Drinnan, 1996), y (3) la presencia de haces y columnas esclerenquimáticas prominentes en el mesófilo de Cordaites, ausentes en Noeggerathiopsis (Singh et al., 2007). Como se puede observar, no hay una separación de estos géneros en base a su tipo de preservación, y dos de las tres características utilizadas para justificar la separación entre ambos se basan ya sea en caracteres anatómicos internos, o cuticulares..

Lamentablemente, hasta el momento, todos los ejemplares de hojas de cordaitales hallados en la Formación La Golondrina fueron preservados como impresiones (por lo que no se puede analizar su cutícula ni estructura interna). Si se considera entonces, únicamente la primera justificación (presencia/ausencia de venas intersticiales o fibras de menor calibre paralelas entre las venas de mayor grosor), los ejemplares de la Formación La Golondrina serían asignables al género Cordaites, sin duda alguna. Sin embargo, en concordancia con lo expresado por Archangelsky y Leguizamón (1980) al respecto de la necesidad de llevar a cabo una minuciosa revisión de todo el material conocido de hojas de cordaitales en Argentina, y en base a la ausencia hasta la fecha de ejemplares con cutícula preservada en La Golondrina, se prefiere mantener la nomenclatura más utilizada para estos casos, donde se clasifica a los ejemplares indistintamente como Cordaites (Noeggerathiopsis) hislopi. 
Orden GLOSSOPTERIDALES Pant, 1982

Familia GLOSSOPTERIDACEAE

Género Glossopteris Brongniart, 1828

Especie tipo: Glossopteris browniana Brongniart, 1828.

Glossopteris ampla Dana, 1849

Lám. XXIV - Figs. 1-8

Referencias: Archangelsky (1957a: 140, 1959a: 55); Arrondo (1969: 85, 1972: 65).

Material nuevo: $\mathrm{BA}-\mathrm{Pb} 13873,13874,13876,13882$, 13883; MPM-Pb 2511 a-b, 2512, 2513 a-d, 2515, 2534, 2545, 2548, 2574, 2576, 2589, 2609 b, 2613, 2650-2651 b, 2668, 2671, 2709(?), 2902, 4960, 4967, 15156.

Discusión: Esta es una especie muy común en La Golondrina. Son en general hojas grandes (de hasta más de $30 \mathrm{~cm}$ de largo y $11 \mathrm{~cm}$ de ancho), con vena media robusta, estriada longitudinalmente (Lám. XXIV, figs. 1, 2, 4) (Archangelsky, 1957a). Las venas laterales salen de la vena media en ángulo agudo, pero se rectifican rápidamente para llegar casi perpendiculares al margen (Lám. XXIV, figs. 3, 5, 8). Las aréolas son largas y angostas, se hacen más cortas y anchas alcanzando el margen (Lám. XXIV, fig. 5).

Glossopteris argentina Archangelsky, 1957a

Lám. XXV - Figs. 1-8 
Glossopteris decipiens var. argentina Archangelsky, 1959a: 59.

Referencias: Archangelsky (1957a: 143; 1959a: 59); Arrondo (1969: 79, 1972: 61).

Material nuevo: BA-Pb 13806, 13857, 13875; MPM-Pb 4469 (?), 4497 (?), 4499, 4512, 4518 (?), 4519, 4523, 4525, 4550, 4551, 4572, 4573, 4583 (?), 4599, 4627, 4635, 4741, 4823 a-b, 4966.

Discusión: Especie común en La Golondrina (Archangelsky, 1957a). El carácter más saliente para identificar a esta especie es la presencia de una vena media robusta, que no llega al ápice, con numerosas y densas puntuaciones (Lám. XXV, figs. 1-8). Las venas laterales salen casi adyacentes a la vena central, luego se arquean, y llegan a los bordes en ángulo de $45^{\circ}$ (20 en el ápice) (Lám. XXV, figs. 4, 5, 6, 8) (Archangelsky, 1957a). Aréolas largas y angostas, con pocas anastomosis.

Glossopteris browniana Brongniart, 1828

Lám. XXVI - Figs. 1-6

Referencias: Archangelsky (1957a: 150; 1959a: 56); Arrondo (1969: 71; 1972: 55).

Material nuevo: BA-Pb 13829, 13832, 13843, 14064, 14068; MPM-Pb 2510, 2526, 2606 a-c, 2728, 4421, 4504 (?), 4524, 4624 (?), 4717 (?).

Discusión: Su presencia no es muy común en La Golondrina (Archangelsky, 1957a). Se caracteriza por tener el ápice siempre agudo, una vena central bien visible, pero no tan conspicua como en G. conspicua o G. stricta. La vena media puede ser lisa o presentar finas estrías longitudinales (Lám. XXVI, figs. 1, 3, 5, 6). Las venas laterales forman aréolas 
de casi la misma forma y tamaño tanto cerca de la vena central como en los márgenes (Lám. XXVI, figs. 2, 3, 5, 6) (Archangelsky, 1957a).

Glossopteris conspicua var. patagonica Archangelsky, 1957a

Lám. XXVII - Figs. 1-9

Referencias: Archangelsky (1957a: 147; 1959a: 61); Arrondo (1972: 63).

Material nuevo: BA-Pb 13580, 13869, 13872, 13889; MPM-Pb 2587, 2606 a-b, 2730, 4431, 4434, 4435 a-b, 4451, 4478, 4500, 4502, 4515, 4543, 4573, 4576 a-b, 4598, 4610, 4614, 4620 a-b, 4638, 4643, 4648, 4651, 4662 a-b, 4663 a-b, 4700 a-b, 4721 a-b, 4724, 4725, 4726, 4731, 4755, 4764 a-b, 4773 a-b, 4783, 4784, 4788, 4826, 4834, 4835, 4837, 4838, 4909, 4954, 4958, 4961, 4962, 4972, 4973, 4990, 4991, 15108, 15113, 15158.

Discusión: Esta especie también se halla en abundancia en varios niveles de la Formación La Golondrina (Archangelsky, 1957a). Las características más conspicuas de esta especie son la vena media con numerosos surcos longitudinales (Lám. XXVII, fig. 2, 7, 9); venas laterales que salen en ángulo agudo de la vena media, se anastomosan repetidamente, y luego, se arquean llegando rectas al margen, en forma casi paralelinervada, con escasas anastomosis (Lám. XXVII, figs. 1-9).

Glossopteris damudica Feistmantel, 1881

Lám. XXVIII - Figs. 1-7 
Referencias: Archangelsky (1957a: 137; 1959a: 54); Arrondo (1969: 75, 1972: 59).

Material nuevo: BA-Pb 13827, 13833, 13856, 14044, 14046; MPM-Pb 2535-2536 b, 2604, 2608, 2609 c, 4740, 4834, 4855, 15116 (?).

Discusión: Hojas comunes en la Formación La Golondrina (Archangelsky, 1957a). Son hojas elípticas, con una nervadura central gruesa, surcada por finas estrías longitudinales, que se adelgaza hacia el ápice (Lám. XXVIII, figs. 1-5). Las venas laterales salen en ángulo de $90^{\circ}$ de la vena media, y llegan rectas al margen, apenas curvándose hacia arriba al llegar a éste (Lám. XXVIII, figs. 1, 3, 4, 7). Las areolas son anchas y cortas cercanas a la vena central, y se adelgazan y alargan hacia el margen. Archangelsky (1959a: 54) mencionó que estas hojas presentaban un "hábito taeniopteroideo: alargado, de bordes subparalelos".

Glossopteris indica Schimper, 1869

Lám. XXIX - Figs. 1-5

Referencias: Archangelsky (1957a: 151; 1959a: 57); Arrondo (1969: 74, 1972: 57).

Material nuevo: BA-Pb 13892; MPM-Pb 4500, 4538 (?), 4557 (?), 4572, 4574, 4644, 4645 a-b, 4649, 4653, 4716, 4720, 4725, 4785, 4811.

Discusión: Hojas relativamente abundantes en la Formación La Golondrina. La forma de la hoja es espatulada u oblanceolada, con su ancho máximo en la 3/4 parte de la hoja (Archangelsky, 1959a), aunque estas características no son siempre visibles en los ejemplares fragmentados. Presentan una vena media robusta con un canal longitudinal central (Lám. XXIV, figs. 1-5). Venas laterales salen en ángulo de la vena media, y alcanzan el margen en ángulo de $60^{\circ}$, con pocas anastomosis, que forman areolas pentahexagonales (Lám. XXIX, fig. 5). 
Archangelsky et al. (1981b) sugirieron la revisión de todas las Glossopteris asignadas a la especie indica para la Argentina, en base al traspaso de los ejemplares de esta especie a Glossopteris wilsonii, provenientes de las formaciones Piedra Shotel y Nueva Lubecka en Chubut. Sin embargo, los ejemplares analizados provenientes de la Formación La Golondrina son mantenidos bajo esta especie, en base a la presencia de una vena media robusta de ancho constante a lo largo de la hoja (Lám. XXIX, figs. 1, 2), y la salida en ángulo de las venas laterales (Lám. XXIX, figs. 3, 5), dos caracteres que difieren de los descriptos para Glossopteris wilsonii (Archangelsky, 1959; Archangelsky et al., 1981).

Glossopteris retifera Feistmantel, 1881

Lám. XXX - Figs. 1-6

Referencias: Archangelsky (1957a: 149; 1959: 58).

Material nuevo: MPM-Pb 2511 c, 2538, 4476, 4601 (?), 4625 (?), 4627, 4639 a-b (?), $4657,4476$.

Discusión: De muy escasa presencia en los niveles de La Golondrina (Archangelsky, 1957a, 1959a), se caracteriza por su pequeño tamaño en general, con una vena media que se atenúa al llegar al ápice, y venas laterales que salen en ángulo de $45^{\circ}$ de ésta, formando areolas cortas y anchas, de forma pentagonal o hexagonal. Las aréolas son siempre más anchas que largas, sobretodo cerca de la vena media (Lám. XXX, figs. 1-6).

Glossopteris stipanicicii Archangelsky, 1957a

Lám. XXXI - Figs. 1-4 
Referencias: Archangelsky (1957a: 153; 1959: 64).

Material nuevo: BA-Pb 13890; MPM-Pb 2536-2536 a, 2606 b-c, 2626, 2793, 4834.

Discusión: Especie poco común en La Golondrina (Archangelsky, 1957a), se caracteriza por la forma acinto-lanceolada de la hoja (Lám. XXXI, figs. 1, 2), con una vena media ancha y marcada, surcada por finas estrías (Lám. XXXI, figs. 2, 3, 4). Las venas laterales salen arqueándose suavemente de la vena media, y forman 2-3 series de aréolas anchas y cortas, que se van alargando al llegar al margen (Lám. XXXI, fig. 4).

Glossopteris stricta Bunbury, 1861

Lám. XXXII - Figs. 1-10

Referencias: Archangelsky (1957a: 152; 1959a: 62); Arrondo (1969: 83, 1972: 64).

Material nuevo: BA-Pb 13870, 13878, 13880; MPM-Pb 4528, 4595, 4614 a-b (?), 4616 ab, 4620, 4654, 4661, 4664, 4722 a-b, 4752, 4810, 4811, 4815, 4822, 4955, 4959, 4964 a-f, 4974 a-b, 4975.

Discusión: Esta especie es abundante en la flora de la Formación La Golondrina (Archangelsky, 1959a). Posee hojas largas y angostas (Lám. XXXII, fig. 4), con una vena media fuerte que disminuye en grosor hacia el ápice. La vena media está compuesta por un grupo de nervaduras menores que se anastomosan longitudinalmente entre sí (Lám. XXXII, figs. $3,8,10)$. Las venas laterales salen casi paralelas de la vena central, y se arquean abruptamente para llegar casi perpendiculares al margen (Lám. XXXII, figs. 1-10). 
Género Gangamopteris McCoy, 1860

Especie tipo: Gangamopteris angustifolia McCoy, 1860

Gangamopteris angustifolia McCoy, 1860

Lám. XXXIII - Figs. 1-6

Referencias: Archangelsky (1957a: 154; 1959a: 66); Arrondo (1969: 89, 1972: 68).

Material nuevo: BA-Pb 13900; MPM-Pb 2789, 2824, 2830, 2846, 2850(?), 2855, 2884, 4496, 4498, 4500, 4511, 4520, 4570, 4572, 4575, 4655, 4659, 4716, 4721 a-b, 4752, 4753, 4777, 4821, 4823 a-b, 4832, 4853, 4874, 4900, 4972, 4975, 4990 a-b, 4992, 4993, 15158.

Discusión: Esta es la especie de Gangamopteris más comúnmente hallada en la Formación La Golondrina (Archangelsky, 1959a). Se la distingue por tener su ancho máximo siempre en la mitad de la hoja (Lám. XXXIII, fig. 1). Desde la base salen una serie de nervaduras paralelas, formando un surco bien visible incluso con algunas anastomosis en los individuos mayores (Lám. XXXIII, figs. 1, 3, 6). Las venas laterales salen del conjunto de venas centrales en forma casi paralela, y se van arqueando suavemente hacia los bordes. Aréolas alargadas y angostas (Lám. XXXIII, figs. 1-6).

Gangamopteris castellanosii Archangelsky, 1957a

Lám. XXXIV - Figs. 1-4 
Referencias: Archangelsky (1957a: 159; 1959a: 68); Arrondo (1969: 94, 1972: 73).

Material nuevo: MPM-Pb 2844, 4498, 4753, 15128 (?).

Discusión: De presencia muy poco común en La Golondrina, esta especie se caracteriza por tener varias robustas nervaduras centrales longitudinales que se anastomosan entre sí en un curso algo sinuoso (Lám. XXXIV, figs. 1-4). Este surco se mantiene hasta el ápice en forma muy visible, y de éste salen venas laterales muy arqueadas, que llegan a los márgenes casi perpendicularmente (Lám. XXXIV, figs. 2, 4). Las venas laterales se anastomosan cercanamente a la venación central, pero luego se mantienen paralelas, casi sin anastomosarse.

Gangamopteris mosesi Dolianiti, 1954

Lám. XXXV - Figs. 1-5

Referencias: Archangelsky, 1957a: 156; Arrondo, 1969: 93, 1972: 71.

Material nuevo: BA-Pb 13835; MPM-Pb 2729, 2737, 2797, 2827(?), 2847, 2883, 4503, 4526, 4554, 4575, 4754, 4777, 4782, 4992, 4994, 4503, 4526, 4554, 4575, 4754, 4777, 4782, 4992, 4994.

Discusión: Especie de presencia relativamente abundante en la Formación La Golondrina, se caracteriza por tener hojas pequeñas, con un surco central de venas notable (hasta 6) (Lám. XXXV, figs. 1-5). Venas laterales salen arqueándose suavemente del conjunto de venas centrales. Particularmente, esta especie posee anastomosis de las venas laterales más largas y angostas cercano a la venación central, mientras que hacia los márgenes, las anastomosis se hacen más cortas y anchas (Lám. XXXV, fig. 2). 
Gangamopteris obovata (Carruthers) White, 1908

Lám. XXXVI - Figs. 1-6

Referencias: Archangelsky (1957a: 154; 1959a: 67); Arrondo (1969: 90, 1972: 69).

Material nuevo: BA-Pb 13830, 13861, 13868; MPM-Pb 2597, 2791, 2792, 4421, 4573, 4626, 4723, 4725, 4822, 4994.

Discusión: Esta especie, poco frecuente en los niveles de La Golondrina, se caracteriza por tener un surco medio central longitudinal del mismo calibre que las venas laterales (Lám. XXXVI, figs. 2, 4, 6). Las venas secundarias salen de este conjunto de venas centrales arqueadas suavemente, y llegan a los bordes en un ángulo aproximado de $45^{\circ}$. Forman aréolas alargadas y angostas en toda la superficie de la lámina (Lám. XXXVI, figs. 1-6).

Género Palaeovittaria Feistmantel, 1876

Especie tipo: Palaeovittaria kurtzii Feistmantel, 1876.

Palaeovittaria kurzi Feistmantel, 1876

Lám. XXXVII - Fig. 1

Referencias: Archangelsky (1957a: 162).

Material nuevo: MPM-Pb 4723 (?). 
Discusión: Material de esta especie fue originalmente hallado en Laguna Salada por Archangelsky (1957a). Un posible ejemplar con daño de insecto (Lám. XXXVII, fig. 1) fue hallado en la campaña de 2010, en la localidad de Laguna Polina, por lo que su presencia estaría tanto en el miembro inferior como en el medio.

Tanto el ejemplar hallado por Archangelsky como el recientemente colectado se asemejan en forma y tamaño a Gangamopteris obovata; sin embargo, se diferencian en su venación: en Palaeovittaria solamente se observan escasas dicotomías de las venas laterales, mientras que en Gangamopteris obovata se ven tanto dicotomías como anastomosis de éstas.

Género Vertebraria Royle, 1833 ex McCoy, 1847

Especie tipo: Vertebraria indica Royle, 1833.

\section{Vertebraria sp.}

Lám. XXXVII - Figs. 2-3

Material nuevo: BA-Pb 13886, MPM-PB 2682.

Descripción: Sistemas rizoidales fragmentados, hasta $7 \mathrm{~cm}$ de largo, y $\sim 2,5 \mathrm{~cm}$ de ancho, que presentan particiones regularmente espaciadas.

Discusión: Vertebraria es un morfogenero utilizado para designar al sistema rizoidal de la planta de Glossopteris, aún cuando nunca se lo ha encontrado en conexión orgánica. Su estructura particionada se debe a la presencia alternada de xilema II y cámaras de aire 
(Neish et al., 1993), lo que le da una apariencia característica e inconfundible (Lám. XXXVII, figs, 2, 3).

Familia DICTYOPTERIDIACEAE Surange y Chandra ex Rigby, 1978 emend.

Maheshwari, 1990 (nom. corr. McLoughlin, 1995)

Género Bifariala Prevec, 2008

Especie tipo: Bifariala intermittens (Plumstead) Prevec, 2008

Bifariala sp. cf. B. intermittens Prevec, 2008

Lám. XXXVIII - Figs. 5-8

Material nuevo: MPM-Pb 2530, 2570.

Descripción: Fructificación femenina isobilateral y dorsiventral. Receptáculo de forma lanceolada (Lám. XXXVIII, figs. 5, 6), relación largo ancho 2:1. Ápice levemente redondeado, se va aguzando gradualmente. Alas primaria (no observada) y secundaria; el ala secundaria presenta un estriado inflexo expandido en el ápice (Lám. XXXVIII, figs. 7, 8).

Medidas: Largo total $=26-30 \mathrm{~mm}$; ancho máximo $=8-13 \mathrm{~mm}$; ancho de ala (altura del ápice) $=1-2 \mathrm{~mm}$.

Discusión: Descriptas por Plumstead (1958) como Hirsutum intermittens, estas fructificaciones permanecieron bajo esa asignación hasta que Adendorff (2005; Prevec et 
$a l .$, 2008), haciendo una re-examinación del material original, nota la presencia de dos (en vez de una) alas periféricas, superpuestas. Por lo tanto, los ejemplares MPM-Pb 2530 y 2570 son asignados a Bifariala, en base tanto a caracteres cuantitativos como cualitativos.

Bifariala intermittens se caracteriza por ser una fructificación ovulífera dorsiventral, con un receptáculo lanceolado con un lado fértil y otro estéril. Presenta dos alas superpuestas a lo largo del margen del receptáculo. El ala primaria se continúa con la superficie del lado fértil del receptáculo, está finamente estriada, y no sobrepasa al ápice del receptáculo pero forma dos lóbulos a cada lado del pedicelo en la base de la fructificación (Adendorff, 2005; Prevec et al., 2008). El ala secundaria, por otra parte, es más robusta que el ala primaria, se continúa con la superficie estéril del receptáculo, y presenta un ápice acuminado, mientras que se adelgaza hacia la base, hasta desaparecer. El ala secundaria también tiene estrías, pero más espaciadas, casi perpendiculares al margen del receptáculo (Adendorff, 2005; Prevec et al., 2008).

Debido a la naturaleza frágil del ala primaria, su preservación es poco común, y sólo se la identifica en fósiles de preservación destacada. Esto explicaría parcialmente la ausencia de un ala primaria en las muestras de La Golondrina, ya que solamente el ala secundaria, más robusta, quedaría preservada.

Género Dictyopteridium Feistmantel emend. McLoughlin, 1990b

Especie tipo: Dictyopteridium sporiferum Feistmantel ex Zeiller, 1902 emend. Mcloughlin, $1990 b$.

Dictyopteridium costatum (Holmes) McLoughlin, 1990b

Lám. XXXIX - Fig. 7 
Material nuevo: MPM-Pb 4394 a-b.

Descripción: Fructificación ovulífera, dorsiventralmente aplanada. Receptáculo lineal con un surco longitudinal medio bien marcado $(\sim 1 \mathrm{~mm}$ de ancho), sin ningún otro tipo de venación visible (Lám. XXXIX, fig. 7). Marcas circulares distribuídas a lo largo de todo el receptáculo. No se observa un ala.

Discusión: Si bien el ejemplar MPM-Pb 4394 a-b (Lám. XXXIX, fig. 7) está incompleto, los caracteres que presenta, como una fuerte vena media, y las marcas circulares irregularmente dispuestas en la superficie de un receptáculo alargado, son suficientes como para asegurar su ubicación taxonómica bajo la especie descripta por Holmes (1974: 138). La ausencia de un ala puede deberse a la curiosa forma en la que esta fructificación se preservó, doblada en un ángulo agudo, por encima de una hoja de Glossopteris sp.

Dictyopteridium natalensis (Lacey, van Dijck y Gordon-Gray) Adendorff, 2005

$$
\text { Lám. XXXIX - Figs. 4-6 }
$$

Material nuevo: MPM-Pb 15157 a-b.

Descripción: Fructificación ovulífera dorsiventral, $\sim 25 \mathrm{~mm}$ de largo y $7 \mathrm{~mm}$ de ancho. Receptáculo aovado, ápice obtuso, redondeado, y base truncada, ligeramente cordada (Lám. XXXIX, fig. 4). Delgada ala con estrías perpendiculares al receptáculo (Lám. XXXIX, figs. $5,6)$. Superficie del receptáculo suave, con cicatrices circulares pequeñas con una marca central distribuídas irregularmente por toda la superficie (Lám. XXXIX, figs. 4, 6).

Discusión: Este espécimen se asigna a D. natalensis en base a la forma del receptáculo, las cicatrices que presenta en la superficie, y el ala estriada. 
Dictyopteridium sporiferum Feistmantel ex Zeiller, 1902 emend. Mcloughlin, 1990b

Lám. XXXIX - Figs. 1-3

Fructificación tipo B Archangelsky y Bonetti, 1963: 31.

Referencias: Archangelsky y Bonetti (1963:31); Archangelsky (1992).

Descripción: Fructificación ovulífera dorsiventral, bilateral simétrica, pedicelada (Lám. XXXIX, fig. 1). Forma elongada, de aproximadamente $60 \mathrm{~mm}$ de largo y $17 \mathrm{~mm}$ de ancho. Ápice obtuso a truncado. Base redondeada, con un corto y ancho pedicelo (Lám. XXXIX, fig. 3). Lado fértil de la fructificación con numerosos "sacos" (¿óvulos?) en filas levemente arqueadas (Lám. XXXIX, fig. 1). Ala angosta, entera, rodeando todo el receptáculo, excepto donde se inserta el pedicelo (Lám. XXXIX, figs. 1-3).

Discusión: La fructificación LIL 1982 fue originalmente descripta por Archangelsky y Bonetti (1963) como Fructificación tipo B. Las características de este ejemplar - ápice truncado, base redondeada, con numerosos cuerpos ovoides densamente dispuestos de forma longitudinal en el receptáculo, en hileras ligeramente arqueadas hacia los márgenes encajaban perfectamente en la descripción de D. sporiferum de Chandra y Surange (1976). Por otra parte, la presencia de un ala marginal contínua a lo largo de todo el receptáculo excepto donde se inserta un corto, grueso pedicelo, agrega evidencia para asignar a este ejemplar bajo el género Dictyopteridium, según la descripción hecha por McLoughlin (1990b).

Género Gonophylloides Maheshwari, 1968a emend. Adendorff, 2005

Especie tipo: Gonophylloides strictum (Plumstead) Maheshwari, 1968a emend. Adendorff, 2005. 
Gonophylloides semnes (Rigby) comb. nov.

Lám. XXXVIII - Figs. 3-4

Fructificación tipo A Archangelsky y Bonetti (1963: 31); Plumsteadia semnes Rigby (1978: 13).

Refencias: Archangelsky y Bonetti (1963: 31).

Descripción: Fructificación femenina, bilateral, dorsiventral. Forma del receptáculo subcircular a lanceolada, base fuertemente cordada (Lám. XXXVIII, figs. 3, 4). El receptáculo está flanqueado por un ala angosta, estriada. Superficie fértil con numerosas marcas circulares o elíticas, densamente agrupadas, de $\sim 1 \mathrm{~mm}$ de diámetro (Lám. XXXVIII, fig. 4). Ancho máximo del receptáculo = 20 $\mathrm{mm}$.

Discusión: Originalmente descripta por Archangelsy y Bonetti (1963) como Fructificación tipo A, los especímenes LIL 1400 y LIL 1978 han permanecido sin ser revisados por casi 50 años. A través de la examinación de estos ejemplares, se asigna a la Fructificación tipo A bajo el género de Gonophylloides, debido a la presencia de una base fuertemente cordada, las cicatrices circulares (¿semillas?) densamente dispuestas sobre toda la superficie fértil del receptáculo, y un ala delgada estriada a lo largo de todo el margen.

El ejemplar LIL 1400 es a su vez, muy similar a aquel descripto por Rigby (1978) como Plumsteadia semnes. Al respecto, en su tesis doctoral, Adendorff (2005: 293) sugiere que $P$. semnes Rigby debiera ser referido al género Gonophylloides, basándose en la base cordada y las características de las cicatrices que presentaba. Por lo tanto, y en concordancia con lo propuesto por Adendorff, se combina esta especie bajo el género Gonophylloides, y se asigna al material de La Golondrina bajo esta nueva combinación. 
La pobre preservación del ejemplar LIL 1978 no permite observar las características superficiales del receptáculo, por lo que no se puede identificar si es el lado fértil (cicatrices) o el estéril (venación) el preservado. Sin embargo, el contorno subcircular de la fructificación, con una base claramente cordada, es evidencia innegable para designar a esta pieza bajo el género de Gonophylloides.

Género Ottokaria Zeiller, 1902 emend. Adendorff, 2005

Especie tipo: Ottokaria bengalensis Zeiller, 1902

\section{Ottokaria sp.}

Lám. XXXIX - Fig. 10

Material nuevo: LIL 101.

Descripción: Fructificación femenina subcircular dorsiventral. Marcas subcirculares a verticalmente elongadas, con una pequeña marca circular central en ellas, distribuídas sobre la superficie del receptáculo (Lám. XXXIX, fig. 10).

Discusión: Si bien el espécimen LIL 101 (Lám. XXXIX, fig. 10) se encuentra fragmentado, su preservación es lo suficientemente buena para observar detalladamente características particulares de las marcas sobre la superficie fértil del receptáculo. De esta forma, estas marcas se pueden comparar con las descriptas para Ottokaria inglisensis (McLoughlin, 1990b), de la Cuenca de Bowen, Pérmico tardío de Australia. Asimismo, las marcas en este ejemplar son afines a las de Ottokaria sp., descripta para la Cuenca de Paganzo (Pérmico temprano de La Rioja) por Barreda y Césari (1995). Lamentablemente, la ausencia de un 
ala y/o pedicelo - dos caracteres definitorios para determinar especies de Ottokaria - no fueron preservados, por lo que no es posible asignar un epíteto específico a este ejemplar.

\section{Ottokaria sp.}

Lám. XXXIX - Figs. 11-12

Material nuevo: MPM-Pb 4852 a-b.

Descripción: Fructificación femenina dorsiventral. Pedicelo no preservado. Receptáculo irregularmente redondeado, cara fértil con varias semillas (Lám. XXXIX, figs. 11, 12). Semillas platispérmicas, angostas en la base, y más anchas en la parte superior, con un corto, puntiagudo ápice, y una quilla central longitudinal (Lám. XXXIX, fig. 12).

Discusión: El ejemplar MPM-Pb 4852 (Lám. XXXIX, figs. 11, 12) se asemeja a un espécimen de O. zeilleri descripto por Pant y Nautiyal (1984, figs 2e, i) en su forma general y tamaño. La presencia de semillas platispérmicas también es mencionada en la descripción de estos autores. Sin embargo, dada la naturaleza fragmentaria de este ejemplar, se prefiere no asignarle una especie, hasta tanto no se encuentren más y mejor preservados ejemplares.

Género Plumsteadia Rigby, 1971 ex McLoughlin, 1990b

Especie tipo: Plumsteadia microsacca Rigby, 1963 
Plumsteadia pedicellata Cariglino, Gutiérrez y Manassero, 2009

Lám. XLI - Figs. 1-4

Referencias: Cariglino et al. (2009).

Material nuevo: MPM-Pb 2524 a-b.

Diagnosis: Fructificación femenina, de forma obovada a espatulada. Ápice redondeado, obtuso, base aguda (Lám. XLI, fig. 1). Cicatrices de óvulos $\sim 0.5 \mathrm{~mm}$ de diámetro, redondeadas, dispuestas densa y azarosamente sobre la superficie del receptáculo (Lám. XLI, fig. 3). No hay ala periférica. Pedicelo de $10 \mathrm{~mm}$ de largo, longitudinalmente estriado, en conexión orgánica con el pecíolo de una hoja de Glossopteris sp. cf. G. pampeana Melchor y Césari (Lám. XLI, figs, 2, 4).

Descripción: El ejemplar MPM-Pb 2524 (Lám. XLI, figs. 1-4) es una impresión y contraimpresión donde se observa una fructificación dorsiventral obovada, de $15 \mathrm{~mm}$ de largo y $7 \mathrm{~mm}$ de ancho. El receptáculo posee un ápice redondeado obtuso, y la base es marcadamente aguda. La fructificación se encuentra en conexión orgánica a través de un largo pedicelo longitudinalmente estriado con el pecíolo de la hoja de Glossopteris que la portaba.

En el margen superior derecho de la fructificación se observa una angosta fila de cicatrices donde estarían las semillas, de aproximadamente $0.5 \mathrm{~mm}$ de diámetro. Dada la pobre preservación del material, no se puede observar estas cicatrices a lo largo de todo el margen. Sí es posible observar algunas de estas cicatrices en la superficie del receptáculo, aunque nuevamente, el detalle observable no es lo suficientemente bueno como para dar más información al respecto. Hay un fino estriado longitudinal en la cara estéril del receptáculo. 
Discusión: Además de ser la primera evidencia del género Plumsteadia para Argentina, este ejemplar es único en ser la primer fructificación en el país en hallarse en conexión orgánica con la hoja de Glossopteris portadora. El largo pedicelo en conexión orgánica con el pecíolo de la hoja representa una característica poco mencionada para estas fructificaciones, ya que generalmente, se hallan en contacto con la hoja de Glossopteris en forma sésil, o a través de un corto pedicelo, por lo general, sobre la vena media de la hoja estéril que la porta, o levemente por encima de la base de éstas. Únicamente $P$. ovata (Kyle, 1974) ha sido descripta en conexión orgánica con la hoja de Glossopteris a través de un pedicelo, como en este ejemplar de La Golondrina. Sin embargo, difiere de éste en el largo (el pedicelo de $P$. ovata es más corto) y en que el pedicelo en $P$. ovata sale del contacto entre el pedicelo y la base de la vena central de la hoja de Glossopteris que la porta.

Género Scutum Plumstead, 1952 emend. Adendorff, 2005

Especie tipo: Scutum leslii Plumstead, 1952.

Scutum cf. S. elongatum Surange y Chandra, 1974a

Lám. XXXVIII - Figs. 1-2

Material nuevo: $\mathrm{BA}-\mathrm{Pb} 13584$.

Descripción: Fructificación dorsiventral ovulada. Receptáculo elongado, ovalado, con su parte más ancha en la mitad (Lám. XXXVIII, fig. 2). Ápice redondeado. Superficie estéril con marcada venación abierta, y numerosas marcas circulares en la fértil. Ala de ancho 
contínuo, con un fuerte festoneado perpendicular al margen del receptáculo. Receptáculo 43 mm de largo y 16 mm de ancho. Ancho de ala 3 mm (Lám. XXXVIII, figs. 1, 2).

Discusión: Inicialmente considerada una fructificación bivalvar por Plumstead (1952), el género Scutum es actualmente aceptado como una estructura dorsiventral con un lado estéril (con venación) y otro fértil (cicatrices de óvulos o semillas), que se encuentra en conexión orgánica con la vena media de la hoja de Glossopteris que la porta a través de un corto pedicelo. El receptáculo se caracteriza por tener variadas formas, aunque siempre está rodeado por un ala fuertemente festoneada de ancho contínuo, a excepción del punto de inserción del pedicelo.

Según Adendorff (2005) la circunscripción del género Scutum es tan amplia que algunos ejemplares podrían solaparse con miembros del género Plumsteadia. Sin embargo, Scutum tiende a tener una relación L:A menor, y el ala en Scutum es marcadamente festoneada y con un ancho contínuo a lo largo del receptáculo. La característica más sobresaliente del ejemplar BA-Pb 13584 (Lám. XXXVIII, figs. 1, 2) es el ala fuertemente festoneada, que mantiene un ancho contínuo a lo largo de todo el receptáculo. Aún si la relación L:A en este ejemplar es más bien alto comparado con aquellas especies conocidas para Sudáfrica, hay especies provenientes del Pérmico superior de la India que se asemejan a BA-Pb 13584, como ser Scutum elongatum Surange y Chandra (1974a). Ambos ejemplares comparten la forma oval-elongada del receptáculo, con un ápice redondeado, y un ala festoneada, comparativamente más delgada que en las especies sudafricanas. La especie de Surange y Chandra (1974) es de menor tamaño que la de La Golondrina, sin embargo, teniendo en cuenta la amplia variación en tamaños y formas que presenta este género, se prefiere dar mayor peso a los caracteres cualitativos más que a los cuantitativos.

Lamentablemente, la base de la fructificación no está preservada. Pero se puede inferir que estaba en conexión orgánica con la hoja de Glossopteris que la portaba (visible por debajo de la misma fructificación) a la altura de la base de la lámina de ésta, siguiendo la curvatura de la parte de hoja preservada. La preservación de la hoja no es lo suficientemente satisfactoria como para asignarle una especie. 
Género Senotheca Banerjee, 1969

Especie tipo: Senotheca murulidihensis Banerjee, 1969

\section{Senotheca sp.}

Lám. XXXIX - Fig. 8

Material nuevo: MPM-Pb 4968; LIL 1126 (?).

Descripción: Fructificación femenina dorsiventral. Receptáculo linear, delgado, rodeado por un ala ancha (Lám. XXXIX, fig. 8). Cuerpos fértiles (¿óvulos?) dispuestos transversalmente a lo largo del ala, a cada lado del receptáculo. Ancho = $8 \mathrm{~mm}$.

Discusión: El ejemplar MPM-Pb 4968 (Lám. XXXIX, fig. 8) es fragmentario, por lo que no posee su parte superior ni inferior. Sin embargo, la forma linear y angosta del receptáculo, sumado a un ala ancha que lo rodea, donde se observan cuerpos ovoides (¿semillas?) transversales a cada lado del receptáculo, permiten inferir que este ejemplar pertenece al género Senotheca.

El ejemplar LIL 1126 también se encuentra incompleto, faltándole ambos extremos, por lo que no se puede asegurar su largo total. Sin embargo, posee la misma estructura general que el espécimen previamente descripto, por lo que se lo incluye bajo este mismo género.

Familia LIDGETTONIACEAE Banerjee, 1984 
Género Lidgettonia Thomas, 1958 emend. Adendorff, 2005

Especie tipo: Lidgettonia africana Thomas, 1958

Lidgettonia africana Thomas, 1958 emend. Anderson y Anderson, 1985

Lám. XL - Figs. 1-3

Material nuevo: LIL 1439.

Descripción: Fructificación compuesta, ovulífera, con una escama estéril portadora de (varios) capítulos unidos a través de un delgado pedicelo a la base de la escama (Lám. XL, fig. 1). Escama de forma rómbica, $38 \mathrm{~mm}$ de largo y $21 \mathrm{~mm}$ de ancho (Lám. XL, fig. 2). Ápice acuminado, con una punta levemente redondeada. Venación divergente, abierta. Venas se bifurcan y arquean alcanzando el margen. Un único capítulo preservado (aunque posiblemente había como mínimo un par), con un receptáculo subcircular con aproximadamente 12 marcas redondas (¿cicatrices de semillas?), unido a la base de la escama portadora a través de un delgado pedicelo de $8 \mathrm{~mm}$ de largo (Lám. XL, fig. 3).

Discusión: Estas fructificaciones difieren de Dictyopteridiaceae por la presencia de una escama estéril portadora de capítulos a través de un corto pedicelo. El espécimen LIL 1439 (Lám. XL, figs. 1-3) es asignado a Lidgettonia africana por poseer una escama estéril de forma rómbica, con ápice acuminado terminado en una punta aguda, y una base elongada. No presenta una vena media, pero sí un conjunto de venas centrales que se van abriendo, arqueando y dicotomizando para alcanzar los márgenes. La venación es divergente, y las venas se bifurcan y anastomosan formando largas y angostas aréolas. Un pedicelo delgado sale de la parte basal de la escama, y porta un capítulo con unas 12 marcas circulares. 
Si bien L. africana posee de 2 a 8 pares de capítulos (Surange y Chandra, 1975; Anderson y Anderson, 1985), en este ejemplar únicamente quedo preservado un capítulo. A pesar de esto, no hay duda que las demás características son suficiente evidencia como para asignar este ejemplar a L. africana.

\section{Escamas tipo A}

Lám. XL - Fig. 4

Material nuevo: LIL 99, MPM-Pb 2609

Descripción: Escamas de forma lanceolada, triangular a subtriangular, más largas que anchas (Lám. XL, fig. 4). Ápice agudo, base truncada. Sin vena media marcada, pero con presencia de un conjunto de venas centrales que llegan al ápice. Las venas nacen en la base y se abren hacia los márgenes, dicotomizándose y anastomosándose (Lám. XL, fig. 4).

Medidas: $\operatorname{Largo}=24-[25,5]-27 \mathrm{~mm} ;$ ancho $=10-[14]-18 \mathrm{~mm} ; \mathrm{L}: \mathrm{A}=1,82$.

Discusión: Las escamas tipo A se asemejan a aquellas descriptas por Pant (1958: 159) para Tanzania. Poseen una forma lanceolada con ápice agudo y una base truncada a redondeada. Un conjunto de venas centrales recorre la parte media de la escama hasta el ápice, con venas laterales que surgen de éstas y de la base, abriéndose y arqueándose al llegar a los márgenes. Estas venas se anastomosan y dicotomizan sucesivas veces a lo largo de su recorrido. Estas escamas son las que se hallan con menor frecuencia en La Golondrina. 


\section{Escamas tipo B}

Lám. XL - Figs. 5-7

Material nuevo: BAFC-Pb 15540, BA-Pb 13925.

Descripción: Formas y tamaños variados, desde triangulares a romboidales, lanceoladas a oblanceoladas, ovadas a obovadas, o espatuladas; más anchas que largas (Lám. XL, figs. 57). Ápice agudo a redondeado, base truncada a ampliamente atenuada. Vena media ausente, un conjunto de venas del mismo calibre, separadas, recorren longitudinalmente hasta el ápice la escama, dividiéndose y anastomosándose en su recorrido, con mayor frecuencia en su parte más apical. Venas laterales se arquean hacia los márgenes, dividiéndose y anastomosándose también, haciéndose más cortas y numerosas en las cercanías del margen (Lám. XL, figs. 5-7).

Medidas: $\operatorname{Largo}=14-[18]-22 \mathrm{~mm}$; ancho = 18-[21,75]-28 mm; L:A = 0,83.

Discusión: Elementos comunes en las floras Pérmicas gondwánicas (Thomas, 1958; Chandra y Surange, 1977; Anderson y Anderson, 1985). En la Formación La Golondrina, se han encontrado varias (Archangelsky, 1957a). Poseen fisionomía muy variada, y su base se encuentra por lo general truncada, perdiéndose la parte más basal, en donde estarían en conexión orgánica las partes fértiles de las fructificaciones (Chandra y Surange, 1977). El patrón de venación es el mismo para todas las escamas de este tipo.

\section{Escamas tipo C}

Lám. XL - Figs. 8-13 
Material nuevo: MPM-Pb 4453, 4454 a-b, 4458, 4460, 4468, 4472.

Descripción: Escamas convexas, triangulares a subrómbicas (Lám. XL, figs. 8-15). Ápice redondeado a agudo, laterales redondeados a angulares. Las escamas poseen gruesos surcos longitudinales, rectos y sub-paralelos. La parte media-inferior está marcada con pequeñas puntuaciones ordenadas (cicatrices de óvulos?) (Lám. XL, figs. 9, 11, 13).

Medidas: Largo = 9-[12,4]-18 mm; ancho = 8-[11]-17 mm; L:A = 1,12.

Discusión: Las escamas tipo C difieren de las A y B en que se las puede reconocer como fértiles en sí. Son en general de un tamaño más pequeño, y en su parte media-inferior presentan un conjunto de marcas circulares, que representarían marcas de óvulos. White (1978) sugirió que estas escamas deciduas, en conjunto con su segmento laminar, conformarían una "fronde escamosa". A su vez, estas "frondes escamosas" estarían agregadas en conos (Adendorff, 2005), ubicados en las partes terminales de las ramas. Las escamas habrían actuado para proteger los esporangios en los conos jóvenes. Cuando éstos maduraban, las escamas caían, permitiendo que los segmentos laminares siguieran desarrollándose, y permitiendo que los esporangios maduren para liberar sus esporas (White, 1978: 477). Aún si no existe evidencia que apoye esta hipótesis de la organización de escamas en un cono, su presencia como elementos aislados, puede contarse como evidencia de estructuras reproductivas agregadas en conos.

\title{
Familia ARBERIACEAE Rigby, 1972
}

\author{
Género Arberia White, 1908 emend. Adendorff, 2005
}

Especie tipo: Arberia minasica White, 1908 emend. Rigby, 1972. 


\section{? Arberia sp.}

Lám. XXXIX - Fig. 9

Material nuevo: MPM-Pb 4856 (?), 4968 (?).

Descripción: Fructificación femenina con un eje principal longitudinalmente estriado, y una parte apical que se ramifica numerosas veces (Lám, XXXIX, fig. 9). No se observaron óvulos. El largo total medido es de $\sim 40 \mathrm{~mm}$.

Discusión: Ambos especímenes, MPM- Pb 4865 y 4968 (Lám. XXXIX, fig. 9), son potencialmente asignables al género Arberia (Rigby, 1972), basado en la presencia de un raquis estriado longitudinalmente, que se divide en su parte superior varias veces. A pesar de su apariencia general, la preservación de los especimenes no es lo suficientemente buena como para observar mayores de detalles, como la presencia de óvulos terminales, o el tipo de ramificación de las ramas. La ausencia de los óvulos se puede deber a que el ejemplar se preservó de su lado estéril (Adendorff, 2005), por lo que las ramas que sostienen a los óvulos estarían tapándolos; o bien, los óvulos pueden haber ya madurado y caído del resto de la fructificación. Por último, está la posibilidad que estas ramificaciones hayan sido únicamente estériles, como lo sugiere Rigby (1972). Cabe destacar que ambos ejemplares presentan un tamaño relativamente mayor al de la media conocida para este género en otras partes de Gondwana. La presencia de este género debe ser reconfirmada a través del hallazgo de nuevos y mejor preservados especímenes. Mientras tanto, se sugiere mantener la presencia de este género en La Golondrina con dudas. 


\subsection{INCERTAE SEDIS}

\section{Coniferofitas indet.}

Lám. XLII - Figs. 1-10

Material nuevo: MPM-Pb 4612, 4613, 4676 a 4678, 4681 a 4685, 4816 a-b, 4817, 4819, 4820 a-b, 4839, 4840, 4845 a 4849, 4862 a 4866, 4876, 4878 a 4892, 4911 a 4921, 4923 a 4931, 4933 a 4935, 4937 a 4940, 4942 a 4944, 4947, 4976, 4978, 4979, 4981 a 4988, 4997, $15103,15104,15132$.

Descripción: Ramas sueltas, en su mayoría estériles (Lám. XLII, figs. 1-3), con hojas uninervadas en forma de aguja, de bases triangulares, acuminadas y ápice recurvado (Lám. XLII, figs. 6, 7, 9, 10). Las hojas se disponen helicoidalmente sobre el tallo, y se encuntran adpresas a levemente separadas del eje (Lám. XLII, figs. 6, 9). Cono fértil femenino, multiovulado, portando lo que aparentan ser óvulos (¿semillas?) libres, platispérmicos y alados (Lám. XLII, figs. 4, 5). No se pudo observar ningún complejo bráctea-escama (¿preservación insuficiente?). El cono tiene posición lateral en el eje que lo porta. Algunas ramas presentan un "botón” estéril terminal (Lám. XLII, figs. 7, 8) o lateral (Lám. XLII, figs. 9, 10).

Discusión: Se presenta aquí el primer hallazgo de ejemplares de coniferofitas para la Formación La Golondrina. Los elementos hallados son mayormente ramas estériles con hojas de base triangular, acuminadas, y curvadas en la punta, que pueden estar adpresas o levemente separadas del eje, dispuestas helicoidalmente. Se identificó hasta el momento una única estructura coniforme femenina. 
De acuerdo a la clasificación actualmente más aceptada (Taylor et al., 2009), las coníferas paleozoicas pertenecerían todas al Orden Voltziales. Dentro de este grupo, habría coníferas del tipo "voltzia", o del tipo "walchia". Dado que todo el material proveniente de la Formación La Golondrina está representado por ramas sueltas, y por lo tanto, no se puede definir si el tipo de ramificación sería plagiotrópico u ortotrópico (Taylor et al., 2009), la presencia de hojas en forma de aguja es la única característica que permitiría agruparlas bajo el tipo "walchia". Asimismo, análisis filogenéticos indican a las "walchia" como un grupo contenido dentro de las "voltzia" (Rothwell et al., 2005, en Taylor et al., 2009). De las coníferas conocidas para Gondwana (ver Archangelsky y Cúneo, 1987 y bibliografía allí mencionada), el material estéril aquí presentado presenta afinidades con Ferugliocladus riojanum Archangelsky y Cúneo (Archangelsky y Cúneo, 1987) en la disposición helicoidal de hojas todas de un mismo tipo, aguzadas, uninervadas. Sin embargo, se diferencia de esta especie en su parte fértil, ya que $F$. riojanum presenta conos terminales, compuestos de brácteas simples y óvulos libres, o bien, de complejos ovulíferos, en los cuales se han observado óvulos ortrótopos con ápices bífidos. Las semillas son platispérmicas y aladas, con un ápice marcademente bífido (asignadas al género Eucerospermum Feruglio, ver A. Archangelsky, 2000). Además de la diferencia en las estructuras fértiles, el material de La Golondrina no posee cutícula preservada que pueda ser analizada como para realizar mayores comparaciones.

Dada la ausencia de material más completo, en conexión orgánica con tallos mayores, la ausencia de cutículas que puedan ser analizadas celularmente, y la única presencia de un cono fértil encontrado hasta el momento, se prefiere mantener a estas coniferofitas como indeterminadas hasta tanto más material con mejor preservación sea hallado para realizar comparaciones más completas que permitan su asignación genérica y específica correcta. 
Género Samaropsis Goeppert, 1864

Especie tipo: Samaropsis ulmiformis Goeppert, 1864

Samaropsis golondrinensis A. Archangelsky, 2000

Lám. XLIII - Figs. 1-13

Referencias: A. Archangelsky (2000).

Material nuevo: BAPb 13826; MPM-Pb 2732, 4424, 4425, 4429, 4482, 4614, 4616, 4638, 4674, 4774, 4777, 4778, 4779, 4781, 4964, 15129.

Discusión: Abundantes semillas asignables a esta especie han sido colectados en recientes campañas. En todas ellas, se reconocen las características típicas de la especie (A. Archangelsky, 2000), a saber: simetría bilateral, contorno ovalado a subredondeado, ápice bífido, chalaza trunca, con esclerotesta bien diferenciada de la sarcotesta en la mayoría de los casos, aunque a veces puede estar indiferenciada (Lám. XLIII, figs. 1-13). Sarcotesta ancha de aspecto coriáceo. Superficie de la semilla a veces estriada longitudinalmente (Lám. XLIII, figs. 2, 4, 7, 10, 11).

? Orden GINKGOALES Warbug, 1913

Género Megistophyllum Archangelsky, 1959a

Especie tipo: Megistophyllum leanzai Archangelsky, 1959a 
Megistophyllum leanzai Archangelsky, 1959a

Lám. XLIV - Figs. 1-9

Referencias: Archangelsky (1959a: 49).

Material nuevo: BAFC-Pb 15421, 15425; MPM-Pb 2793, 4946, 4980, 4996.

Discusión: Un primer, único ejemplar fue colectado por De Giusto en la Laguna Salada, en 1954, y luego estudiada por Archangelsky (1959a). Durante la revisión de la colección de paleobotánica de la Facultad de Ciencias Exactas y Naturales de la U.B.A, hallé unos ejemplares fragmentarios que serían asignables a esta especie (Lám. XLIV, figs. 1-3, 5-7), colectados en la localidad de Laguna Polina, por Azcuy, Césari, Longobucco y Ottone en una campaña de 1982. Asimismo, en la campaña de 2010, en niveles asociados a coníferas, se hallaron más restos fragmentarios de Megistophyllum leanzai (Lám. XLIV, figs. 4, 8, 9).

Esta especie fue propuesta por Archangelsky (1959a) para describir hojas de posición sistemática incierta, aparentemente enteras, de forma orbicular a suborbicular, de hasta $20 \mathrm{~cm}$ de diámetro, con venación dicotómica abierta, y margen superior con formas suavemente redondeadas. Esta hoja poseía una nerviación principal, más marcada, y venas de menor calibre que las acompañaban, rectas a levemente curvadas hacia los márgenes laterales. El tipo de inserción de la hoja, el cual Archangelsky (1959a) no pudo observar con claridad debido a la preservación de ésta, planteaba dos posibles afinidades: con las ginkgoales si el punto de inserción era a través de un pecíolo (sumada a la venación dicotómica que presentaba la hoja), o con las articuladas (aff. Actinopteris sp.), si la inserción se daba a través de un tallo.

El hallazgo de especímenes con pecíolo (BAFC-Pb 15425 y MPM-Pb 4642, Lám. XLIV, figs. 1, 3, y 4) corroboraría la inserción de la hoja del primer tipo mencionado. Por lo tanto, las hojas de Megistophyllum leanzai serían los primeros registros, y hasta el 
momento, únicos elementos representativos del grupo de las ginkgoales hallados para la Formación La Golondrina. Sin embargo, ante la ausencia de estructuras reproductivas asociadas y/o en conexión orgánica asignables a este grupo en la formación, se prefiere mantener con duda su asignación superior (Orden).

? Familia NYSTROEMIACEAE Wang y Pfefferkorn, 2009

Género Chiropteris Schimper, 1869

Especie tipo: Chiropteris kurriana Schimper, 1869

Chiropteris harrisii Archangelsky, 1960b

Lám. XLV - Figs. 1-2

Referencias: Archangelsky (1960b: 289 - 293).

Material nuevo: $\mathrm{BA}-\mathrm{Pb} 13920,13921,13922 ; \mathrm{MPM}-\mathrm{Pb} 4411$.

Discusión: Estas hojas de peculiares características son poco comunes en La Golondrina, donde únicamente un ejemplar (MPM-Pb 4411, Lám. XLV, fig. 2) ha sido hallado en las campañas recientes. Además, entre el material de colección del Museo Argentino de Ciencias Naturales "B. Rivadavia" se reconocieron ejemplares con pobre estado de preservación que pertenecerían a esta especie.

Género de confusa posición sistemática (Frenguelli, 1942; Retallack, 1980; Herbst et al., 2001; Wang et al., 2003; Wang y Pfefferkorn, 2009), representa hojas de formas 
variadas (coriáceas profusamente disectas, reniformes a cordadas con densa venación, y cordadas semicirculares con venación abierta [Retallack en Herbst et al., 2001]) con una amplia distribución temporal (Carbonífero a Triásico Superior) y geográfica (Cathaysia y Gondwana). Los ejemplares asignados a $C$. harrisii provenientes de la Formación La Golondrina fueron primeramente descriptos por Archangelsky (1960b) como hojas pecioladas de bordes lisos, de forma orbicular reniformes, y venación abierta (en abanico), con venas de igual calibre en toda la lámina que se anastomosaban formando aréolas sinuosas (Archangelsky, 1960b) (Lám. XLV, figs. 1, 2). De acuerdo a esta descripción, las hojas de Chiropteris de La Golondrina estarían representados por la segunda forma (grupo de las "reniformes", según Retallack, 1980), y son comparables con C. reniformis Kawasaki del Pérmico Superior de China (Archangelsky 1960b). Ésta última fue hallada en conexión orgánica con su parte ovulífera, por lo que se la considera una gimnosperma de la familia Nystroemiaceae (Wang y Pfefferkorn, 2009). Aquí se prefiere mantener con duda su asignación a nivel Familia hasta tanto no se halle evidencia de su parte fértil. 
4.8 - Discusión general.

A partir de este estudio, al listado de especies reconocidas hasta el momento para la Formación La Golondrina se le incorporan los siguientes nuevos elementos:

Asterotheca sp. 1

Asterotheca sp. 2

Asterotheca sp. 3

Caulopteris sp.

Lilpopia sp.

Paraschizoneura sp.

Cyclodendron golondrinensis

Bifariala cf. B. intermittens
Dictyopteridium costatum

Dictyopteridium natalensis

Plumsteadia pedicellata

Ottokaria sp.

Scutum cf. S. elongatum

Senotheca sp.

Lidgettonia africana

Coniferofitas

Aunque con dudas, también estarían representados en la Formación La Golondrina:

Phyllotheca sp.

Arberia sp.

Asimismo, de acuerdo a una sistemática más actualizada, se reasignaron las siguientes especies:

"Lepidodendron" patagonicum $\quad \rightarrow \quad$ Bumbudendron patagonicum

Sigillaria sp $\quad \rightarrow \quad$ Licófita sp. A 


$\begin{array}{lll}\text { Lepidophloios laricinus } & \rightarrow & \text { Licófita sp. B } \\ \text { Fructificación tipo A } & \rightarrow & \text { Gonophylloides semnes } \\ \text { Fructificación tipo B } & \rightarrow & \text { Dictyopteridium sporiferum }\end{array}$

Entre los elementos novedosos más abundantes se destacan las fructificaciones de glossopterídeas. A excepción de Dictyopteridium cf. sporiferum (Archangelsky, 1992), y las "Fructificaciones A y B" de Archangelsky y Bonetti (1963), ningún otro elemento fértil del más representativo de todos los grupos en la flora de la Formación La Golondrina, las glossopterídeas, había sido identificado. Este estudio aporta de esta manera, un total de 8 nuevas fructificaciones de glossopterídeas, y la reasignación de otras dos. Además, una fructificación de sphenophyllal (Lilpopia sp) es descripta por primera vez tanto para La Golondrina, como Gondwana.

También se incrementa el número de taxa de helechos asterothecáceos de 4 a 7 , y se describe por primera vez para la formación la presencia de tallos (Caulopteris sp). Al no haberse hallado aún la parte fértil de Sphenopteris (sp II), se prefiere mantener su nomenclatura abierta.

Las licófitas conocidas para la formación fueron redescriptas y reasignadas. A partir de su estudio, se concluye la presencia de Bumbudendron en La Golondrina, se agrega un género (Cyclodendron), y se prefiere dejar con nomenclatura abierta dos elementos fragmentarios y únicos, previamente asignados a Sigillaria y Lepidophloios (ambos géneros típicamente nórdicos cuyo registro no ha sido hallado hasta la fecha en ninguna parte de Gondwana).

La presencia de nuevo y más completo material asignable a Megistophyllum leanzai permite especular la posible presencia de las Ginkgoales en la Formación La Golondrina, grupo hasta ahora ausente. Sin emabrgo, se prefiere mantener cierta precaución en lo que a 
su presencia respecta hasta tanto no se hallen estructuras reproductivas que lo puedan confirmar.

Por último, el hallazgo de coniferofitas en una campaña llevada a cabo recientemente (Noviembre 2010), establece definitivamente la presencia de este grupo hasta el momento totalmente desconocido para la Formación La Golondrina, abriendo nuevas líneas de análisis fitoecológicos y bioestratigráficos. Se espera que a través de futuros hallazgos de material en mejor estado de preservación, se pueda lograr su correcta clasificación, lo que posibilitará asimismo dilucidar acerca de las relaciones filogenéticas con los demás grupos de coniferofitas paleozoicas.

De esta manera, el total de especies reconocidas para la Formación La Golondrina llega a 65, haciendo de ésta una de las más diversas floras desarrolladas durante el Pérmico en Argentina. 


\section{- LÁMINAS -}


I. Asterotheca sp. 1. Fig. 1- BAPb 13801. Ejemplar donde se observan pínnulas fértiles y estériles. Escala 1cm. Fig. 2- BAPb 13801. Detalle de las pínnulas fértiles, con hasta 10 sinangios redondeados a cada lado de la vena media de la pínnula, ocupando parcialmente el envés de ésta. Escala 5 mm. Fig. 3- BAPb 13801. Detalle de las pínnulas estériles, con una vena media recta que llega hasta casi el ápice de la pínnula, y venas laterales hasta una vez bifurcadas. Escala $5 \mathrm{~mm}$. 


\section{LÁMINA I}
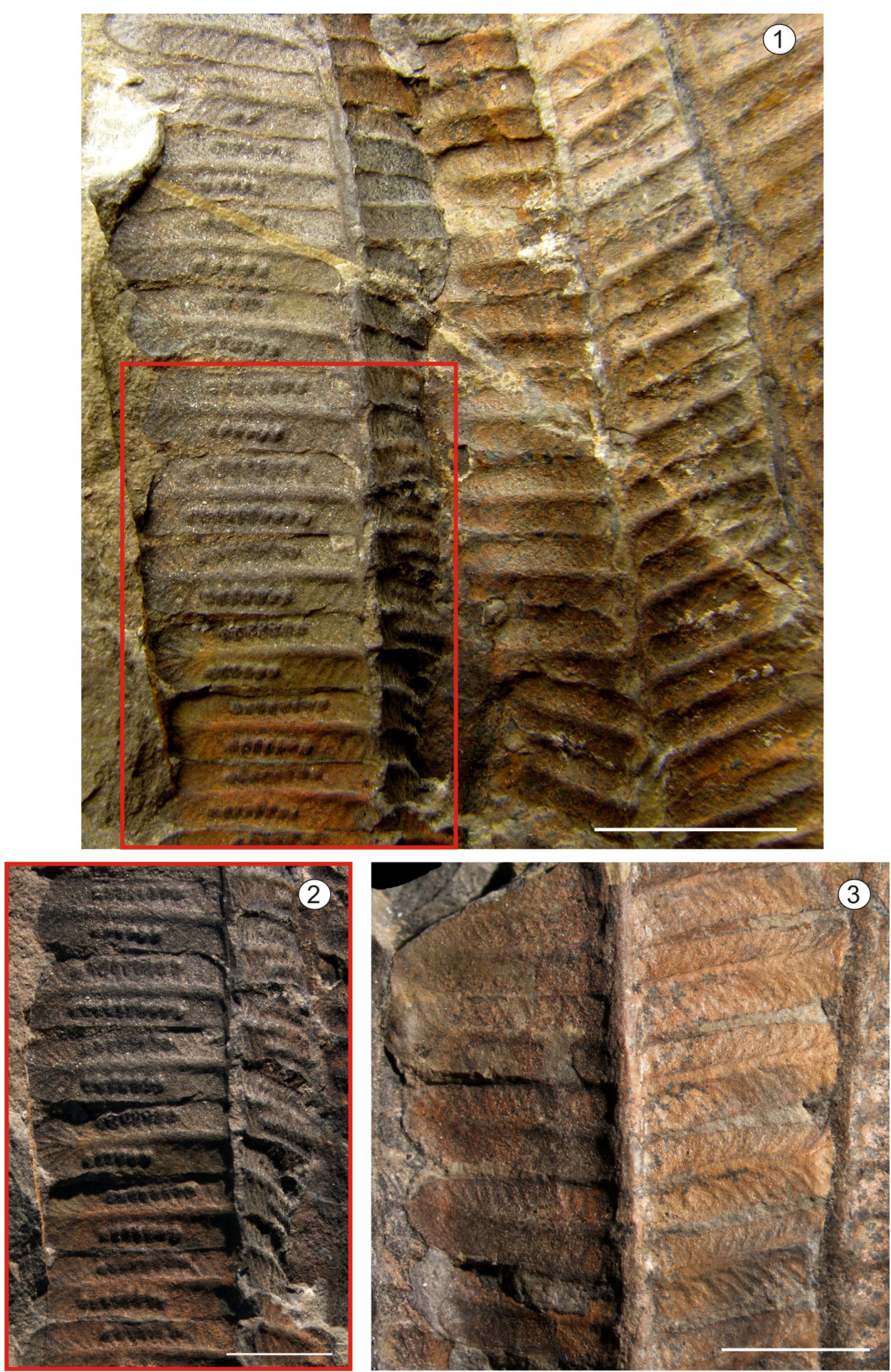
II. Asterotheca sp. 2. Fig. 1- BAPb 13854. Fragmento de fronde bi-pinnada donde se observan pínnulas fértiles y esteriles. Escala $1 \mathrm{~cm}$. Fig. 2- BAPb 13854. Pínnulas fértiles con hasta 4 sinangios a cada lado de la vena media, mostrando un estadío levemente más avanzado que en Fig. 3. Escala 5 mm. Fig. 3- BAPb 13854. Pínnulas fértiles con 4 sinangios, cada uno porta 4 esporangios, y pínnulas estériles con vena media que no llega al ápice, y venas laterales simples. Escala $2 \mathrm{~mm}$. Fig. 4- Detalle de pínnula fértil donde se observan claramente 4 esporangios en un sinangio (flecha amarilla). Escala 1 mm. Fig. 5- BAPb 13756. Fragmento de frondo bi-pinnada donde se observan pínnulas fértiles. Escala $1 \mathrm{~cm}$. Fig. 6- BAPb 13756. Detalle de dos pinnas portando pínnulas fértiles con 2-3 sinangios a cada lado de la vena media (hasta 6 en total). Escala 5 mm. Fig. 7- BAPb 13756. Pinnas portando pínnulas con 5-6 sinangios en total. Escala 5 mm. Figs. 8-9 BAPb 13758. Pinnas portando pínnulas fértiles, con hasta 4 sinangios (detalle recuadro rojo). Escala Fig. 8: 1cm, Fig. 9: $5 \mathrm{~mm}$. 


\section{LÁMINA II}
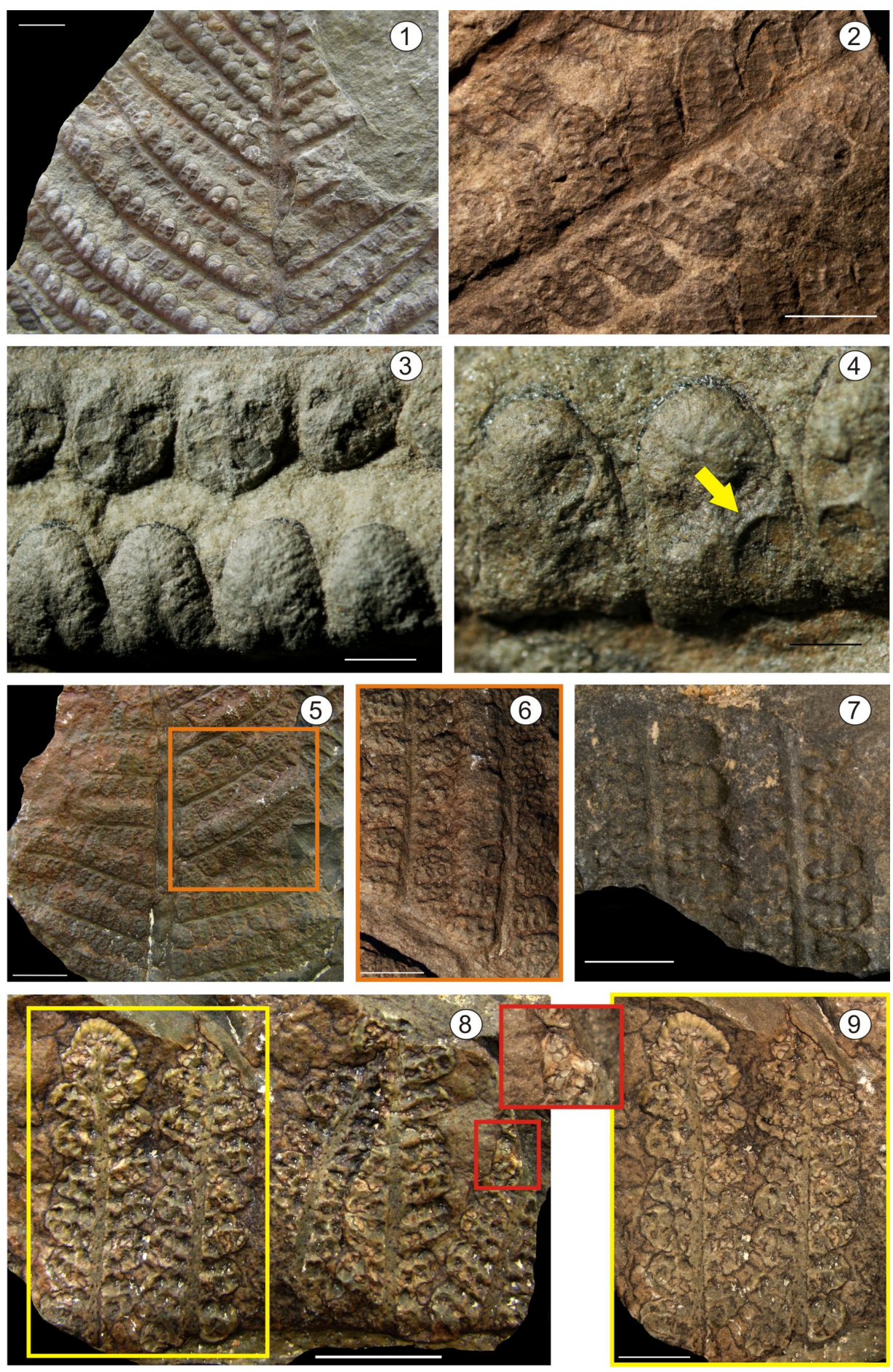
III. Asterotheca sp. 3. Fig. 1- MPM-Pb 2637. Cara y contracara de fragmento de fronde fértil, donde se observan pínnulas falcadas, opuestas, con aproximadamente hasta 8 sinangios a cada lado de la vena media, mal definidos. Escala $1 \mathrm{~cm}$. Fig. 2- MPM-Pb 2637. Detalle de pinnas fértiles. Escala $1 \mathrm{~cm}$. Fig. 3- MPM-Pb 15141/7. Fragmento de fronde donde se observan pínnulas estériles, opuestas, elongadas y con ápice agudo. Escala $1 \mathrm{~cm}$. Fig. 4- MPM-Pb 15141/7. Detalle de las pínnulas opuestas. Escala 5 mm. Fig. 5- MPM-Pb 4421. Pinnas portando pínnulas estériles opuestas, elongadas, falcadas, mostrando una leve separación entre ellas. Escala $1 \mathrm{~cm}$. Fig. 6- MPM-Pb 4422. Detalle de las pínnulas estériles, mostrando su disposición opuesta a subopuesta sobre el raquis de la pinna. Escala $5 \mathrm{~mm}$. Fig. 7- MPM-Pb 4441. Pinnas con pínnulas opuestas, estériles, falcadas. Escala $1 \mathrm{~cm}$. 


\section{LÁMINA III}
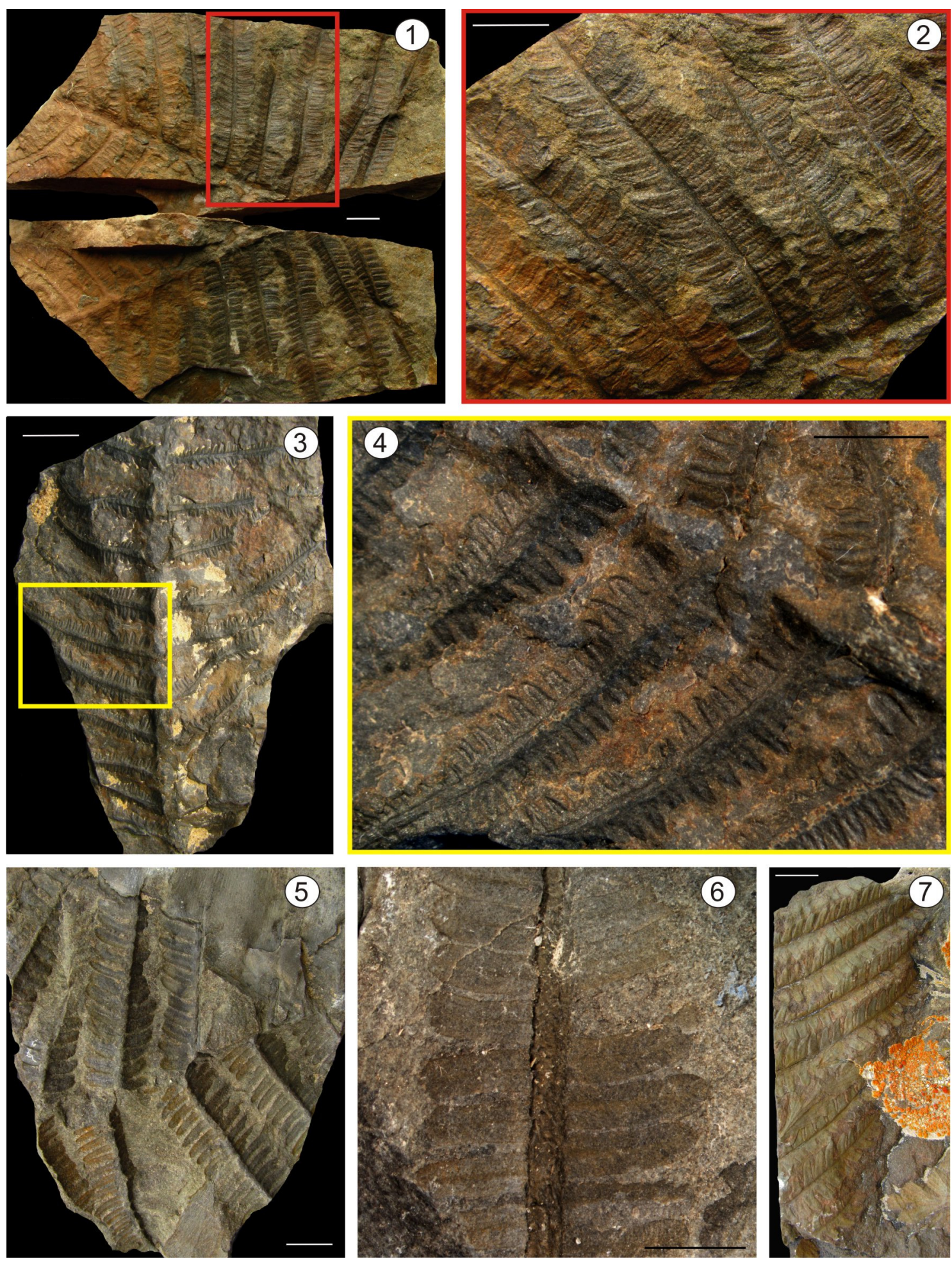
IV. Asterotheca anderssonii. Fig. 1- BAPb 13927. Detalle de pínnulas estériles, con vena media decurrente, y venas laterales 2 o más veces furcadas. Escala $5 \mathrm{~mm}$. Fig. 2- BAPb 14050. Detalle de pínnulas fértiles, con vena media decurrente, y hasta 8 sinangios a cada lado de la vena media, portando 5-6 esporangios. Observar el raquis estriado de la pinna, característico de la especie. Escala 5 mm. Fig. 3- BAPb 14045. Detalle de pínnulas fértiles con hasta 11 sinangios por pínnula, portando 6 esporangios. Raquis de pinna estirado. Escala 5 mm. Fig. 4- BAPb 14050. Pínnula portando sinangios con 5 esporangios (graficado). Fig. 5- MPM-Pb 4395. Pinna portando pínnulas con venas laterales hasta 3 veces divididas. Escala $1 \mathrm{~cm}$. Fig. 6- MPM-Pb 4489. Fragmento apical de pinna. Escala $5 \mathrm{~mm}$. 


\section{LÁMINA IV}
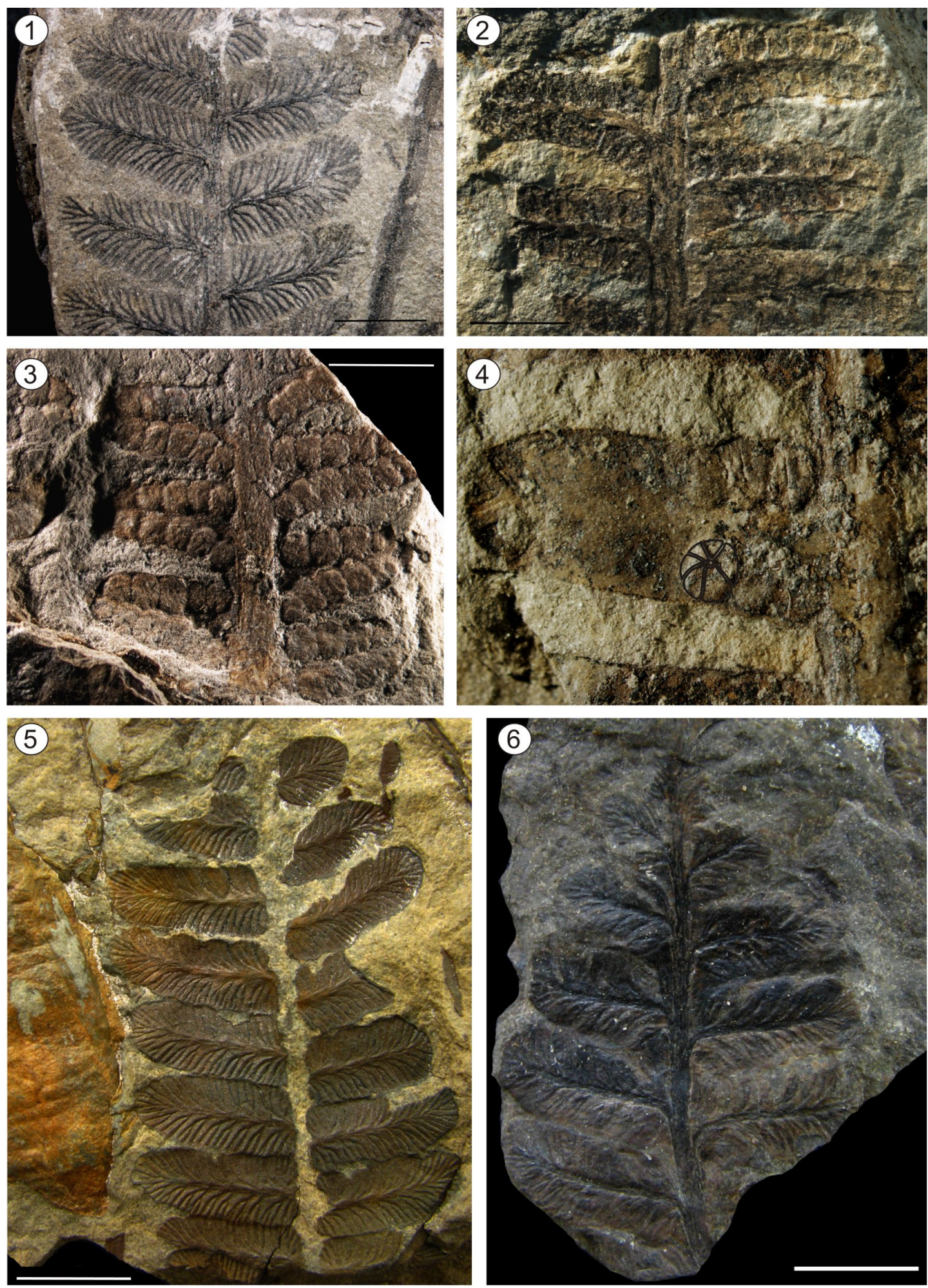
V. Asterotheca golondrinensis. Fig. 1- MPM-Pb 15148. Fronde bi-pinnada estéril. Escala $1 \mathrm{~cm}$. Fig. 2Detalle de dos pinnas, con pínnulas que muestran la típica venación de la especie. Escala 5 mm. Fig. 3MPM-Pb 15107. Fronde bi-pinnada estéril. Escala 1 cm. Fig. 4- MPM-Pb 15148. Detalle ampliado de pínnulas, donde se observa claramente el tipo de venación abierta. 


\section{LÁMINA V}
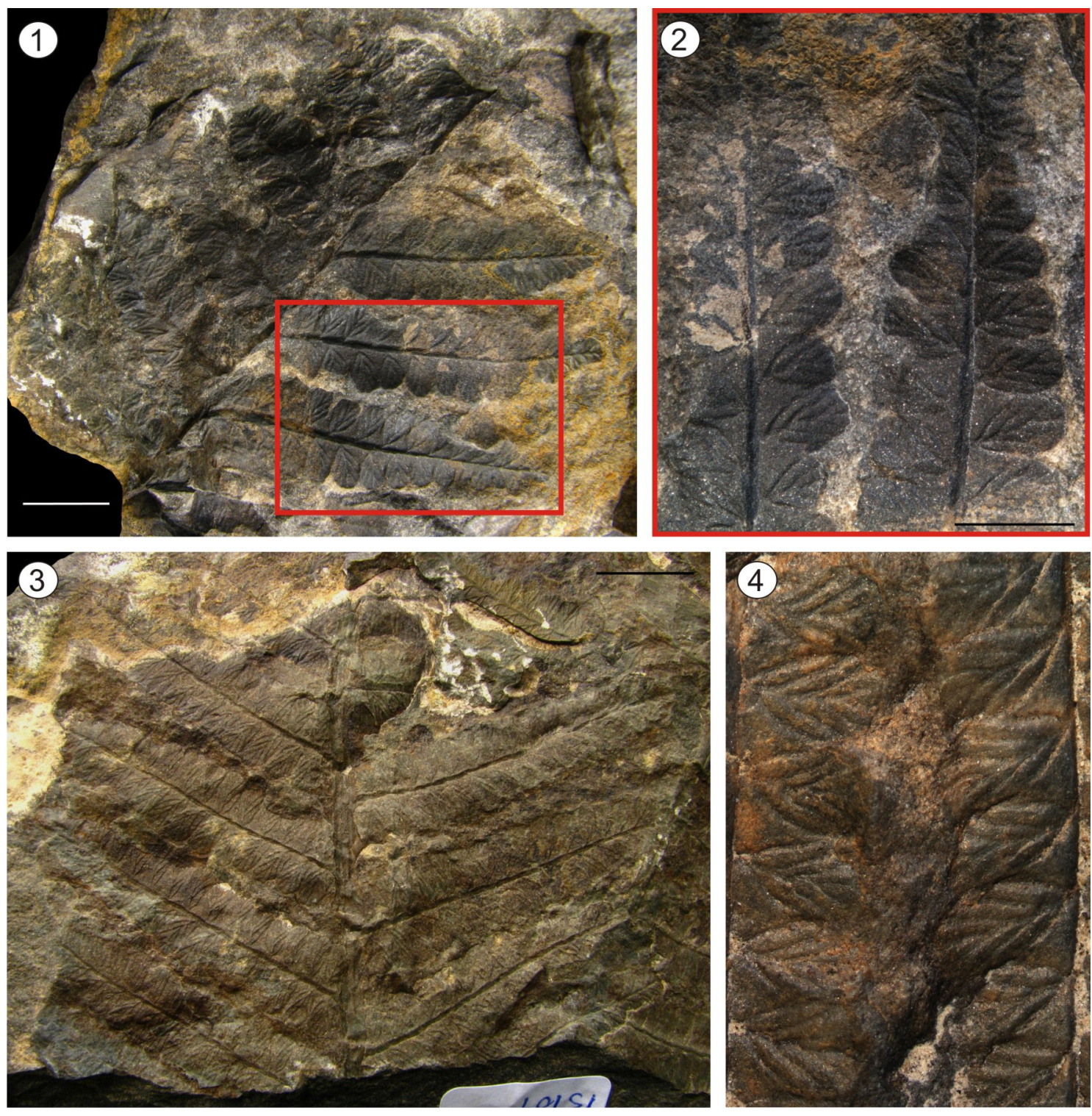
VI. Asterotheca piatnitzkyi. Fig. 1- BAPb 13785. Fragmento de pinna con pínnulas fértiles. Escala $1 \mathrm{~cm}$. Fig. 2- BAPb 13785. Pínnula con 9 sinangios, donde se observan exquisitamente preservados los 5 esporangios. Escala $1 \mathrm{~mm}$. Fig. 3- BAPb 13857. Pinnas fértiles. Escala $1 \mathrm{~cm}$. Fig. 4- MPM-Pb 4438. Detalle de pínnulas fértiles con hasta 13 sinangios portando 5 esporangios. Escala $5 \mathrm{~mm}$. Fig. 5- BAPb 13810. Fragmentos de frondes fértiles. Escala $1 \mathrm{~cm}$. Fig. 6- MPM-Pb 4510. Pinna portando pínnulas con hasta 13 sinangios. Escala 5 $\mathrm{mm}$. 


\section{LÁMINA VI}
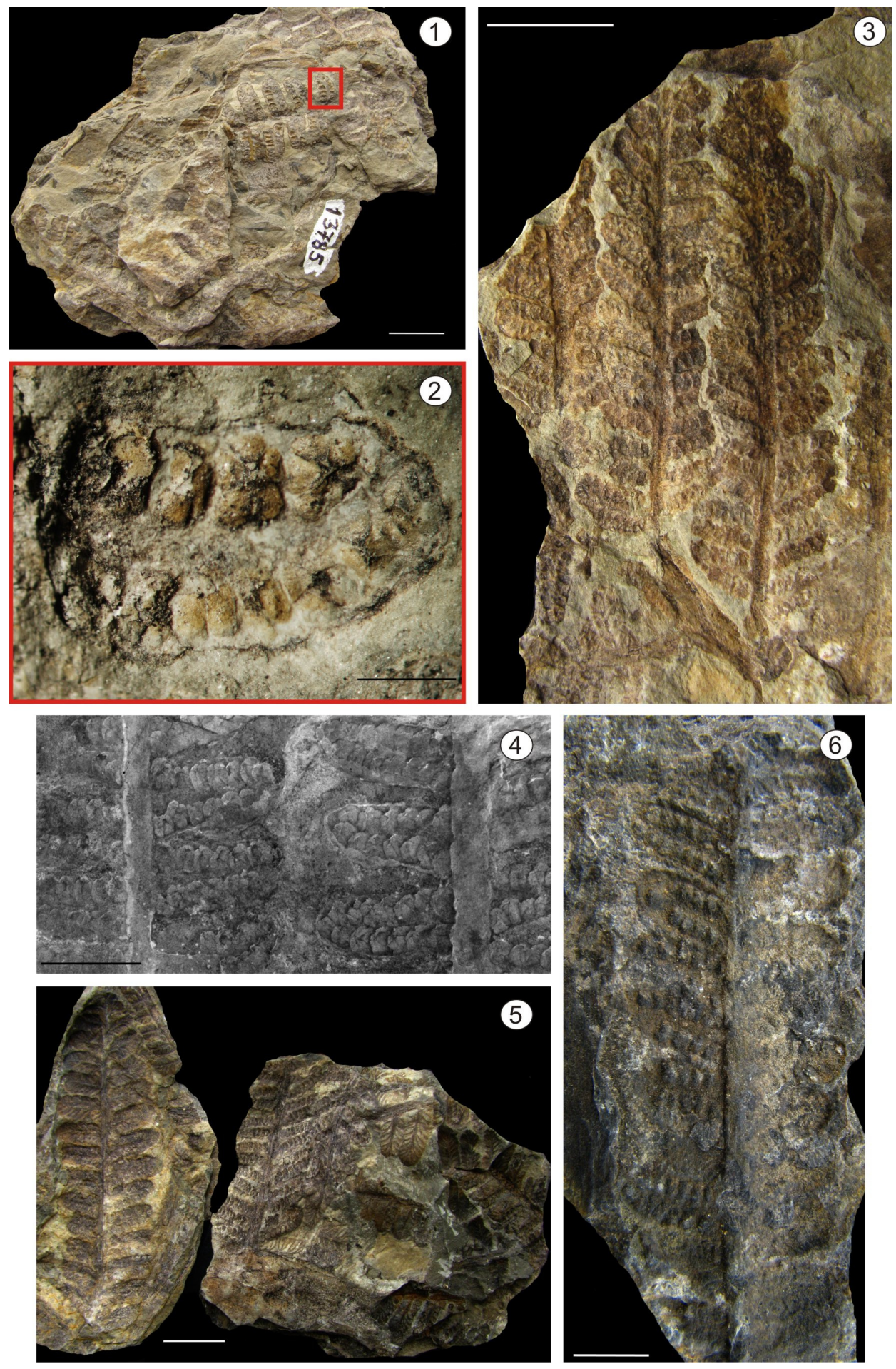
VII. Asterotheca singeri. Fig. 1- MPM-Pb 4766. Ejemplar esteril mostrando la vena media recta que llega hasta el ápice y venas laterales una vez bifurcadas. Escala $1 \mathrm{~cm}$. Fig. 2- BAPb 13816. Detalle de pínnulas estériles. Escala $5 \mathrm{~mm}$. Fig. 3- BAPb 13819. Pinnas fértiles, con +8 sinangios a cada lado de la vena media. Escala $1 \mathrm{~cm}$. Fig. 4- BAPb 13819. Detalle de pínnula mostrando sinangios 6-7 esporangiados. Escala $5 \mathrm{~mm}$. Fig. 5- BAPb 13819. Detalle aumentado de los sinangios, donde se contabilizan hasta 7 esporangios por sinangio. Fig. 6- MPM-Pb 2870. Ejemplar de Asterotheca singeri hallado en el miembro inferior Laguna Lillo. Escala $1 \mathrm{~cm}$. Fig. 7- MPM-Pb 2870. Detalle de las pínnulas fértiles, con +8 sinangios a cada lado de la vena media, recta que llega hasta el ápice. Escala $5 \mathrm{~mm}$. 


\section{LÁMINA VII}
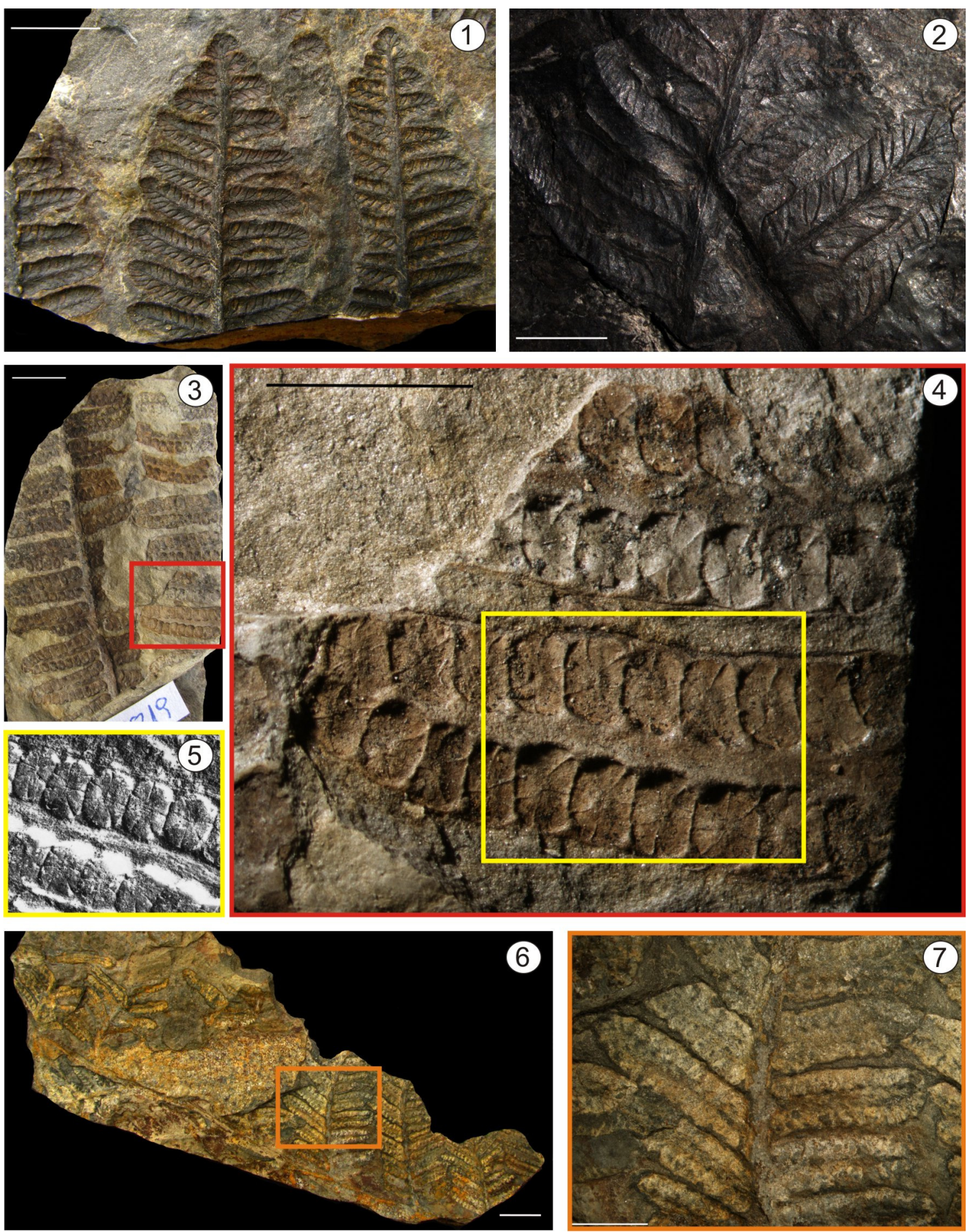
VIII. Dizeugotheca furcata. Fig. 1- BAPb 13838. Pinnas portando pínnulas alternadas estériles, mostrando la venación furcada típica de la especie. Escala 5 mm. Fig. 2- BAPb 13793. Fragmento apical de pinna fértil. Escala $1 \mathrm{~cm}$. Fig. 3- BAPb 13793. Detalle de pínnula mostrando las tecas, ocupando todo el envés de la pínnula. Escala $5 \mathrm{~mm}$. Fig. 4- BAPb 13793. Detalle aumentado de las tecas. Escala $1 \mathrm{~mm}$. Dizeugotheca waltonii. Fig. 5- MPM-Pb 4482. Ejemplar con pínnulas alternadas fértiles, mostrando tecas en menor número que en D. furcata. Escala 5 mm. Fig. 6- MPM-Pb 2544. Pinna fragmentada fértil. Escala 5 mm. 


\section{LÁMINA VIII}
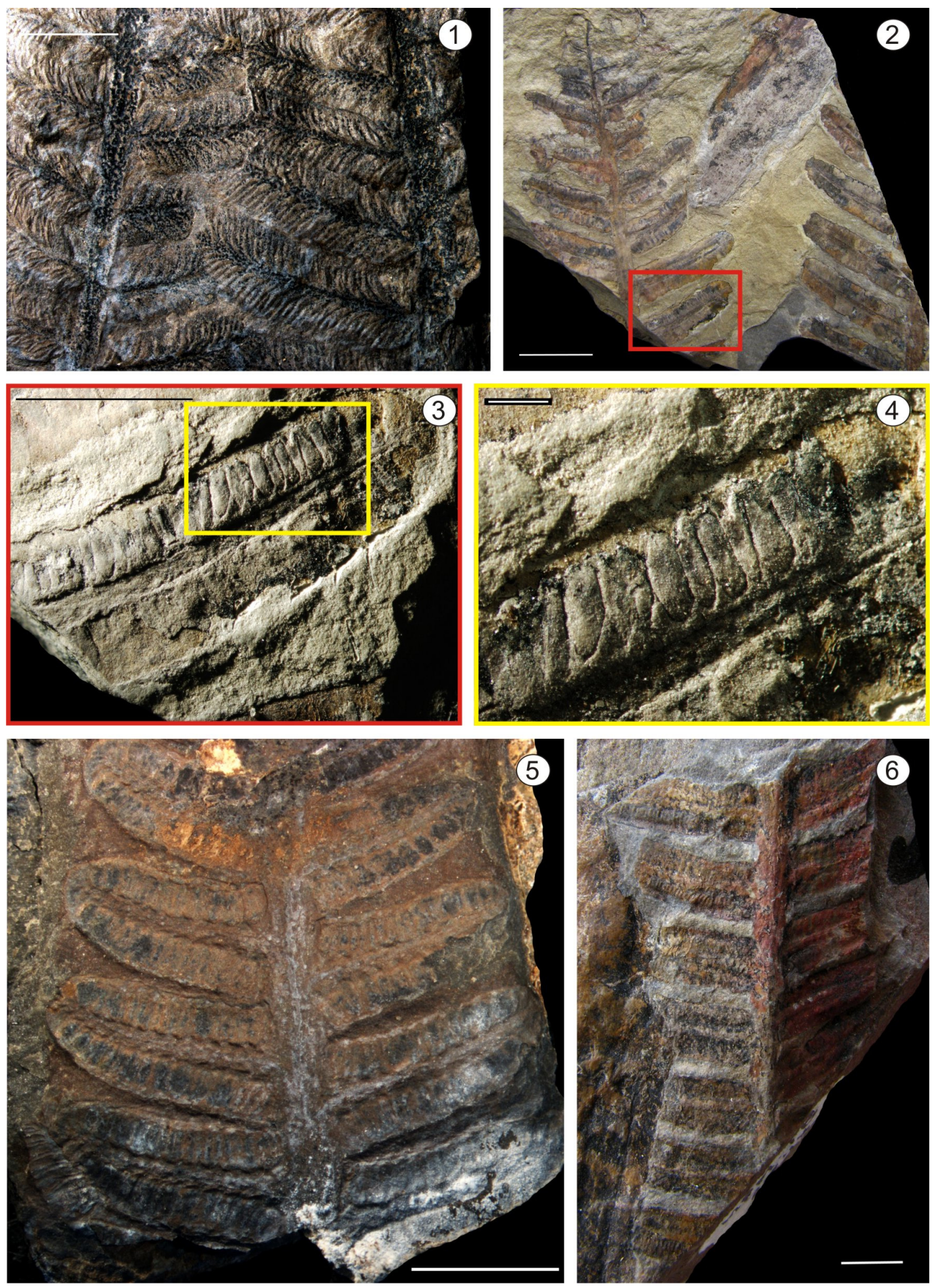
IX. Dizeugotheca neuburgiae. Fig. 1- BAPb 13752. Pinnas estériles con pínnulas dispuestas en forma opuesta. Escala $1 \mathrm{~cm}$. Fig. 2- MPM-Pb 2521. Ejemplar estéril mostrando la disposición opuesta de las pínnulas. Escala $1 \mathrm{~cm}$. Fig. 3- MPM-Pb 2523. Ejemplar fértil mostrando la disposición opuesta de las pínnulas. Escala $1 \mathrm{~cm}$. Fig. 4- MPM-Pb 2581. Detalle de pínnulas fértiles, con tecas abundantes ocupando todo el envés de la pínnula. Escala $1 \mathrm{~cm}$. 


\section{LÁMINA IX}
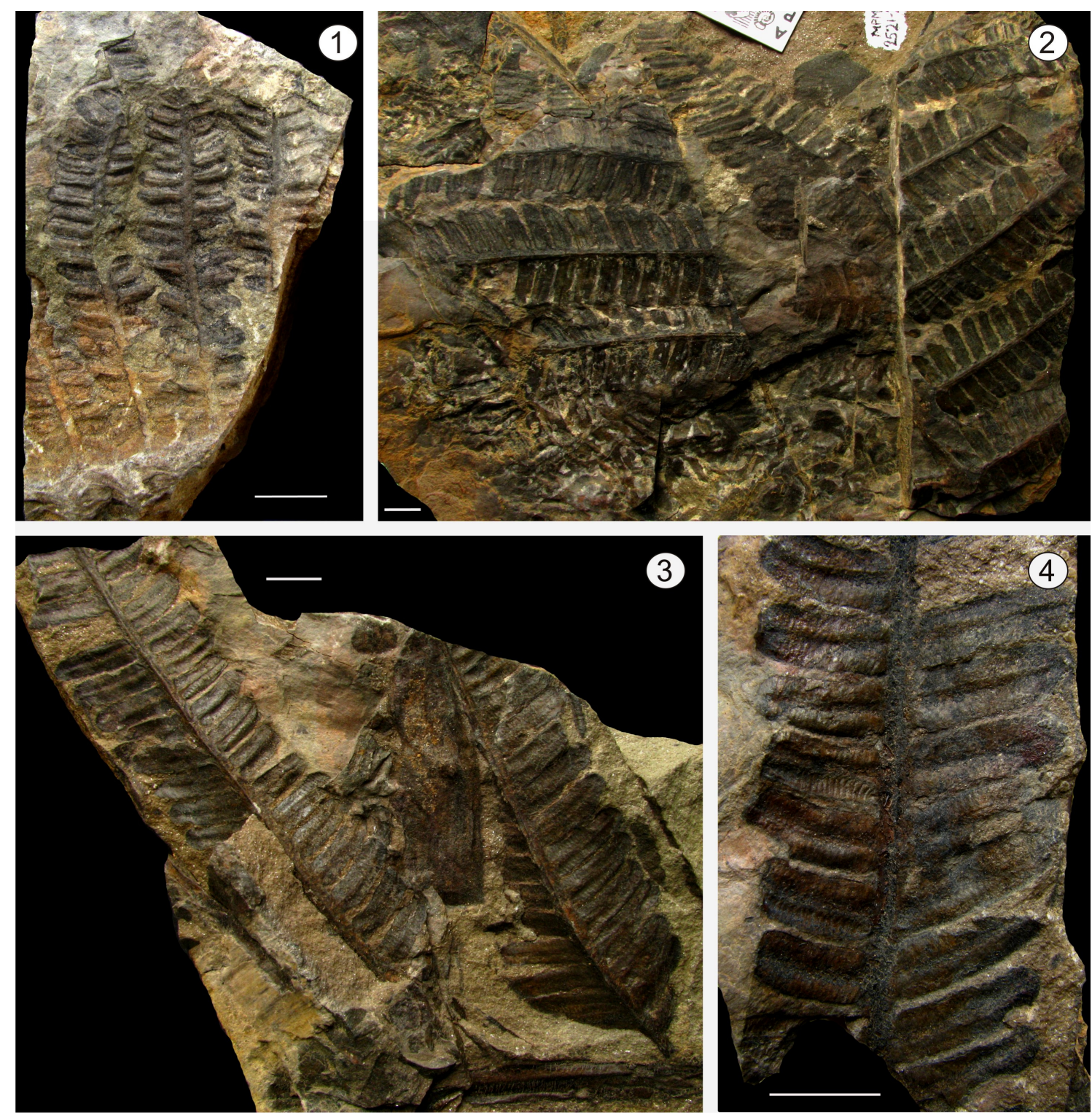
X. Pecopteris sp A. Fig. 1- BAPb 13928. Ejemplar estéril mostrando detalles de la venación pinnular. Escala 5 mm. Fig. 2- BAPb 13928. Detalle venación de pínnula estéril. Escala 5 mm. Fig. 3- BAPb 13928. Detalle de venación de pínnulas estériles. Pecopteris sp I. Fig. 4- Detalle de venación de pínnula estéril de muy mala preservación. Pecopteris sp IV. Figs. 5 y 6- BAPb 14066. Pinnas estériles con raquis punteado. Escala 5 mm. 


\section{LÁMINA X}
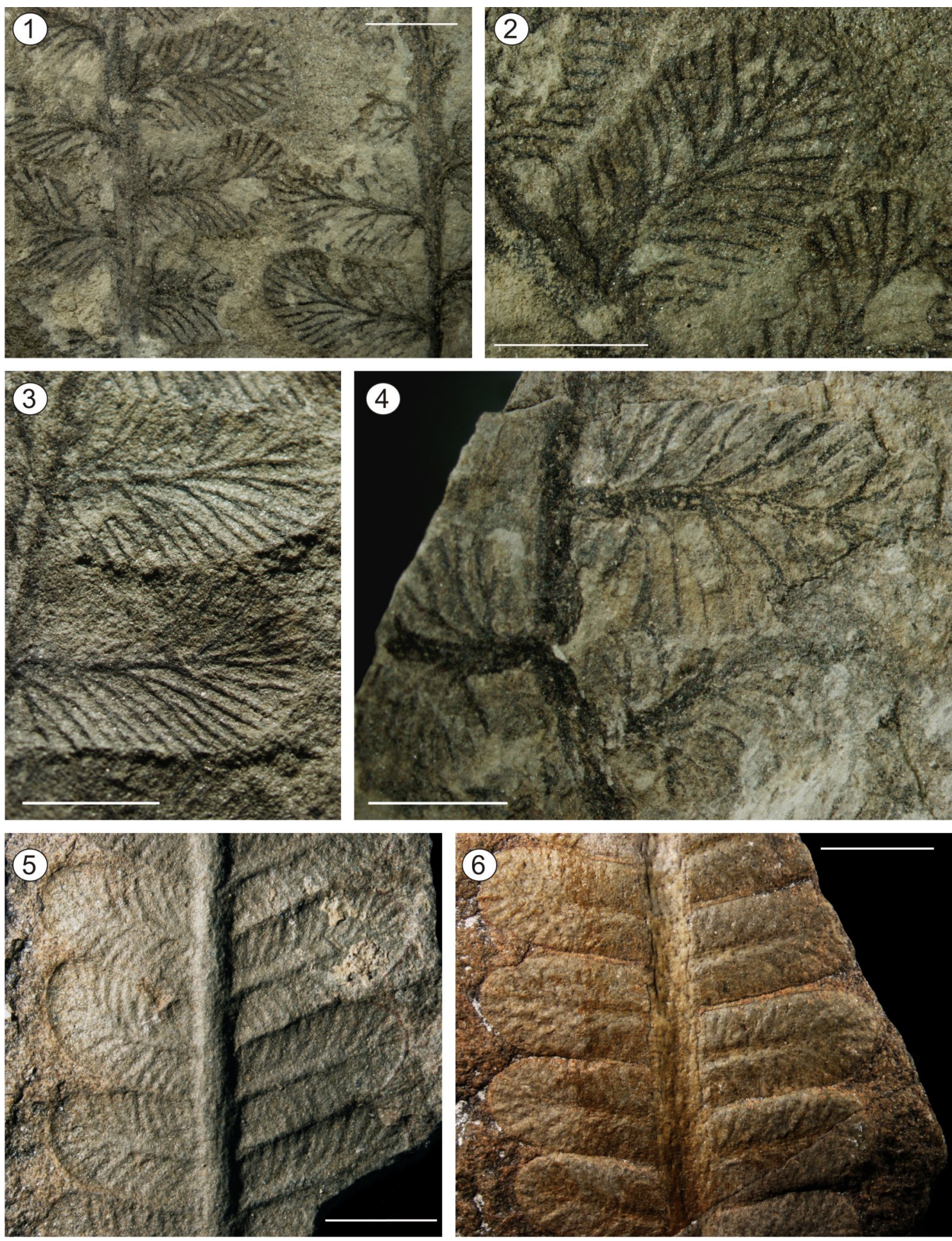
XI. Caulopteris sp. Fig. 1- MPM-Pb 15106. Fragmento de tallo. Escala 1 cm. Fig. 2- MPM-Pb 15106. Detalle de cicatriz. Escala 5 mm. Fig. 3- MPM-Pb 15124. Fragmento de tallo. Escala $1 \mathrm{~cm}$. Fig. 4- MPM-Pb 15137. Fragmento de tallo. Escala $1 \mathrm{~cm}$. Fig. 5- MPM-Pb 15137. Detalle de las cicatrices. Escala $1 \mathrm{~cm}$. Fig. 6- MPM-Pb 15158. Fragmento de tallo. Escala $1 \mathrm{~cm}$. Fig. 7- MPM-Pb 15158. Detalle de cicatrices. Escala 5 $\mathrm{mm}$. 


\section{LÁMINA XI}
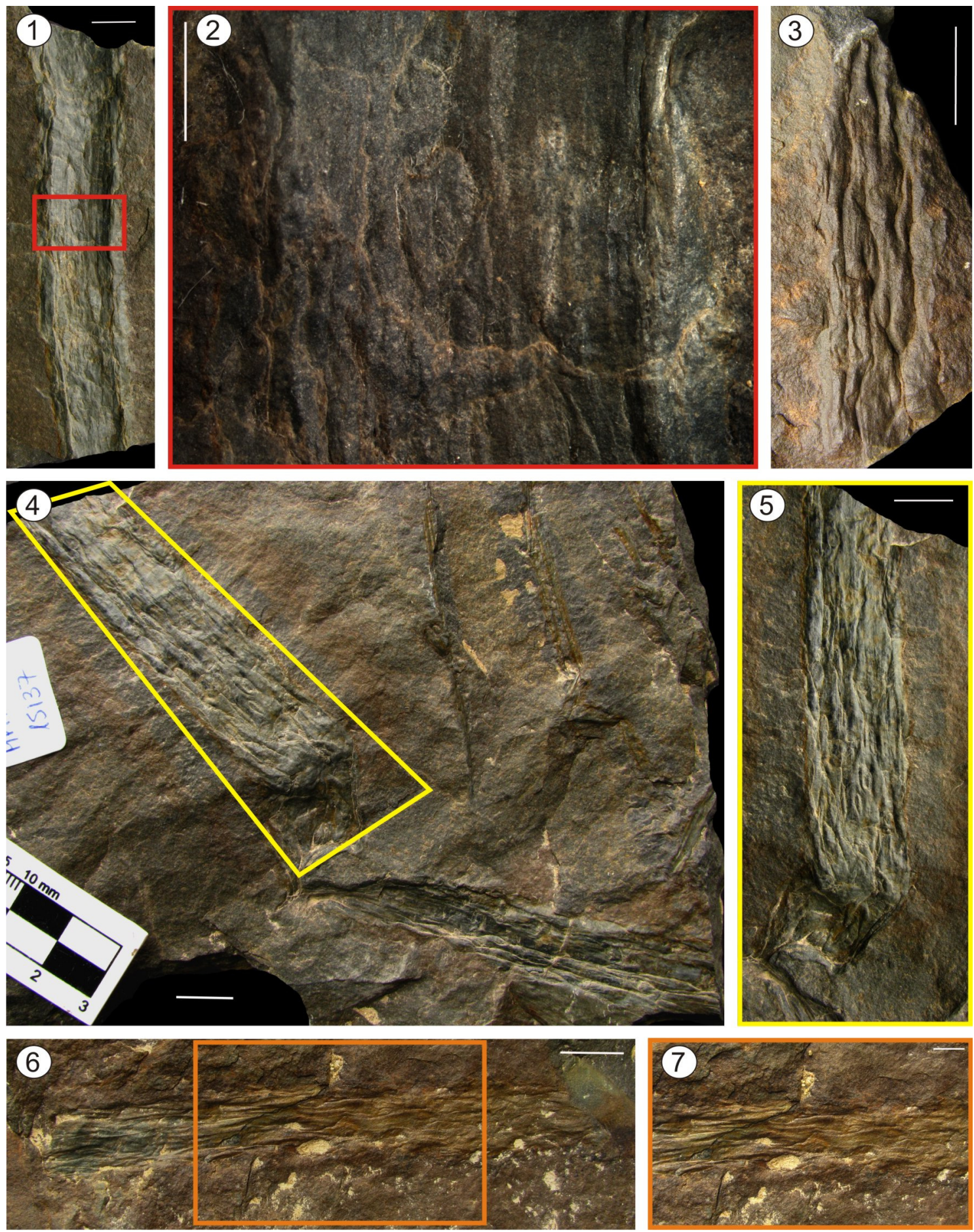
XII. Dichotomopteris hirundinis. Fig. 1- BAPb 13815. Ejemplar fértil, mostrando la disposición de los esporangios, y la venación delicada. Escala 5 mm. Dichotomopteris ovata. Fig. 2- BAPb 14060. Ejemplares fragmentarios estériles. Escala $1 \mathrm{~cm}$. Fig. 3- BAPb 13581. Ejemplar estéril donde se observan las pínnulas redondeadas y la venación dicotómica abierta. Escala $5 \mathrm{~mm}$. Fig. 4- BAPb 13581. Detalle de pínnula con su venación. Escala 5 mm. Fig. 5- BAPb 13869. Ejemplar estéril donde se observa daño de insecto. Escala 5 mm. Fig. 6- BAPb 13869. Ejemplar estéril. Escala 5 mm. 


\section{LÁMINA XII}
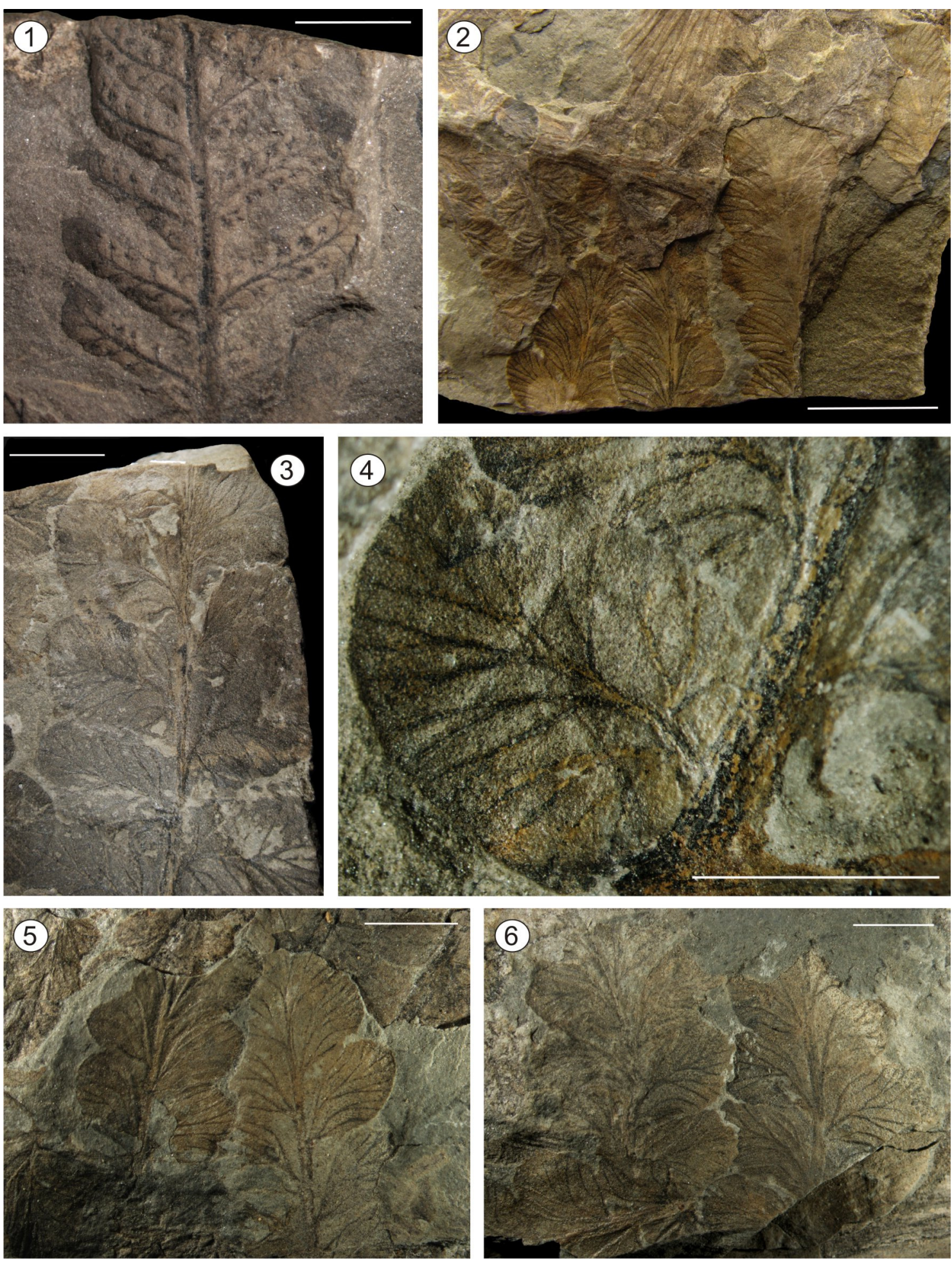
XIII. Sphenopteris sp II. Fig. 1- MPM-Pb 4484. Detalle de pínnulas estériles. Escala 5 mm. Fig. 2- MPM-Pb 4449. Fragmento de fronde bipinnada estéril. Escala $1 \mathrm{~cm}$. Fig. 3- MPM-Pb 4449. Detalle apical de una pinna, con pínnula con daño de insecto. Fig. 4- MPM-Pb 4449. Detalle de pínnulas estériles mostrando la venación, y dodne se observa el raquis estriado longitudinalmente de la pinna. Escala $5 \mathrm{~mm}$. 


\section{LÁMINA XIII}
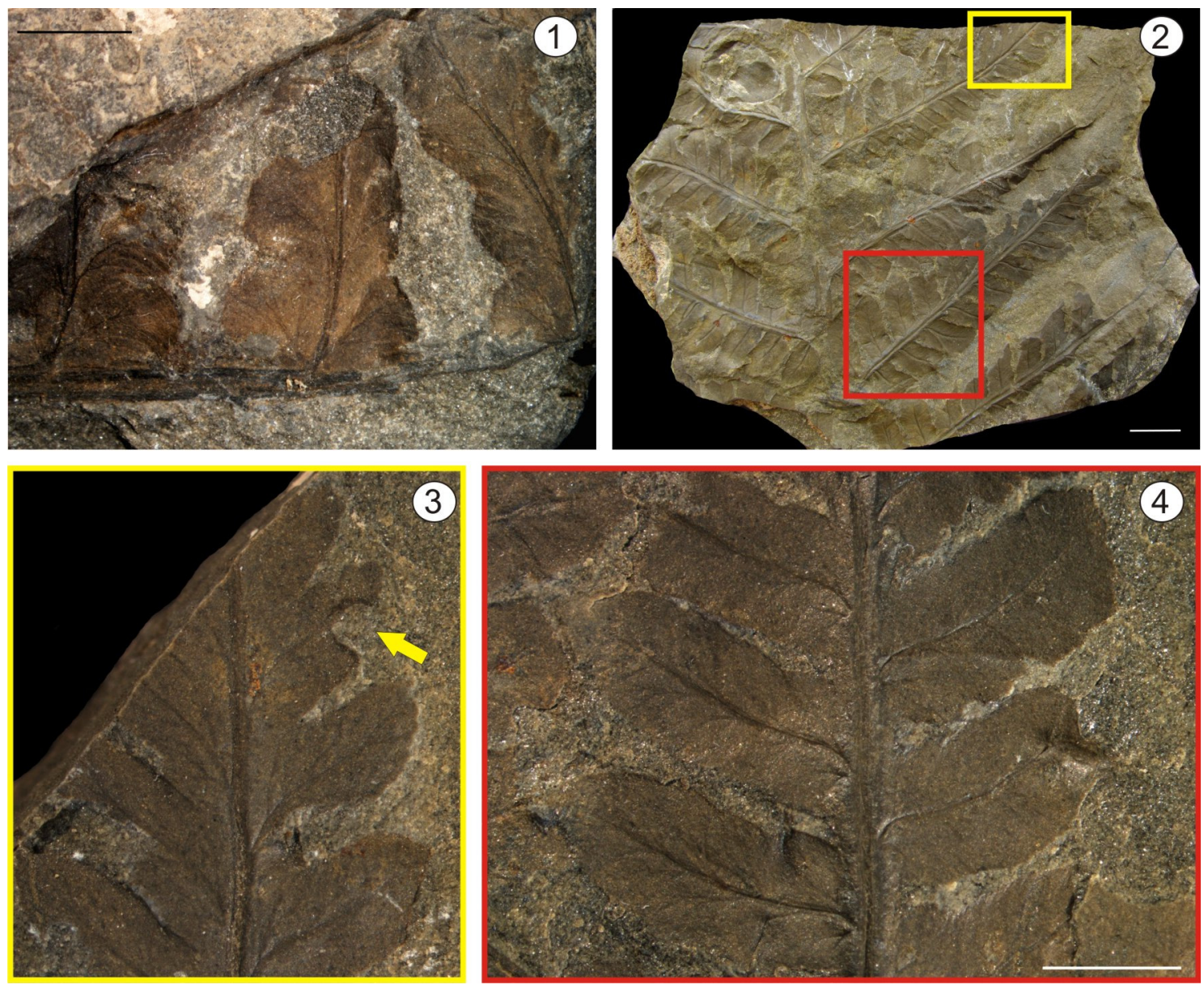
XIV. Sphenophyllum speciosum. Fig. 1- MPM-Pb 4417. Ejemplar con 9 anillos. Escala $1 \mathrm{~cm}$. Fig. 2- BAPb 13739. Cara y contracara de un ejemplar incompleto donde se observan los folíolos alargados y su venación. Escala 1 cm. Fig. 3- MPM-Pb 4873. Ejemplar con 8 anillos. Escala 1 cm. Fig. 4- MPM-Pb 4439. Ejemplar incompleto con 6 anillos donde se observa la disposición de a pares de los folíolos (3 pares de distinto tamaño). Escala $1 \mathrm{~cm}$. Fig. 5- BAPb 13747. Ejemplar con folíolos más redondeados, algunos con daño de insecto. Escala $1 \mathrm{~cm}$. Fig. 6- BAPb 13740. Dos ejemplares de la especie, done se observa la forma y disposición de a pares de los folíolos. Escala $1 \mathrm{~cm}$. 


\section{LÁMINA XIV}
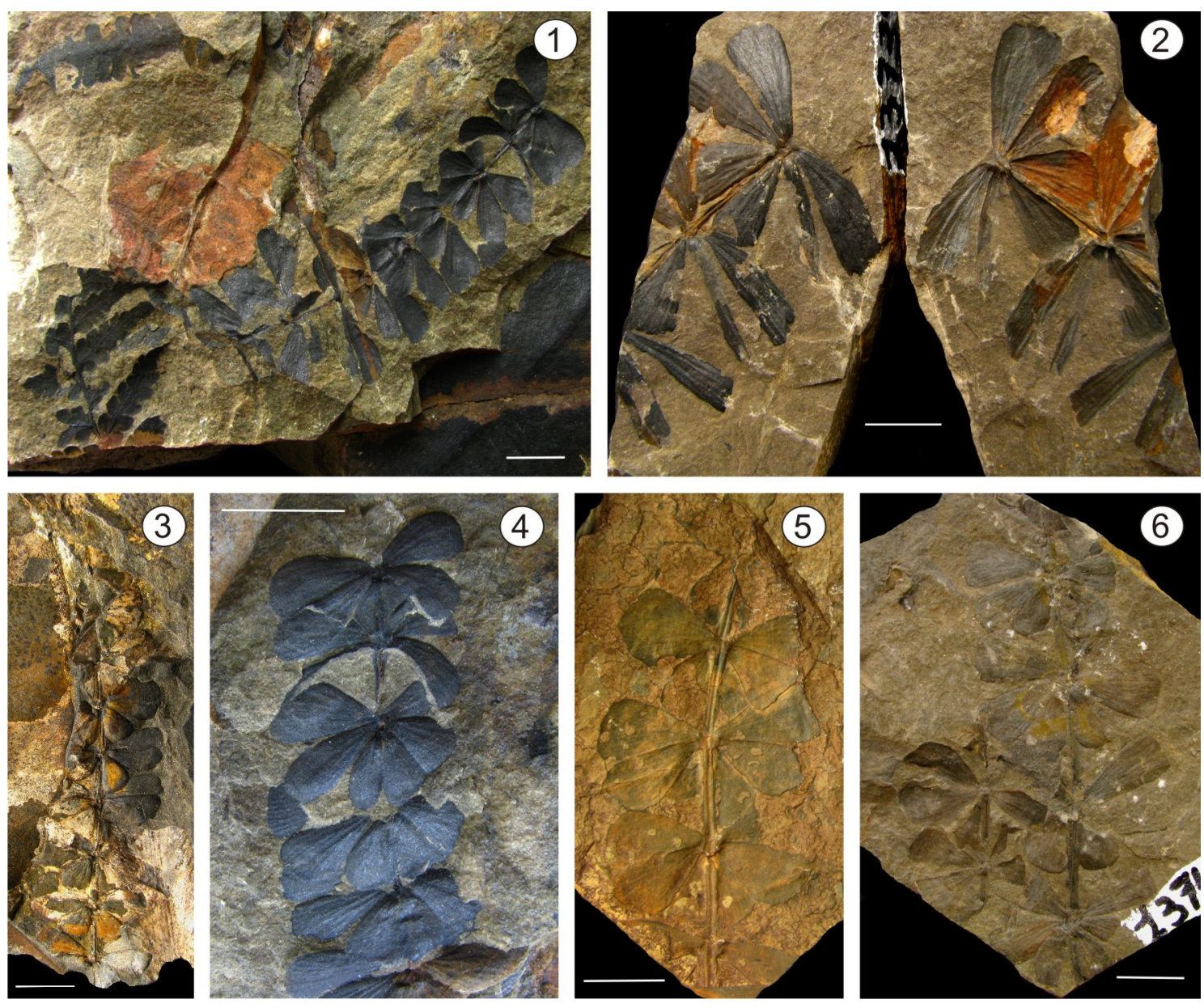
XV. Sphenophyllum thonii. Fig. 1- MPM-Pb 4872. Anillo mostrando 6 folíolos dispuestos en círculo alrededor del eje, con venación dicotómica abierta. Escala 1 cm. Fig. 2- BAPb 13743. Anillo mostrando 6 folíolos. Escala $1 \mathrm{~cm}$. Fig. 3- BAPb 13742. Dos anillos dispuestos en el eje. Escala $1 \mathrm{~cm}$. Fig. 4- BAPb 13744. Anillo incompleto, donde se ve un folíolo con daño de insecto. Escala 1 cm. Figs. 5-7 - MPM-Pb 4851. Cara y contracara de ejemplar con cono fértil (Lilpopia?). Detalles de la estructura fértil en recuadros amarillo y rojo. Escala Figs. 5 y 6: $1 \mathrm{~cm}$, Fig. 7: $5 \mathrm{~mm}$. 


\section{LÁMINA XV}
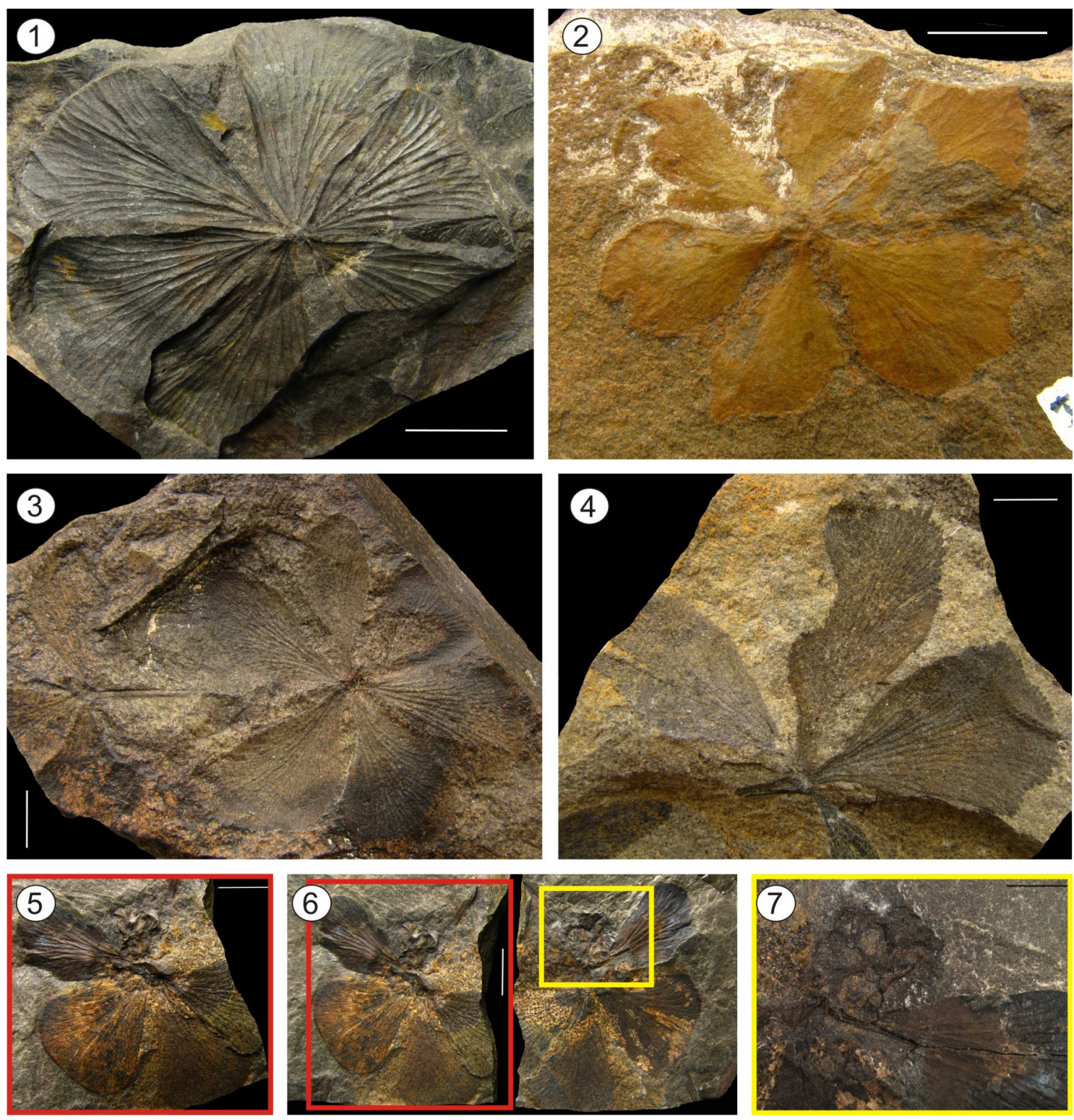
XVI. Lilpopia sp. Fig. 1- MPM-Pb 2715. Cara y contracara de fructificación de sphenophyllal asignada a Lilpopia sp. Las flechas amarillas indican posición del pedicelo. Escala 1 cm. Fig. 2- MPM-Pb 2715. Fructificación ampliada, donde se observan las placas hexagonales que la conforman. Flecha amarilla indica posición del pedicelo. Escala 5 mm. Fig. 3- MPM-Pb 2715. Detalle de placas hexagonales. Fig. 4- MPM-Pb 2715. Imagen invertida de la fructificación donde resalta la forma hexagonal de las placas que lo componen, y la disposición alternada de estas. Flecha amarilla indica posición del pedicelo. Escala 5 mm. 


\section{LÁMINA XVI}
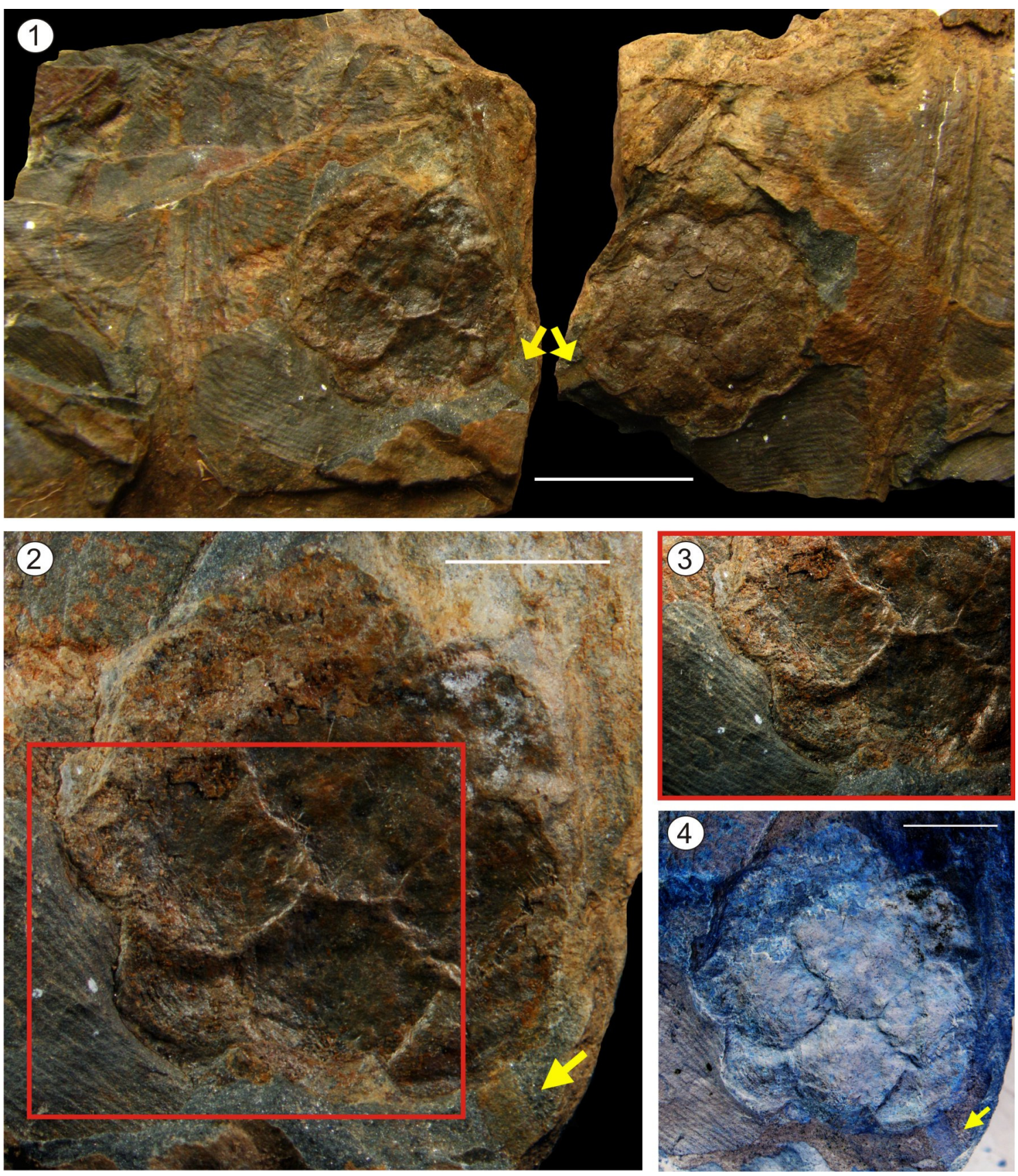
XVII. Annularia kurtzii. Fig. 1- MPM-Pb 4641. Ejemplar fragmentario con al menos tres anillos compuestos por al menos 15 hojas alargadas espatuladas. Escala 1 cm. Fig. 2- MPM-Pb 4728. Anillo de Annularia suelto, donde se observan las largas hojas espatuladas con su venación abierta longitudinal. Escala $1 \mathrm{~cm}$. Fig. 3MPM-Pb 4630. Ejemplar con dos anillos mostrando sus hojas. Escala 5 mm. ?Phyllotheca sp. Fig. 4- Lil 1145. Ejemplar potencialmente asignable a Phyllotheca, con tallo dividido en nudos y entrenudos. Escala 1 $\mathrm{cm}$. 


\section{LÁMINA XVII}
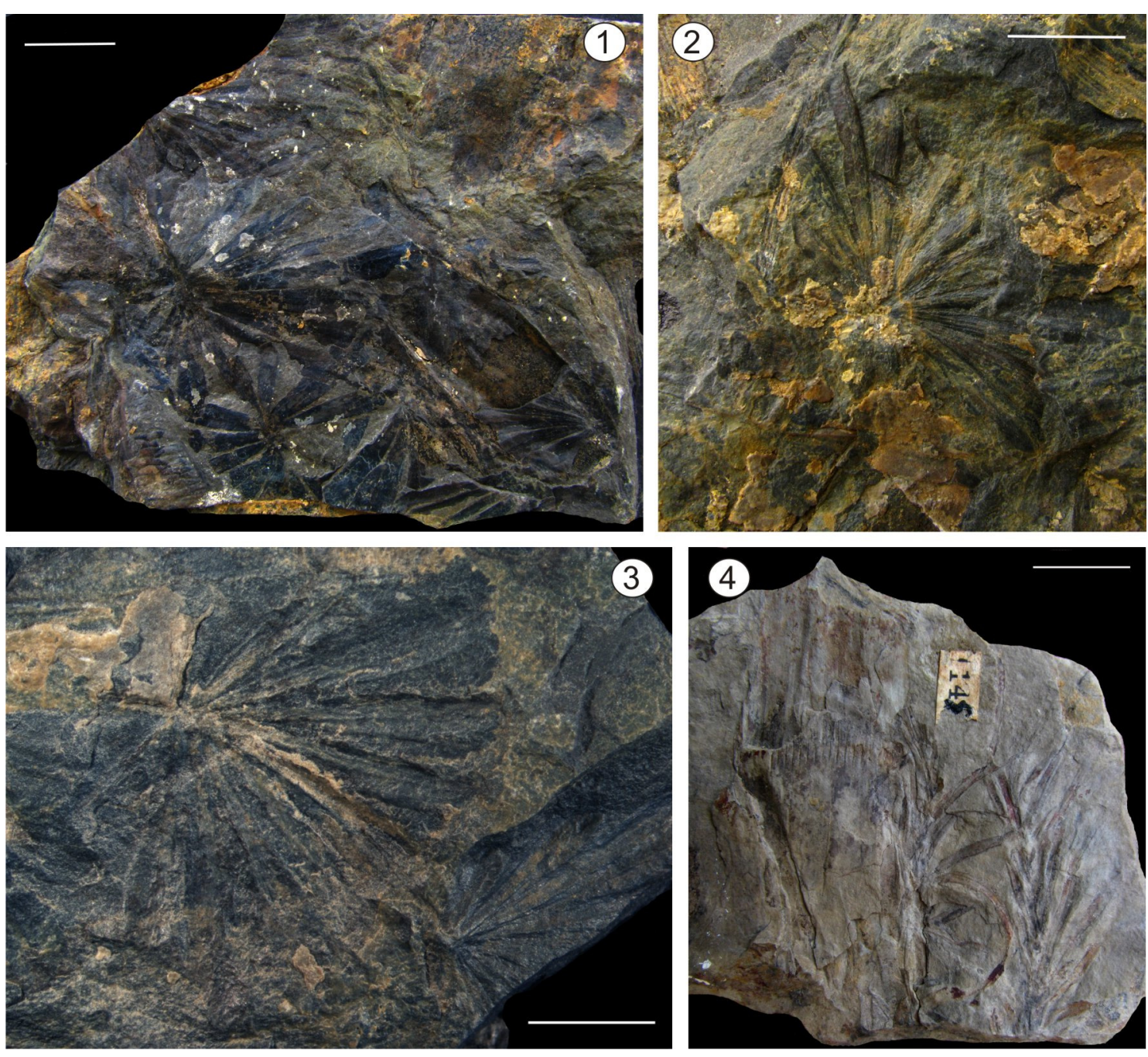
XVIII. Paraschizoneura sp. Fig. 1- Lil 1136. Anillo con 7 hojas acintadas paralelinervadas. Escala $1 \mathrm{~cm}$. Fig. 2- Lil 1135. Ejemplar incompleto donde se observan 4 hojas acintadas paralelinervadas. Escala $1 \mathrm{~cm}$. Fig. 3Lil 1135- Contracara del ejemplar anterior, más completo, con 7 hojas acintadas paralelinervadas. Escala 1 cm. Fig. 4- Lil 1135. Detalle del ejemplar anterior, donde se observa daño de insecto en algunas hojas. Escala $1 \mathrm{~cm}$. 


\section{LÁMINA XVIII}
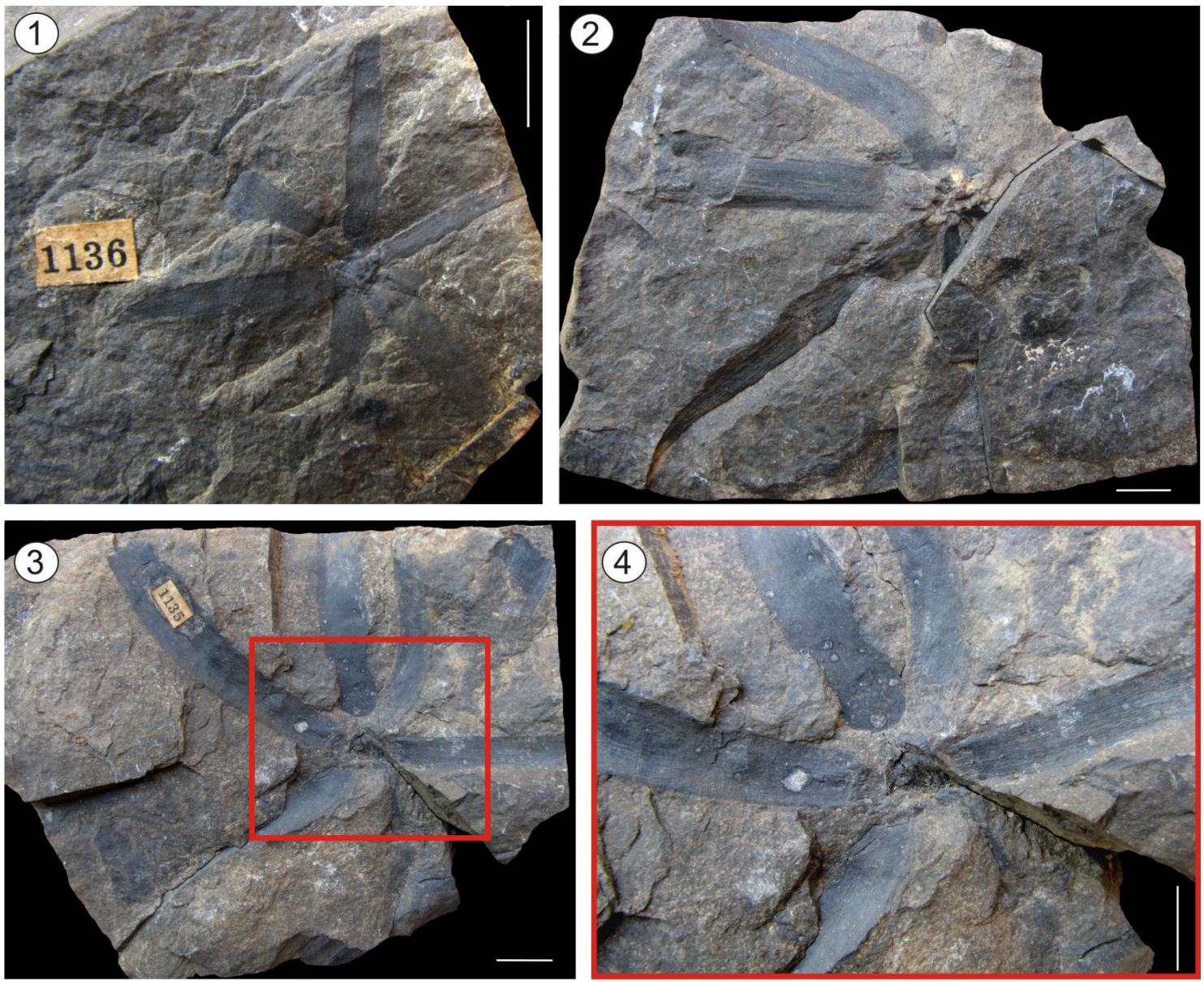
XIX. Bumbudendron patagonicum sp. nov. Fig. 1- Lil 525. Holotipo de Bumbudendron patagonicum. Escala $1 \mathrm{~cm}$. Fig. 2- Lil 525. Detalle de cojinetes mostrando un menor grado de decorticación (estadío A). Escala $1 \mathrm{~cm}$. Fig. 3- Lil 525. Detalle de cojinetes mostrando un mayor grado de decorticación (estadío B), donde se observan las características más definitorias de esta especie, incluyendo la lámina infrafoliar. Escala 1 cm. Fig. 4- MPM-Pb 2802. Impronta muy decorticada (estadío C) donde se observan únicamente los cojinetes y la lámina infrafoliar. Escala 1 cm. Fig. 5- MPM-Pb 2802. Detalle de los cojinetes y lámina infrafoliar. Escala 5 mm. Fig. 6- MPM-Pb 2802. Detalle de molde de latex de la impronta, donde se resalta la presencia de una lámina infrafoliar. Escala $5 \mathrm{~mm}$. Fig. 7- Grafico mostrando los distintos tipos de decorticación en Bumbudendron, de menor (A) a mayor (C). 


\section{LÁMINA XIX}
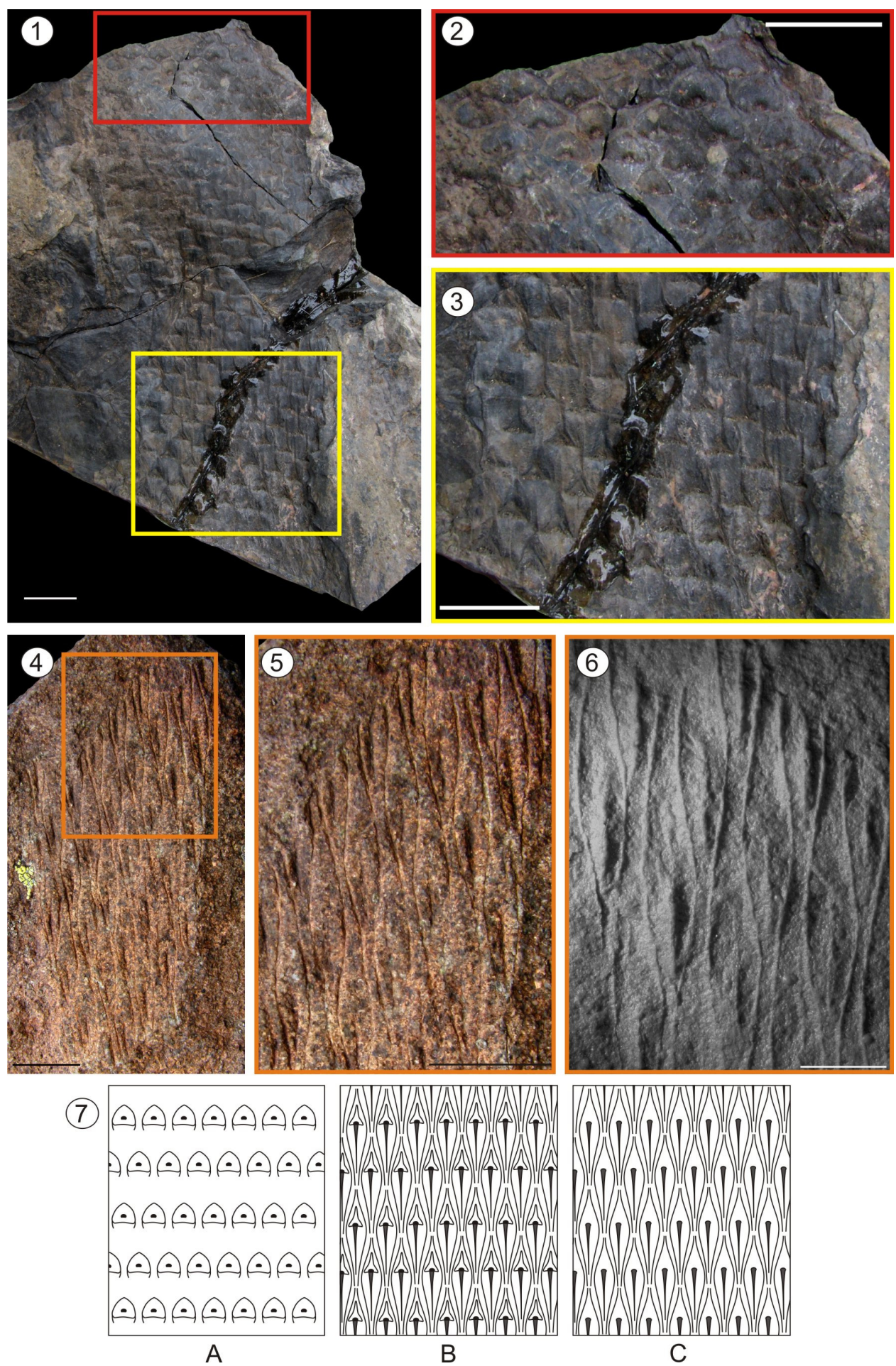
XX. Cyclodendron golondrinensis sp. nov. Fig. 1- Lil 527. Holotipo de Cyclodendron golondrinensis. Fragmento de tallo con cicatrices foliares romboidales marcadas. El ejemplar fue ubicado en base a la correcta posición de sus cicatrices, por lo que los micrófilos se encuentran movidos por deformación de su posición original. Escala $1 \mathrm{~cm}$. Fig. 2- Lil 527. Detalle de las cicatrices foliares, donde se observa la presencia de la marca de la traza vascular en la parte superior central de éstas. Escala $5 \mathrm{~mm}$. Fig. 3- Lil 527. Detalle de MEB de cicatriz foliar, donde se observa la marca de la traza vascular. Escala 2 mm. Fig. 4- Lil 1013. Ejemplar decorticado (estadío C) donde se observan las cicatrices foliares con la marca de la traza vascular. Escala 1 cm. Fig. 5- Lil 2083. Ejemplar decorticado (estadío C). Escala 1 cm. Fig. 6- Lil 2083. Detalle de cicatriz foliar romboidal, con marca de la traza vascular. Escala $1 \mathrm{~cm}$. Fig. 7- Lil 1037. Ejemplar con estadío de decorticación A. Escala 1 cm. Fig. 8- Lil 1034. Ejemplar con estadío de decorticación B. Escala $1 \mathrm{~cm}$. Fig. 9- Lil 2090. Ejemplar con estadío de decorticación C. Escala 1 cm. Fig. 10- Grafico mostrando los distintos tipos de decorticación en Bumbudendron, de menor (A) a mayor (C). 


\section{LÁMINA XX}
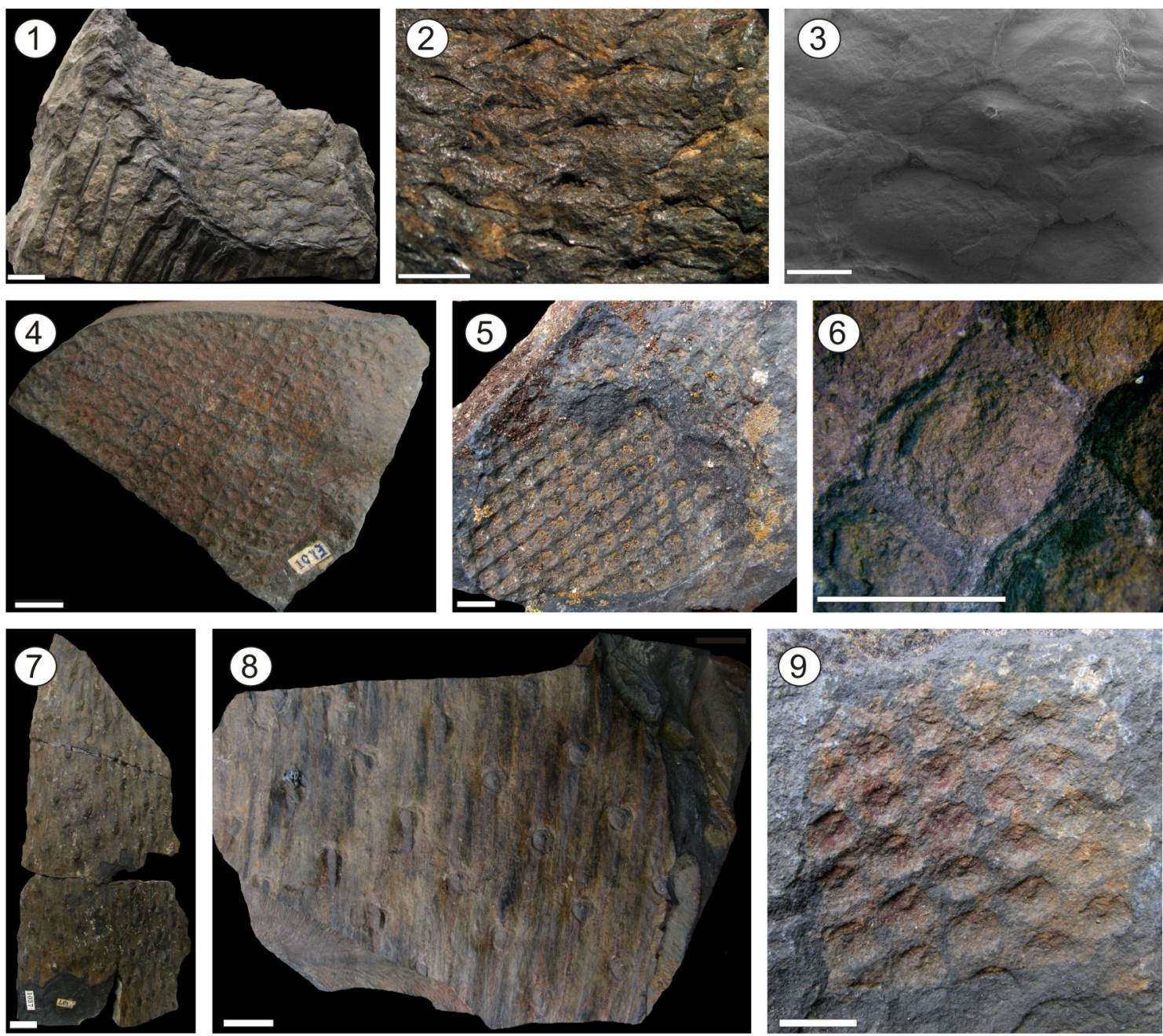

(10)

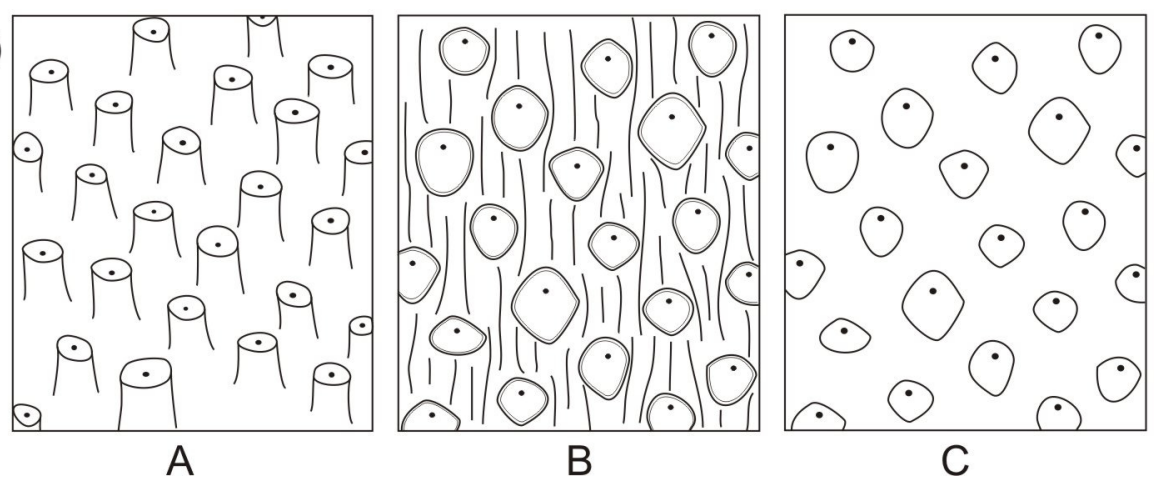


XXI. Licófita sp. A. Fig. 1- Lil 1014. Fragmento de tallo donde se observan los cojinetes hexagonales con la marca de la traza vascular central superior, tanto en sobre como en bajorelieve. Escala $1 \mathrm{~cm}$. Fig. 2- Lil 1014. Detalle ampliado de uno de los cojinetes mostrando su forma hexagonal y la marca de la traza vascular. Licófita sp. B. Fig. 3- Lil 1012. Fragmento de tallo donde se observan los cojinetes romboidales alargados horizontalmente, con cicatriz foliar ubicada en la parte basal del cojinete, y marca de traza vascular basal central. Escala $1 \mathrm{~cm}$. Fig. 4- Lil 1012. Detalle de MEB de cicatriz foliar, donde se observa la forma elongada horizontalmente, y la cicatriz foliar basal con marca de la traza vascular central. Escala $2 \mathrm{~mm}$. 


\section{LÁMINA XXI}

XXII. Eremopteris golondrinensis. Fig. 1- MPM-Pb 4416. Fragmento de fronde estéril. Escala $1 \mathrm{~cm}$. Fig. 2MPM-Pb 4419. Fragmento de fronde estéril. Escala $1 \mathrm{~cm}$. Fig. 3- MPM-Pb 4423. Fragmento de fronde estéril. Escala $1 \mathrm{~cm}$. Fig. 4- Detalle de dos pinnas, con folíolos mostrando su venación abierta. Escala $5 \mathrm{~mm}$. 


\section{LÁMINA XXII}
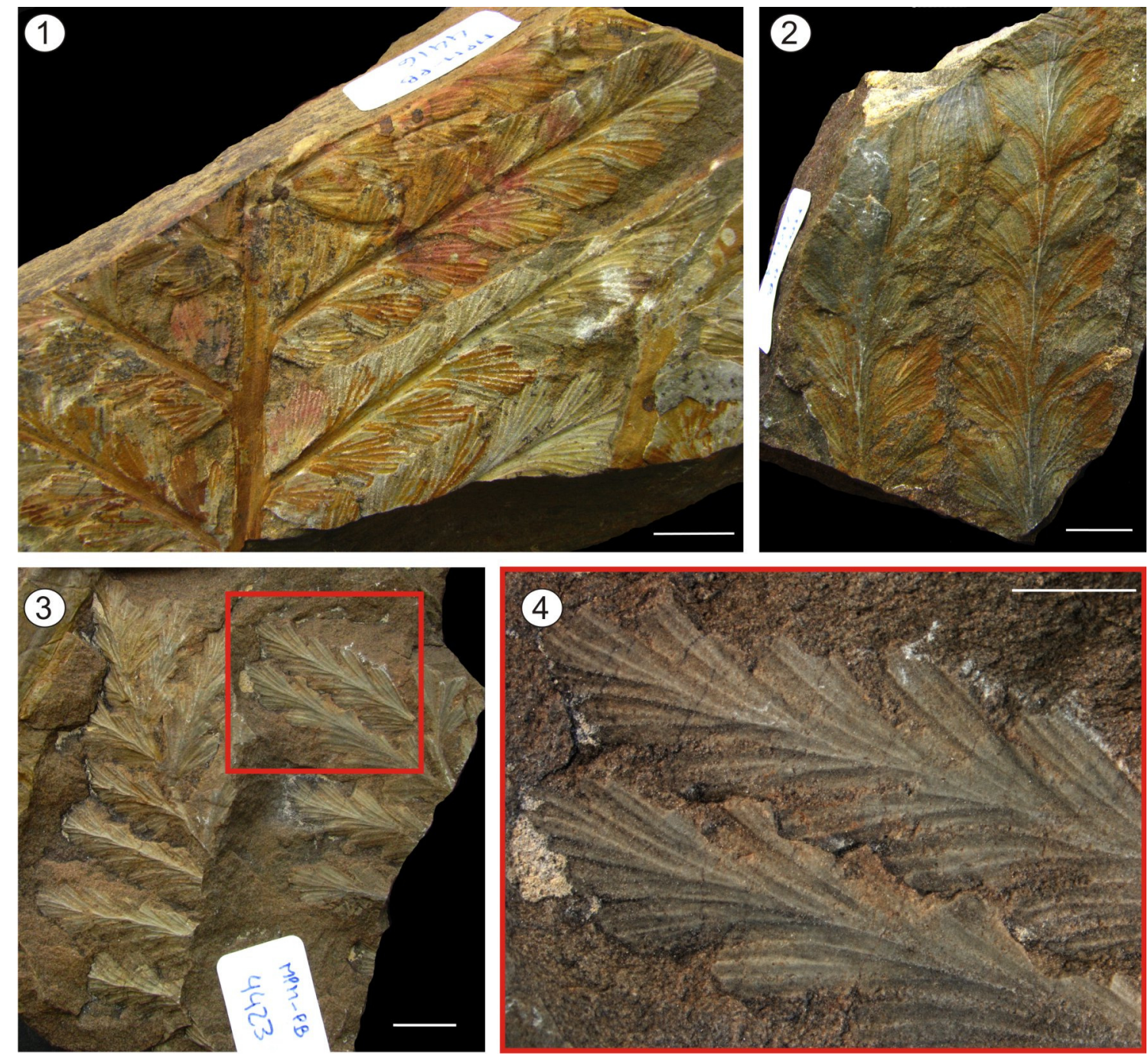
XXIII. Cordaites (Noeggerathiopsis) hislopi. Fig. 1- MPM-Pb 4542. Hojas de Cordaites (Noeggerathiopsis) hislopi fragmentadas. Escala $1 \mathrm{~cm}$. Fig. 2- MPM-Pb 4542. Detalle de la venación paralelinervada. Escala 5 mm. Fig. 3- MPM-Pb 4736. Hoja fragmentada. Escala $1 \mathrm{~cm}$. Fig. 4- MPM-Pb 4736. Detalle de la venación paralelinervada. Escala 5 mm. Fig. 5- MPM-Pb 4607. Hojas fragmentadas de Cordaites (Noeggerathiopsis) hislopi, asociadas a Megistophyllum leanzai. Escala $1 \mathrm{~cm}$. Fig. 6- MPM-Pb 4607. Detalle de la venación paralelinervada. Escala 5 mm. Fig. 7- MPM-Pb 4737. Hojas fragmentadas de Cordaites (Noeggerathiopsis) hislopi. Observar el gran tamaño de éstas. Escala $1 \mathrm{~cm}$. Fig. 8- MPM-Pb 4737. Detalle de la venación paralelinervada. Escala $5 \mathrm{~mm}$. 


\section{LÁMINA XXIII}
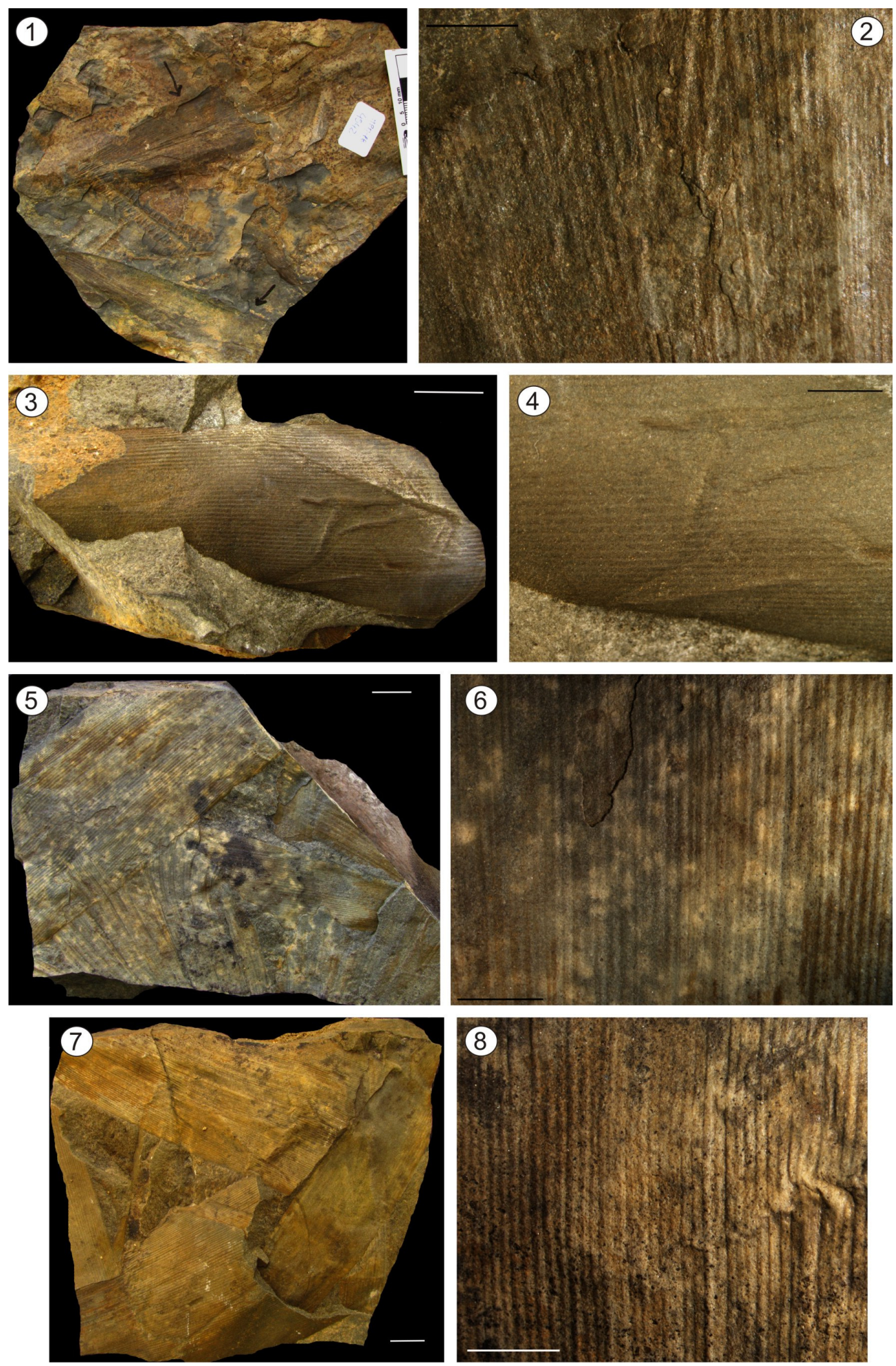
XXIV. Glossopteris ampla. Fig. 1- MPM-Pb 2548. Ejemplar preservado desde su parte media al ápice, donde se observan claramente las características de la venación. Escala 1 cm. Fig. 2- MPM-Pb 2902. Ejemplar de tamaño grande, cuya preservación, pese a ser regular, permite la observación de la venación. Escala 1 cm. Fig. 3- MPM-Pb 2902. Detalle de la venación en la parte basal de la hoja. Escala $1 \mathrm{~cm}$. Fig. 4MPM-Pb 2589. Ejemplar preservado en su parte media-superior, donde se observan detalles de la venación. Escala $1 \mathrm{~cm}$. Fig. 5- Detalle ampliado del recuadro amarillo en la Fig. 4. Escala 5 mm. Fig. 6- BAPb 13876. Ejemplar con oviposición y daño de insecto. Escala 1 cm. Fig. 7- BAPb 13874. Ejemplar con daño de insecto. Escala $1 \mathrm{~cm}$. Fig. 8- BAPb 13882. Detalle del ápice y venación. Escala 5 mm. 


\section{LÁMINA XXIV}
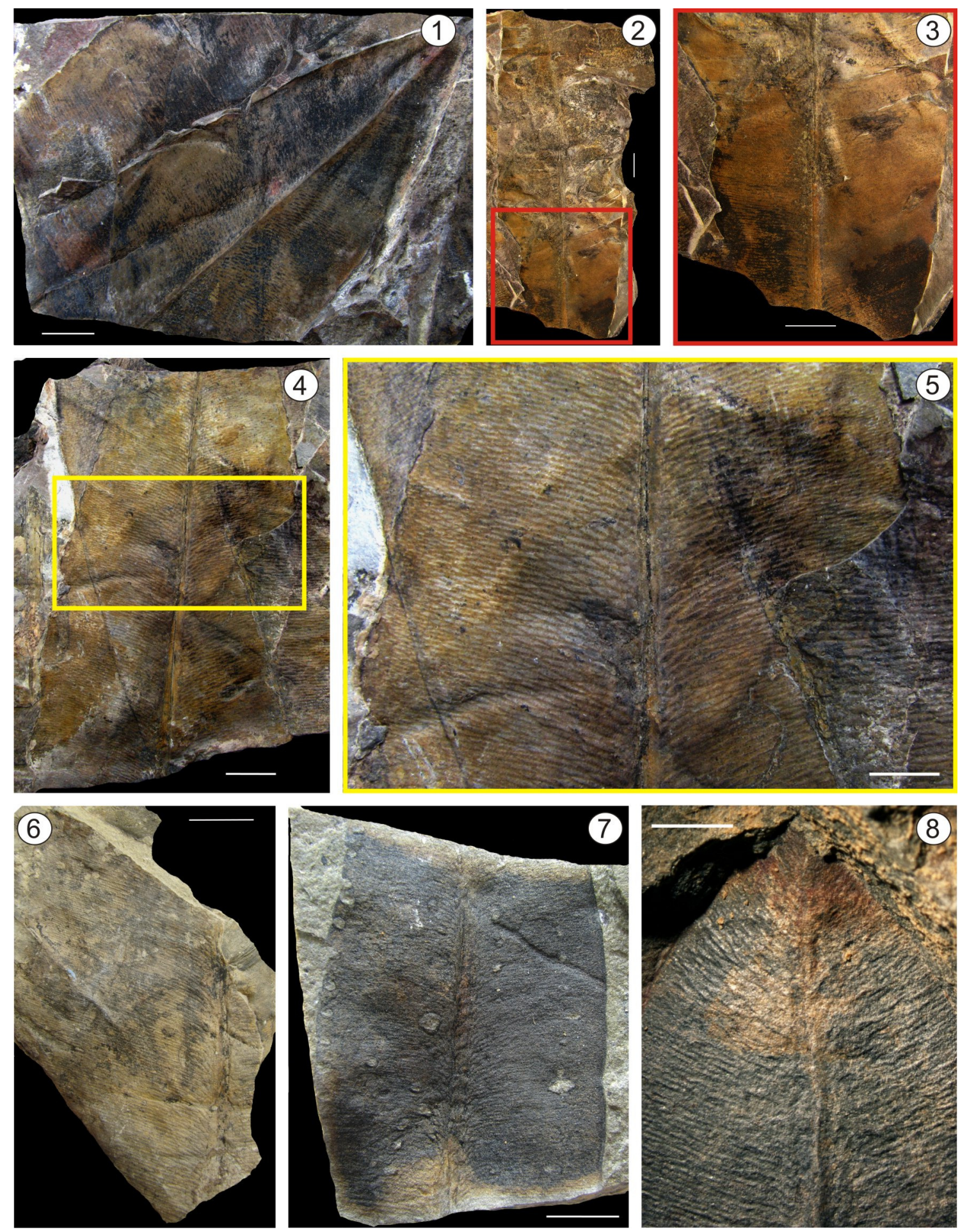
XXV. Glossopteris argentina. Fig. 1- MPM-Pb 4519. Parte media-inferior de hoja, donde se observa claramente la vena media gruesa con puntuaciones. Escala $1 \mathrm{~cm}$. Fig. 2- MPM-Pb 4523. Parte media-inferior de hoja, con vena media puntuada. Escala $1 \mathrm{~cm}$. Fig. 3- MPM-Pb 4635. Ejemplar fragmentado pero de excelente preservación donde se observa la vena media puntuada y la venación secundaria. Escala $1 \mathrm{~cm}$. Fig. 4- MPM-Pb 4966. Ejemplar fragmentado donde se observan las puntuaciones de la vena media. Escala $1 \mathrm{~cm}$. Fig. 5- MPM-Pb 4822. Ejemplar fragmentado donde se observan las puntuaciones de la vena media. Escala 1 cm. Fig. 6- BAPb 13806. Ejemplar casi completo con vena media puntuada y venación secundaria bien marcada. Escala $1 \mathrm{~cm}$. Fig. 7- BAPb 13875. Parte media de una hoja de G. argentina con venación típica. Escala $1 \mathrm{~cm}$. Fig. 8- BAPb 13875. Detalle de la vena media donde se observan las punteaduras. Escala $5 \mathrm{~mm}$. 


\section{LÁMINA XXV}
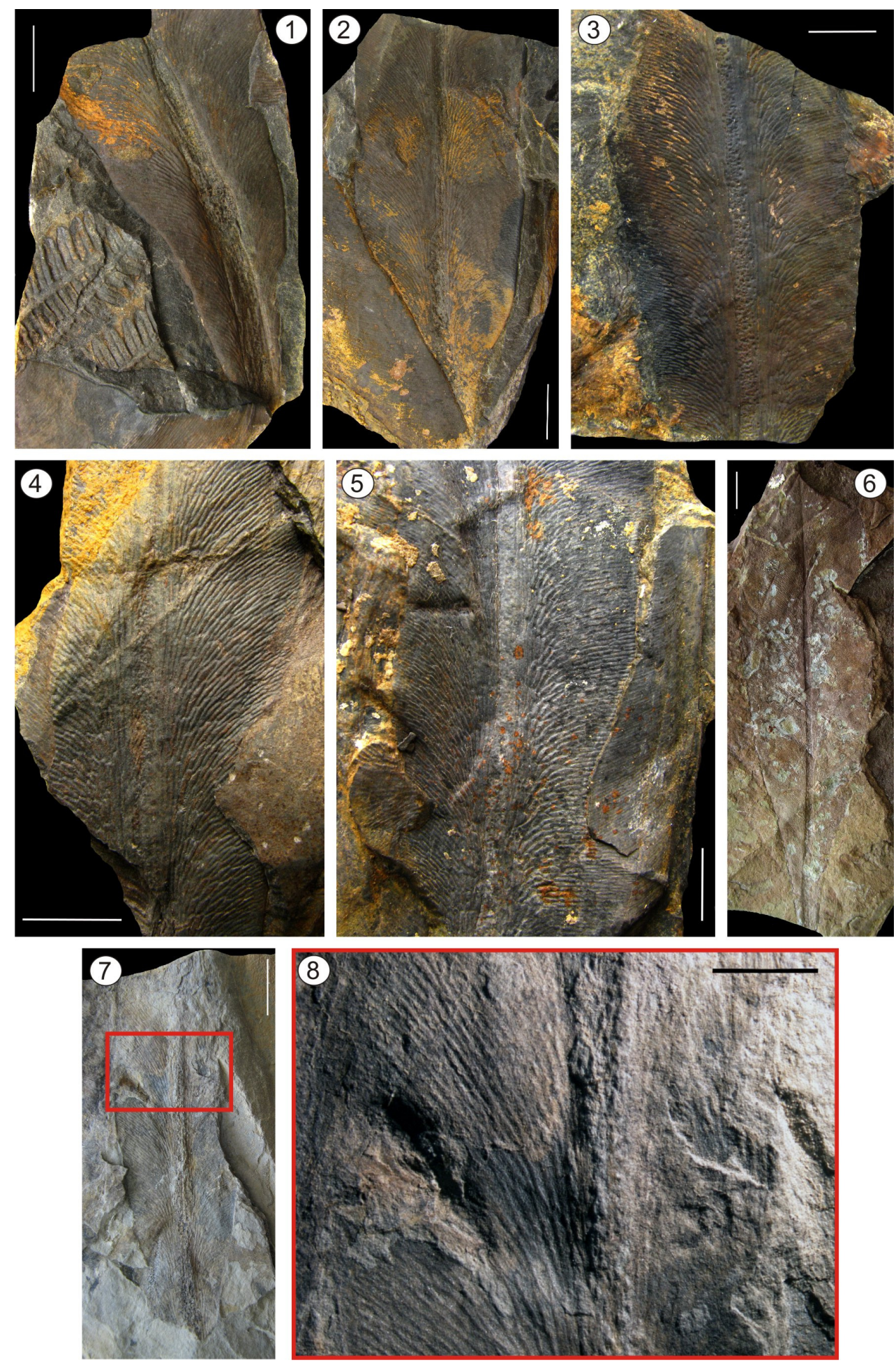
XXVI. Glossopteris browniana. Fig. 1- BAPb 13829. Hemilámina de la parte media y superior de una hoja de G. browniana. Escala 1 cm. Fig. 2- MPM-Pb 2510. Hoja casi completa donde se observa la venación típica de la especie. Escala $1 \mathrm{~cm}$. Fig. 3- BAPb 13832. Parte media de la hoja con daño de insecto. Escala $1 \mathrm{~cm}$. Fig. 4- MPM-Pb 4524. Parte media-superior de una hoja fragmentada de G. browniana con buena preservación de su venación. Escala $1 \mathrm{~cm}$. Fig. 5- Detalle de la venación en recuadro de Fig. 4. Escala 1cm. Fig. 6- BAPb 14064. Fragmento de hoja asociado a helecho pecopterídeo. Escala $1 \mathrm{~cm}$. 


\section{LÁMINA XXVI}
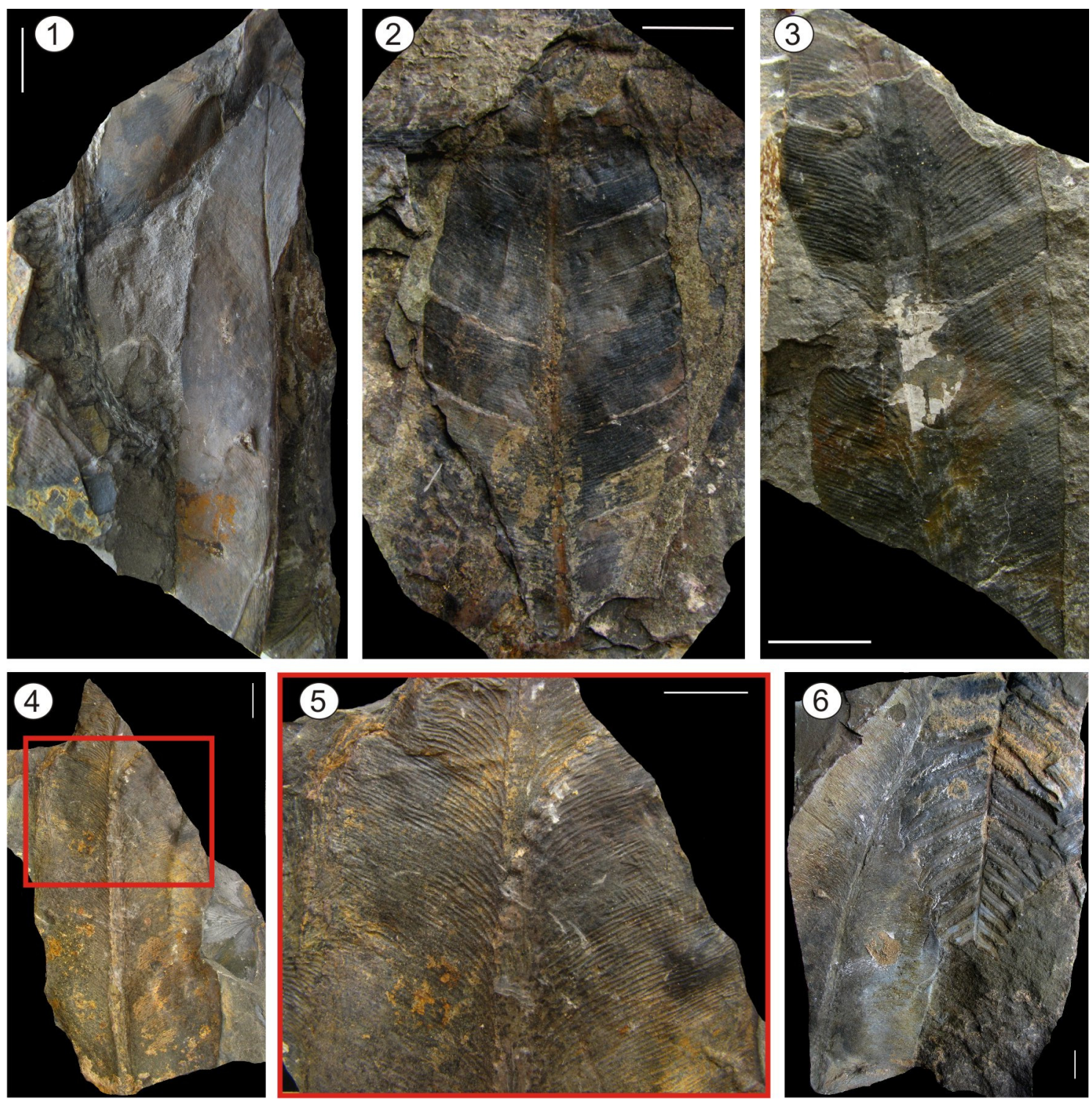
XXVII. Glossopteris conspicua variedad patagonica. Fig. 1- MPM-Pb 15108. Hoja casi completa mostrando buena preservación de la venación. Escala 1 cm. Fig. 2- MPM-Pb 4451. Parte media de hoja, mostrando venación primaria y secundaria. Escala $1 \mathrm{~cm}$. Fig. 3- MPM-Pb 4576. Detalle de la venación en la parte media de la hoja. Escala 5 mm. Fig. 4- MPM-Pb 4721. Detalle de la venación en la parte media de la hoja. Escala 1 cm. Fig. 5- MPM-Pb 4576. Hoja (casi) completa de G. conspicua var. patagonica, con posible presencia de cutícula. La hoja está asociada a una fructificación aún indeterminada, así como otros elementos (helechos, etc). Escala $1 \mathrm{~cm}$. Fig. 6- MPM-Pb 4576. Detalle de la parte media de la hoja, donde se observa la venación y la posible presencia de cutícula (parte con brillo). Escala 5 mm. Fig. 7- MPM-Pb 4500. Fragmento de hoja con venación típica. Escala $1 \mathrm{~cm}$. Fig. 8- MPM-Pb 4764. Cara y contracara de hoja casi completa de G. conspicua var. patagonica. Escala $1 \mathrm{~cm}$. Fig. 9- MPM-Pb 4764. Detalle de la venación en la parte media de la hoja. Escala $5 \mathrm{~mm}$. 


\section{LÁMINA XVII}
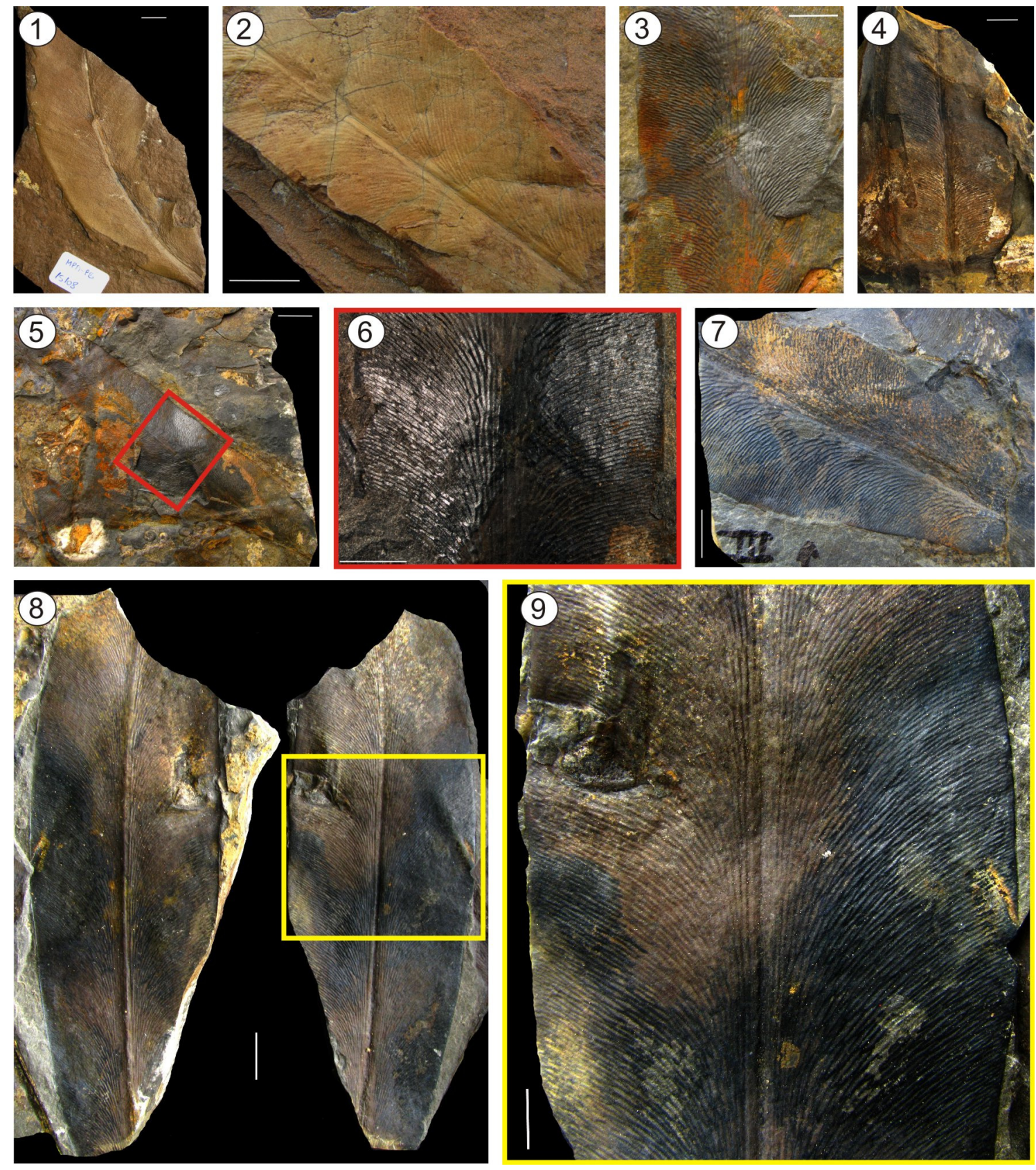
XXVIII. Glossopteris damudica. Fig. 1- BAPb 13833. Fragmento de hoja con daño de insecto. Escala $1 \mathrm{~cm}$. Fig. 2- MPM-Pb 2604. Hoja incompleta con venación típica de la especie. Escala $1 \mathrm{~cm}$. Fig. 3- MPM-Pb 2604. Detalle del recuadro en Fig. 2. Escala 5 mm. Fig. 4- BAPb 14046. Parte media de hoja muy fragmentada, donde se observa la venación típica de la especie. Escala 1 cm. Fig. 5- BAPb 13827. Ejemplar de tamaño grande fragmentado en su parte inferior. Escala $1 \mathrm{~cm}$. Fig. 6- BAPb 13827. Detalle de la venación en la parte media-superior. Escala 5 mm. Fig. 7- BAPb 13827. Detalle de la venación en la parte mediainferior. Escala $5 \mathrm{~mm}$. 


\section{LÁMINA XXVIII}
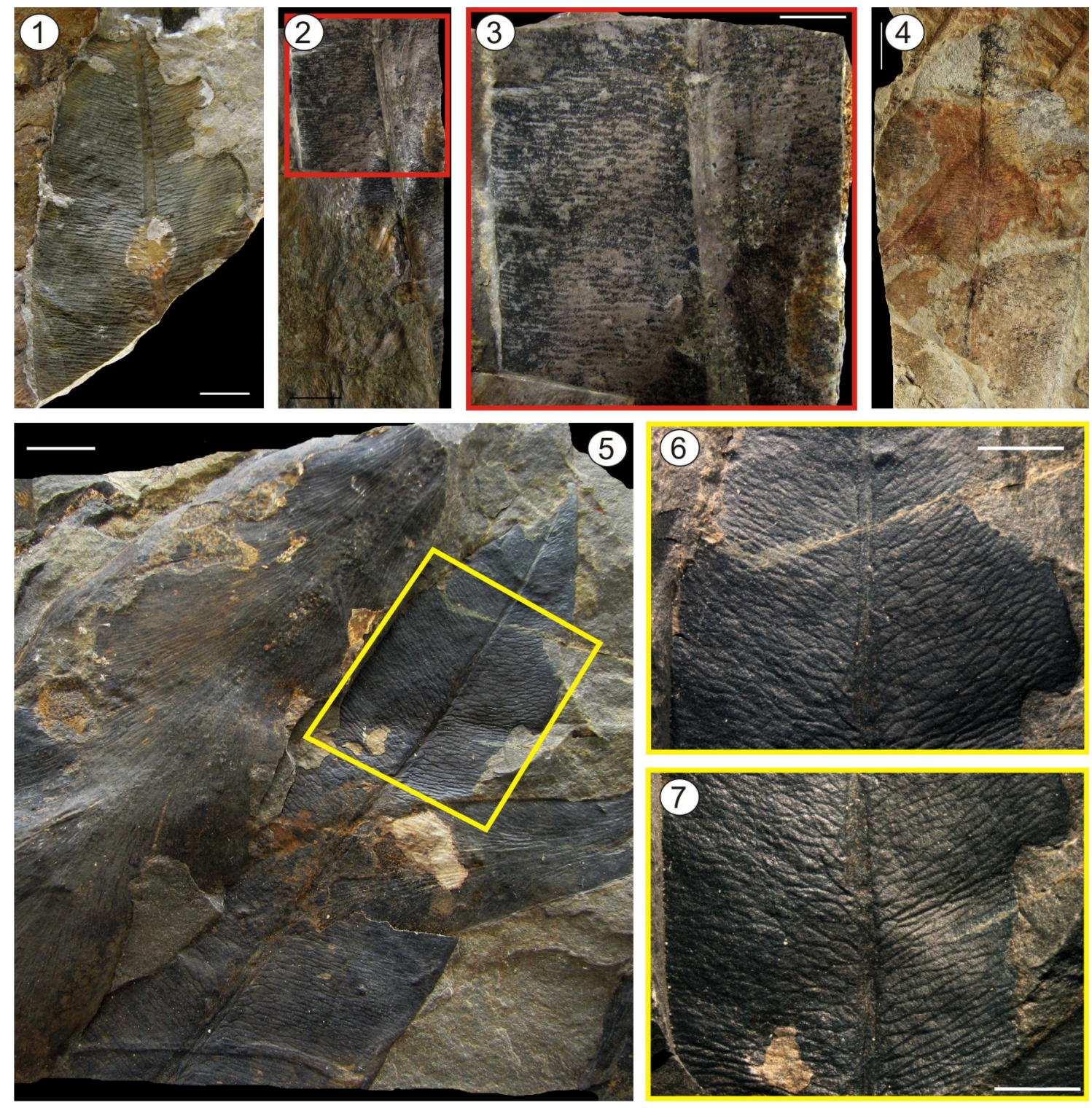
XXIX. Glossopteris indica. Fig. 1- MPM-Pb 4653. Parte media de hoja fragmentada mostrando la venación típica de la especie. Escala $1 \mathrm{~cm}$. Fig. 2- MPM-Pb 4785. Hoja casi completa, con vena media robusta. Escala $1 \mathrm{~cm}$. Fig. 3- MPM-Pb 4500. Ejemplar fragmentado pero bien preservado, donde se observa la venación típica de la especie. Escala $1 \mathrm{~cm}$. Fig. 4- MPM-Pb 4649. Parte media de hoja de G. indica. Escala $1 \mathrm{~cm}$. Fig. 5- MPM-Pb 4649. Detalle del recuadro en Fig. 4. Escala 5 mm. 


\section{LÁMINA XXIX}

XXX. Glossopteris retifera. Fig. 1- MPM-Pb 4657. Parte media-inferior de hoja con la venación típica de la especie. Escala $1 \mathrm{~cm}$. Fig. 2- Detalle del recuadro en Fig. 1. Escala 5 mm. Fig. 3- MPM-Pb 4625. Parte media de hoja. Escala $1 \mathrm{~cm}$. Fig. 4- MPM-Pb 2527/8. Hoja muy fragmentada donde se observa la venación típica de la especie. Escala $1 \mathrm{~cm}$. Fig. 5- MPM-Pb 4601. Fragmento de hoja con venación típica de la especie. Escala 5 mm. Fig. 6- MPM-Pb 2541. Hemilámina muy fragmentada pero de buena preservación donde se observan la venación típica de la especie. Escala $1 \mathrm{~cm}$. 


\section{LÁMINA XXX}
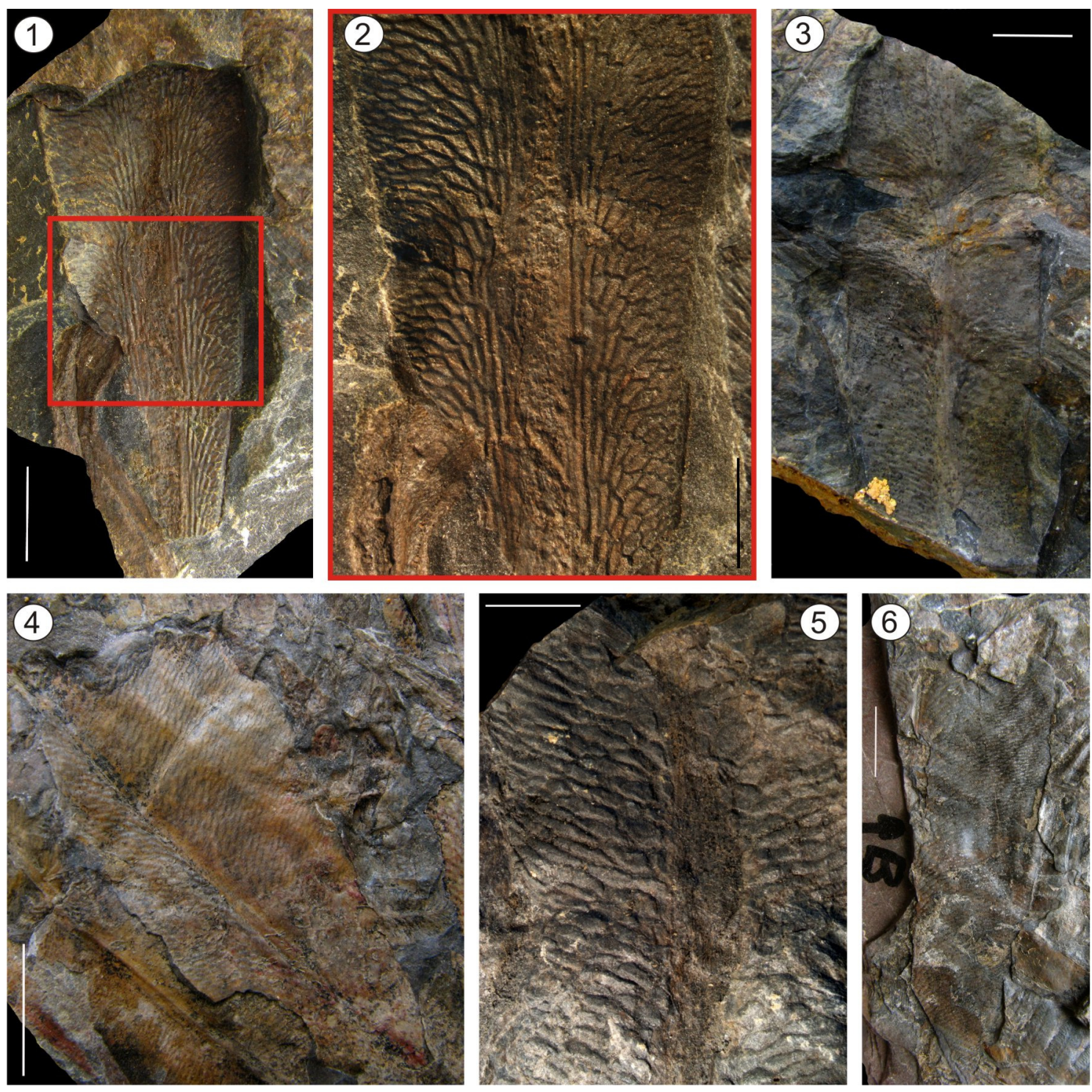
XXXI. Glossopteris stipanicicii. Fig. 1- MPM-Pb 4834. Ejemplar angosto e incompleto en su base y ápice, pero con característica vena media poderosa, finamente estriada, y venas laterales que forman 2-3 series de anchas y cortas areolas al salir de ésta. Escala $1 \mathrm{~cm}$. Fig. 2- MPM-Pb 2626. Ejemplar de mayor tamaño que el anterior, donde se observa la vena media ancha y estriada, y un mayor número de areolas en el ancho de la hoja. Escala 1 cm. Fig. 3- BAPb 13890. Ejemplar bastante completo y con venación típica de la especie. Escala $1 \mathrm{~cm}$. Fig. 4- Detalle de la venación del recuadro en Fig. 3. Escala 5 mm. 


\section{LÁMINA XXXI}
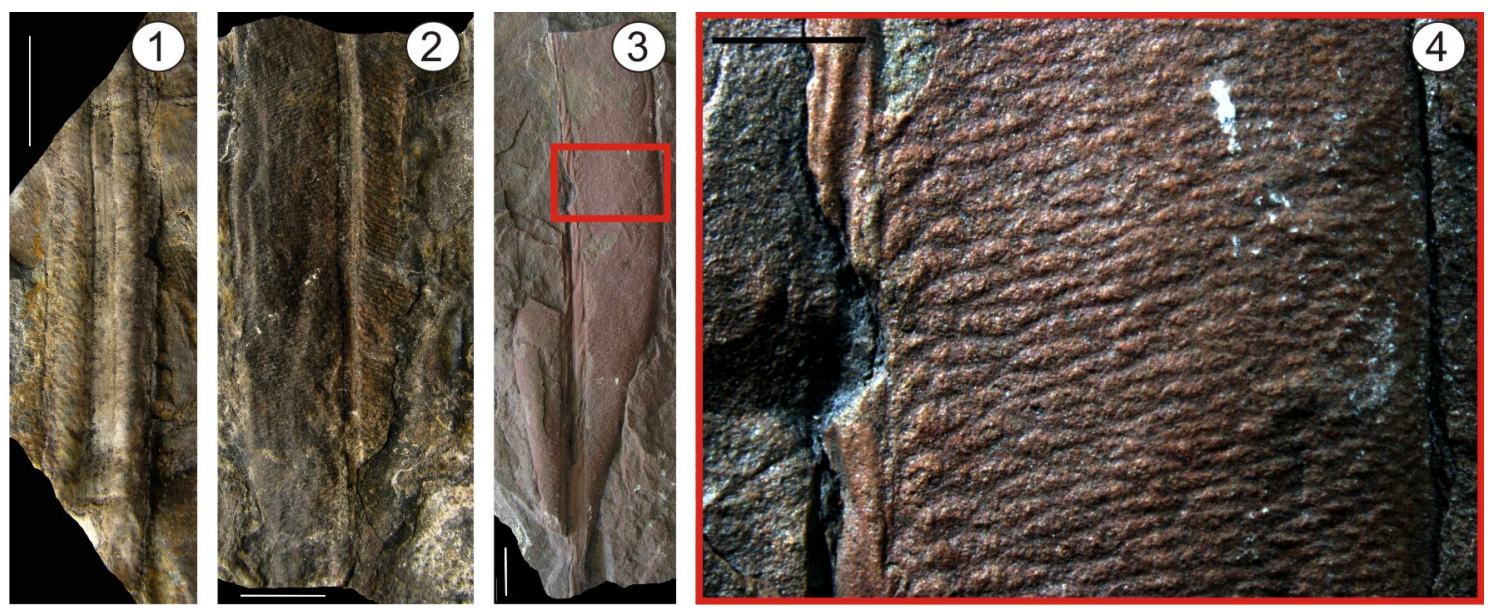
XXXII. Glossopteris stricta. Fig. 1- MPM-Pb 4645. Ejemplar incompleto con venación bien preservada. Escala $1 \mathrm{~cm}$. Fig. 2- MPM-Pb 4595. Parte media de la hoja con venación típica de la especie. Escala $5 \mathrm{~mm}$. Fig. 3- MPM-Pb 4661. Parte media-inferior de la hoja, con buena preservación de la venación. Escala $1 \mathrm{~cm}$. Fig. 4- MPM-Pb 4722. Cara y contracara de un ejemplar delgado con veanción característica. Escala $1 \mathrm{~cm}$. Fig. 5- MPM-Pb 4823. Parte media de la hoja con venación bien definida. Escala $1 \mathrm{~cm}$. Fig. 6- MPM-Pb 4823. Detalle de venación del recuadro en Fig. 5. Escala 5 mm. Fig. 7- MPM-Pb 4616. Parte media-inferior de la hoja con venación típica de la especie. Escala $1 \mathrm{~cm}$. Fig. 8- MPM-Pb 4975. Hoja fragmentada con venación bien definida. Escala $1 \mathrm{~cm}$. Fig. 9- MPM-Pb 4528. Hoja fragmentada en su base y ápice, con venación típica de la especie. Escala $1 \mathrm{~cm}$. Fig. 10- MPM-Pb 4528. Detalle de la venación del recuadro en Fig. 9. Escala $5 \mathrm{~mm}$. 


\section{LÁMINA XXXII}
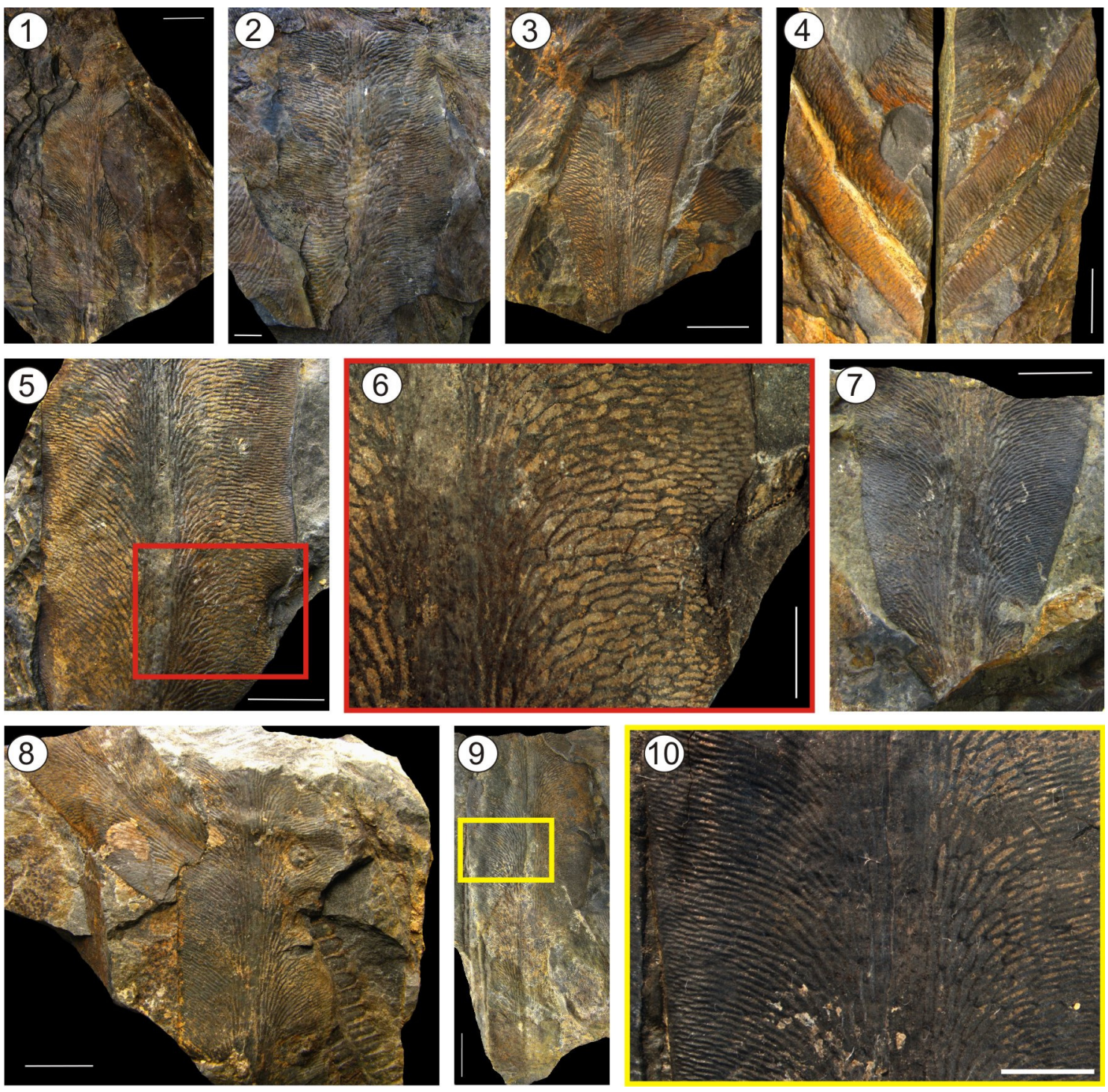
XXXIII. Gangamopteris angustifolia. Fig. 1- BAPb 13900. Ejemplar completo de hoja, con venación típica de la especie. Escala $1 \mathrm{~cm}$. Fig. 2- BAPb 13900. Detalle de la venación en recuadro de Fig. 1. Escala $5 \mathrm{~mm}$. Fig. 3- MPM-Pb 4822. Ejemplar casi completo con venación típica de la especie. Escala $1 \mathrm{~cm}$. Fig. 4- MPM$\mathrm{Pb}$ 2824. Ejemplar casi completo con venación típica de la especie. Escala $1 \mathrm{~cm}$. Fig. 5- MPM-Pb 4655. Hoja casi completa con venación típica de la especie. Escala $1 \mathrm{~cm}$. Fig. 6- MPM-Pb 4655. Detalle de la venación en recuadro de Fig. 5 . Escala $5 \mathrm{~mm}$. 


\section{LÁMINA XXXIII}
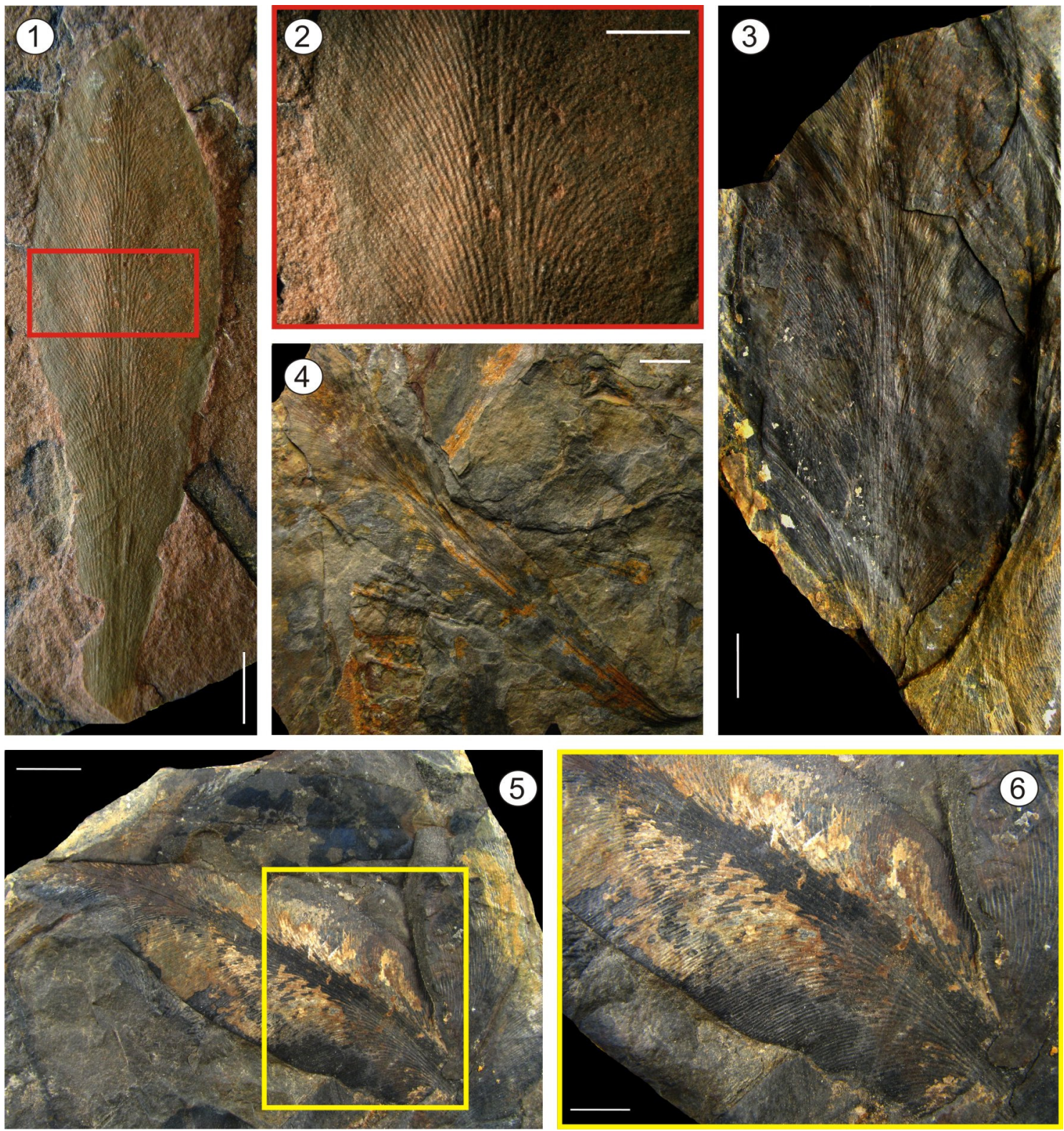
XXXIV. Gangamopteris castellanosii. Fig. 1- MPM-Pb 4753. Hoja fragmentada con buen detalle de la venación. Escala $1 \mathrm{~cm}$. Fig. 2- MPM-Pb 4575. Hoja completa con venación típica de la especie. Escala 5 mm. Fig. 3- MPM-Pb 4496. Hoja casi completa, con venación típica de la especie. Escala 1 cm. Fig. 4- MPM-Pb 4498. Hoja casi completa con venación bien preservada. Escala $1 \mathrm{~cm}$. 


\section{LÁMINA XXXIV}
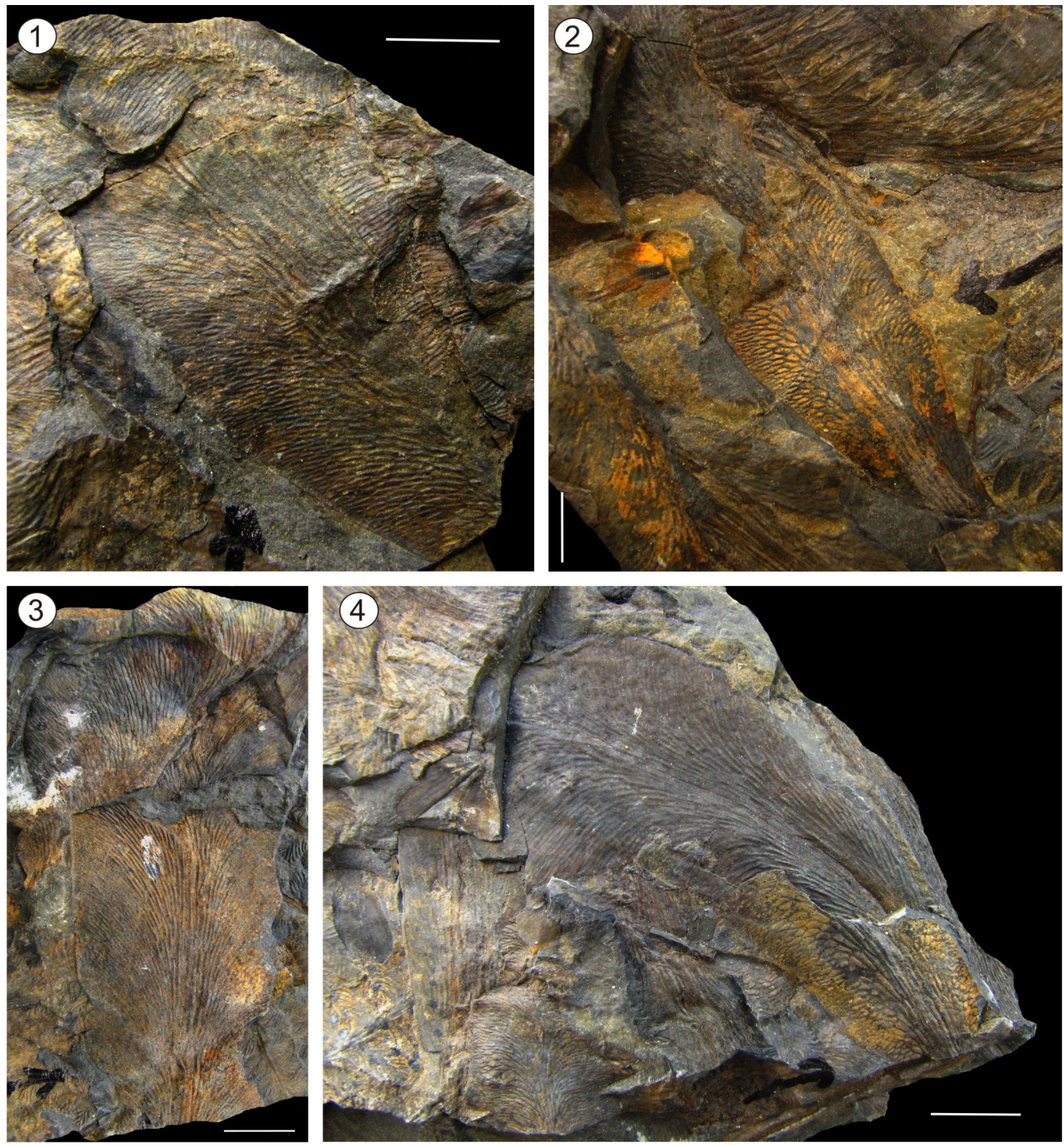
XXXV. Gangamopteris mosesii. Fig. 1- BAPb 13835. Parte media de hoja con venación bien definida. Escala $1 \mathrm{~cm}$. Fig. 2- BAPb 13835. Detalle de la venación en recuadro de Fig. 1. Escala 5 mm. Fig. 3- MPM$\mathrm{Pb}$ 4503. Parte media-superior de la hoja con venación típica de la especie. Escala $1 \mathrm{~cm}$. Fig. 4- MPM-Pb 4782. Ejemplar incompleto de tamaño grande. Escala $1 \mathrm{~cm}$. Fig. 5- MPM-Pb 4777. Ejemplar casi completo con venación bien preservada. Escala $1 \mathrm{~cm}$. 


\section{LÁMINA XXXV}
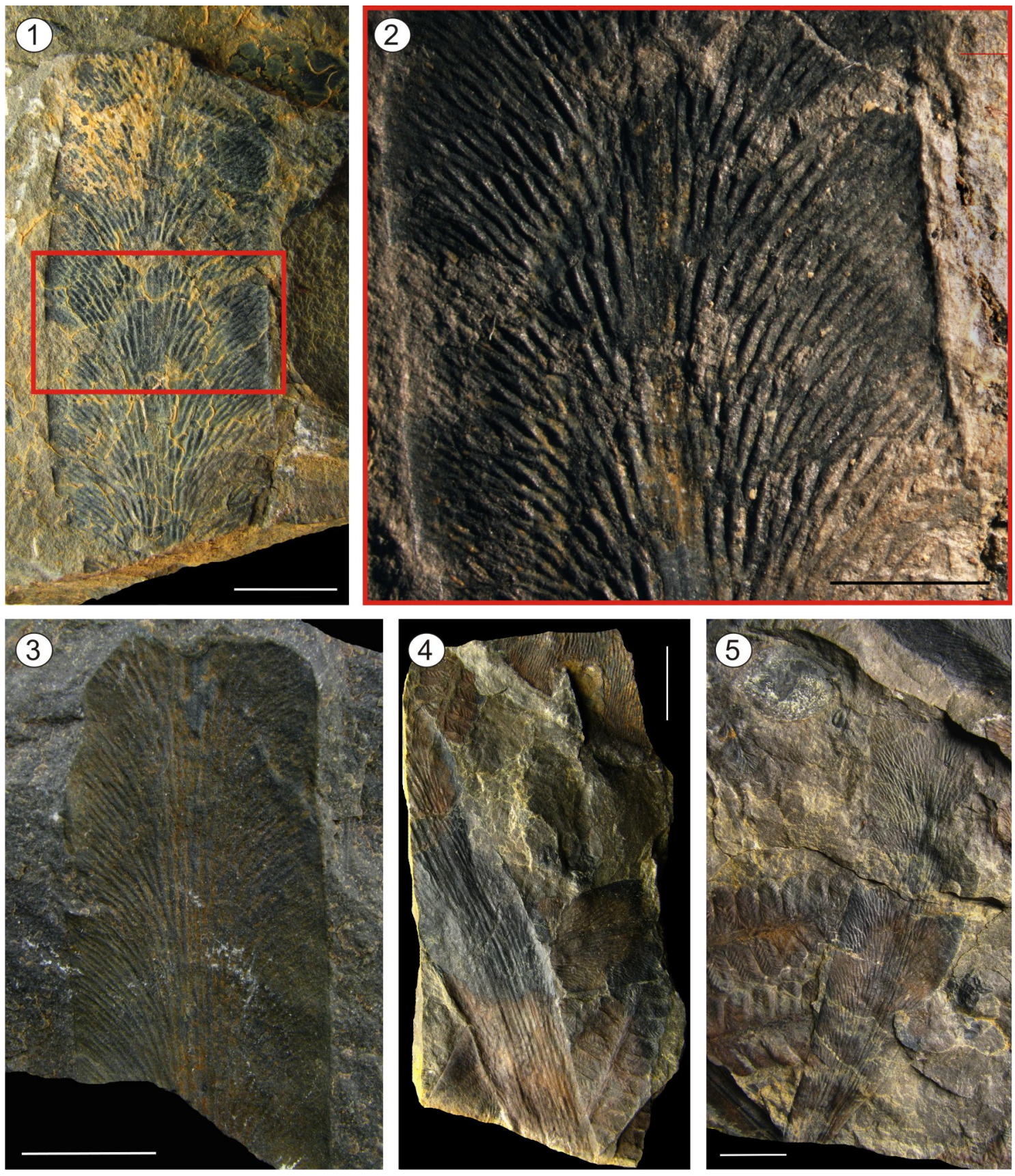
XXXVI. Gangamopteris obovata. Fig. 1- MPM-Pb 15128. Ejemplar casi completo de hoja con venación bien preservada. Escala $1 \mathrm{~cm}$. Fig. 2- MPM-Pb 4421. Parte media inferior de una hoja de tamaño grande con venación típica de la especie. Escala $1 \mathrm{~cm}$. Fig. 3- MPM-Pb 4626. Parte media-inferior de una hoja con venación bien definida. Escala 1 cm. Fig. 4- MPM-Pb 4626. Detalle de la venación en recuadro de Fig. 3. Escala 5 mm. Fig. 5- MPM-Pb 13830. Parte media de la hoja con venación bien definida. Escala $1 \mathrm{~cm}$. Fig. 6 MPM-Pb 2597. Ejemplar de tamaño pequeño, casi completo, de pobre preservación, pero con la venación visible típica de la especie. Escala $1 \mathrm{~cm}$. 


\section{LÁMINA XXXVI}
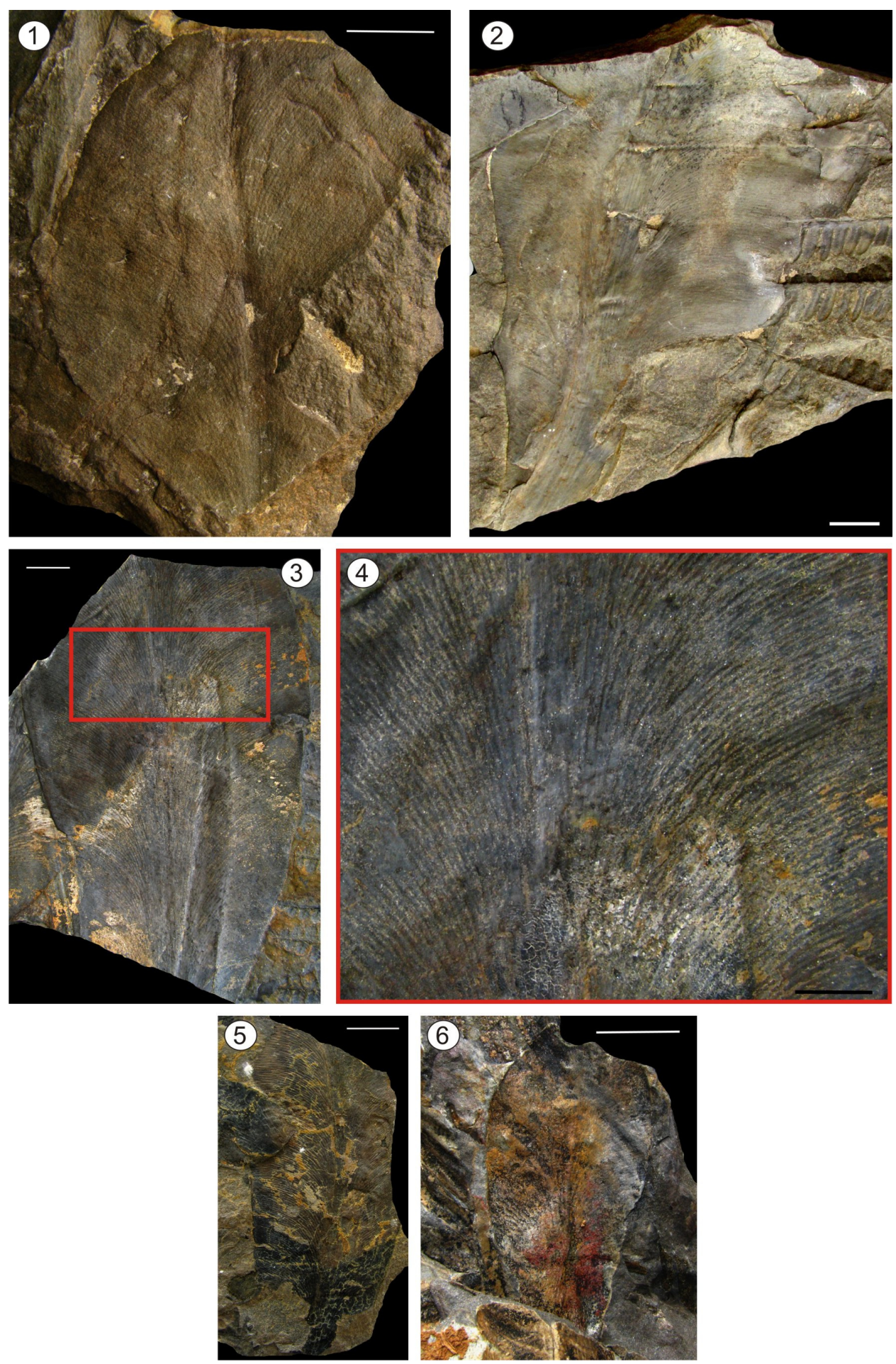
XXXVII. Palaeovittaria kurtzii. Fig. 1- MPM-Pb 4723. Ejemplar casi completo, con daño de insecto marginal (?). Escala $1 \mathrm{~cm}$. Vertebraria sp. Fig. 2- MPM-Pb 2682. Fragmento de Vertebraria sp. Escala $1 \mathrm{~cm}$. Fig. 3- BAPb 13886. Fragmento de Vertebraria sp. Escala $1 \mathrm{~cm}$. 


\section{LÁMINA XXXVII}
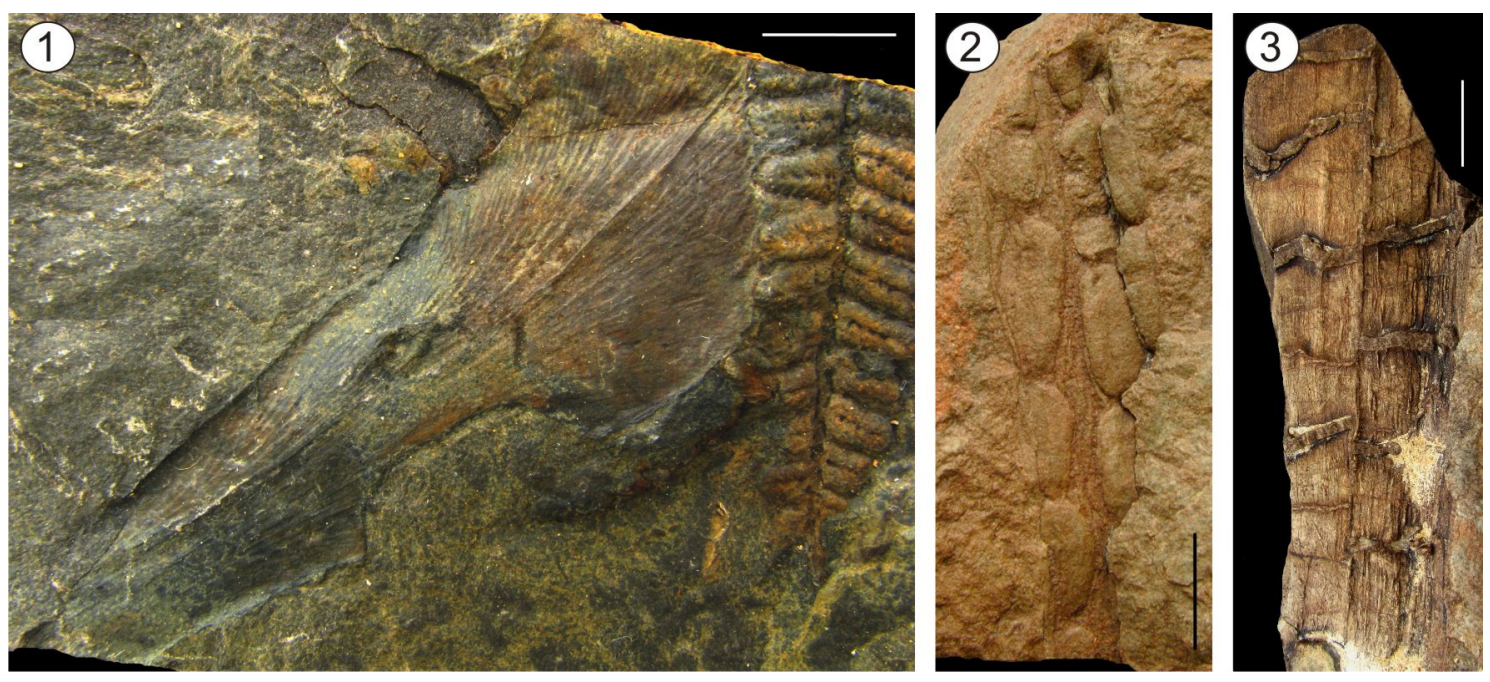
XXXVIII. Scutum cf. S. elongatum. Fig. 1- BAPb 13584. Ejemplar tapado por la hoja de Glossopteris sp. que lo portaba. Escala $1 \mathrm{~cm}$. Fig. 2- BAPb 13584. Fructificación luego de la limpieza mecánica del material, donde se observa el ala festoneada de ancho contínuo, y la superficie rugosa de la cara estéril de ésta. Escala 1 cm. Gonophylloides semnes comb. nov. Fig. 3- Lil 1400. Fructificación incompleta donde se observa la base cordada, y un ala rodeando el cuerpo fructífero. Escala $1 \mathrm{~cm}$. Fig. 4- Lil 1400. Detalle de los cuerpos fructíferos (¿semillas?) y margen alado. Escala $2 \mathrm{~mm}$. Bifariala cf. B. intermittens. Fig. 5- MPM-Pb 2530. Fructificación entera. Escala $1 \mathrm{~cm}$. Fig. 7- MPM-Pb 2530. Detalle del ápice donde se observa el ala II. Escala 5 mm. Fig. 6- MPM.Pb 2570. Fructificación entera. Escala 1 cm. Fig. 8- MPM-Pb 2570. Detalle del ápice donde se observa el ala II. Escala $5 \mathrm{~mm}$. 


\section{LÁMINA XXXVIII}
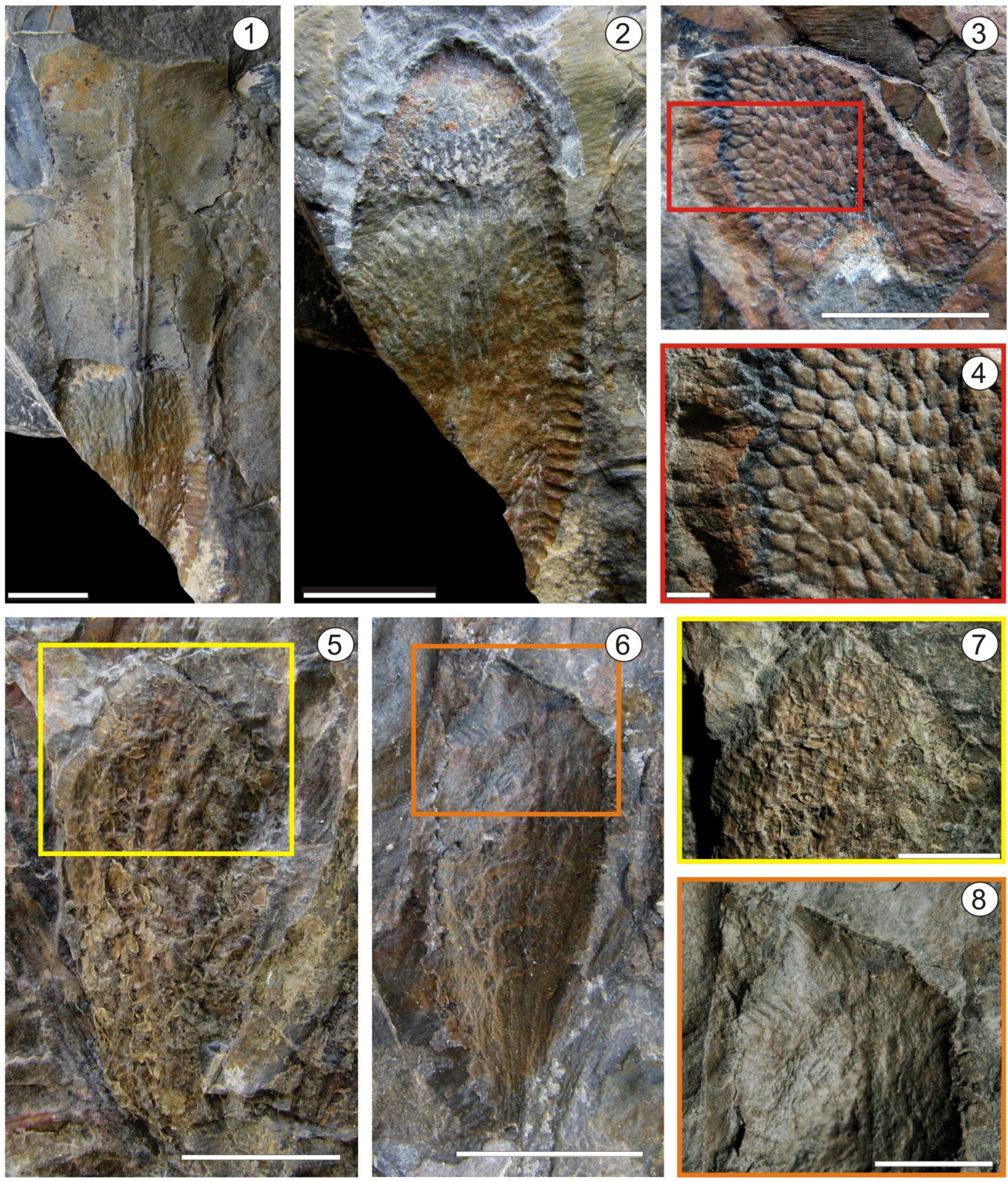
XXXIX. Dictyopteridium sporiferum. Fig. 1- Lil 1982. Fructificación entera. Escala 1 cm. Fig. 2- Lil 1982. Detalle del margen alado. Escala $2 \mathrm{~mm}$. Fig. 3- Lil 1982. Detalle del pedicelo. Escala $2 \mathrm{~mm}$. Dictyopteridium natalensis. Fig. 4- MPM-Pb 15157. Fructificación entera. Escala 1 cm. Fig. 5- MPM-Pb 15157. Detallle del ápice con margen alado (flecha). Escala 5 mm. Fig. 6- MPM-Pb 15157. Detalle de las cicatrices de óvulos (recuadro) y margen alado (flecha). Escala $5 \mathrm{~mm}$. Dictyopteridium costatum. Fig. 7- Fructificación fragmentada en su parte apical y basal, donde se observa la fuerte vena media, y las marcas circulares de los óvulos. Escala $1 \mathrm{~cm}$. Senotheca sp. Fig. 8- MPM-Pb 4968. Fructificación fragmentada en su parte apical y basal, donde se observan las marcas de los óvulos alineadas longitudinalmente a ambos lados del delgado cuerpo fructífero. Escala $1 \mathrm{~cm}$. ?Arberia sp. Fig. 9- MPM-Pb 4968. Fructificación (?) donde se observa un raquis estriado longitudinalmente (flecha blanca) ramificado en su parte superior (flechas negras). Escala 1 cm. Ottokaria sp. Fig. 10- Lil 101. Fructificación fragmentada de muy buena preservación. Escala $1 \mathrm{~cm}$. Ottokaria sp. Fig. 11- MPM-Pb 4852. Fructificación lobada con semillas, pero sin pedicelo. Escala $5 \mathrm{~mm}$. Fig. 12- MPM-Pb 4852. Detalle de semilla platispérmica con quilla central. Escala $2 \mathrm{~mm}$. 


\section{LÁMINA XXXIX}
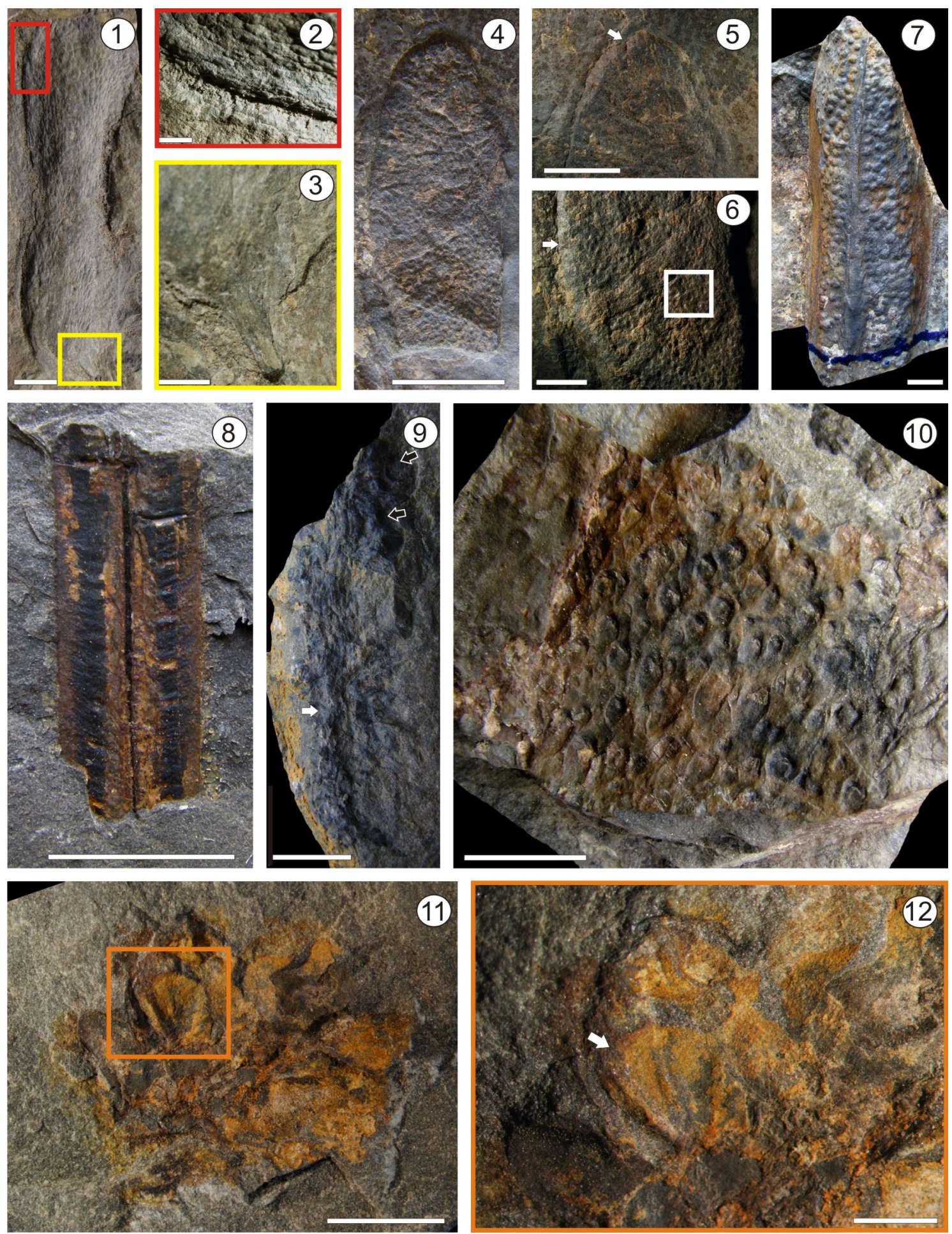
XL. Lidgettonia africana. Fig. 1- Lil 1439. Ejemplar con fructificación y escama tipo B asociada. Escala 1 cm. Fig. 2- Lil 1439. Detalle de venación de la escama. Escala 5 mm. Fig. 3- Lil 1439. Detalle del capítulo ovulífero. Escala 5 mm. Escama tipo A. Fig. 4- Lil 99. Escama casi completa donde se observa la venación abierta con algunas anastomosis. Escala 5 mm. Escama tipo B. Fig. 5- Lil 1436. Escama sin su parte basal, asociada a una escama tipo C (flecha). Escala $5 \mathrm{~mm}$. Fig. 6- Lil 101. Escama sin su parte basal donde se observa el tipo de venación. Escala $5 \mathrm{~mm}$. Fig. 7- BAFC-Pb 15540. Escama sin su parte basal. Escala $1 \mathrm{~cm}$. Escama tipo C. Fig. 8- LP-Pb 7121. Escama con cicatrices de óvulos. Escala 5 mm. Fig. 9- LP-Pb 7121. Imagen MEB. Escala $2 \mathrm{~mm}$. Fig. 10- LP-Pb 7147. Escama con cicatrices de óvulos. Escala 5 mm. Fig. 11LP-Pb 7147. Imagen MEB. Escala 2 mm. Fig. 12- LP-Pb 7361. Escama con cicatrices de óvulos. Escala 5 mm. Fig. 13- LP-Pb 7361. Imagen MEB. Escala 2 mm. Fig. 14- MPM-Pb 4453. Dos escamas de distinto tamaño asociadas. Escala $1 \mathrm{~cm}$. Fig. 15- MPM-Pb 4468. Dos escamas (flechas amarillas) de distinto tamaño asociadas. Escala $5 \mathrm{~mm}$. 


\section{LÁMINA XL}
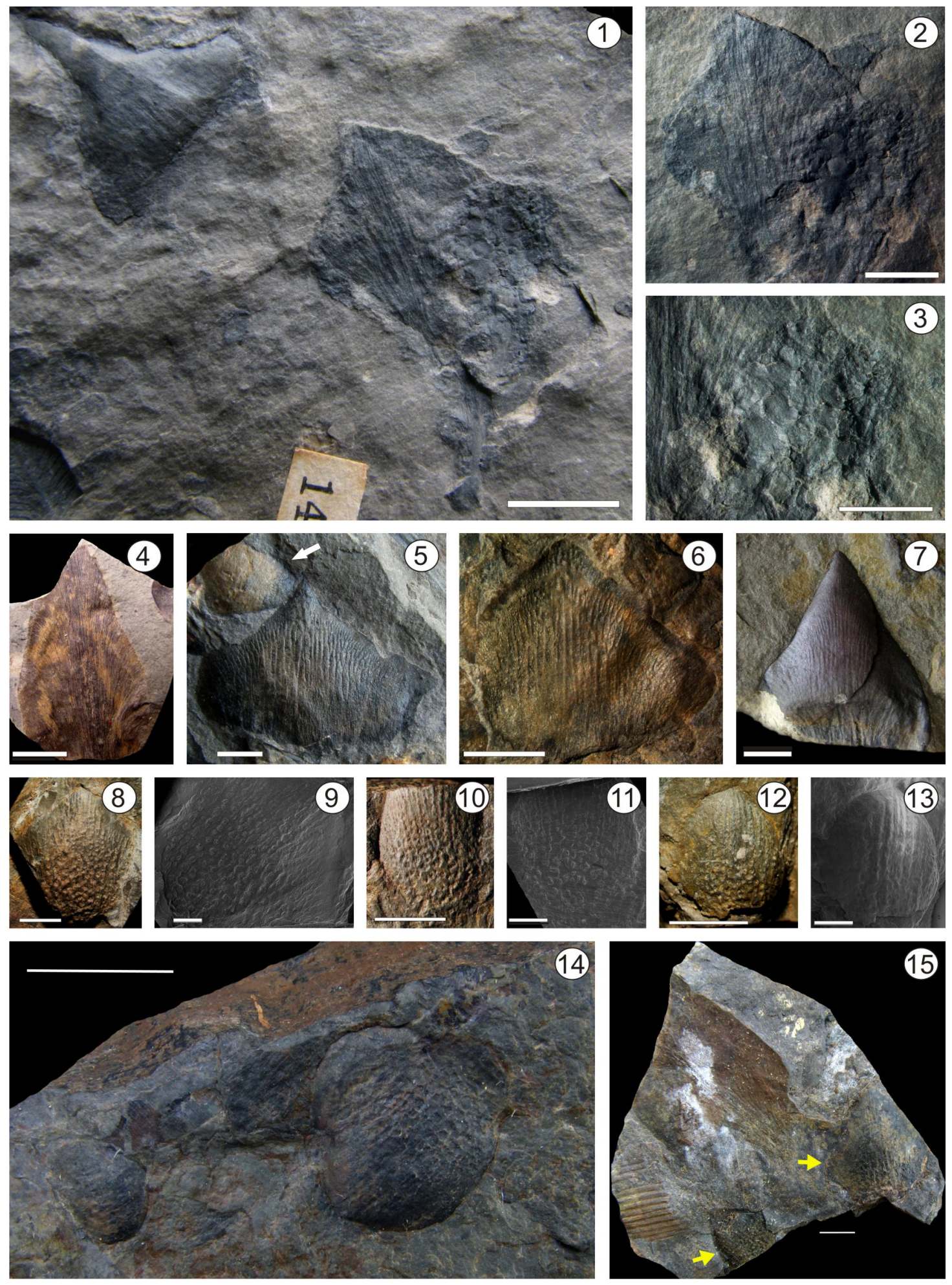
XLI. Plumsteadia pedicellata sp. nov. Fig. 1- MPM-Pb 2524. Fructificación en conexión orgánica con la hoja de Glossopteris cf. G. pampeana que la porta. Escala $1 \mathrm{~cm}$. Fig. 2- MPM-Pb 2524. Detalle de la venación de la hoja. Escala 2,5 mm. Fig. 3- MPM-Pb 2524. Cuerpo fructífero con pedicelo. Escala $5 \mathrm{~mm}$. Fig. 4- MPM-Pb 2524. Detalle de la conexión entre el pedicelo de la fructificación y el pecíolo de la hoja. Escala $2,5 \mathrm{~mm}$. 


\section{LÁMINA XLI}
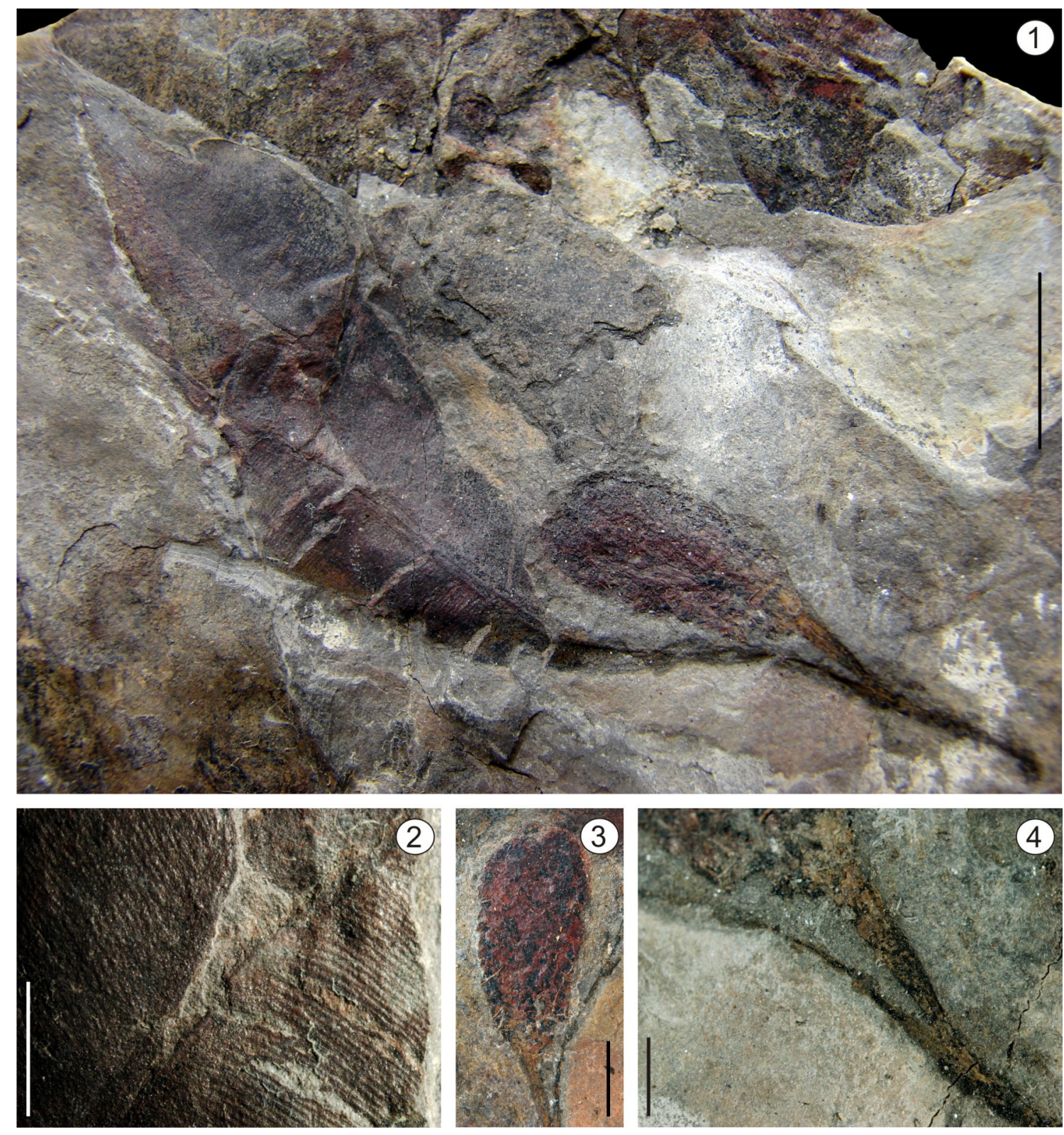
XLII. Coniferofitas. Fig. 1- MPM-Pb 4986. Ramitas estériles de coniferofitas. Escala $1 \mathrm{~cm}$. Fig. 2- MPM-Pb 4678. Ramita esteril de coniferofita con hojas alargadas puntiagudas. Escala $1 \mathrm{~cm}$. Fig. 3- MPM-Pb 4682. Rama estéril con hojas de base triangular, alargadas, y punta recurvada. Escala $5 \mathrm{~mm}$. Figs. 4 y $5-\mathrm{MPM}-\mathrm{Pb}$ 4816. Cara y contracara de cono fértil y rama estéril de coniferofita. Escala $5 \mathrm{~mm}$. Fig. 6- MPM-Pb 4916. Detalle de hojas con base triangular y punta recurvada de rama estéril de coniferofita. Escala $5 \mathrm{~mm}$. Fig. 7MPM-Pb 4976. Conjunto de ramitas estériles de coniferofitas terminadas en "botones". Escala 5 mm. Fig. 8MPM-Pb 15103. Ramitas estériles y cono (?). Escala 1 cm. Fig. 9- MPM-Pb 4882. Parte terminal de ramita estéril con "botón" lateral. Escala 5 mm. Fig. 10- MPM-Pb 4883. Ramita estéril de coniferofita con "botón" lateral y hojas de base triangular y curvadas. Escala $5 \mathrm{~mm}$. 


\section{LÁMINA XLII}
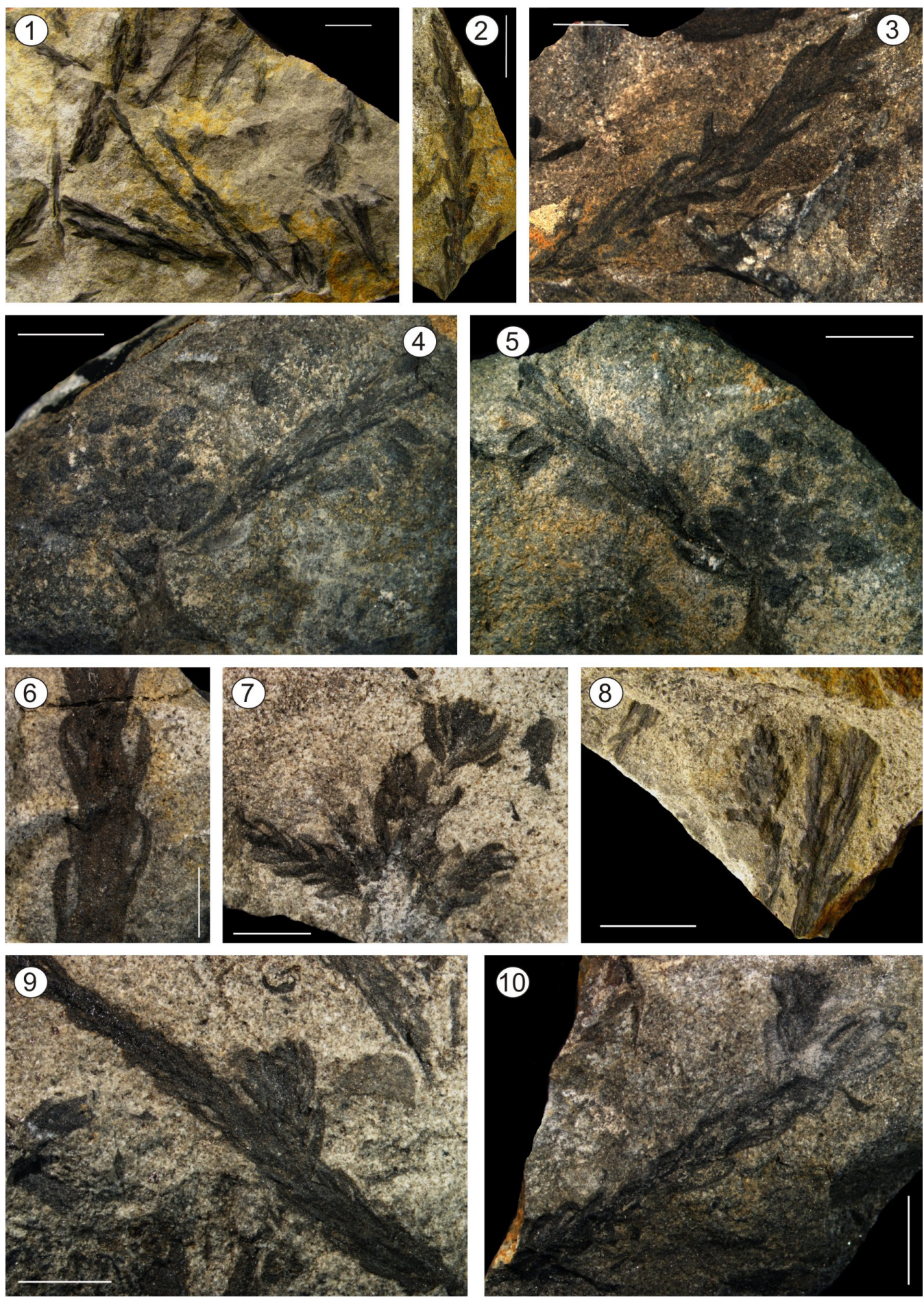
XLIII. Samaropsis golondrinensis. Fig. 1- MPM-Pb 4616. Escala 5 mm. Fig. 2- MPM-Pb 4674. Se observa el estriado del cuerpo. Escala 2 mm. Fig. 3- MPM-Pb 15129. Sarcotesta claramente diferenciable de la esclerotesta. Escala 2 mm. Fig. 4- MPM-Pb 4614. Escala 5 mm. Fig. 5- MPM-Pb 4779. Se observa el estriado longitudinal del cuerpo seminal. Escala 5 mm. Fig. 6- MPM-Pb 4964. Conjunto de semillas. Escala $1 \mathrm{~cm}$. Fig. 7- MPM-Pb 4778. Escala 2 mm. Fig. 8- MPM-Pb 4781. Conjunto de semillas. Escala 5 mm. Fig. 9- MPM-Pb 4777. S. golondrinensis con semilla más pequeña, indeterminada. Escala 5 mm. Fig. 10- MPM-Pb 4774. Escala 5 mm. Fig. 11- MPM-Pb 2732. Se observa el estriado del cuerpo de la semilla. Escala 5 mm. Fig. 12BAPb 13826. Cara y contracara con cuerpo estriado. Escala 5 mm. Fig. 13- MPM-Pb 4425. Escala 5 mm. 


\section{LÁMINA XLIII}
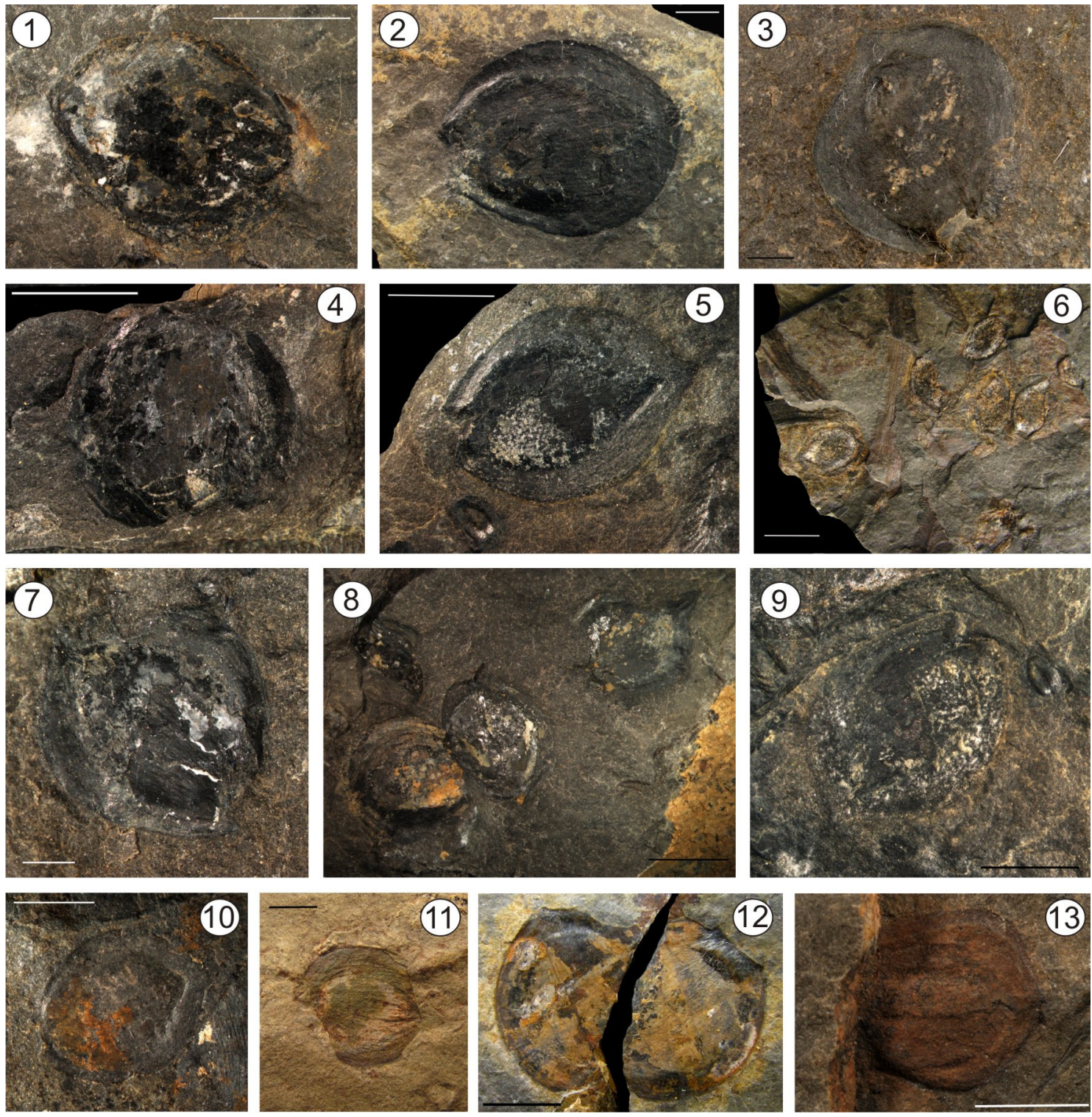
XLIV. Megistophyllum leanzai. Fig. 1- BAFC-Pb 15425. Escala $1 \mathrm{~cm}$. Fig. 2- BAFC-Pb 15425. Detalle del margen en recuadro de Fig. 1. Escala $5 \mathrm{~mm}$. Fig. 3- BAFC-Pb 15425. Detalle de la base y pecíolo en recuadro de Fig. 1. Escala 5 mm. Fig. 4- MPM-Pb 4642. Hoja casi entera con venación recta marcada y pecíolo ancho. Escala $1 \mathrm{~cm}$. Figs. 5-7 - BAFC-Pb 15421. Fragmento de hoja, con detalle del margen superior y venación basal. Escala Fig. 6: 1 cm, Figs. 5 y 7: 5 mm. Fig. 8- MPM-Pb 2793. Parte media-superior de hoja, con nervaduras marcadas que se recurvan hacia el margen. Escala $5 \mathrm{~mm}$. Fig. 9- MPM-Pb 4607. Detalle ampliado de la venación central recta y lateral que se curva hacia el margen. Escala $5 \mathrm{~mm}$. 


\section{LÁMINA XLIV}
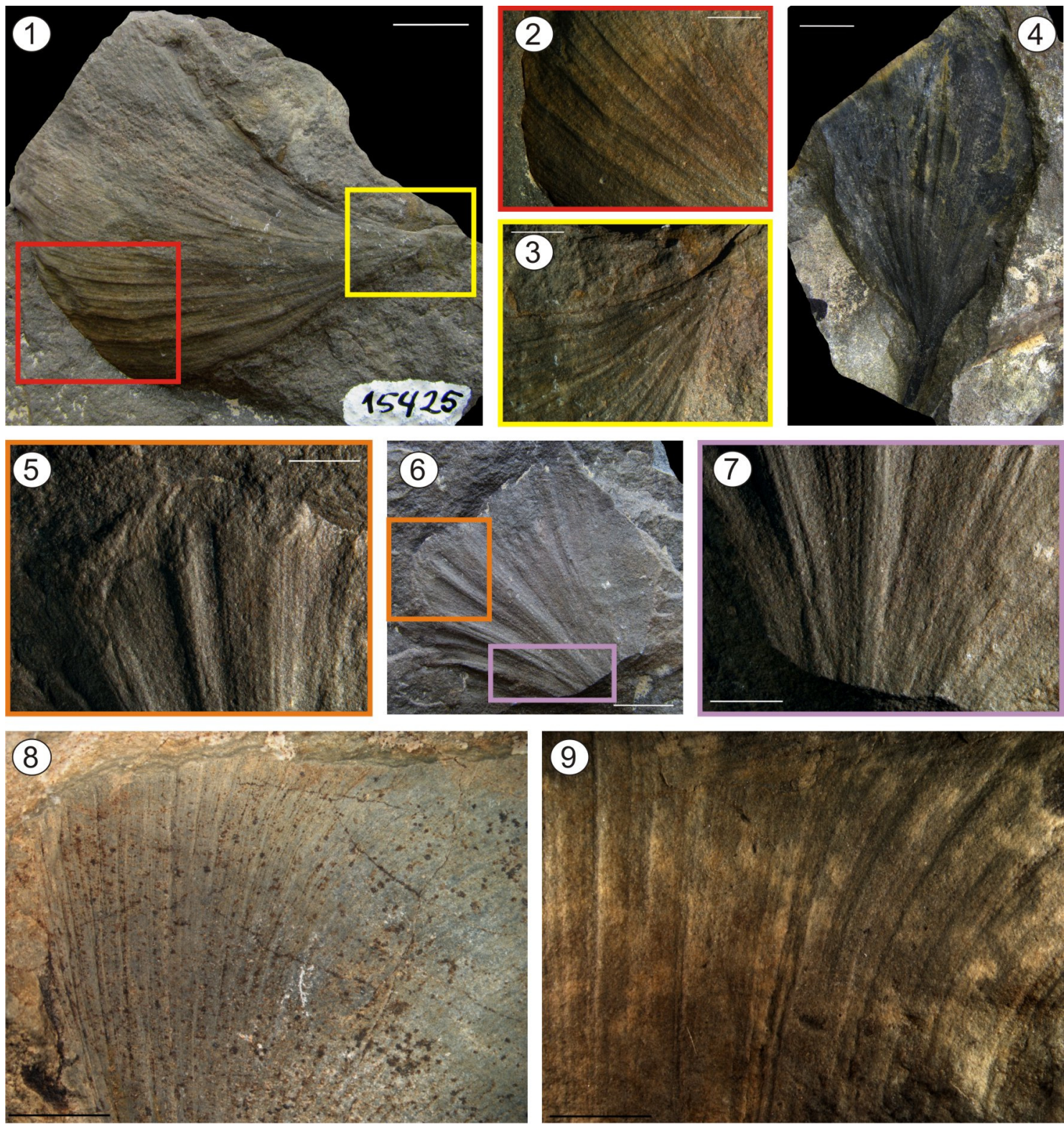
XLV. Chiropteris harrisii. Fig. 1- Lil 69. Chiropteris harrisii hallado por el Dr. Archangelsky, y depositado en el Instituto Lillo (ver Archangelsky, 1960b). Escala 1 cm. Fig. 2- MPM-Pb 4411. Fragmento de hoja reniforme, con venación dicotómica abierta. Escala $1 \mathrm{~cm}$. 


\section{LÁMINA XLV}
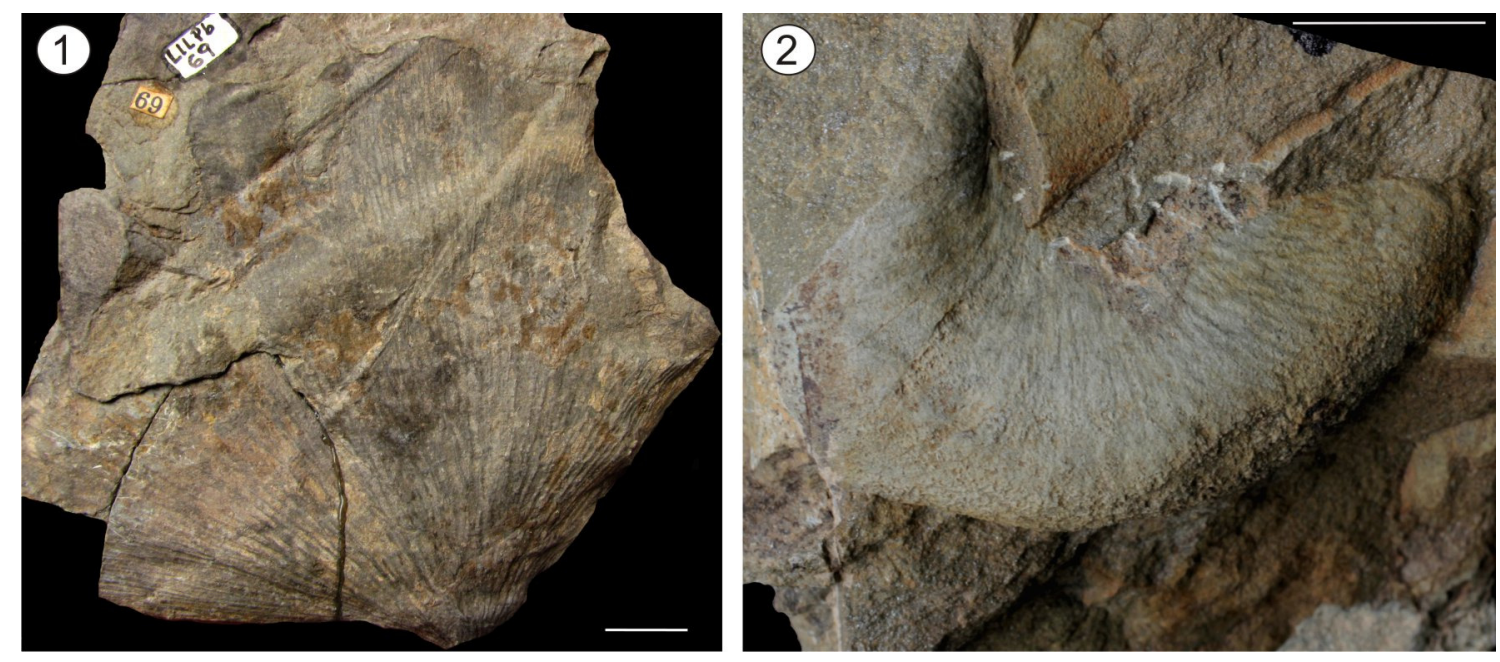


$$
\begin{gathered}
\text { - CAPÍTULO } 5 \text { - } \\
\text { BIOESTRATIGRAFÍA Y EDAD }
\end{gathered}
$$




\section{0 - BIOESTRATIGRAFÍA Y EDAD}

\section{1 - Antecedentes}

Los primeros estudios comparativos entre la flora de la Formación La Golondrina y otras coetáneas fueron llevados a cabo por Archangelsky (1959a), quien al ubicar estratigráficamente las especies descriptas en los 13 niveles fosilíferos del perfil tipo de Laguna Polina, y correlacionar esos niveles con los de las otras localidades, concluyó en base a la litología y paleontología - que la serie sedimentaria podía ser dividida en dos secciones, una inferior (nivel fosilífero I-X), y otra superior (nivel fosilífero XI-XIII). A toda esta serie la denominó Serie La Golondrina, e infirió para ella una edad pérmica temprana, “desde Asseliana hasta Artinskiana” (Archangelsky 1959a: 120). Posteriormente, Lesta y Ferello (1972) utilizaron el término Formación La Golondrina en lugar de Serie, adecuándose a la nomenclatura requerida por el Código Estratigráfico Internacional.

A través del completo estudio de los afloramientos pérmicos en el área de la Estancia La Juanita, Arrondo $(1969,1972)$ amplió el conocimiento de la tafoflora de La Golondrina, y sumó una nueva unidad litoestratigráfica de edad pérmica (Formación La Juanita) que se diferenciaba de La Golondrina por ser completamente estéril. De esta manera, quedó conformado el Grupo Tres Cerros. Para este autor, la edad de la Formación La Golondrina seguía siendo - de acuerdo a lo indicado por el registro florístico - pérmica temprana, con la posible presencia de un Pérmico Tardío representado por las sedimentitas de la Formación La Juanita.

Posteriormente, Jalfin (1987) y Jalfin et al. (1990) propusieron dividir a la Formación La Golondrina en tres miembros: Laguna Lillo (inferior), Laguna Polina (medio) y Dos Hermanos (superior). Esta propuesta es la aceptada en la actualidad y la que se mantiene en este estudio. 
Un análisis más detallado y actualizado, que comparaba las floras pérmicas conocidas en Argentina, fue llevado a cabo por Archangelsky y Cúneo (1984), quienes propusieron una esquema de zonación paleoflorística para las distintas tafofloras, incluyendo a la de la Formación La Golondrina en la Superzona de Dizeugotheca, caracterizada por la presencia de las especies Dizeugotheca neuburgiae, Glossopteris argentina, G. ampla y Asterotheca golondrinensis. Esta Superzona abarcaba únicamente las floras presentes en el miembro medio (Laguna Polina) y el miembro superior (Dos Hermanos), ya que aún no había elementos megaflorísticos conocidos ni descriptos provenientes del miembro inferior (Laguna Lillo). De esta manera, se propuso una Zona de Dizeugotheca waltonii para la flora del miembro medio, entre cuyas especies exclusivas se hallaban Annularia kurtzii, Dichotomopteris hirundinis, D. ovata, Glossopteris stricta, G. retifera y Gangamopteris castellanosii. Asimismo, algunas especies tenían su último registro en esta zona, a saber, Asterotheca piatnitzkyi, Sphenophyllum speciosum, Gangamopteris mosesii y G. obovata (Archangelsky y Cuneo, 1984).

Para la flora recuperada del miembro superior, se propuso la designación de Zona de Asterotheca singeri, al ser ésta la única especie exclusiva. Además, en estos niveles tenía su techo de distribución Asterotheca anderssonii. Dado que dichos autores estaban de acuerdo en que si bien las tafofloras patagónicas de Tepuel Genoa (Chubut) y La Golondrina (Santa Cruz) presentaban elementos en común, las asociaciones paleoflorísticas eran lo suficientemente distintas como para separarlas en biozonas diferentes. De esta forma, Archangelsky y Cúneo (1984) sugieren una cronoestratigrafía regional propia para cada zona paleobotánica, refiriéndolas con el nombre de Lubeckense para referirse a la unidad (=piso) de Tepuel Genoa, y Golondrinense para el correspondiente a La Golondrina. Al respecto, el piso Golondrinense se correspondía con la edad regional Golondriniana, la cual abarcaría a "sus dos miembros, coronada por sedimentitas cuarcíticas concordantes" (Archangelsky y Cúneo, 1984: 151) de la Formación La Juanita.

Los trabajos más recientes acerca de la Formación La Golondrina hacen referencia a estas biozonas, sin nuevos aportes relacionados a la bio y cronoestratigrafía. Asimismo 
distintos autores suelen asignar una edad para la Formación La Golondrina que abarca desde el Sakmariano hasta el pérmico más tardío ( $\sin$ especificar una edad), basada únicamente en la evidencia aportada por la paleoflora, sin otros datos que apoyen y/o acoten esta visión (Jalfin, 1987; Andreis y Archangelsky, 1996; Archangelsky et al., 1996a, b; Archangelsky y Cúneo, 2002).

\section{2 - Comparación bioestratigráfica con otras floras Pérmicas}

Estudios comparativos entre la tafoflora de La Golondrina y aquellas consideradas coetáneas han sido llevados a cabo por Archangelsky (1959a), Arrondo (1972), Archangelsky y Cúneo (1984), Archangelsky et al. (1996b), y Andreis y Archangelsky (1996), quienes compararon esta flora con otras floras pérmicas de Argentina, diferentes localidades de Gondwana, e incluso floras extra-Gondwánicas.

Cuadro I - Zonas florísticas del Pérmico argentino, basado en Archangelsky y Cúneo (1984) y Archangelsky et al. (1996b, c). Edades de acuerdo a la IUGS (2009).

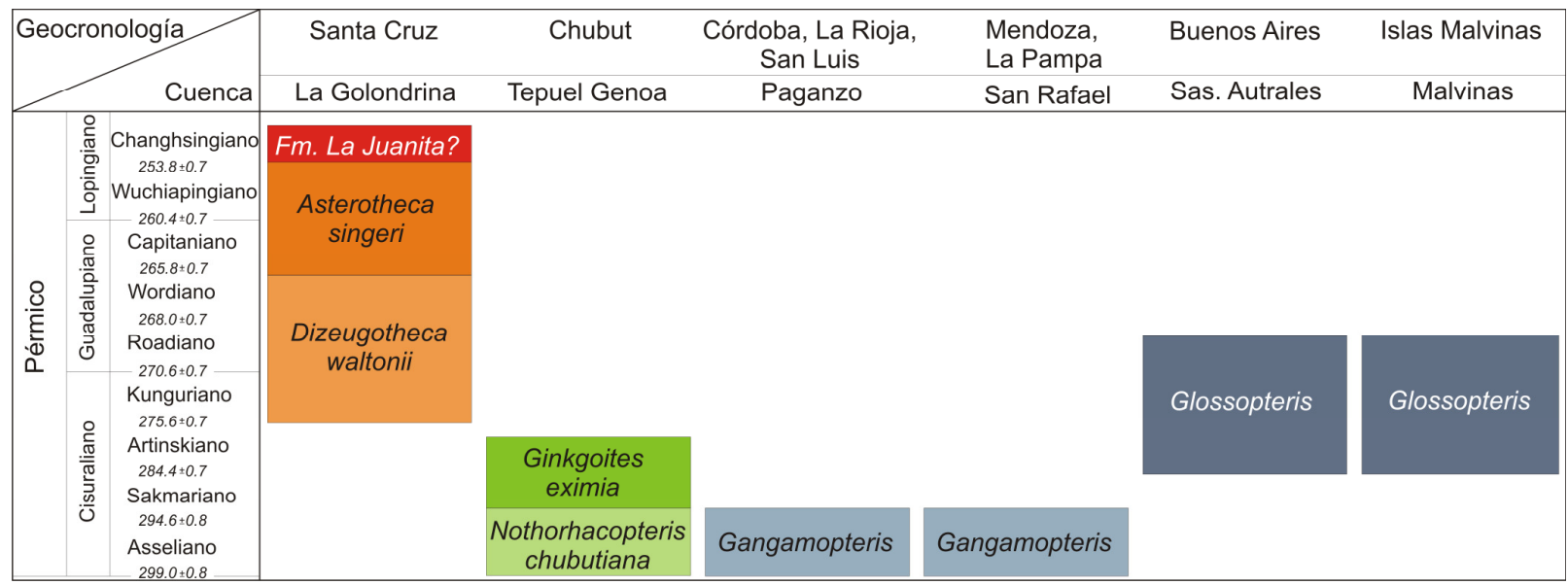


Una de las propuestas bioestratigráficas más completas para el Pérmico continental de Argentina fue hecha en base a tafofloras por Archangelsky y Cúneo (1984), en la cual se evaluaron las distribuciones de especies fósiles en las cuencas de Paganzo, Sierras Australes, Islas Malvinas, Tepuel Genoa, y La Golondrina (Cuadro I). En base a ése y posteriores análisis (ver Archangelsky et al., 1996b, c), se sugirió mantener la Zona de Gangamopteris para las cuenca Paganzo y San Rafael, la Zona de Glossopteris para las Cuencas Sierras Australes e Islas Malvinas, y propusieron dos nuevas Superzonas para referirse a las Cuencas Tepuel Genoa y La Golondrina: Superzona de Ferugliocladus (dividida en una zona inferior de Nothorachopteris chubutiana, y una superior de Ginkgoites eximia) y Superzona de Dizeugotheca (dividida en una zona inferior de Dizeugotheca waltonii y una superior de Asterotheca singeri), respectivamente (Cuadro I).

A su vez, plantearon mantener al Piso Lubeckense como unidad cronoestratigráfica (edad regional Lubeckiana), y crearon el Piso Golondrinense (edad regional Golondriniana) para referirse a la unidad por encima del Lubeckense, y en reemplazo del Lubeckense B. Este esquema estratigráfico es el aceptado y vigente hasta la fecha.

Por una cuestión de cercanía geográfica y temporal, la flora de La Golondrina ha sido ampliamente analizada en comparación con la flora de Tepuel Genoa (Pérmico Inferior de Chubut). Consideradas previamente como pertenecientes a la misma cuenca - Cuenca Central Patagónica (Amos, 1964; Lesta y Ferello, 1972; Archangelsky et al., 1985) - ambas tafofloras presentan elementos en común (Anexo I), mientras que otros son propios de cada una. Esta evidencia paleobiológica, sumada a la sedimentológica, llevó a considerar a ambas cuencas como entidades estratigráficas separadas, visión actualmente apoyada por la mayoría de los investigadores (Jalfin y Bellosi, 1984; Jalfin, 1987; Andreis y Archangelsky, 1996).

Los elementos paleoflorísticos predominantes en Tepuel Genoa serían los helechos pecopterídeos, asterothecáceas, sphenophyllales, y licófitas. También estaban representadas las glossopterídeas, aunque en comparación con La Golondrina, el número de especies de Glossopteris sería menor. Por otra parte, una diferencia fundamental entre la flora de 
Tepuel Genoa con la de La Golondrina, radicaba en la diversa presencia de coniferofitas para la primera (con representantes de los géneros: Ugartecladus, Ferugliocladus, Paranocladus, y Genoites), mientras que la ausencia de registro para La Golondrina era una característica notable de esta flora con las demás tafofloras pérmicas en Argentina (Archangelsky et al., 1996a; Andreis y Archangelsky, 1996). Los recientes hallazgos de coniferofitas en las campañas llevadas a cabo por quien aquí suscribe (mayormente ramas estériles, con la potencial presencia de conos), confirman su presencia en La Golondrina.

Entre los elementos paleoflorísticos predominantes de La Golondrina figuraban los helechos tanto estériles como fértiles, y las glossopterídeas, muy diversificadas y abundantes (Cuadro IV). Menos diversas, pero también abundantes, aparecían las sphenophyllales, y en menor medida, se encontraban las cordaitales y licófitas. A partir del presente estudio, el número de especies de glossopterídeas, particularmente en lo que respecta a sus estructuras fértiles, aumentó considerablemente; además, se documenta la primera evidencia de la presencia de coniferofitas, grupo hasta el momento totalmente desconocido entre los elementos paleoflorísticos para la Formación La Golondrina (Cuadro IV).

Si bien las tafofloras de La Golondrina y Tepuel Genoa tenían varios elementos en común (Anexo I) (Archangelsky, 1957, 1959a; Archangelsky y de la Sota, 1960; Arrondo, 1972), las diferencias entre éstos eran lo suficientemente marcadas como para reconfirmar una edad más joven para Formación La Golondrina, tal cual fue propuesto en varias contribuciones (Archangelsky 1959a; Arrondo, 1972; Archangelsky y Cúneo, 1984; Jalfin, 1987; Archangelsky et al. 1996a, b; Andreis y Archangelsky, 1996). Esto se evidencia también a través de varios aspectos paleobiológicos: la presencia de un número mayor (tanto en abundancia como en diversidad) de especies de Glossopteris, con un patrón de venación más complejo en aquellos ejemplares de La Golondrina versus los de Tepuel Genoa, el mismo patrón que se repite para las fructificaciones del grupo de las glossopterídeas, siendo marcadamente más diversas en La Golondrina que en Tepuel Genoa, así como la ausencia de especies típicamente pertenecientes al Carbonífero Tardío 
(Nothorhacopteris chubutiana y Ginkgoites eximia, ambas presentes en la tafoflora chubutense), son algunos ejemplos de las claras diferencias entre una y otra flora que marcan un desarrollo temporalmente desfasado.

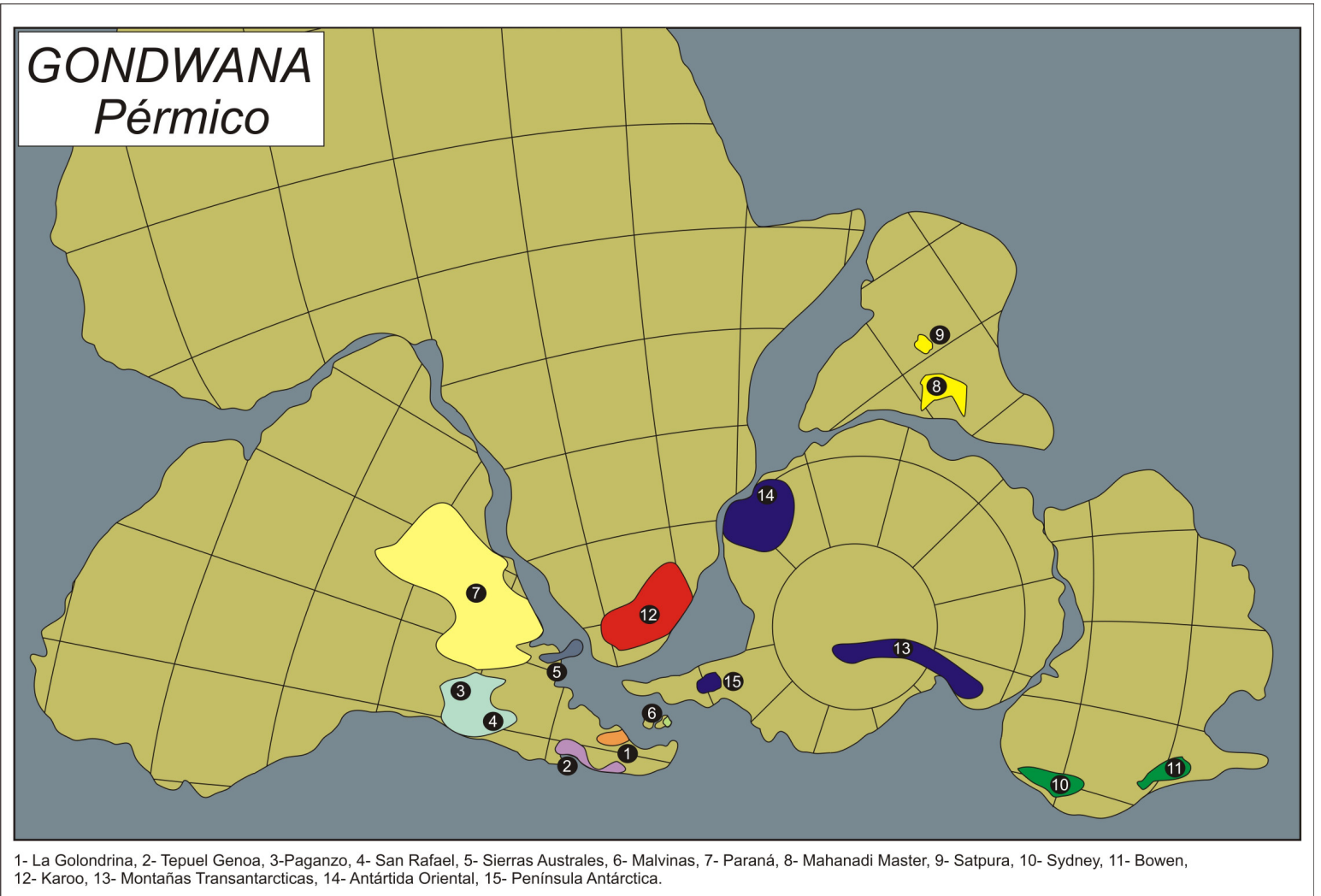

Figura 10 - Mapa esquemático de Gondwana durante el Pérmico (Modificado de Schopf y Askin, 1980). Ubicación de la Cuenca La Golondrina y demás cuencas de importancia mencionadas (ver Anexo I).

Respecto a la comparación de la tafoflora de la Formación La Golondrina con otras Gondwánicas pertenecientes al mismo período (Figura 10; Cuadro II), la abundancia de nuevos elementos hallados permite encontrar mayor afinidad con aquellas floras pérmicas de la India, Sudáfrica y Australia, principalmente (Anexo I). Esto se destaca, nuevamente, debido a la cantidad de nuevas fructificaciones de glossopterídeas descriptas para la Formación La Golondrina y previamente desconocidos, aún cuando los elementos claramente predominantes eran las partes estériles (hojas) de este grupo. 
Cuadro II- Estratigrafía de las formaciones consideradas en este estudio para la comparación con la flora de la Formación La Golondrina.

\begin{tabular}{|c|c|c|c|c|c|c|c|c|c|c|c|}
\hline & & PAís & BRASIL & & & AUS & ALIA & $\begin{array}{c}\text { SUD } \\
\text { ÁFRICA }\end{array}$ & & NTÁRTID & \\
\hline & & JENCA & Paraná & $\begin{array}{c}\text { Mahanadi } \\
\text { Master }\end{array}$ & Satpura & Sydney & Bowen & Karoo & Mont. Trans. & $\begin{array}{c}\text { Antártida } \\
\text { Oriental }\end{array}$ & $\begin{array}{l}\text { Península } \\
\text { Antárctica }\end{array}$ \\
\hline & 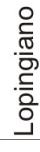 & $\begin{array}{c}\text { Changhsingiano } \\
253.8 \pm 0.7 \\
\text { Wuchiapingiano } \\
260.4 \pm 0.7\end{array}$ & $\begin{array}{l}\text { Rio do } \\
\text { Rasto }\end{array}$ & $\begin{array}{l}\text { Raniganj } \\
\text { Lower Khamti }\end{array}$ & Bijori & $\begin{array}{l}\text { Newcastle } \\
\text { C.M. } \\
= \\
\text { llawarra }\end{array}$ & $\begin{array}{l}\text { Baralaba }^{* * *} \\
\text { Black Alley } \\
\text { Shales }\end{array}$ & $\begin{array}{c}\text { Normandien } \\
= \\
\text { Estcourt }\end{array}$ & $\begin{array}{c}\text { Buckley } \\
= \\
\text { Weller }\end{array}$ & $\begin{array}{l}\text { Bainmedart } \\
\text { C.M. }\end{array}$ & $\begin{array}{l}\text { "Erehwon } \\
\text { beds" }\end{array}$ \\
\hline . & 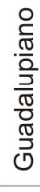 & $\begin{array}{c}\text { Capitaniano } \\
265.8 \pm 0.7 \\
\text { Wordiano } \\
268.0 \pm 0.7 \\
\text { Roadiano } \\
270.6 \pm 0.7\end{array}$ & & $\begin{array}{l}\text { Barren } \\
\text { Measures }\end{array}$ & & $\begin{array}{l}\text { Tomago } \\
\text { C.M. } \\
\text { Mulbring }\end{array}$ & Pcawaddy & Volksrust & Fairchild & $\begin{array}{l}\text { "Fossilrygen } \\
\text { flora" }\end{array}$ & \\
\hline & 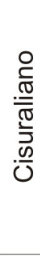 & $\begin{array}{c}\text { Kunguriano } \\
275.6 \pm 0.7 \\
\text { Artinskiano } \\
284.4 \pm 0.7 \\
\text { Sakmariano } \\
294.6 \pm 0.8 \\
\text { Asseliano } \\
299.0+0.8\end{array}$ & Rio Bonito & Barakar & Barakar & Murree & $\begin{array}{l}\text { Blair Athol } \\
\text { C.M. }\end{array}$ & Vryheid & Pagoda & & \\
\hline
\end{tabular}

$*$ Fm. Peawaddy $=$ Fms. Fair Hill y MacMillan; **Fm. Black Alley Shale $=$ Fm. Burngrove; $* * *$ Fm. Baralaba $=$ Fm. Rangal Coal Measure, formaciones equivalentes en otras localidades de la Cuenca Bowen.

En base a la presencia de los taxones representados en la Formación La Golondrina que se encuentran en otras cuencas del mundo (Anexo I), se deduce que de un total de 31 géneros confirmados ${ }^{1}$, la flora de La Golondrina comparte 20 géneros (64,5\% en común) con las cuencas de la India, siguiéndole la cuenca sudafricana (18 géneros, 58,1\% en común), las australianas (16 géneros, $51,6 \%$ en común), las brasileras (13 géneros, 41,9\% en común), y en menor medida, las cuencas antárticas en conjunto, y Paganzo en Argentina, con 10 géneros $(32,3 \%)$ en común con La Golondrina. Con menos de 10 géneros en común con La Golondrina, y en orden decreciente, están las Cuenca Tepuel Genoa ( 9 géneros, 29\%), San Rafael (6 géneros, 19,3\%), Sierras Australes (5 géneros, 16,1\%), y por último, la Cuenca Malvinas (3 géneros, 9,7\%) (Cuadro III).

\footnotetext{
${ }^{1}$ Se excluyen del análisis las coníferas, y ambas Licófita sp. A y B. Ver Anexo II.
} 
A nivel específico, el total de especies ${ }^{2}$ reconocidas para la Formación La Golondrina alcanza a 43, compartiendo con las cuencas indias y la sudafricana 16 del total de las especies consideradas (37,2\% en común), siguiéndole las cuencas australianas (12 especies, $28 \%$ en común), la paranaense en Brasil (10 especies, 23,2\% en común), y con menos de 10 especies en común, el resto de las cuencas, siendo la de mayor semejanza en sus elementos la de Tepuel Genoa (con 9 especies, 20,9\% en común) (Cuadro III).

Cuadro III- Elementos florísticos a nivel genérico y específico entre las distintas cuencas consideradas en este estudio.

\begin{tabular}{|l|c|c|c|c|}
\hline \multirow{2}{*}{ CUENCAS } & \multicolumn{2}{|c|}{ GÉNEROS EN COMÚN } & \multicolumn{2}{c|}{ ESPECIES EN COMÚN } \\
\cline { 2 - 5 } & $\mathbf{N}^{\circ}$ & $\mathbf{\%}$ & $\mathbf{N}^{\circ}$ & $\mathbf{\%}$ \\
\hline Tepuel Genoa & 9 & 29 & 9 & 20.9 \\
Paganzo & 10 & 32.3 & 6 & 13.9 \\
San Rafael & 6 & 19.3 & 5 & 11.6 \\
Sas. Australes & 5 & 16.1 & 5 & 11.6 \\
Malvinas & 3 & 3 & 3 & 7 \\
Paraná & 13 & 41.9 & 10 & 23.2 \\
Hindúes & 20 & 64.5 & 16 & 37.2 \\
Australianas & 16 & 51.6 & 12 & 28 \\
Sudafricana & 18 & 58.1 & 16 & 37.2 \\
Antárcticas & 10 & 32.3 & 5 & 11.6 \\
\hline
\end{tabular}

A partir de los datos que surgen del Cuadro III, se observa que la tafoflora de la Formación La Golondrina presenta mayor afinidad con las floras de la India, Sudáfrica y Australia (en ese orden), tanto a nivel genérico como específico. Dentro del territorio sudamericano, esta flora posee mayor afinidad con la flora pérmica de Brasil (Cuenca Paraná), sobrepasando en número de géneros y especies coincidentes incluso a aquellas

\footnotetext{
${ }^{2}$ No se toman en cuenta aquellas especies con nomenclatura abierta (por ejemplo, Asterotheca sp. 1-3), ni los géneros no asignados específicamente (por ejemplo, Phyllotheca sp.), al ser éstos ya considerados en el conteo genérico. Sí se consideran, en cambio, aquellos asignados como cf., (por ejemplo, Scutum cf. S. elongatum). Ver Anexo II.
} 
floras del Pérmico argentino. Por último, La Golondrina presenta más géneros en común con la flora de Paganzo que con la de Tepuel Genoa, sin embargo, esta tendencia a nivel específico, se invierte.

5.3 - Distribución estratigráfica de las especies presentes en la Formación La Golondrina

Como fue mencionado previamente, hasta la presentación de este trabajo no había elementos megaflorísticos conocidos ni descriptos provenientes del miembro inferior de la Formación La Golondrina. La realización de viajes de campo a la zona de Laguna Lillo, donde aflora el miembro inferior, permitió la colección de abundante material fósil (ver 3.2), entre los que se hallaron algunos elementos novedosos (por ejemplo, Lilpopia sp). Además de la prospección y colección de material fósil del miembro inferior, nuevo material fue colectado de los miembros medio y superior. De esta manera, la distribución estratigráfica de los taxones fue re-analizada, y correspondientemente ubicada, por lo que se presenta a continuación, un cuadro detallando la presencia de cada taxón en los miembros correspondientes en los que fueron hallados, y la relación entre los taxa presentes para cada grupo taxonómico mayor (en negrita) en cada miembro respecto al número total para dicho grupo en toda la formación (Cuadro IV).

Cuadro IV - Distribución de taxa presente en la Formación La Golondrina.

\begin{tabular}{|lccc|}
\hline \multicolumn{1}{|c}{ Taxón } & $\begin{array}{c}\text { Miembro Inferior } \\
\text { (Laguna Lillo) }\end{array}$ & $\begin{array}{c}\text { Miembro Medio } \\
\text { (Laguna Polina) }\end{array}$ & $\begin{array}{c}\text { Miembro Superior } \\
\text { (Dos Hermanos) }\end{array}$ \\
\hline Asterotheca sp. 1 & & $\mathrm{x}$ & \\
Asterotheca sp. 2 & & $\mathrm{x}$ & \\
Asterotheca sp. 3 & $\mathrm{x}$ & $\mathrm{x}$ & $\mathrm{x}$ \\
A. anderssonii & & $\mathrm{x}$ & $\mathrm{x}$ \\
A. golondrinensis & & $\mathrm{x}$ & \\
A. piatnitzkyi & & $\mathrm{x}$ & $\mathrm{x}$ \\
A. singeri & $\mathrm{x}$ & $\mathrm{x}$ & \\
\hline
\end{tabular}




\begin{tabular}{|c|c|c|c|}
\hline Dizeugotheca furcata & & $\mathrm{X}$ & \\
\hline D. neuburgiae & $\mathrm{x}$ & $\mathrm{x}$ & $\mathrm{x}$ \\
\hline D. waltonii & & $\mathrm{x}$ & $\mathrm{x}$ \\
\hline Pecopteris sp. A & & $\mathrm{x}$ & \\
\hline Pecopteris sp. I & & $\mathrm{x}$ & \\
\hline Pecopteris sp. III & & $\mathrm{x}$ & \\
\hline Pecopteris sp. IV & & $\mathrm{x}$ & \\
\hline Caulopteris sp. & & $\mathrm{x}$ & \\
\hline Dichotomopteris hirundinis & & $\mathrm{x}$ & \\
\hline D. ovata & & $\mathrm{x}$ & \\
\hline Damudopteris bengalensis & & $\mathrm{x}$ & \\
\hline Sphenopteris sp. II & & $\mathrm{X}$ & \\
\hline PTERIDOFITAS & $3 / 19$ & $19 / 19$ & $5 / 19$ \\
\hline Sphenophyllum speciosum & & $\mathrm{x}$ & $\mathrm{x}$ \\
\hline S. thonii & $\mathrm{x}$ & $\mathrm{x}$ & $\mathrm{x}$ \\
\hline Lilpopia sp. & $\mathrm{x}$ & & \\
\hline Annularia kurtzii & & $\mathrm{x}$ & \\
\hline Neocalamites sp. & & & $\mathrm{x}$ \\
\hline Paraschizoneura sp. & & $\mathrm{x}$ & \\
\hline ?Phyllotheca sp. & & $\mathrm{x}$ & \\
\hline ESFENOFITAS & $2 / 7$ & $5 / 7$ & $3 / 7$ \\
\hline Bumbudendron patagonicum & $\mathrm{X}$ & $\mathrm{x}$ & \\
\hline Cyclodendron golondrinensis & $\mathrm{x}$ & $\mathrm{x}$ & \\
\hline Licofita sp. A & & $\mathrm{x}$ & \\
\hline Licofita sp. B & & $\mathrm{x}$ & \\
\hline LICOFITAS & $2 / 4$ & $4 / 4$ & $0 / 4$ \\
\hline Eremopteris golondrinensis & & $\mathrm{x}$ & \\
\hline PTERIDOSPERMOFITAS & $\mathbf{0} / \mathbf{1}$ & $1 / 1$ & $\mathbf{0} / \mathbf{1}$ \\
\hline Cordaites (Noegg.) hislopi & $\mathrm{x}$ & $\mathrm{x}$ & \\
\hline Glossopteris ampla & $\mathrm{x}$ & $\mathrm{x}$ & $\mathrm{x}$ \\
\hline G. argentina & & $\mathrm{x}$ & $\mathrm{x}$ \\
\hline G. browniana & $\mathrm{x}$ & $\mathrm{x}$ & $\mathrm{x}$ \\
\hline G. conspicua var. patagonica & $\mathrm{x}$ & $\mathrm{x}$ & $\mathrm{x}$ \\
\hline G. damudica & & $\mathrm{x}$ & $\mathrm{x}$ \\
\hline G. indica & & $\mathrm{x}$ & $\mathrm{x}$ \\
\hline G. retifera & & $\mathrm{x}$ & $\mathrm{x}$ \\
\hline G. stipanicicii & $\mathrm{X}$ & $\mathrm{x}$ & \\
\hline G. stricta & & $\mathrm{x}$ & \\
\hline Gangamopteris angustifolia & $\mathrm{X}$ & $\mathrm{x}$ & \\
\hline G. castellanosii & $\mathrm{x}$ & $\mathrm{x}$ & \\
\hline
\end{tabular}




\begin{tabular}{|c|c|c|c|}
\hline G. mosesii & $X$ & $\mathrm{X}$ & \\
\hline G. obovata & $\mathrm{x}$ & $\mathrm{x}$ & \\
\hline Palaeovittaria kurzi & & $\mathrm{x}$ & \\
\hline Vertebraria sp. & $\mathrm{x}$ & $\mathrm{x}$ & \\
\hline Bifariala cf. B. intermittens & & $\mathrm{x}$ & \\
\hline Dictyopteridium costatum & & $\mathrm{x}$ & \\
\hline D. natalensis & & $\mathrm{x}$ & \\
\hline D. sporiferum & & $\mathrm{x}$ & \\
\hline Gonophylloides semnes & & $\mathrm{x}$ & \\
\hline Ottokaria sp. & & $\mathrm{x}$ & \\
\hline Plumsteadia pedicellata & & $\mathrm{x}$ & \\
\hline Scutum cf. S. elongatum & & $\mathrm{x}$ & \\
\hline Senotheca sp. & & $\mathrm{x}$ & \\
\hline Lidgettonia africana & & $\mathrm{x}$ & \\
\hline ?Arberia sp. & & $\mathrm{x}$ & \\
\hline Escamas tipo A & & $\mathrm{x}$ & \\
\hline Escamas tipo B & & $\mathrm{x}$ & \\
\hline Escamas tipo $\mathrm{C}$ & & $\mathrm{x}$ & \\
\hline Coniferofitas a determinar & & $\mathrm{x}$ & \\
\hline Samaropsis golondrinensis & & $\mathrm{x}$ & \\
\hline GYMNOSPERMOFITAS & $10 / 32$ & $32 / 32$ & $7 / 32$ \\
\hline Megistophyllum leanzai & $\mathrm{x}$ & $\mathrm{x}$ & \\
\hline Chiropteris harrisii & & $\mathrm{x}$ & \\
\hline INCERTAE SEDIS & $1 / 2$ & $2 / 2$ & $0 / 2$ \\
\hline Total taxones & $18 / 65$ & 63/65 & $15 / 65$ \\
\hline
\end{tabular}

Una de las características de la flora de la Formación La Golondrina, es la abundancia y variabilidad de especímenes presentes en el miembro medio (Laguna Polina), en comparación con aquellos de los otros dos miembros (Cuadro IV). Como se puede observar a través de los números finales, casi el total de las especies reconocidas para la Formación La Golondrina provienen de ese miembro (63 taxones de un total de 65), mientras que un número considerablemente menor (18 y 15 taxones de un total de 65) fueron registrados para el miembro inferior y superior, respectivamente. Asimismo, la presencia de helechos y gimnospermofitas (representadas por las glossopterídeas 
mayormente) predomina sobre el resto de los grupos (esfenofitas, licófitas, pteridospermas, y otros), siendo éste un patrón común en los tres miembros (Cuadro IV).

Esto podría responder principalmente a dos factores: (1) El miembro medio posee una extensión areal de afloramiento mayor a la reconocida hasta el momento para los otros dos miembros. Esto genera en consecuencia, que la mayor parte del material colectado provenga del miembro Laguna Polina; y (2) el estado de preservación de los elementos fósiles es considerablemente mejor para aquellos provenientes del miembro medio en comparación con la hallada en los miembros inferior y superior, por lo que subsecuentes campañas han sido llevadas a cabo poniendo un mayor énfasis en la búsqueda de material novedoso en las áreas donde aflora este miembro (por ejemplo, Laguna Polina, Lagunas Castellanos, Laguna de los Fósiles, etc).

Cabe destacar además, que las litologías del miembro medio poseen un mayor potencial paleontolólogico, al ser éstas de un grano predominantemente más fino (psamítico a pelítico), en comparación con los de los otros dos miembros, donde predominan litologías conglomerádicas y psamíticas gruesas, con escasos niveles de litologías más finas. Esto conlleva también a su relación con el ambiente de depositación para cada uno de los miembros, los cuales serán discutidos en la próxima sección (Capítulo 6).

\section{4 - Potencial como indicadores bioestratigráficos de los géneros y especies} presentes en la Formación La Golondrina

Para considerar la edad de las asociaciones florísticas de la Formación La Golondrina, se discutirán a continuación la distribución temporal y geográfica de los géneros y especies reconocidos para la Formación La Golondrina en esta tesis. Además, se hará hincapié en las características biogeográficas y estratigráficas de relevancia, con especial énfasis en aquellas especies que son comunes a las distintas cuencas nombradas en 
este estudio (Fig. 10). En el Anexo I, se indica la presencia/ausencia de cada género y especie en las cuencas analizadas.

SPHENOPHYLLUM: Género de distribución cosmopolita presente a partir del Devónico Superior, que tuvo su mayor desarrollo en el Carbonífero, y cuya presencia se hace menos visible hacia finales del Pérmico (Boureau, 1964). Su utilidad a nivel genérico como índice bioestratigráfico es baja, sin embargo, a nivel específico se puede señalar que $S$. speciosum (=Trizygia speciosa, ver 5.6) es una especie común en todo Gondwana (Maheshwari, 1968b; Lacey et al., 1974, 1975; Lacey, 1978; McLoughlin, 1992; Anderson y Anderson, 1985; Prevec et al., 2010; Srivastava y Agnihotri, 2010b), con mayor presencia en el Pérmico superior. El mismo patrón se observó para las cuencas argentinas, donde a excepción de la Cuenca Tepuel Genoa (Archangelsky y Cúneo, 1984), esta especie no fue registrada en ninguna de las cuencas de edad Pérmico Inferior. Por su parte, S. thonii es una especie de escasa presencia en el resto de las cuencas gondwánicas, donde únicamente se la registró en Sudáfrica (le Roux, 1976).

ANNULARIA. Común durante el Paleozoico Tardío, sobretodo en el cinturón paleoecuatorial (Banerjee et al., 2009), y con menor registro en el Gondwana, este género se habría desarrollado preferentemente en ambientes cálidos y húmedos. Annularia kurtzii se ha registrado en La Golondrina y en el Pérmico Inferior de la India (Banerjee et al., 2009).

NEOCALAMITES. Este género se habría distribuído ampliamente por todo el mundo durante el Triásico y Jurásico. El espécimen de La Golondrina (descripto por Escapa y Cúneo, 2006) representa el primer registro para el Pérmico del Gondwana, y sigue siendo el único reconocido hasta el momento.

PARASCHIZONEURA. Género poco común, ha sido citado hasta el momento para el Triásico Inferior de Australia (Holmes, 2001) y Pérmico Superior de Rusia (Boureau, 1964) 
hasta el momento. Schizoneura africana (Anderson y Anderson, 1985), de gran similitud con el material proveniente de La Golondrina, fue registrado para el Pérmico MedioSuperior de Sudáfrica.

PHYLLOTHECA. Este género, cuyo rango estratigráfico abarca desde el Carbonífero Superior al Cretácico (Gee, 1989), estaba ampliamente distribuido en todo Gondwana durante el Paleozoico Tardío (Boureau, 1964).

LILPOPIA. Esta fructificación se registra hasta el momento, únicamente para el Pérmico Inferior de Europa (Boureau, 1964; Lipiarski, 1972a, b; Kerp, 1984). El ejemplar de La Golondrina representa la primera evidencia de su presencia en el Gondwana.

ASTEROTHECA. Este género tiene una amplia distribución temporal (Carbonífero a Triásico), y espacial (cosmopolita) (Boureau, 1975). Las especies descriptas para la Formación La Golondrina son compartidas mayormente con la Cuenca Tepuel Genoa (Archangelsky y Cúneo, 1984). Además, Asterotheca anderssonii fue registrada en la Formación Tasa Cuna (Córdoba) (Archagelsky y Cúneo, 1984), A. piatnitzkyi en Brasil (Vieira et al., 2007), y A.cf. singeri, en Sudáfrica (le Roux, 1976).

DIZEUGOTHECA. Además de estar presente en La Golondrina, este género se registra en el Pérmico de Bolivia (cuenca no analizada en este estudio), Pérmico Superior de Brasil (Arrondo, 1967; Cazzulo-Klepzig, 1978; Rösler, 1978a, b; Vieira et al., 2004, 2005a, b), y de la India (Goswami et al., 2006a), por lo que su presencia podría ser utilizada como indicadora del Pérmico Tardío. Las especies descriptas para La Golondrina son exclusivas de esta formación.

PECOPTERIS. Género permocarbonífero y cosmopolita (Boureau, 1975). La utilización de una nomenclatura abierta para asignar a las especies de La Golondrina no permite inferir su ubicación estratigráfica en tanto no sean halladas frondes estériles en conexión o íntimamente asociadas a frondes fértiles, con lo que se las pueda ubicar específicamente. 
DICHOTOMOPTERIS. Presente en el Pérmico de la India (Goswami et al., 2006a, c) y el Pérmico Superior de Australia (McLoughlin, 1992). De las especies descriptas para la Formación La Golondrina, únicamente D. ovata es hallada en la cuenca de Tepuel Genoa.

DAMUDOPTERIS. La especie presente en La Golondrina, Damudopteris bengalensis, se registra en el Pérmico Inferior de las Cuencas Tepuel Genoa y Paganzo (Archangelsky et al., 2004), y Pérmico Superior de la India (Goswami et al., 2006a).

SPHENOPTERIS. Género de amplia distribución geográfica (cosmopolita) presente durante todo el Carbonífero y Pérmico (Boureau, 1975). Nuevamente, al no conocerse la parte fértil de $S$. sp II, se prefiere mantener abierta su designación específica, por lo que su utilidad como índice bioestratigráfico es nula.

CORDAITES (=NOEGGERATHIOPSIS). Género cosmopolita, presente durante el Carbonífero Superior y Pérmico (Archangelsky y Arrondo, 1973; Archangelsky et al., 1981b; Anderson y Anderson, 1985; McLoughlin, 1992; McLoughlin y Drinnan, 1996; Melchor y Césari, 1997; Goswami et al., 2006b; Singh et al., 2007; Iannuzzi, 2010).

VERTEBRARIA. Órgano rizoidal de las glossopterídeas, este género es común en todo el Pérmico de Gondwana, con mayor presencia en el Pérmico Superior (McLoughlin et al., 2005; Retallack et al., 2005; Goswami et al., 2006a, b; Prevec et al., 2010; Shi et al., 2010; Srivastava y Agnihotri, 2010b).

PALAEOVITTARIA. Género considerado como una forma primitiva de glossopteridal, su registro es más común en el Pérmico Inferior de Gondwana, aunque se han hallado especímenes asignables a este género en el Pérmico Medio y Superior también (India, por ejemplo) (Menéndez, 1962; Anderson y Anderson, 1985; Pant, 1996; Singh, 2000; Goswami et al., 2006a, b).

GANGAMOPTERIS. Al igual que Palaeovittaria, éste es un género que se encuentra en mayor abundancia y diversidad en el Pérmico Inferior de todo Gondwana (Rigby, 1972; Archangelsky y Cúneo, 1984; Anderson y Anderson, 1985; Melchor y Césari, 1997; Singh, 
2000; Goswami et al., 2006a,b; Ianuzzi et al., 2010; Srivastava y Agnihotri, 2010a). Sin embargo, también presenta registros dudosos en el Pérmico Superior de la India (Srivastava y Agnihotri, 2010a). A excepción de G. castellanosii, el resto de las especies de la Formación La Golondrina son compartidas con cuencas del resto de Sudamérica y del Gondwana, sin presentar ningún valor bioestratigráfico en particular.

GLOSSOPTERIS. Las hojas de este género son el elemento más característico de todas las floras Gondwánicas a lo largo de todo el Pérmico, por lo que su abundante presencia en estratos rocosos es utilizada como un indicador bioestratigráfico para el período Pérmico (Menéndez, 1962; Rigby, 1962; Archangelsky y Arrondo, 1965; Lacey et al., 1974; Chandra y Surange, 1979; Archangelsky et al., 1981b; Archangelsky y Cúneo, 1984; Gee, 1989; McLoughlin, 1990b, 1994a, b; Melchor y Césari, 1997; Singh, 2000; McLoughlin et al., 2005; Goswami et al., 2006a, b; Iannuzzi, 2010; Srivastava y Agnihotri, 2010b). Sin embargo, su utilidad como indicador temporal en una escala más acotada (Edad o menor) pierde valor por la falta de una clara jerarquización en la elección de caracteres, lo que genera una abundancia ficticia de especies para este género.

BUMBUDENDRON. Su presencia hasta el momento ha sido registrada en Sudamérica (Argentina y Brasil), desde el Carbonífero al Pérmico Inferior (Archangelsky et al., 1981; Arrondo y Petriella, 1978, 1985; Gutiérrez et al., 1986; Archangelsky et al., 1996a; Salvi et al., 2008).

CYCLODENDRON. Género presente en el Carbonífero y Pérmico del Gondwana, se registra en el Pérmico de India, Australia, Sudáfrica, Brasil, Paraguay (Kräusel, 1928; Lejal-Nicol y Bernardes de Oliveira, 1979; Anderson y Anderson, 1985; Rayner, 1985; Herbst, 1986; Beeston, 1990; Cúneo, 1996; Goswami et al., 2006b, c), y Argentina, en las cuencas de Tepuel Genoa y La Golondrina (Cúneo, 1996).

CAULOPTERIS. Morfogénero utilizado para designar tallos pertenecientes a helechos de la familia Marattiaceae (Pfefferkorn, 1976), su utilidad bioestratigráfica es baja, por poseer 
un amplio biocrón (Carbonífero y Pérmico). Fue registrado en las cuencas argentinas de La Golondrina y Tepuel Genoa (Cúneo, 1987).

EREMOPTERIS. Género conocido desde el Carbonífero al Pérmico Inferior para Norteamérica, Europa, y Sudamérica (Archangelsky, 1959b; Boureau, 1975).

CHIROPTERIS. Chiropteris es un género que posee una amplia distribución geográfica (Catahysia y Gondwana), pero no presenta ninguna utilidad como indicador bioestratigráfico debido a su amplio biocrón, que abarca desde el Carbonífero al Triásico (Herbst et al., 2001; Wang et al., 2003; Wang y Pfefferkorn, 2009).

MEGISTOPHYLLUM. Este género fue propuesto por Archangelsky (1959a) para ubicar un único ejemplar recuperado de la Laguna Salada. Si bien nuevos ejemplares (aunque fragmentarios) han sido hallados en las colecciones (Fac. de Cs. Naturales y Exactas, UBA) y posteriores campañas llevadas a cabo recientemente por la autora, su posición sistemática sigue siendo incierta. Dado que es un género hasta ahora únicamente reconocido en la Formación La Golondrina, no tiene utilidad bioestratigráfica alguna.

CONÍFERAS indeterminadas. Los primeros ejemplares de coniferofitas registrados para la Formación La Golondrina han sido recientemente hallados por la autora (campaña 2010). Su estado mayormente fragmentario y la ausencia de estructuras fértiles bien preservadas no permitió asignarlas con certezas a un género determinado, por lo que su presencia en la formación no reviste de importancia bioestratigráfica por el momento.

SAMAROPSIS. Este género tiene una distribución cosmopolita (regiones gondwánicas y extragondwánicas), abarcando todo el Paleozoico Superior (A. Archangelsky, 2000).

Según Adendorff (2005: 355), un elemento es de utilidad como indicador bioestratigráfico cuando es "fácilmente identificable a partir de características propias distinguibles, posee una distribución geográfica amplia, y se encuentra restringido a rocas 
de un rango temporal acotado". Del listado previo, se desprende que muchos de los elementos a nivel género no son de mucha utilidad como indicadores bioestratigráficos (Asterotheca, Pecopteris, Annularia, Vertebraria, Cyclodendron, Chiropteris, Caulopteris, etc.), pero sí lo son a nivel especie, por ejemplo, Sphenophyllum (S. speciosum), indicativa del Pérmico superior. Por otro lado, en La Golondrina también hay géneros de importancia bioestratigráfica a gran escala, como ser Glossopteris (y afines, Palaeovittaria, y Gangamopteris) géneros cuya presencia es mayormente indicativa del Período Pérmico en todo el Gondwana. Asimismo, Glossopteris pierde valor estratigráfico a nivel específico por lo que fuera mencionado previamente: la inconsistencia en la definición de los caracteres diagnósticos para su asignación específica genera un número irreal de especies (Chandra y Surange, 1979; Kovâcs-Endrödy, 1979, 1984; Gee, 1989; McLoughlin, 1990b; Adendorff, 2005), lo que se traduce en la pérdida de su potencial valor como índice bioestratigráfico. Un caso similar se da en aquellos elementos que tienen una asignación sistemática aún debatida, ya sea por errores en la definición de la Especie tipo, o inconsistencias en las diagnosis que las definen. Ejemplos de estos se dan para helechos estériles vs. fértiles como Sphenopteris (="Neomariopteris"=Damudopteris). Aquellos elementos que son exclusivos para una Formación no tienen utilidad, al no poder ser correlacionados con los de otras cuencas, por lo cual su utilidad bioestratigráfica queda también descartada (Megistophyllum leanzai, y especies de Dizeugotheca, entre otros). Estos elementos, sin embargo, sí pueden ser útiles para la asignación de biozonas (por ejemplo, Dizeugotheca waltonii) en caso de ser abundantes. Por último, elementos fragmentarios, desasociados, y únicos o escasos en número (como ser Lilpopia) no presentan utilidad hasta tanto no se hallen más y mejores ejemplares.

Debido a todas las razones expuestas, las fructificaciones de glossopterídeas serían los elementos pérmicos más confiables para correlaciones bioestratigráficas (Adendorff, 2005), aunque algunos autores (Rigby en Bajpai, 2001) consideran que tanto Glossopteris como sus partes serían más bien indicadores de condiciones ambientales que estratigráficos. En esta tesis se acepta el punto de vista de Adendorff (2005), por lo que a continuación, se 
expone la importancia de cada fructificación como indicador bioestratigráfico para la Formación La Golondrina, y las razones por las cuales se las considera como tales.

DICTYOPTERIDIUM. Género típico del Pérmico Superior de Gondwana. Utilizado como un buen indicador bioestratigráfico para el Pérmico Tardío, especies de este género han sido halladas en India (Surange y Chandra, 1973a), Sudáfrica (Benecke, 1976, Adendorff, 2005), Australia (Rigby, 1978; McLoughlin, 1990a, b) y Sudamérica (Archangelsky, 1992; Melchor y Césari, 1997). Fue precisamente a partir de la identificación de Dictyopteridium cf. sporiferum en sedimentos de la Formación La Golondrina, que Archangelsky (1992) sugirió que la formación era más joven (Cisuraliano tardío - Lopingiano) que lo aceptado hasta el momento (Cisuraliano temprano) (Archangelsky, 1959a; Arrondo, 1972; Archangelsky y Cúneo, 1984). Dictyopteridium tiene un alto potencial como indicador bioestratigráfico para el Pérmico Superior debido a su rango temporal acotado, y morfología característica, aunque aquellos elementos mal preservados pueden conllevar a la clasificación errónea por especímenes de Plumsteadia (Adendorff, 2005).

PLUMSTEADIA. El amplio espectro temporal y geográfico (Maheshwari, 1965, 1968a; White, 1964; Rigby, 1962, 1969, 1971, 1978; Kyle, 1974; Chandra y Surange, 1977; Srivastava, 1978; McLoughlin, 1990a; Lacey et al., 1975; Benecke, 1976; Anderson y Anderson, 1985; Adendorff, 2005; Cariglino et al., 2009) que presenta este género lo convierte en un taxón de baja a nula utilidad como índice bioestratigráfico.

GONOPHYLLOIDES. Género hasta el momento registrado en el Pérmico Inferior de India, Sudáfrica, Australia, y con duda para el Pérmico Medio de Antártida. El de La Golondrina es el primer registro de este género para Sudamérica. Su potencial como indicador bioestratigráfico es alta, dada las particulares características que lo distinguen (base cordada, ala festoneada delgada). 
SCUTUM. Este género ha sido registrado en el Pérmico Superior de India (Surange y Chanda, 1974a), Australia (McLoughlin, 1990a), y el Pérmico Inferior de Sudáfrica (Plumstead, 1952, 1956a, 1958; Anderson y Anderson, 1985; Adendorff, 2005). Como ocurre con Plumsteadia, el amplio espectro temporal y geográfico que presenta este género hace que tenga poca utilidad como índice bioestratigráfico. Sin embargo, a nivel específico, puede ser un indicador más preciso. En el caso de Scutum elongatum Surange y Chandra, su registro proviene del Pérmico Superior de India.

BIFARIALA. Los elementos previamente asignados como Hirsutum intermittens en las distintas localidades Gondwánicas donde se hayan hallado deben ser revisadas, y de ser necesario, reubicadas en el nuevo género Bifariala (ver Adendorff, 2005; Prevec et al., 2008). Hasta el momento, presenta registro en el Pérmico Inferior de Sudáfrica, por lo que el material descripto para La Golondrina representa una novedad en su distribución geográfica.

SENOTHECA. Género presente en el Pérmico Superior de India, Australia, y Antártida (Banerjee, 1969; Rigby, 1978; McLoughlin, 1990b). El ejemplar de La Golondrina es el primer representante de este género para Sudamérica. Debido a su particular morfología (fructificación elongada de receptáculo reducido con hileras de óvulos a los lados, y ala delgada ancha), y su amplia distribución en Gondwana, Senotheca puede ser considera un indicador bioestratigráfico para el Pérmico Tardío.

OTTOKARIA. Género común en el Pérmico Inferior de Gondwana (White, 1908; Thomas, 1921; Plumstead, 1956b; Menéndez, 1962; Srivastava, 1978; Pant y Nautiyal, 1984; Barreda and Césari, 1995; Bernardes de Oliveira et al., 2000; Adendorff, 2005), aunque en menor medida, también se registra en el Pérmico Medio de Antártida (Schopf, 1976) y Superior de India y Australia (Banerjee, 1978; White, 1978; McLoughlin, 1990b). Más precisamente, O. inglisensis McLoughlin (semejante al ejemplar Lil 101) proviene del Pérmico Superior de Australia (McLoughlin, 1990b), mientras que O. zeilleri Pant y Nautiyal (semejante al ejemplar MPM-Pb 4852), del Pérmico Inferior de India. Su 
potencial como indicador bioestratigráfico a nivel género es bajo dado su amplia distribución temporal, sin embargo, a nivel específico, puede tener utilidad.

LIDGETTONIA. Género típico del Pérmico superior, presente en Australia, India y Sudáfrica (Thomas, 1958; Surange y Maheshwari, 1970; Holmes, 1974; Surange y Chandra, 1974a, b, 1975; Lacey et al., 1975; Chandra y Surange, 1977; White, 1978; Anderson y Anderson, 1985; Adendorff, 2005; Prevec et al., 2009). El ejemplar hallado en La Golondrina es el primer registro para Sudamérica. Utilizado como indicador bioestratigráfico para el Pérmico Tardío, dada su morfología particular y el rango temporal acotado que presenta.

ARBERIA. Género típico del Pérmico Inferior, se encuentra ampliamente distribuído en todo Gondwana (White, 1908; Rigby, 1972; Archangelsky y Arrondo, 1973; Chandra y Srivastava, 1981; Archangelsky et al., 1995; Bernardes de Oliveira et al., 2000; Adendorff, 2005; Gallego et al., 2008), a excepción de la Antártida, por lo que se lo considera un útil indicador bioestratigráfico para el Pérmico Temprano. Por el momento, y hasta tanto no se hallen ejemplares mejor preservados, su presencia en la Formación La Golondrina es dudosa.

A partir de todo lo expuesto, se puede señalar que las fructificaciones de glossopterídeas halladas en la Formación La Golondrina - todas ellas provenientes del miembro medio - abarcan, en conjunto, todo el Pérmico. Sin embargo, entre los géneros más comunmente considerados como indicadores bioestratigráficos confiables, debido a que han sido consistentemente hallados en las mismas unidades litoestratigráficas se pueden mencionar a Dictyopteridium, Lidgettonia, y Senotheca, todos ellos presentes en el Pérmico Superior. El género Arberia es también considerado un indicador bioestratigráfico confiable del Pérmico Inferior, sin embargo, su presencia en la Formación La Golondrina no está del todo confirmada. A nivel específico, el registro de Scutum cf. S. elongatum (especie del Pérmico Superior de India), y un ejemplar de Ottokaria (que si bien por su 
estado fragmentario no fue específicamente asignado, pero por las características que presenta sería afín a $O$. inglisensis) aportarían de más evidencias para especular con una edad Pérmico Medio-Tardío al menos para el miembro Laguna Polina.

\section{5 - Discusión general}

\section{$\underline{\text { Propuesta bioestratigráfica para la Formación La Golondrina }}$}

A partir del hallazgo de Asterotheca singeri tanto en el miembro medio (Laguna Polina) como en el inferior (Laguna Lillo), la biozona homónima, que caracterizaba al miembro superior (Dos Hermanos) de la Formación La Golondrina, perdería validez tal como fuera definida originalmente ("Asterotheca singeri es la única especie exclusiva de la zona" Archangelsky y Cúneo, 1984: 147). Por otra parte, la zona de Dizeugotheca waltonii, asignada para definir la flora del miembro medio de la Formación La Golondrina, ya no tiene con exclusividad a la especie Asterotheca golondrinensis, hallada en la cuenca de Tepuel Genoa. Asimismo, Glossopteris retifera y Gangamopteris castellanosii fueron encontradas en el miembro superior y el inferior, respectivamente, por lo que tampoco servirían como elementos que caractericen a la zona de D. waltonii. Dadas estas condiciones, se sugiere redefinir a las biozonas propuestas por Archangelsky y Cúneo (1984; ver Cuadro I), tomando en cuenta los nuevos elementos reconocidos para el miembro inferior también (Cuadro V).

De los tres tipos de biozonación aceptados por el Código Argentino de Estratigrafía (1992), la de asociación sería la que mejor define la distribución estratigráfica de las distintas especies presentes en la Formación La Golondrina, dado que como ocurrió recientemente a partir de las campañas al área, la presencia/ausencia de los taxa en los distintos miembros no está definida. A partir de esto, se podrían definir tres biozonas, una para cada uno de los miembros (inferior, medio y superior), caracterizados de la siguiente forma: 
Biozona 1: No presenta especies exclusivas (se excluye a Lilpopia sp. por ser un único ejemplar), pero sí se caracteriza por la predominancia de Gangamopteris por sobre Glossopteris, la aparición de Megistophyllum leanzai, y la presencia de helechos pecopterídeos mayormente de pínnulas pequeñas (ej., Asterotheca sp. 3). Es la primera vez que se describen fósiles para el miembro inferior, por lo que se sugiere mantener a esta biozona bajo una denominación abierta, hasta que se realicen más hallazgos que la puedan definir con mayor precisión (Cuadro V).

Se propone como sección tipo para esta biozona al Perfil Laguna Lillo descripto por Jalfin (1987: 27), paraestratotipo de la Formación La Golondrina realizado en dicha laguna donde se encuentran representados los miembros inferior y medio.

Biozona 2 (biozona de Dizeugotheca waltonii de Archangelsky y Cúneo, 1984). La biozona de $D$. waltonii fue originalmente propuesta para definir la asociación del miembro medio Laguna Polina (sensu Jalfin, 1987). Esta zona se caracteriza por la presencia exclusiva de los taxones Annularia kurtzii, Dichotomopteris hirundinis, D. ovata, Glossopteris stricta, y Eremopteris golondrinensis. A su vez, marca la aparición de Dizeugotheca waltonii, y en ella predominan las fructificaciones de glossopterídeas (hasta el momento, sólo halladas en el miembro medio). Por último, es el techo de todas las especies de Gangamopteris, las cuales se ven claramente reemplazadas en número y abundancia por las Glossopteris. La asociación caracterizada por Archangelsky y Cúneo (1984) se ratifica en este estudio, aunque se sugiere mantener abierta su denominación, dado que la especie que le da nombre (D. waltonii), no es exclusiva de ésta, ya que su rango alcanza el miembro superior (Cuadro V).

Para esta biozona, se propone mantener como sección tipo al Perfil Laguna Polina de Jalfin (1987: 25), holoestratotipo de la Formación La Golondrina, realizado en la orilla norte de dicha laguna, y donde se encuentran representados los miembros medio y superior.

Biozona 3 (biozona de Asterotheca singeri de Archangelsky y Cúneo, 1984). La biozona propuesta por Archangelsky y Cúneo (1984) definía originalmente la asociación 
específicamente más empobrecida del miembro superior (sensu Jalfin, 1987). Al ser hasta el momento $A$. singeri la especie exclusiva, le daba nombre a la biozona. Sin embargo, el reciente hallazgo de esta especie en los miembros inferior y medio de la formación, invalidarían su denominación, por lo que también se propone dejar su denominación abierta. Esta biozona se caracteriza (además de un claro empobrecimiento de la flora en general comparado con la biozona anterior), por la predominancia de las especies Glossopteris damudica, G. retifera, y Asterotheca golondrinensis, la total ausencia de especies de Gangamopteris, y por ser el techo de distribución de la especie Asterotheca anderssonii (Cuadro V).

Para la biozona 3, se propone mantener como sección tipo al Perfil Dos Hermanos (Jalfin, 1987: 28), paraestratotipo de la Formación La Golondrina, realizado en la localidad de Dos Hermanos, donde se encuentra representado el miembro superior.

Cuadro V - Nueva propuesta bioestratigráfica para la Formación La Golondrina, comparada con las zonas florísticas del Pérmico argentino, basado en Archangelsky y Cúneo (1984) y Archangelsky et al. (1996b, c). Edades de acuerdo a la IUGS (2009).

\begin{tabular}{|c|c|c|c|c|c|c|c|c|}
\hline \multirow{2}{*}{\multicolumn{3}{|c|}{ Cuenca }} & Santa Cruz & Chubut & $\begin{array}{c}\text { Córdoba, La Rioja, } \\
\text { San Luis }\end{array}$ & $\begin{array}{l}\text { Mendoza, } \\
\text { La Pampa }\end{array}$ & Buenos Aires & Islas Malvinas \\
\hline & & & La Golondrina & Tepuel Genoa & Paganzo & San Rafael & Sas. Autrales & Malvinas \\
\hline \multirow{10}{*}{$\frac{O}{.0}$} & \multirow{3}{*}{ 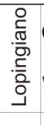 } & \multirow{3}{*}{$\begin{array}{c}\text { Changhsingiano } \\
253.8 \pm 0.7 \\
\text { Wuchiapingiano } \\
260.4 \pm 0.7\end{array}$} & Fm. La Juanita? & & & & \multirow{10}{*}{ Glossopteris } & \multirow{10}{*}{ Glossopteris } \\
\hline & & & Biozona 3 & & & & & \\
\hline & & & \multirow{3}{*}{ Biozona 2} & & & & & \\
\hline & $\stackrel{\circ}{\sim}$ & Capitaniano & & & & & & \\
\hline & $\frac{\frac{10}{2}}{\frac{2}{\frac{10}{6}}}$ & $\begin{array}{c}265.8 \pm 0.7 \\
\text { Wordiano } \\
268.0 \pm 0.7\end{array}$ & & & & & & \\
\hline & ०े & Roadiano & \multirow{5}{*}{ Biozona 1} & & & & & \\
\hline & \multirow{4}{*}{ 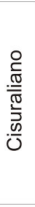 } & $\begin{array}{l}\text { Kunguriano } \\
275.6 \pm 0.7\end{array}$ & & & & & & \\
\hline & & $\begin{array}{l}\text { Artinskiano } \\
284.4 \pm 0.7\end{array}$ & & \multirow{2}{*}{$\begin{array}{l}\text { Ginkgoites } \\
\text { eximia }\end{array}$} & & & & \\
\hline & & Sakmariano & & & & & & \\
\hline & & $\begin{array}{l}294.6 \pm 0.8 \\
\text { Asseliano }\end{array}$ & & $\begin{array}{c}\text { Nothorhacopteris } \\
\text { chubutiana }\end{array}$ & Gangamopteris & Gangamopteris & & \\
\hline
\end{tabular}




\section{$\underline{\text { Edad para la Formación La Golondrina }}$}

Entre las numerosas especies novedosas para la Formación La Golondrina, figuran 9 fructificaciones de glossopterídeas, con la potencial presencia de un género más (Arberia), de confirmarse con material mejor preservado su presencia definitiva. Curiosamente, muchas de estas fructificaciones fueron halladas a través de la revisión de material de colección (LIL y BA-Pb principalmente). El hallazgo y posterior reconocimiento de tales ejemplares es de suma importancia para el análisis bioestratigráfico de la flora de La Golondrina, debido a que su presencia en otras localidades gondwánicas permite su correlación temporal con mayor precisión que utilizando elementos aislados o estériles.

Además del uso de especies determinadas como indicadoras cronoestratigráficas, existen algunas evidencias de base biológica que suelen ser utilizadas como indicadores temporales. Por ejemplo, se suele considerar que existe una correlación positiva entre el número y complejidad de las glossopterídeas estériles y fértiles con el avance temporal a lo largo del Pérmico (Bajpai, 2001; Retallack et al., 2005; Shi et al., 2010). La presencia de abundantes fructificaciones en la Formación La Golondrina aportaría evidencia para inferir una edad neopermica. Al considerar a las fructificaciones de la Formación La Golondrina como indicadores bioestratigráficos de utilidad, surgen problemas de importancia relacionados en cuanto al número en la que éstas se hallan (con escasas excepciones, hay un solo ejemplar de cada especie), y la preservación que presentan (ya sea por su estado fragmentario o mala preservación en general del ejemplar). Sin embargo, la inequívoca presencia de géneros típicos del Pérmico Tardío como Dictyopteridium, Lidgettonia y Senotheca, proveen evidencia de peso suficiente como para estimar una edad pérmica media-tardía con seguridad a partir del miembro medio (Laguna Polina) de la Formación La Golondrina (Cuadro V).

Otras evidencias comúnmente utilizadas como indicadores temporales por algunos autores incluyen la evolución en el patrón de venación de las hojas de Glossopteris, donde se considera como "avanzado" la presencia de celdas bien definidas, con anastomosis

numerosas y complejas (Anderson y Anderson, 1985; Srivastava, 1992; Melchor y Césari, 
1997; Singh, 2000; Maheshwari y Bajpai, 2001; Goswami et al., 2006b; Iannuzzi, 2010; Srivastava y Agnihotri, 2010a, b). También se considera la presencia de Palaovittaria y Gangamopteris como indicadores del Pérmico más temprano (Anderson y Anderson, 1985; Pant, 1996; Srivastava y Agnihotri, 2010a), aunque su ocurrencia - si bien considerablemente en menor abundancia - también se ha registrado en el Pérmico Medio y Superior en distintas localidades de Gondwana (Retallack et al., 2005; Srivastava y Agnihotri, 2010a).

Por otra parte, Dizeugotheca es un género que se encuentra mayormente en rocas del Pérmico Superior (Rösler, 1978a, b; Vieira et al., 2004, 2005a, b; Goswami et al., 2006a). En la Formación La Golondrina está representado hasta el momento por tres especies. Semejante es el caso de Sphenophyllum speciosum (=Trizygia speciosa) cuya ocurrencia es mayormente indicativa de un Pérmico avanzado, al ser una especie hallada en abundancia en estratos del Pérmico Superior en todo Gondwana (Anderson y Anderson, 1985; McLoughlin, 1992; Goswami et al., 2006b; Prevec et al., 2010; Shi et al., 2010; Srivastava y Agnihotri, 2010b).

La presencia de fructificaciones típicamente reconocidas para el Pérmico Inferior de Gondwana, como ser Arberia, Gonophylloides y Bifariala, plantean un problema al tratar de acotar la edad para la Formación La Golondrina. Estos géneros, especialmente Arberia, son reconocidos como buenos indicadores del Pérmico Temprano (Rigby, 1972; Chandra y Srivastava, 1981; Archangelsky et al., 1995; Bernardes de Oliveira et al., 2000; Adendorff, 2005; Gallego et al., 2008). Sin embargo, cabe destacar que la presencia de Arberia no está totalmente confirmada para la Formación La Golondrina, ya que como ha sido previamente mencionado, el material en el cual se basa su posible registro se encuentra pobremente preservado. Respecto a Gonophylloides y Bifariala, Adendorff (2005) y Prevec et al. (2008) redescribieron y emendaron las diagnosis de ambos géneros, por lo que se sugiere que hasta en tanto no haya sido revisado todo el material de las distintas localidades gondwánicas que registren 'Hirsutum' intermittens (ahora Bifariala intermittens) y especímenes de Plumsteadia que presenten una base cordada y ala marcada, no sean 
utilizados como indicadores bioestratigráficos. Una vez llevada a cabo la revisión de dicho material y en caso de confirmarse su presencia en el Pérmico Inferior del resto de Gondwana, el de la Formación La Golondrina podría estar representando el primer registro para el neopérmico, perdiendo su utilidad como indicadores bioestratigráficos.

Asimismo, está generalmente aceptado que aquellas floras con una baja biodiversidad se desarrollaron o muy tempranamente durante el Pérmico o en momentos posteriores pero bajo condiciones menos favorables, como aquellas que se desarrollaron a altas latitudes (Gee, 1989; McLoughlin et al., 1997, 2005; Retallack et al., 2005; Shi et al., 2010). Las tafofloras de las localidades antárcticas serían un claro ejemplo de lo segundo; la mayoría presenta elementos claramente representativos del Pérmico Tardío (por ejemplo, Senotheca, Rigbya, Dictyopteridium), pero el número de especies presentes es considerablemente menor al de aquellas floras que se desarrollaban en el mismo tiempo, a latitudes más favorables. Estudios palinológicos y sedimentológicos llevados en las localidades antárcticas aportan aún más evidencia para confirmar una edad Pérmica mediatardía para estas tafofloras (McLoughlin et al., 2005; Retallack et al, 2005). Por otra parte, aquellas floras representativas del Pérmico más Tardío (Lopingiano tardío) también suelen estar pobremente diversificadas, lo que sería indicativo de cambios ambientales tendientes a una aridización (Gastaldo et al., 2005; Prevec et al., 2010; Shi et al., 2010).

La mayoría de las unidades litoestratigráficas argentinas tomadas en cuenta para este estudio representan el Pérmico Temprano (Cuadro I). La única excepción es la Formación Carapacha (Cuenca San Rafael, Provincia de La Pampa). La flora descripta por Melchor y Césari (1997) presenta un alto número de especies de Glossopteris, todas con un patrón de venación complejo, y en esta flora también registraron un ejemplar de Dictyopteridium sporiferum. Si bien ni a nivel genérico como específico se hallaron grandes congruencias entre las tafofloras de La Golondrina con la de Carapacha, a partir de los elementos presentes (Cuadro III), entre las floras pérmicas de la Argentina, la de Carapacha sería la más afín a la de La Golondrina. El registro de nuevas fructificaciones de 
glossopterídeas para la Formación La Golondrina, hace que la afinidad de esta flora con otras floras pérmicas sea mayor con aquellas no sudamericanas. Tanto a nivel genérico, como específico, la mayor cantidad de elementos comunes presentes en La Golondrina se dieron con aquellas floras de las cuencas Pérmicas de India, y cercanamente a éstas, con las de Sudáfrica y Australia (Cuadros II, III; Anexo I).

Claramente, esto está fundado principalmente por las especies de fructificaciones aquí descriptas. Si bien todas las floras consideradas tienen como elementos predominantes las hojas de Glossopteris, es en las cuencas no sudamericanas donde se han registrado mayor número de elementos glossopterídeos fértiles. Es a partir de estos elementos, que se genera una mayor afinidad de la flora de La Golondrina con aquellas no sudamericanas. Posibles razones que puedan explicar esto incluyen un sesgo en los métodos de colección, el difícil acceso a algunas de estas floras (Islas Malvinas), o una menor área de afloramiento expuesta (Antártida, aunque el registro de fructificaciones para las localidades antárcticas es considerablemente numeroso). También, podría influir el hecho que las glossopterídeas se diversificaron con intensidad a partir de fines del Pérmico Temprano, alcanzando su acmé en el Pérmico Medio y Superior, para decaer en número nuevamente hacia fines del Permico. En este trabajo se sostiene que la ausencia de elementos fértiles en la mayoría de las floras pérmicas de Argentina está dada principalmente por un sesgo en la colección, y que a partir de campañas llevadas a cabo en estas formaciones, con un especial énfasis puesto en el hallazgo de fructificaciones, la diversidad de éstas puede aumentar considerablemente. Hasta tanto esto no se realice, la Formación La Golondrina seguirá presentando una mayor afinidad con aquellas floras de India, Sudáfrica y Australia, más que con las de otras cuencas argentinas y sudamericanas.

En base a todo lo mencionado, y tomando en cuenta la distribución estratigráfica de las distintas especies en cada miembro de la Formación La Golondrina (Cuadro IV; Anexo I), se propone acotar los tiempos en que la flora del miembro inferior se habría desarrollado hacia fines del Cisuraliano y principios del Guadalupiano (Artinskiano-Roadiano?), 
mientras que la del miembro medio lo habría hecho desde el Guadalupiano al Lopingiano (Roadiano-Wuchiapingiano?). El miembro superior, por ende, habría tenido su desarrollo a finales del Pérmico, durante el Lopingiano (Wuchiapingiano-Changhsingiano?). Aún desconociéndose cualquier tipo de indicio que pueda ayudar a asignar la edad de la Formación La Juanita (conformantemente suprayacente a la Formación La Golondrina) se propone una edad de Pérmico más superior, casi en el límite con el Triásico para tal formación (Cuadro V).

Entre la evidencia que reforzaría una edad Cisuraliano tardío - Guadalupiano para el miembro inferior (Laguna Lillo) se pueden mencionar la presencia predominante de Gangamopteris spp. sobre Glossopteris spp., la ausencia de especies mayormente representativas del Pérmico Medio-Superior, como Sphenophyllum speciosum, y especies de Dizeugotheca (únicamente D. neuburgiae presente), así como la ausencia total de fructificaciones de glossopterídeas típicas del Pérmico Superior, como Dictyopteridium, Senotheca, o Lidgettonia.

Entre las razones que apoyarían una edad Guadalupiano - Lopingiano para el miembro medio Laguna Polina se cuentan el aumento en la diversidad de especies comparado al miembro inferior, la abundante presencia de tipos de glossopterídeas tanto de sus partes estériles como fértiles, donde se entremezclan especies de Gangamopteris con Glossopteris de tipo avanzado (en cuanto al tipo de venación), fructificaciones típicas del Pérmico más alto (Dictyopteridium, Senotheca, Lidgettonia), y especies comúnmente reconocidas como indicadoras de un Pérmico medio-superior, como Sphenophyllum speciosum y Dizeugotheca spp.

Por último, la disminución en la diversidad de especies en el miembro superior comparada a la que había en el miembro medio, la total ausencia de especies de Gangamopteris, y la presencia de especies de Dizeugotheca, y Sphenophyllum speciosum, aportarían evidencias para suponer una edad Lopingiana para el miembro Dos Hermanos. 
En resumen, la edad propuesta para la Formación La Golondrina abarcaría desde el Cisuraliano tardío al Lopingiano (Cuadro V), reconfirmando lo sugerido por Archangelsky (1992), Archangelsky et al. (1996a, b), Andreis y Archangelsky (1996), y Andreis (2002), y utilizando como escala temporal la propuesta por la IUGS (2009). Esto se evidencia tanto a través de la mezcla de elementos de amplia distribución estratigráfica, como la de unos pocos elementos diagnósticos que puedan ser utilizados para afirmar con una mayor precisión el tiempo en el que la tafoflora de La Golondrina se desarrolló, en este caso, mayormente representados por fructificaciones de glossopterídeas (Dictyopteridium, Lidgettonia, y Senotheca) indicativas del Pérmico Tardío. Hasta el presente, ningún análisis palinológico llevado a cabo para sedimentos de La Golondrina dio resultados que puedan ayudar a establecer con mayor precisión el lapso temporal en el cual la flora de La Golondrina se desarrolló.

\section{6 - ¿Flora de Glossopteris, flora Mixta, o flora de La Golondrina?}

El Paleozoico Superior ha sido históricamente dividido en 4 provincias florísticas mayores (Li, 1986; Archangelsky, 1990; Ziegler, 1990; Wnuk, 1996; McLoughlin, 2001; McAllister Rees et al., 2002; Srivastava y Agnihotri, 2010b): Euroamerica, Angara, Cathaysia, y Gondwana (Fig. 11).

De acuerdo a Wnuk (1996), estas “provincias fitogeográficas” podían ser definidas en base a una distribución paleogeográfica de taxa distintitva, a nivel de familia (por ejemplo, Gigantopterídeas para Cathaysia, y Glossopterídeas para Gondwana). Las "provincias" estarían a su vez divididas en distintas "regiones", definidas en base a una distribución paleogeográfica de taxa distintiva a nivel genérico y específico (por ejemplo, la provincia Gondwánica tendría una región de Gangamopteris, indicativa de un clima más frío, y una de Glossopteris, indicativa de un clima más templado). 
El mismo autor menciona, asimismo, los distintos problemas que surgen al utilizar elementos florísticos para reconstrucciones paleogeográficas (explicado en mayor detalle en Raymond et al., 1985). Entre los problemas más comunes (Wnuk, 1996: 7), se encuentran (1) la diversidad ficticia generada a partir de elementos disociados que en realidad pertenecen a un mismo organismo (por ejemplo, hojas de Glossopteris sp y fructificaciones); (2) el uso de nomenclaturas regionales que generan floras artificialmente diferentes; y (3) variados sesgos en el protocolo de colección que pueden provocar que una flora "mejor estudiada" presente mayor diversidad que una que no lo fue, entre otros.

En relación al primer punto, pareciera inevitable que en tanto las partes no sean halladas en evidente conexión orgánica, se genere una diversidad mayor a la real en base a los elementos disociados hallados. Lamentablemente, este es un hecho recurrente - en mayor o menor medida - en análisis paleobotánicos de todos los tiempos y regiones.

Respecto al segundo punto, hallamos un claro ejemplo en Meyen (1969), McLoughlin (1992), McLoughlin y Drinnan (1996), Singh et al. (2007), y Srivastava y Agnihotri (2010b), acerca de la mención sobre si utilizar Cordaites para hojas de forma espatulada con una marcada venación paralela presentes en sedimentos del hemisferio norte (Euramerica), o Noeggerathiopsis, para las mismas hojas pero que se encuentran en el hemisferio sur (Gondwana). Si bien hay una base anatómica y morfológica que justificaría su separación genérica (Srivastava, 1992; McLoughlin y Drinnan, 1996), algunos autores prefieren mantener a todos los ejemplares de este tipo bajo el nombre de Cordaites (Meyen, 1969; Rigby et al., 1980), aduciendo que las diferencias morfológicas se podrán o no identificar en base al tipo y estado de preservación del fósil.

Por último, y al respecto del tercer punto, un ejemplo se hizo mención previamente en esta tesis (ver 4.5), en relación a la mayor afinidad de la flora de la Formación La Golondrina que este estudio demuestra tener con floras no-Sudamericanas, y que potencialmente, esto podría deberse a recientes campañas llevadas a cabo a la zona por la autora, donde se hizo especial énfasis en la colección de elementos novedosos, entre los cuales se recuperaron abundantes fructificaciones de glossopterídeas, cuyo registro sigue 
siendo escaso a nulo en el resto de las floras Sudamericanas utilizadas en la comparación de elementos florísticos.

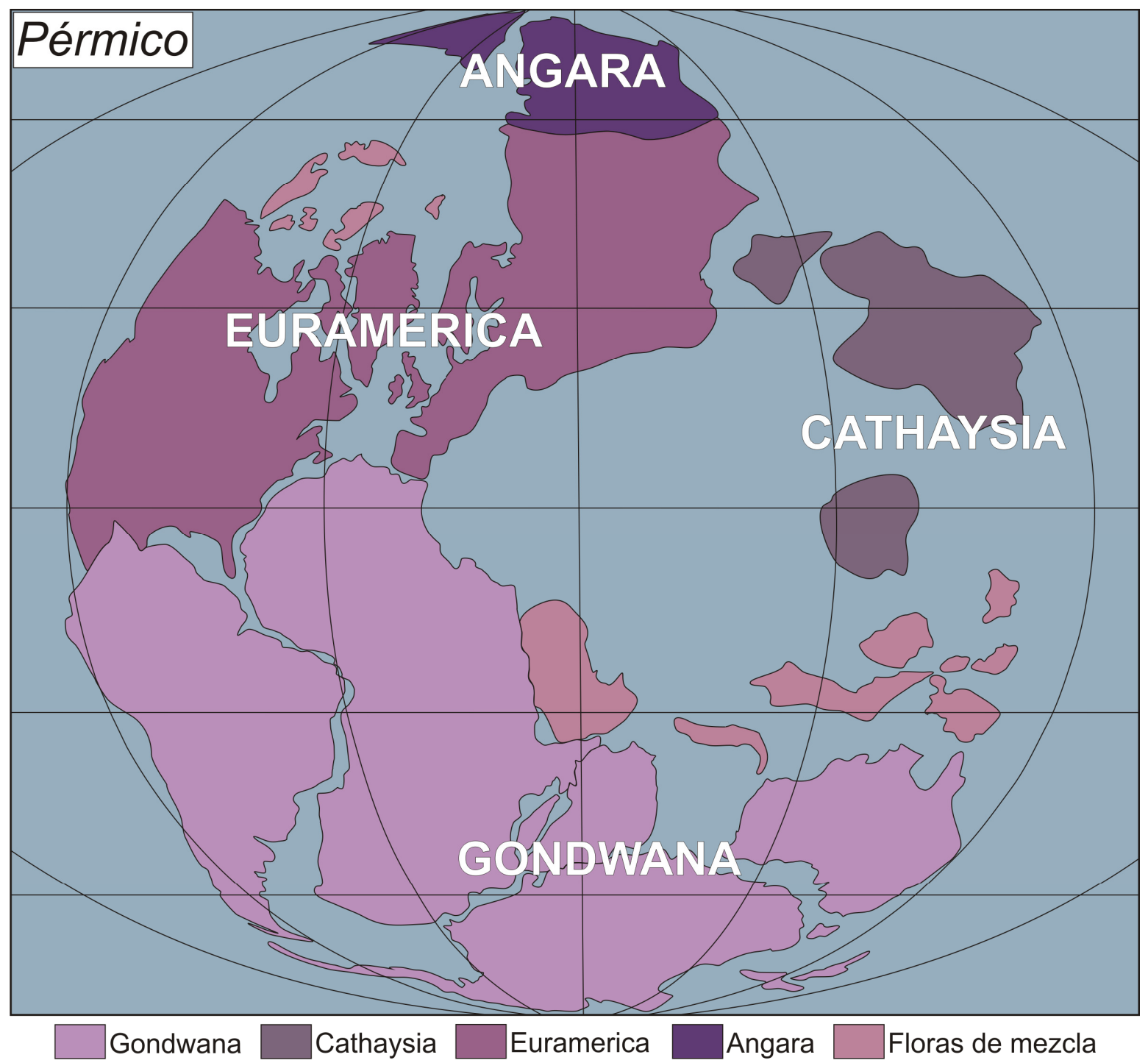

Figura 11 - Reconstrucción paleogeográfica del Pérmico, con sus provincias fitogeográficas (Modificado de McAllister Rees et al., 2002). 
Desde que fuera primeramente descripta por Archangelsky (1959a), se reconocieron tanto elementos típicamente gondwánicos (Glossopterídeas en general), como nórdicos (Sphenophyllales y varios helechos, entre otros) en la tafoflora de La Golondrina. Es por ello, que se la suele considerar desde entonces como una "flora de mezcla" (Archangelsky, 1959a: 117 - si bien no utilizó esos términos, infiere la mezcla de elementos típicos de Gondwana con otros del hemisferio norte -; Arrondo, 1972: 35; Archangelsky y Cúneo, 2002: 402), aún si los elementos gondwánicos se encontraban en clara predominancia. Era precisamente la presencia de estos elementos de origen nórdico los que diferenciaban a la tafoflora de La Golondrina de aquellas otras floras Pérmicas Argentinas (Sierras Australes, Malvinas) consideradas como "Floras de Glossopteris" 'puras' (Archangelsky et al., 1996b).

Entre los géneros presentes en la Formación La Golondrina considerados típicamente nórdicos, se destacan los helechos pecopterídeos (Pecopteris, Asterotheca), Sphenopteris, Chiropteris, Eremopteris, Annularia, Phyllotheca y Cordaites (=Noeggerathiopsis). A través de estudios actualizados llevados a cabo en subsecuentes revisiones, varios elementos que originalmente habían sido descriptos bajo géneros nórdicos, fueron posteriormente ubicados bajo una identidad propia de flora Gondwánica (Srivastava y Agnihotri, 2010b). Ese fue el caso para helechos como Neomariopteris (Sphenopteris) polymorpha Maithy (1974a, 1977), Damudopteris sp. [género propuesto para aquellos ejemplares de Neomariopteris polymorpha fértiles (Chandra y Rigby, 1983)], y Dichotomopteris (Merianopteris) sp. Maithy (1974b), entre otros.

Algunas de estas reasignaciones han sido avaladas en el material de La Golondrina. Sin embargo, hay algunos casos donde se ha preferido mantener una nomenclatura abierta a futuro cambio, al no considerarse que la evidencia fósil sea suficiente como para asignar con certeza una especie determinada. Es el ejemplo de Sphenopteris sp. II, que desde que fuera descripto por Archangelsky (1959a), hasta la fecha, no se ha podido establecer con certeza a qué especie pertenece, dada la ausencia de material fértil. 
En otros casos donde las asignaciones son también debatibles, se ha preferido mantener el nombre de Cordaites (=Noeggerathiopsis) hislopi para aquellos ejemplares de morfología claramente cordaital, pero en los que no se ha podido observar con certeza la presencia de venillas entre las venas paralelas primarias. Dado que esto se puede deber exclusivamente a un tema de preservación, y al no contar con hojas completas ni con cutícula presente, se considera riesgoso determinar su asignación a uno u otro género, aún si varios autores prefieren utilizar Noeggerathiopsis para referirse a los ejemplares Gondwánicos (Singh et al., 2007).

La diferencia entre los géneros Sphenophyllum y Trizygia - éste último propuesto por Royle en 1839, sin especificar la razón para la separación de éstos - ha sido discutida por varios autores. Entre las variadas propuestas para la separación entre uno y otro género, se destacan la presencia de pares de hojas de distinto tamaño en Trizygia, no así en Sphenophyllum (Arber, 1905); la disposición radial de éstas en Sphenophyllum, y de un lado del tallo en Trizygia (Feistmantel, 1879; Asama, 1970); y diferencias a nivel cuticular (Maheshwari, 1974). En una breve revisión de la historia de ambos géneros, McLoughlin (1992) sugirió que hasta tanto no se encuentren especímenes en conexión orgánica con su parte fértil, la afinidad natural entre las formas gondwánicas y nórdicas no podrá ser determinada. Asimismo, este autor prefirió utilizar Trizygia para las formas gondwánicas, sin mayores precisiones. Posteriores hallazgos de especies de Sphenophyllum en Gondwana con un patrón de hojas asimétricas dispuestas radialmente en el tallo (Srivastava y Agnihotri, 2010b), refutarían los caracteres sugeridos para separar a ambos géneros. Es por esta razón, además de la ausencia de cutículas preservadas que puedan ser analizadas, que aquí prefiere mantenerse en uso Sphenophyllum speciosum en lugar de Trizygia speciosa para describir aquellos ejemplares de sphenophyllales halladas en La Golondrina que presentan 3 pares de hojas de distinto tamaño, y donde se observa que la disposición de éstas es radial y no asimétrica, dada la prioridad que tiene Sphenophyllum sobre Trizygia.

Por todo lo aquí expuesto se podría plantear la pregunta acerca de si la presencia de géneros y especies nórdicas en floras Gondwánicas hacen necesariamente de éstas "floras 
de mezcla". Según Archangelsky y Arrondo (1967), las floras de mezcla se podían explicar a través de tres hipótesis: (1) las tafofloras con elementos "nórdicos" serían más antiguas que aquellas consideradas floras "puras de Glossopteris", (2) los elementos "nórdicos" se habrían originado independientemente por homoplasia (evolución paralela, en este caso), y (3) los elementos "nórdicos" habrían migrado a zonas marginales de Gondwana con características climáticas similares. De acuerdo a lo planteado, la hipótesis 1 no explicaría la presencia de elementos del norte en la tafoflora de la Formación de La Golondrina, dado que existían varias cuencas más antiguas (del Pérmico Inferior, como la flora de la Formación Bonete, en la Cuenca Sierras Australes) que poseían una flora exclusivamente de Glossopteris. Archangelsky y Arrondo (1967) prefirieron explicar la presencia de elementos nórdicos en floras gondwánicas a través de la hipótesis 3 (migración), sugiriendo que si bien paralelismos habrían sucedido en algunos casos, en tanto no hubieran estudios filogenéticos, se considerara esta hipótesis con precaución. Para estos autores, la presencia de helechos (pecopterídeos y sphenopterídeos) era una clara evidencia de la cercanía entre las masas continentales que habrían posibilitado la migración de elementos entre el norte y el sur, explicando estas floras de mezcla.

Una propuesta diferente fue la sugerida por Asama (1967). En ella, propuso que la presencia de formas similares en continentes separados se debía meramente a procesos de homoplasia, más específicamente, a través de la evolución paralela de los elementos, lo que indicaría que éstos no habrían derivado de un ancestro común (por lo que no estaban filogenéticamente relacionados). La similitud entre elementos sería producida a través de un proceso de "retardamiento en el crecimiento", causado por condiciones paleoclimáticas de desmejoramiento a lo largo del Pérmico. Para ello, las pinnas de una planta pasarían por un proceso de fusión, alargamiento, o ambos, evolucionando de una forma tripinnada, a una bipinnada, hasta llegar finalmente a un hoja simple (Asama, 1967: 129). Esto explicaría, por ejemplo, las semejanzas entre hojas de Glossopteris (Gondwana) y Gigantopteris (Cathaysia), y la presencia de elementos como Schizoneura o Sphenophyllum speciosum (Asama, 1966) en floras de Gondwana y Cathaysia. 
Por último, en el mismo volumen, Meyen (1967) propuso que si bien la presencia de elementos en floras de distintos continentes se podía explicar por homoplasia (Phyllotheca, Schizoneura, entre otros), procesos de intercambio a través de migración de elementos también habrían sido de importancia para explicar estas floras de mezcla.

Si se considera cuáles son aquellos elementos que históricamente han sido designados con nombres típicamente nórdicos, observamos que en todos los casos, están referidos a elementos estériles. Sin embargo, cuando algunos de estos elementos fueron hallados con sus partes fértiles, o bien, re-estudiados encontrándose diferencias significativas entre los nórdicos y gondwánicos, fueron posteriormente reasignados, utilizándose para ellos un nombre distinto de aquellos conocidos para otras floras nogondwánicas. Tal cual fue sugerido por McLoughlin (1992), hasta tanto no se encuentren las partes fértiles de aquellas partes estériles conocidas, no se puede más que asumir una semejanza superficial de los elementos presentes en La Golondrina (y cualquier otra flora Gondwánica), que bien puede deberse a la evolución paralela de especies distintas en condiciones ambientales semejantes.

En el caso particular de la flora de la Formación La Golondrina, la presencia de elementos tanto "nórdicos" como gondwánicos (los cuales se hallan además en clara predominancia), serían indicio que ésta es una "flora de mezcla". Sin embargo, a medida que se encuentren más ejemplares con sus partes fértiles, mejores descripciones y asignaciones correctas podrán ser llevadas a cabo (por ejemplo, Archangelsky et al., 2004), con lo que se especula que esta flora, como muchas otras, mostrará claras diferencias con las nórdicas, demostrando ser una flora típicamente Gondwánica. 


\author{
- CAPÍTULO 6 - \\ PALEOECOLOGÍA e \\ INFERENCIAS \\ PALEOAMBIENTALES
}




\section{0 - PALEOECOLOGÍA e INFERENCIAS PALEOAMBIENTALES}

\section{$6.1-$ Antecedentes}

Los escasos estudios paleoecológicos que hacen referencia a la Formación La Golondrina (Archangelsky, 1979; Cúneo, 1986, 1996) se basaron en comparaciones entre floras del Paleozoico Superior e inferían condiciones ambientales propicias para el desarrollo de una flora caracterizada por una alta diversidad, sin profundizar en mayores detalles.

A partir de un extenso y detallado análisis sedimentológico y facial llevado a cabo como parte de su tesis doctoral, Jalfin (1987) brindó un esquema interpretativo de los ambientes depositacionales para cada uno de los 3 miembros de la Formación La Golondrina. De esta manera, concluyó que la depositación inicial (Miembro Laguna Lillo) del relleno de cuenca se habría producido a través de un sistema fluvial multicanalizado (=entrelazado) gravoso de baja sinuosidad. Por su parte, el Miembro Laguna Polina incluiría depósitos de un sistema fluvial también entrelazado, pero arenoso, donde se observaba un incremento en la sinuosidad dada por la aparente disminución en la pendiente. Si bien la abundante vegetación presente habría actuado fijando las márgenes de los ríos, esta cobertura vegetal no habría alcanzado a inhibir totalmente la migración lateral de los canales. Ambos períodos de depositación se habrían dado bajo condiciones tectónicas estables, alcanzando un grado de mayor madurez durante la depositación del miembro medio (Jalfin, 1987), lo que resulta concordante con el gran desarrollo de la vegetación. Por el contrario, la depositación del miembro superior (Dos Hermanos) en la cuenca se habría producido por el desarrollo de un sistema de abanicos aluviales que alimentaba a un sistema fluvial entrelazado de baja sinuosidad. La formación de estos abanicos se vio favorecida por un abrupto levantamiento tectónico en la parte NE de la cuenca, lo que generó a su vez un claro cambio en las paleocorrientes, pasando de ser predominantemente NO-SE en los primero estadíos de depositación, a NE-SO en los finales (Jalfin, 1987; Jalfin et al., 1990). Asimismo, las características sedimentológicas de estos abanicos indicarían su desarrollo bajo un clima húmedo (Jalfin, 1987: 152), en coincidencia con la evidencia aportada por la 
flora fósil hallada en la zona de Dos Hermanos. Basándose en todos estos datos, Jalfin (1987) sugirió - como previamente lo habían hecho Archangelsky (1959a, 1979) y Cúneo (1986) - que las condiciones climáticas bajo las cuales se habría desarrollado la flora de La Golondrina habrían sido "benignas", con altos niveles de humedad.

El esbozo paleoambiental propuesto por Jalfin (1987) fue ampliamente aceptado y utilizado por distintos autores (Jalfin et al., 1990; Andreis y Archangelsky, 1996; Archangelsky et al., 1996a; Archangelsky y Cúneo 2002), donde independientemente de la posición latitudinal, se asumía que el clima imperante en la Formación La Golondrina había sido subtropical, lluvioso, estacional, con inviernos no muy fríos (temperaturas medias siempre mayores a $0^{\circ} \mathrm{C}$ ) y veranos calurosos, homologable al clima Tipo Cfa de la clasificación de Köppen (Fig. 12) (Jalfin, 1987; Archangelsky et al., 1996a).

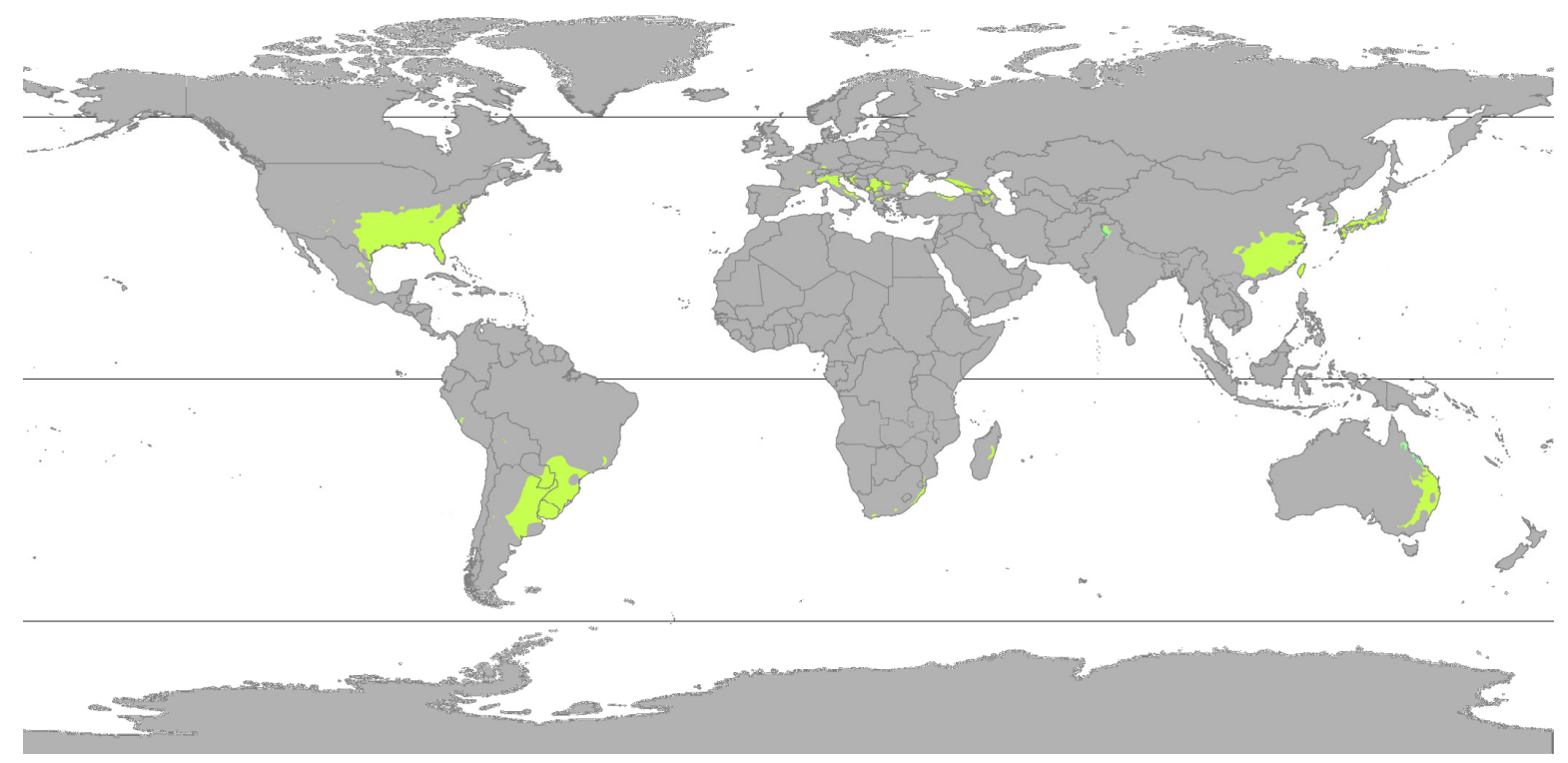

Fig. 12- Distribución en un mapa actual del tipo climático $C f a$ (clima subtropical húmedo) según la clasificación de Köppen (modificado de http://en.wikipedia.org/wiki/Humid_subtropical_climate). 


\section{2 - Análisis petrográfico de areniscas}

Para el análisis paleoambiental de la cuenca se optó por un enfoque novedoso aún no ejecutado en La Golondrina, a través del estudio de cortes petrográficos de muestras de areniscas de grano medio y grueso provenientes de dos de los tres miembros de la formación: Laguna Lillo (inferior) y Laguna Polina (medio). Muestras del Miembro Dos Hermanos (superior) no resultaron adecuadas para su análisis debido al alto grado de alteración que éstas presentaban, por lo que este miembro no fue considerado en este estudio.

El estudio de cortes delgados permite determinar el origen y la ubicación de las áreas fuentes a través de la composición modal de los detritos arenosos terrígenos (Dickinson et al., 1983). Además de la procedencia, estos estudios permiten realizar inferencias acerca de las condiciones tectónicas (evolución de la cuenca, procesos diagenéticos, etc), y climáticas durante el tiempo de sedimentación, ya que estos factores juegan un rol importante en la composición final de las areniscas terrígenas (Basu, 1976; Suttner et al., 1981; Dickinson et al., 1983; Suttner y Dutta, 1986; Mack y Jerzykiewicz, 1989; Girty, 1991; Espejo y López-Gamundí, 1994; Hota et al., 2011).

El análisis de muestras en el microscopio de polarización se desarrolló en dos partes. Primero, se identificaron las propiedades texturales de los clastos de roca, utilizando las escalas convencionales y estandarizadas en función del porcentaje de matriz presente, grado de redondez y esfericidad de los clastos, selección, y tamaño de grano (Powers, 1953, 1982; Krumbein y Sloss, 1955; Compton, 1962; Tucker, 2003) (Anexo III). A partir de los datos obtenidos, se seleccionaron aquellas muestras de mejor condición, con el menor (o nulo) grado de alteración posible, descartando aquellas menos aptas. Para hacer el estudio más ajustado, se eligieron 8 muestras representativas por cada miembro prospectado.

\section{Laguna Lillo}

De un total de 13 muestras, resultaron como las más aptas para su análisis composicional las muestras P2, P3, P4, P5, P8, P9, P12, y P13 (Fig. 5; Cuadro V). De éstas, 
únicamente la P13 pertenecería al miembro medio (Laguna Polina). Todas las muestras analizadas provienen de areniscas finas a gruesas (Fig. 5), y pueden ser consideradas areniscas sublíticas y subfeldespáticas en base a su variable composición y apariencia, (Folk et al., 1970).

Las propiedades microscópicas observadas se asemejan para todas las muestras (Anexo III; Lám. 3). En general, presentan poca matriz (nunca más del 20\%), con clastos desde redondeados a subangulosos, de esfericidad predominantemente subdiscoidal a subprismático, moderada a pobremente seleccionadas, y tamaño de granos muy variable, con valores más comunmente entre 350 y 500 micrones, pero una amplia oscilación entre 100 y 1400 micrones.

\section{Laguna Polina}

De un total de 9 muestras, se consideró a las P2, P3, P4, P5, P6, P7, P8, y P9 como las de mejor condición para su análisis (Fig. 6; Cuadro V). Todas las muestras pertenecen al miembro medio, a excepción de la muestra P4, que pertenece al miembro superior (Dos Hermanos). Todas las muestras analizadas provienen de areniscas medianas a gruesas y conglomerados (Fig. 6), y en base a su composición y apariencia, pueden ser clasificadas como areniscas feldespáticas (Folk et al., 1970).

Las propiedades microscópicas observadas (Anexo III; Lám. 3) son similares a aquellas del miembro inferior, donde en muy pocos casos se observó más de un $10 \%$ de matriz, los clastos presentaron redondez variable (predominando aquellos subangulosos), mayormente de esfericidad subprismática, y en algunos casos, con buena selección, pero más comúnmente, presentando entre una selección moderada a pobre, y tamaño de los granos variable, con partículas generalmente entre 177 y 250 micrones, pero oscilando desde los 100 y 1400 micrones también. 


\section{LÁMINA 3}

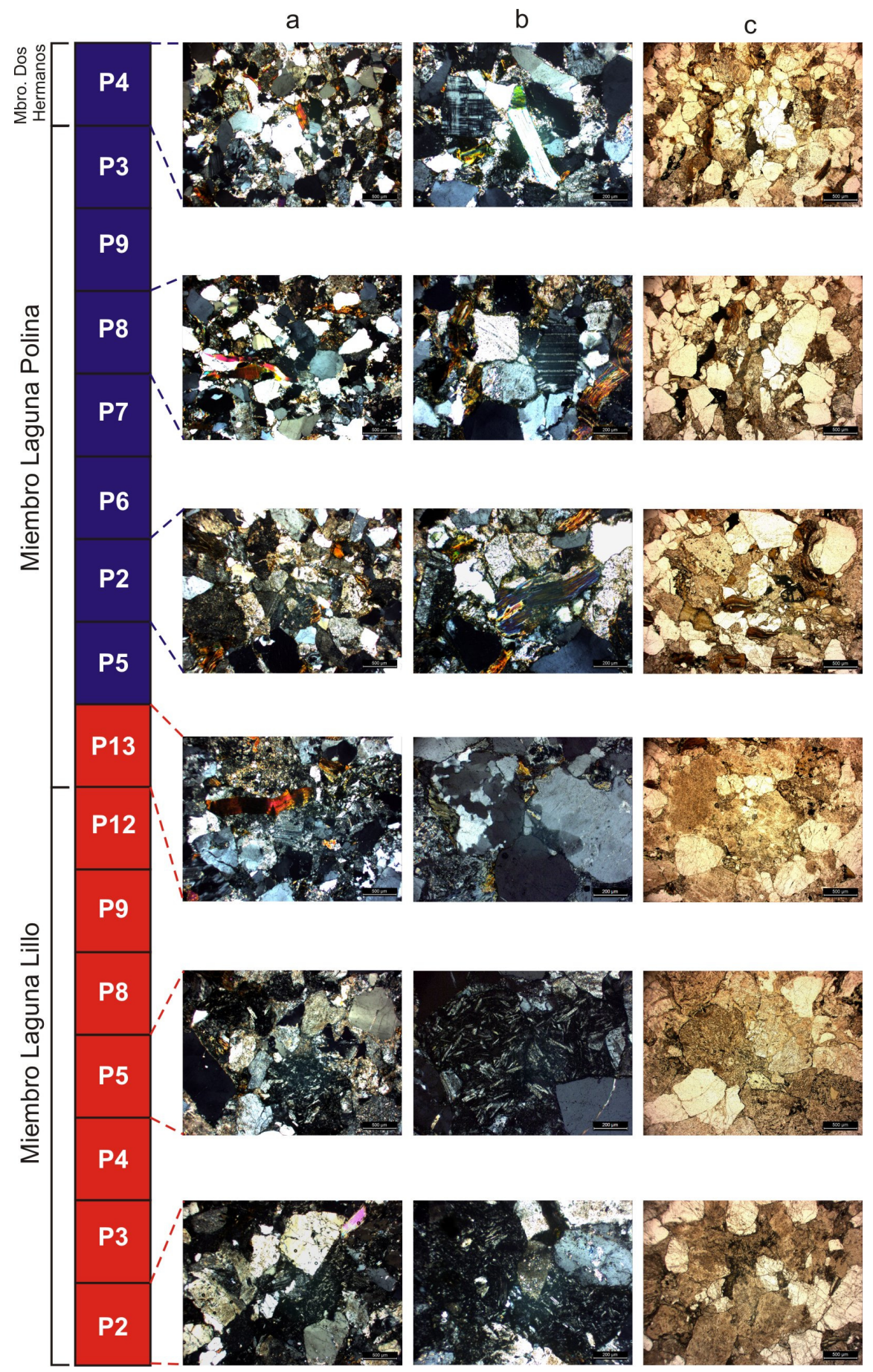

a) Nicoles cruzados, 500 micrones, b) Nicoles cruzados, 200 micrones, c) Nicoles sin cruzar, 500 micrones. 
Cuadro V- Conteo de partículas sedimentarias. En rojo, muestras de Laguna Lillo; en azul, muestras de Laguna Polina.

\begin{tabular}{|l|cccccccccc|c|}
\hline Muestra & Qm & Qp & P & Fk & Mtx & Ls & Lv(b) & Lv(a) & M & Mc & Total \\
\hline P4 & 62 & 3 & 86 & 0 & 82 & 7 & 1 & 0 & 59 & 0 & 300 \\
P3 & 67 & 18 & 74 & 0 & 89 & 4 & 4 & 0 & 38 & 6 & 300 \\
P9 & 109 & 23 & 75 & 4 & 51 & 8 & 0 & 2 & 19 & 9 & 300 \\
P8 & 96 & 46 & 81 & 10 & 41 & 6 & 4 & 3 & 10 & 3 & 300 \\
P7 & 44 & 2 & 109 & 0 & 103 & 10 & 0 & 0 & 29 & 3 & 300 \\
P6 & 70 & 7 & 94 & 8 & 56 & 10 & 5 & 4 & 45 & 1 & 300 \\
P2 & 81 & 17 & 106 & 4 & 50 & 3 & 17 & 0 & 19 & 2 & 300 \\
P5 & 61 & 8 & 113 & 18 & 57 & 2 & 8 & 6 & 25 & 2 & 300 \\
P13 & 64 & 20 & 60 & 0 & 44 & 15 & 7 & 0 & 76 & 14 & 300 \\
P12 & 72 & 9 & 71 & 0 & 31 & 6 & 35 & 0 & 61 & 15 & 300 \\
P9 & 45 & 1 & 94 & 4 & 38 & 6 & 96 & 8 & 6 & 2 & 300 \\
P8 & 40 & 3 & 75 & 2 & 51 & 4 & 108 & 7 & 9 & 1 & 300 \\
P5 & 59 & 4 & 66 & 4 & 29 & 5 & 126 & 3 & 4 & 0 & 300 \\
P4 & 98 & 7 & 78 & 0 & 14 & 2 & 39 & 0 & 62 & 0 & 300 \\
P3 & 75 & 5 & 112 & 3 & 24 & 10 & 49 & 0 & 22 & 0 & 300 \\
P2 & 58 & 3 & 105 & 15 & 41 & 0 & 62 & 2 & 14 & 0 & 300 \\
\hline
\end{tabular}

La segunda parte del análisis bajo el microscopio involucró el conteo de 300 clastos por muestra, para posteriormente calcular las modas detríticas de composición y procedencia (Dickinson et al., 1983). Se contabilizaron los siguientes tipos de granos: cuarzo monocristalino $(\mathrm{Qm})$, cuarzo policristalino $(\mathrm{Qp})$, plagioclasa $(\mathrm{P})$, feldespato potásico (Fk), matriz/cemento (Mtx), líticos sedimentarios (Ls), líticos volcánicos andesíticos [básicos, Lv(b)] y riolíticos [ácidos, Lv(a)], mica (M), y microclinos (Mc). El Cuadro V muestra los resultados obtenidos de este conteo. 


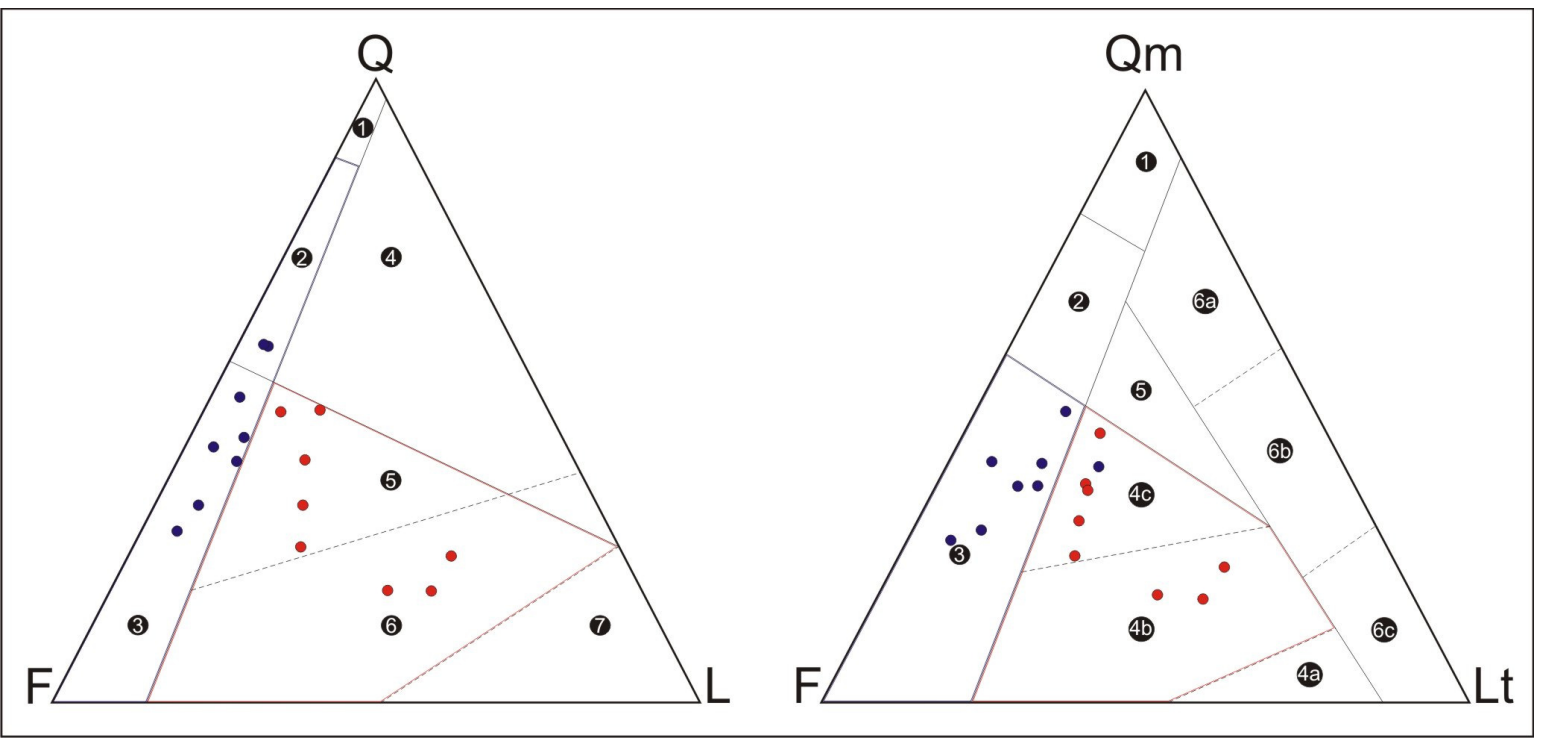

Fig. 13 - Triángulos composicional (izq.) y de proveniencia (der.) de Dickinson et al. (1983). Miembro inferior (Laguna Lillo) en rojo; miembro medio (Laguna Polina) en azul. $\mathbf{Q F L}$ : 1) Interior cratónico, 2)

Continental transicional, 3) Basamento elevado, 4) Orógeno reciclado, 5) Arco disectado, 6) Arco transicional, 7) Arco no disectado. $\mathbf{Q m F L t : ~ 1 ) ~ I n t e r i o r ~ c r a t o ́ n i c o , ~ 2 ) ~ C o n t i n e n t a l ~ t r a n s i c i o n a l , ~ 3 ) ~ B a s a m e n t o ~}$ elevado, 4a) Arco no disectado, 4b) Arco transicional, 4c) Arco disectado, 5) Mezcla, 6a) Orógeno reciclado cuarzoso, 6b) Orógeno reciclado transicional, 6c) Orógeno reciclado lítico.

Los datos obtenidos fueron ploteados en los triángulos de Dickinson et al. (1983) para analizar la composición y procedencia de los detritos que conforman las rocas de los miembros inferior y medio en la Formación La Golondrina (Fig. 13). De acuerdo a Dickinson et al. (1983), las variaciones composicionales de areniscas terrígenas pueden interpretarse en función de dos esquemas ternarios, cuyos extremos representan las categorías principales de granos: QFL y QpFLt (Fig. 13). Las relaciones proporcionales entre estos tres tipos composicionales son considerados como "guías naturales" que indicarían el terreno de proveniencia de los detritos que componen las rocas (Dickinson et al., 1983). 
Según los análisis de modas detríticas (Fig. 13), existe una clara diferencia entre las muestras del miembro inferior y medio, donde las areniscas provenientes primero presentan una menor madurez composicional que las del miembro medio. Asimismo, el miembro inferior presenta abundantes líticos (predominantemente volcánicos), en comparación con el miembro medio, donde éstos están prácticamente ausentes.

Respecto a la procedencia, la distribución de las muestras en los triángulos de Dickinson indican que el origen detrítico de los depósitos en Laguna Lillo (miembro inferior mayoritariamente) caen en la zona de Arco (transicional y disectado), mientras que las de Laguna Polina (miembro medio predominantemente) caen en la zona de Continental transicional y Basamento elevado (Fig. 13). Estos datos están concuerdan con lo sugerido por Jalfin (1987:129) quien señaló que “desde un comienzo la Cuenca La Golondrina habría recibido aportes de por lo menos dos áreas fuentes", visión apoyada por la medición de paleocorrientes en las tres comarcas principales (Bajo de La Leona, Ea. La Juanita-Cerro Chato, y Ea. Dos Hermanos).

Asimismo, Jalfin (1987: 129) agregó que las rocas madres habrían sido esencialmente las mismas, ya que no identificó diferencias composicionales entre las distintas localidades que estudió. Sin emabrgo, a partir del análisis de los cortes petrográficos aquí realizado, se evidencia un claro aporte de roca madre distinta entre el miembro inferior y el medio, si bien ambos muestreos fueron llevados a cabo en la misma localidad (Bajo de La Leona).

Los análisis de paleocorrientes realizados por Jalfin (1987) y Jalfin et al. (1990) en el Bajo de La Leona, Ea. La Juanita-Cerro Chato, y la Ea. Dos Hermanos indican que la dirección predominante durante la depositación del miembro inferior era NNO-SSE, cambiando gradualmente a una marcada dirección NNE-SSO en el miembro superior, dada por el ascenso tectónico del Macizo del Deseado (Jalfin, 1987). De acuerdo a esto último, los detritos mayoritariamente volcánicos que conforman las areniscas del miembro inferior tendrían su origen hacia el NNO de la cuenca, en tanto que los detritos mayormente graníticos que conforman las areniscas del miembro medio provendrían del NNE. El 
conjunto de información obtenida indicaría que el miembro inferior estuvo claramente influenciado por el aporte de un evento volcánico de magnitud previo o durante su depositación, mientras que este aporte habría cesado para la depositación del miembro medio, donde la influencia provino mayormente de un bloque continental.

Hacia fines del Paleozoico, habrían ocurrido al menos dos episodios magmáticos de importancia, registrados en varios continentes gondwánicos; el primero habría sucedido durante el Pérmico Temprano a Medio, mientras que el segundo lo habría hecho a principios del Triásico (Rapela y Kay, 1988; Kay et al., 1989; López-Gamundí et al., 1992, 1995; López-Gamundí, 2006). Niveles tobáceos datados en un intervalo de 280-260 Ma. (Pérmico Temprano a Medio) han sido correlacionados en todo Gondwana. En Argentina, se los ha registrado especialmente en las Cuencas Paganzo, San Rafael, y Sierras Australes (=Sauce Grande) (López-Gamundí et al., 1992, 1995; López-Gamundí, 2006), por lo que este evento de intenso vulcanismo a lo largo del margen continental del SO de Gondwana se lo ha asociado con el evento volcánico del Grupo Choiyoi. De acuerdo a reconstrucciones paleogeográficas (López-Gamundí et al., 1995; López-Gamundí, 2006), este arco magmático se habría extendido a lo largo de todo Gondwana con una dirección EO por aproximadamente $7000 \mathrm{~km}$ (Visser, 1995), lo que evidenciaría la gran magnitud de este evento (Fig. 14). Si bien no se han registrado niveles tobáceos en la Cuenca La Golondrina, la abundante presencia de líticos volcánicos en los cortes delgados analizados del miembro inferior podrían estar indicando una fuente de origen relacionado a este evento magmático. La dirección de paleocorrientes predominates en el Bajo de La Leona, donde aflora el miembro inferior (y de donde provienen las muestras de Laguna Lillo aquí analizadas) era, como se mencionó previamente, NNO-SSE (Jalfin, 1987). Esto estaría en concordancia con una ubicación de la Cuenca La Golondrina al sur del arco magmático, tal cual suele ser representado en distintas reconstrucciones paleogeográficas (Fig. 14). Asimismo, cabría esperar el hallazgo de niveles tobáceos en la Cuenca que aporten mayor evidencia para soportar esta hipótesis. 


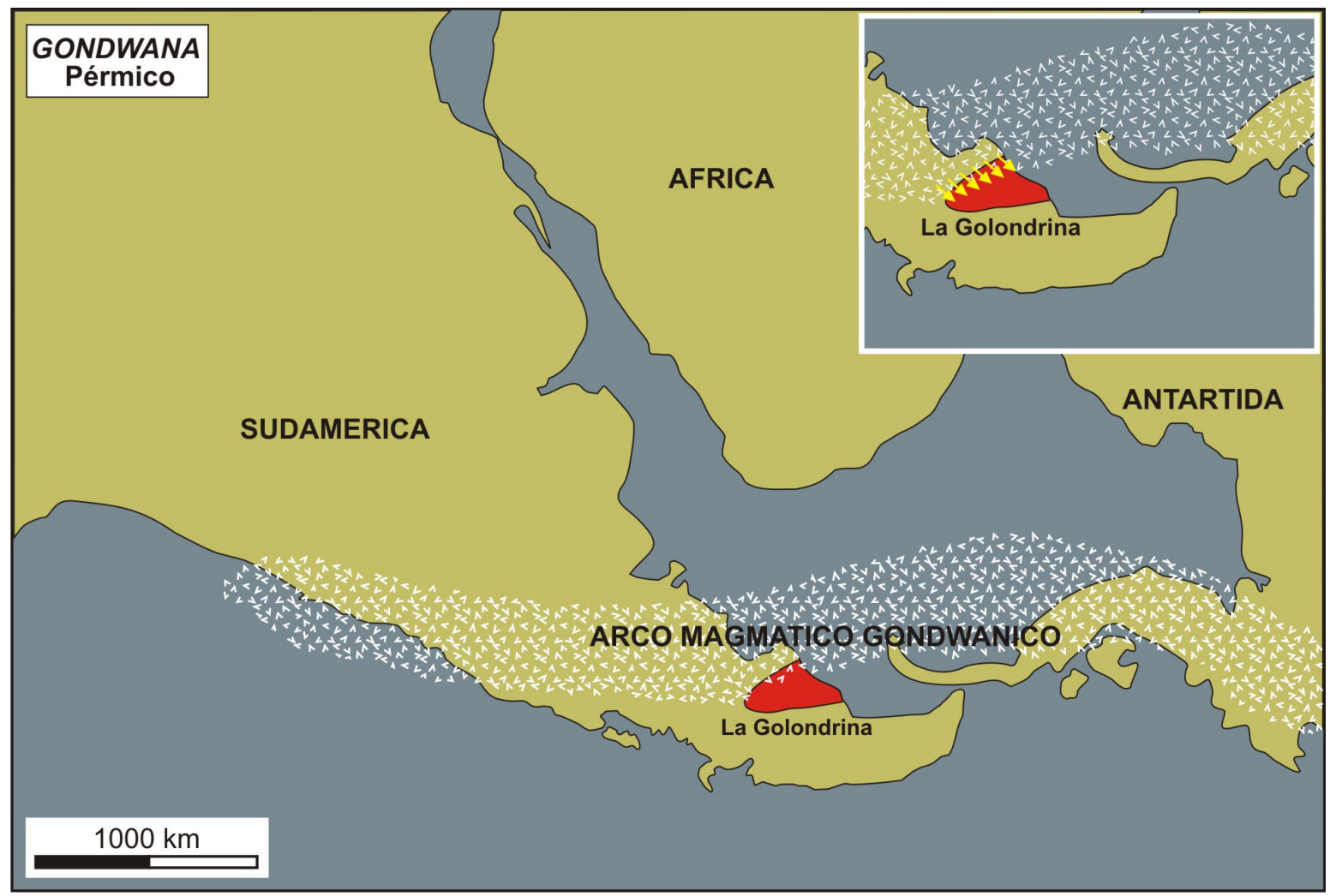

Fig. 14- Reconstrucción paleogeográfica del Gondwana occidental durante el Pérmico con presencia del arco magmático (modificado de López-Gamundí et al., 1995). El recuadro interno muestra la dirección NNO del aporte detrítico durante la depositación del miembro inferior Laguna Lillo, en el Pérmico temprano tardío (flechas amarillas).

Tomando en cuenta que el aporte detrítico del miembro inferior tendría su origen en el arco magmático gondwánico, cuya actividad está radimétricamente datada en el intervalo de 280-260 Ma., o sea, en un período que abarcaría desde finales del Pérmico temprano al Pérmico medio, la edad de la Formación La Golondrina no sería más antigua del Artinskiano. Esto aportaría además, un tipo de evidencia diferente al ya dado por el registro paleobotánico, que acotaría las edades de los distintos miembros que componen a la Formación La Golondrina en Artinskiano-Roadiano(?) para el miembro Laguna Lillo, Roadiano-Wuchiapingiano(?) para el miembro Laguna Polina, y Wuchiapingiano para el miembro Dos Hermanos, como fuera propuesto en base a la evidencia florística (4.5). 
Respecto de los sedimentos aportados durante la depositación del miembro medio (Laguna Polina), la casi total ausencia de líticos volcánicos como el aumento en el aporte de detritos cuarzosos sostienen una fuente de origen diferente a la del miembro inferior. El aporte granítico durante el período de depositación del miembro medio se vio favorecido por la aparente disminución de la actividad del arco magmático gondwánico, conllevando a que los niveles de aporte de líticos volcánicos sea casi nula. Las paleocorrientes medidas por Jalfin (1987) en las distintas localidades donde aflora el miembro medio indican una dirección predominante NE, aunque se registró una dispersión de datos significativa. De todas formas, la fuente de aporte de detritos durante la depositación del miembro medio habría estado localizada hacia el norte, con una tendencia desde el noreste.

Según lo sugerido por Guido y de Barrio (2004) y Guido et al. (2004), de acuerdo a las semejanzas petrográficas y a su estrecha vinculación con las sedimentitas de La Golondrina, dicho aporte de granitos podría tener su fuente en los "Leucogranitos de la Mina La Leona", datados en el Carbonífero Temprano, cuyo origen estaría relacionado a un evento de subducción del arco magmático (Pankhurst et al., 2006). Esta visión es apoyada también por Pankhurst et al. (2003), quienes a través de un estudio geocronológico en rocas del basamento pre-Pérmico en la Patagonia austral, obtuvieron unas edades SHRIMP entre

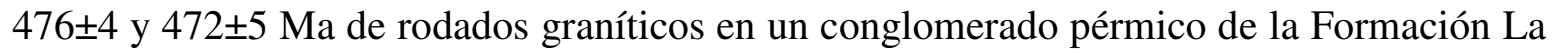
Golondrina, en el área de Dos Hermanos (ubicada apenas al NNE del área del Bajo de La Leona, de donde provienen las muestras de cortes delgados), lo que estaría evidenciando una actividad intrusiva durante el Ordovícico Temprano en los alrededores de la cuenca. Por otra parte, obtuvieron edades entre $422 \pm 2.4$ y 346ะ4 Ma (Silúrico Tardío a Carbonífero Temprano) para intrusivos graníticos in situ. El tamaño relativamente grande de los conglomerados analizados sugeríría que el transporte de éstos no fue prolongado, por lo que el área de aportes habría estado cercana a la cuenca de La Golondrina. Estos eventos fueron también identificados en otros sectores de Sudamérica y la Península Antártica, por lo que sugirieron que estas áreas habrían evolucionado juntas desde el Cámbrico hasta el Jurásico. 
En base a lo propuesto por dichos autores, se puede inferir como una posible fuente de aporte de los detritos durante la depositación del miembro medio al leucogranito de la Mina La Leona (Guido et al., 2004), que habrían intruído el basamento metamórfico en el área de la Cuenca La Golondrina (y al norte de ésta) durante el Silúrico tardío-Carbonífero Temprano (Pankhurst et al., 2003, 2006) (Fig. 15).

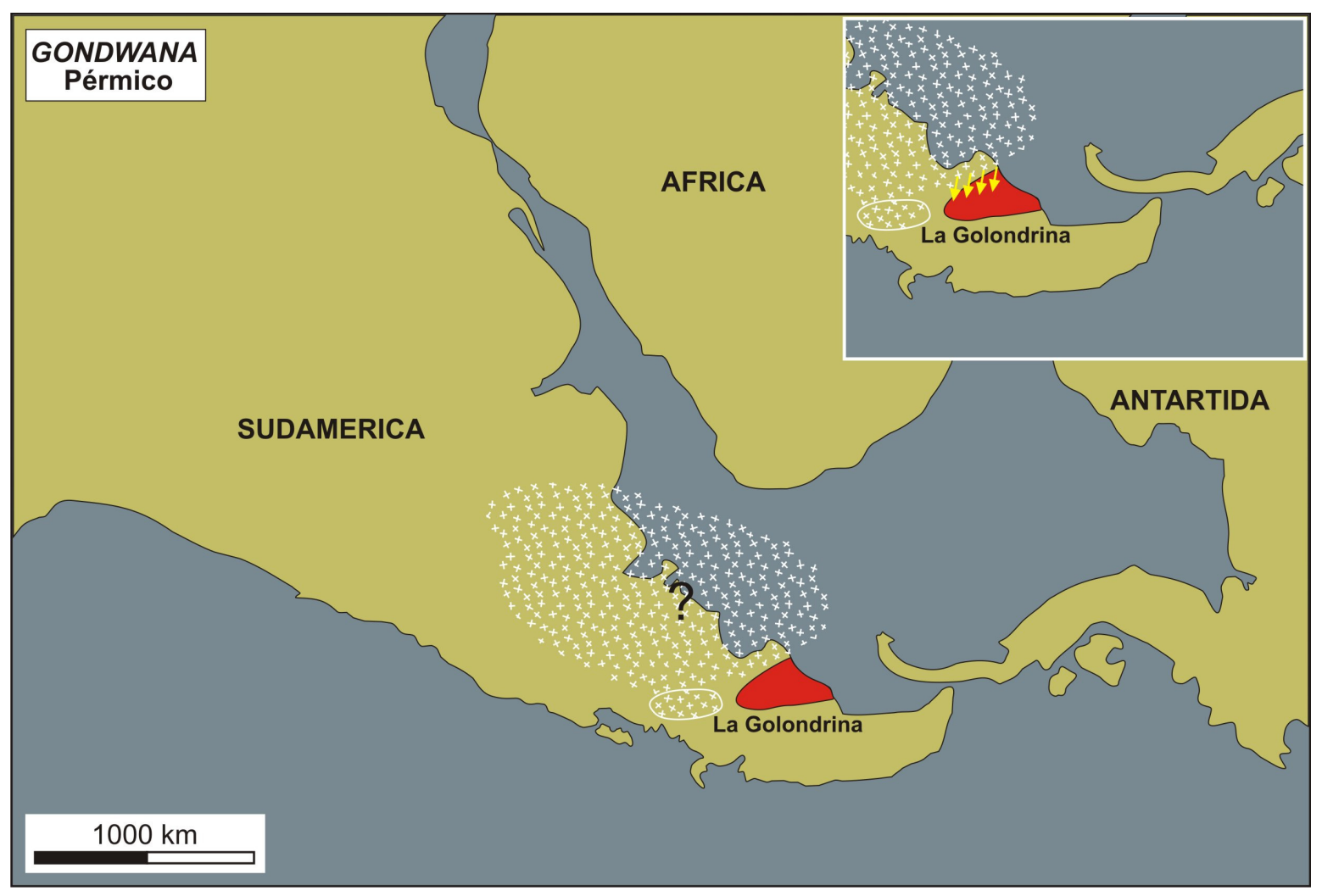

Fig. 15- Reconstrucción paleogeográfica del Gondwana occidental durante el Pérmico donde se infiere la presencia de un macizo granítico hacia el norte de la Cuenca La Golondrina (modificado de López-Gamundí et al., 1995, y Pankhurst et al., 2006). El recuadro interno muestra la dirección NNO (flechas amarillas) del aporte detrítico mayormente granítico durante la depositación del miembro medio Laguna Polina (Pérmico

Medio). El signo de interrogación se refiere a la correcta edad del granito: según Pankhurst et al., 2006, tendrían una edad pérmica temprana; aquí considerada pre-pérmica, en coincidencia con lo sugerido por otros autores (Jalfin, 1987; Pankhurst et al., 2003; Guido y de Barrio, 2004). La zona de granitos delimitada tendría una edad Carbonífero medio (Pankhurst et al., 2006). 


\section{3 - Inferencias paleoambientales}

Además de datos acerca de la evolución y fuente de origen de los detritos aportados durante la depositación en la Cuenca La Golondrina, los análisis petrográficos de cortes delgados de areniscas permiten hacer inferencias sobre las condiciones paleoclimáticas que habrían imperado durante su depositación (Basu, 1976; Suttner y Dutta, 1986; Espejo y López-Gamundí, 1994).

Los diagramas Q:F:L representan las distintas proporciones de esos minerales en una muestra de roca. Esas proporciones se ven sujetas a variaciones no solamente de la fuente de origen y ambiente tectónico, sino también de las condiciones ambientales en donde fueron depositadas, dado que los elementos minerales actúan como indicadores sensibles de la herencia climática (Suttner y Dutta, 1986; Hota et al., 2011), especialmente a datos referidos a la humedad (precipitación media anual, por ejemplo).

Los análisis llevados a cabo por distintos autores han permitido detectar signaturas paleoclimáticas en rocas de origen plutónico, volcánico y metamórfico (Suttner et al., 1981; Suttner y Dutta, 1986; Mack y Jerzykiewicz, 1989; Girty, 1991; Espejo y López-Gamundí, 1994; Hota et al., 2011). Idealmente, las muestras para estos estudios se restringieron a areniscas de primer ciclo (transporte $<100 \mathrm{~km}$ ), que además hubieran sido depositadas preferentemente en ambientes de tectonismo extensional, con nula o escasa influencia marina (con menor retrabajo), grano predominantemente mediano a grueso de la roca madre (para evitar sesgos producidos por una mayor abrasión mecánica y química de los minerales), y que hubieran sufrido un enterramiento diagenético relativamente superficial (Suttner et al., 1981; Suttner y Dutta, 1986). Para Suttner et al. (1981), sin embargo, un dato de extrema relevancia a tener en cuenta en este tipo de análisis, es que aún bajo esas condiciones ideales de depositación, las condiciones tectónicas son más determinantes en la composición final de las areniscas que el clima.

Dichos estudios permitieron concluir que los fragmentos de roca se disgregaban en minerales individuales con más facilidad en ambientes húmedos que áridos (Basu, 1976; 
Suttner y Dutta, 1986; Girty, 1991). De los resultados, también se desprendía que la ausencia de minerales lábiles (feldespatos, plagioclasas, micas, anfíboles) así como la predominancia de minerales cuarzosos (cuarzo mono o policristalino), eran indicativas de ambientes con niveles de humedad altos; mientras que aquellas areniscas derivadas de rocas volcánicas y depositadas en regiones áridas deberían presentar mayor proporción de líticos volcánicos que plagioclasas y otros minerales accesorios que aquellas areniscas de regiones húmedas (Mack y Jerzykiewicz, 1989). Esto se debía a que los minerales lábiles, al ser más inestables, sufrían una abrasión química y mecánica mayor en comparación a elementos química y mecánicamente más resistentes y maduros como el cuarzo, en ambientes bajo un clima húmedo y temperaturas cálidas (Suttner et al., 1981; Mack y Jerzykiewicz, 1989).

Entre los métodos desarrollados para identificar las condiciones climáticas a partir del análisis de cortes delgados de areniscas, se destacan los índices RFP (relación líticos volcánicos: plagioclasa+líticos volcánicos) y RFA (relación líticos volcánicos: minerlaes accesorios+líticos volcánicos) de Mack y Jerzykiewicz (1989), y el gráfico de dispersión de Suttner y Dutta (1986), este último el más utilizado (Fig. 16). Ambos métodos se enfocan en la relación proporcional de la tríada Q:F:L.

El método desarrollado por Suttner y Dutta (1986) - el utilizado para el análisis de las muestras en este estudio - consiste en un gráfico de dispersión cuyos ejes en escala logarítmica representaban las fórmulas

$$
Q t / F+R(\text { eje } \mathrm{x}) \quad \text { y } Q p / F+R(\text { eje y), }
$$

donde $Q p$ : cuarzo policristalino, $F$ : feldespatos en sentido amplio, $R$ : líticos de roca en sentido amplio, y $Q t$ : cuarzo policristalino más cuarzo monocristalino. 
La Fig. 16 muestra los resultados obtenidos a partir de la aplicación de dicho método a las muestras de los miembros inferior y medio de la Formación La Golondrina.

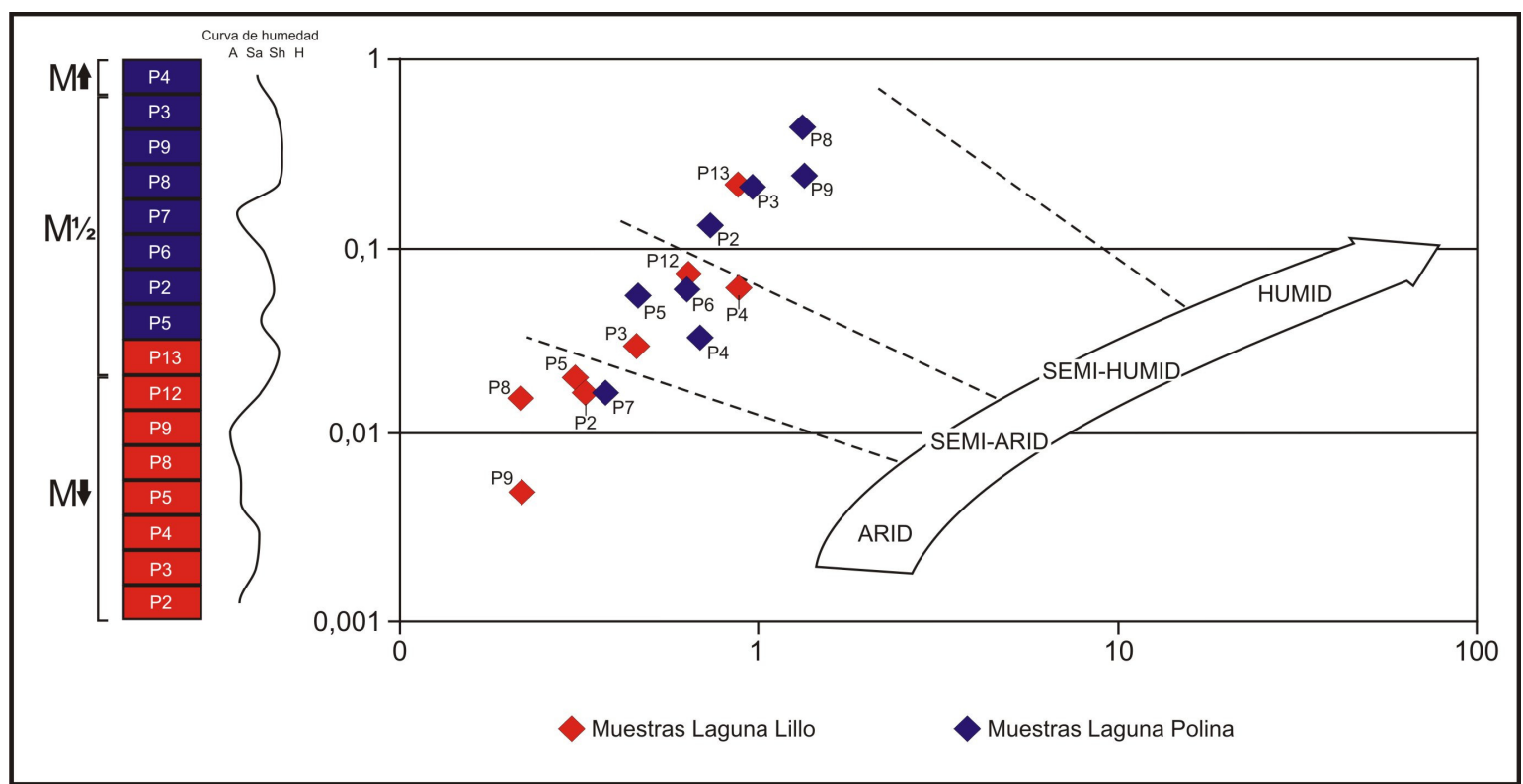

Fig. 16 - Ploteo de las muestras de roca tomadas en las localidades de Laguna Lillo (miembro inferior y medio, en rojo), y Laguna Polina (miembro medio y superior), de acuerdo al gráfico bivariado de Suttner y Dutta (1986). A la izquierda, representación esquemática de la ubicación estratigráfica de las muestras (ver también Figs. 5 y 6 de esta tesis).

Como se puede observar, los resultados obtenidos (si bien preliminares), estarían evidenciando una tendencia al aumento en las condiciones de humedad desde el miembro inferior al medio, lo que demostraría cambios ambientales en la cuenca a lo largo del tiempo de depositación (Fig. 16). A continuación (5.4), se analizan y discuten estos resultados. 


\section{4 - Discusión general}

Los datos que se desprenden del gráfico de la Fig. 16 indican una tendencia al aumento en los niveles de humedad a lo largo de la depositación de los miembros inferior y medio de la Formación La Golondrina. De acuerdo a lo especificado en el capítulo 4, el Miembro Laguna Lillo representaría una edad Cisuraliano tardío-Guadalupiano, mientras que el Miembro Laguna Polina, Guadalupiano-Lopingiano temprano.

El registro global indica que las condiciones climáticas a lo largo del Pérmico pasaron por varias etapas bien diferenciadas dadas por el cambio de una etapa de 'Ice House' a 'Hot House', aunque los gradientes latitudinales eran similares a los actuales, según lo evidenciado por la biogeografía florística (Ziegler, 1990; Cúneo, 1996; Scotese et al., 1999; McAllister Rees et al., 2002; Poulsen et al., 2007). A inicios del Pérmico aún se registraba la glaciación de finales del Carbonífero en las latitudes más altas, y medias del hemisferio Sur. La subsiguiente deglaciación comenzó a retraer las capas de hielo de los continentes, por lo que para mediados del Pérmico, las condiciones fueron ameliorándose hacia temperaturas más cálidas y un aumento progresivo en los niveles de humedad. Hacia finales de este período, la temperatura siguió en aumento, y consecuentemente, la aridización se incrementó (Ziegler, 1990; Visser, 1995; Cúneo, 1996; Scotese et al., 1999; Chumakov y Zharkov, 2002, 2003).

Entre los factores que afectan las condiciones climáticas de una determinada región, se encuentran la posición latitudinal y las características fisiogeográficas. Si bien se suele considerar a Gondwana como una masa continental única, las diferentes partes (subcontinentes mayores) que la componían (Sudamérica, India, Australia, África, Antártida) tuvieron movimientos migratorios diferenciales a lo largo del Pérmico. Por ejemplo, los elementos florísticos de las cuencas Pérmicas tanto de la India como del África evidencian un movimiento de latitudes altas a medias (Visser, 1995, 1996; Hota et al., 2011), mientras que la posición de Australia y Antártida se mantuvo relativamente estable, a altas latitudes (McLoughlin, 2001). El movimiento registrado para el bloque Sudamericano de acuerdo a las reconstrucciones paleogeográficas más aceptadas (Irving, 
1983; Scotese y McKerrow, 1990; Scotese et al., 1999) indica una migración hacia el norte (latitudes más bajas). Sin embargo, la posición de la Cuenca La Golondrina en particular, no presentó un cambio de posición latitudinal significativa a lo largo del Pérmico (Fig. 17), por lo que el cambio en las condiciones climáticas evidenciado entre el miembro inferior y medio (Fig. 16) no se debería a priori a un cambio en la posición latitudinal. Respecto a las características fisiogeográficas, se desconoce la presencia de una cadena montañosa o altos geográficos importantes, así como tampoco se registran grandes lagos que pudieran haber influenciado el clima en la cuenca. Cabe destacar que la cuenca tampoco habría estado cercana a un océano, en base a la ausencia de cualquier tipo de evidencia de origen marino en el área (Jalfin, 1987). Posiblemente, la ubicación de esta cuenca dentro del continente, sin presencia cercana de grandes cuerpos de agua que pudieran influenciar las condiciones del ambiente (actuando como efecto regulador, por ejemplo), habrían ayudado a que las condiciones en la cuenca sean más extremas (Scotese et al., 1999; Yemane, 1993; LópezGamundí et al., 1995).

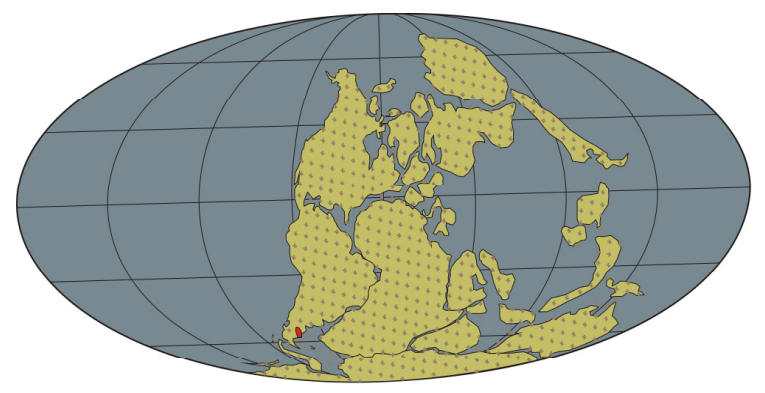

Pérmico temprano

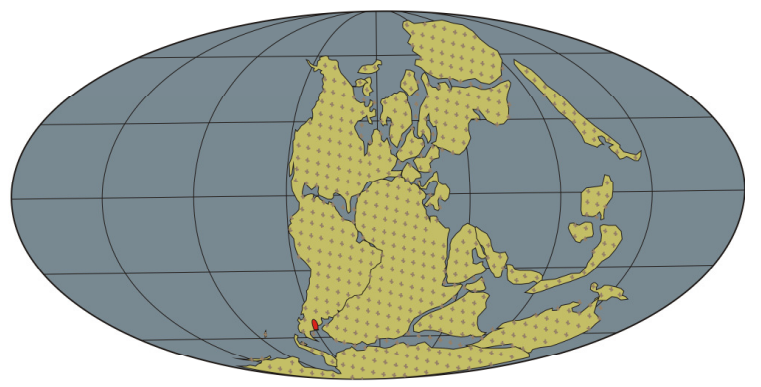

Pérmico tardío

Fig. 17 - Representación paleogeográfica comparativa entre el Pérmico Temprano y Tardío. Observar la posición latitudinal casi invariable de la Cuenca La Golondrina (en rojo) entre uno y otro momento.

(Modificado de Scotese y McKerrow, 1990). 
Por otra parte, se acepta que los valores de los niveles del $\mathrm{CO}_{2}$ en la atmósfera durante el Pérmico, posterior a la glaciación, eran más elevados que en la actualidad (Royer, 2006; Poulsen et al., 2007), lo que habría tenido un claro impacto en el clima y por ende, en la vegetación. La presencia de intensa actividad magmática generada por el arco gondwánico habría ayudado a incrementar los valores de $\mathrm{CO}_{2}$ en la atmósfera, tal cual lo sugirieron Crowley y Baum (1992), y Visser (1995), afectando el desarrollo de las floras en la zonas aledañas al arco (Axelrod, 1981; López-Gamundí et al., 1995).

La actividad volcánica, sumada a la continentalidad, habrían actuado como factores determinantes en la configuración del clima durante la depositación del miembro inferior de la Formación La Golondrina a finales del Pérmico Temprano y comienzos del Pérmico Medio, posterior a la deglaciación del Pérmico más temprano. Esto se vería representado tanto a través del gráfico de la Fig. 16, donde los datos para las muestras de la localidad de Laguna Lillo (miembro inferior mayormente) indican condiciones áridas a semi-áridas, como por los aportados por el registro florístico, donde se observó una flora más pobre, tanto en diversidad como en abundancia, para el miembro inferior (Cuadro I; Anexo I). La notable escasez de helechos (solamente dos especies de Asterotheca, una de Dizeugotheca), la predominancia de especies de Gangamopteris y Glossopteris (especies decíduas con alta adaptabilidad), sumada a la de algunas cordaitales (Cordaites sp.) sugieren que las condiciones habrían sido estacionales, con un período de escasez hídrica y temperaturas en aumento. La presencia de licófitas (Bumbudendron patagonicum y Cyclodendron golondrinensis) sugiere condiciones de relativa humedad y temperaturas más bien cálidas, pero en este caso, podría deberse a condiciones locales en la cuenca, sobretodo desarrolladas a los márgenes de los ríos, o en las planicies de inundación. Faltarían evidencias de índole litológica (evaporitas, marcas de grietas de desecación, por ejemplo) que ayuden a confirmar esto. La evidencia sedimentológica aportada por Jalfin (1987) indica que la depositación del miembro inferior se llevó a cabo en un sistema de ríos entrelazados de baja sinuosidad (ver 5.1). Este tipo de ríos pueden desarrollarse tanto en climas áridos como húmedos, por lo que el aporte de la evidencia sedimentológica no 
agrega mayor información para determinar las condiciones relacionadas a los niveles de humedad presentes durante la depositación del miembro inferior.

De acuerdo a lo expresado en el gráfico de la Fig. 16, las condiciones ambientales del miembro medio indicarían un aumento en los niveles de humedad, pasando a estadíos mayormente semi-húmedos, creciendo progresivamente la humedad hacia la parte superior del miembro medio (Fig. 16). Como fuera mencionado previamente, el Miembro Laguna Polina habría sido depositado mayormente durante el Guadalupiano (Pérmico Medio). Para ese entonces, la actividad del arco magmático gondwánico habría disminuido o bien, cesado momentáneamente (5.2). La evidencia paleoflorística concuerda con un aumento en las condiciones de humedad, que se habría dado conjuntamente con un incremento progresivo en las temperaturas. La abundancia y diversidad de la flora colectada del Miembro Laguna Polina, sumada a la presencia de varias especies de helechos y licófitas (Cuadro I; Anexo I), evidenciarían mejoras en las condiciones ambientales. Tal cual ocurriera con el miembro inferior, aún no se han registrado características litológicas que indiquen particularmente alguna de estas condiciones ambientales, pero futuros trabajos de campo con una atención enfocada en su hallazgo, pueden aportar la evidencia requerida. Por otra parte, de los datos obtenidos en el gráfico de la Fig. 16, se observan dos (P5, P7) que indican condiciones de semi-aridez, contrastando con la tendencia predominante a un aumento en la humedad ambiental. Respecto a la muestra P5, se puede mencionar que la muestra presentaba alteración leve, por lo que quizás ello influyó en las modas detríticas finales. Respecto a la muestra P7, su ubicación en el gráfico de la Fig. 16 indica condiciones áridas. No he podido deducir las causas para que se genere este resultado en tal muestra, por lo que puedo únicamente especular con un episodio de clima árido intercalado, o un potencial error de muestreo.

Finalmente, la imposibilidad de muestreo del miembro superior hasta el momento no permitió realizar inferencias climáticas para ese miembro. Sin embargo, de acuerdo a la tendencia global, se esperaría que los datos marquen condiciones predominantemente semiáridas a áridas, dado que el Miembro Dos Hermanos se habría depositado en la parte más 
tardía del Pérmico (Lopingiano), cuando las condiciones globales eran de altas temperaturas y marcada aridez. Esto estaría en contraste a la evidencia sedimentológica descripta por Jalfin (1987; Jalfin et al., 1990), en base a la presencia de los abanicos aluviales típicos de condiciones húmedas que se habrían desarrollado. ¿Estaría esto acaso, marcando condiciones locales de humedad? Si es así, ¿qué lo causaría? Hasta tanto no se realice un muestreo, no se puede discutir más al respecto.

Resumiendo, los registros paleobotánicos y sedimentológicos de la Formación La Golondrina estarían evidenciando las tendencias climáticas globales sucedidas a lo largo del Pérmico, donde la flora se desarrolló primeramente bajo condiciones post-deglaciación, caracterizadas por temperaturas templadas con una tendencia a aumentar, y aridez relativa (Miembro Laguna Lillo), para luego desarrollarse bajo condiciones más favorables, con temperaturas más altas y humedad alta (Miembro Laguna Polina). La tendencia indica que durante la depositación del miembro superior, las condiciones bajo las cuales se habría desarrollado la flora habrían sido de mayor temperatura aún, y marcada aridez generada por este aumento de temperatura, pero la falta de datos aún no permite llegar a una conclusión al respecto. A diferencia de otras cuencas pérmicas, como Paganzo, donde hubo una mayor influencia de las condiciones glacial y post-glacial, o Tepuel-Genoa, donde la influencia marina presente durante su depositación ejerció un efecto buffer en las condiciones ambientales (Cúneo, 1986; López-Gamundí et al., 1992; Cúneo, 1996; Limarino et al., 1996; Limarino y Spalletti, 2006; González y Díaz Saravia, 2010), los factores más determinantes que afectaron el clima y por ende, el desarrollo de la flora de la Formación La Golondrina, estarían relacionados con la actividad del arco magmático gondwánico durante el desarrollo del miembro inferior, así como el aumento en la continentalidad a nivel global. Durante los tiempos de depositación del miembro medio, la actividad magmática habría cesado, por lo que las condiciones se habrían atenuado, dando lugar a temperaturas más estables, y niveles de humedad más elevados, aunque en ambos casos, habría habido una marcada estacionalidad, evidenciada sobretodo por la presencia predominante de glossopterídeas y algunas cordaitales, plantas típicamente decíduas 
(considerado una adaptación para la supervivencia durante períodos desfavorables) en ambos miembros (Axelrod, 1966; Lele, 1976; Gould y Delevoryas, 1977).

La aplicación del método de análisis paleoclimático a partir del estudio de cortes delgados de areniscas, en conjunción con el control simultáneo de la evidencia paleobotánica, demuestra claramente, aún por medio de estos resultados preliminares, un alto potencial para desarrollar mejores inferencias utilizando este método en toda la Cuenca La Golondrina. En un futuro cercano, se espera poder aumentar el muestreo tanto para el miembro inferior como el medio, así como generar un set de datos del miembro superior, donde queden reflejadas las tendencias paleoclimáticas que sucedieron durante la depostiación de la Formación La Golondrina con mayor exactitud. 


\section{- CAPÍTULO 7 -}

CONCLUSIONES 


\section{0 - CONCLUSIONES}

\section{1- Conclusiones generales}

Todos los objetivos generales y particulares propuestos (Capítulo 1), fueron cumplidos a lo largo de esta tesis.

Se planteó y siguió un protocolo que implicaba la visita a colecciones paleontológicas de varias instituciones del país (Instituto Lillo en Tucumán, Museo de La Plata en La Plata, Facultad de Ciencias Exactas y Naturales de la U.B.A en Buenos Aires, y Museo Argentino de Ciencias Naturales "B. Rivadavia" en Buenos Aires), donde se revisó todo el material fósil proveniente de La Golondrina. Se realizaron 2 viajes de campo (2008 y 2010) al área donde afloran sedimentos pérmicos de la Formación La Golondrina para colectar nuevo material megaflorístico, y se colectaron muestras de areniscas provenientes de los distintos miembros de la Formación La Golondrina para posteriormente analizar sus propiedades petrográficas en el gabinete (Capítulo 2).

El nuevo material fósil colectado fue ubicado estratigráficamente en los perfiles sedimentarios relevados en el campo por la autora. A su vez, estos perfiles fueron correlacionados con las secciones de referencia de las unidades realizados por Archangelsky (1959a) y Jalfin (1987) para cada una de las localidades donde fueron levantados (Capítulo 3).

Se revisó taxonómicamente el material fósil de la Formación La Golondrina, tanto el depositado en las colecciones institucionales (más de 2100 ejemplares) como el colectado por la autora (1100 ejemplares). Todo el material fue examinado, identificado, redescripto y asignado cuando fue necesario, y los ejemplares de mejor preservación y más representativos fueron fotografiados e ilustrados en detalle (Capítulo 4).

La distribución vertical de los 65 taxones identificados en la Formación La Golondrina permitió proponer la modificación del esquema bioestratigráfico conocido para 
la Cuenca (Archangelsky y Cúneo, 1984). El nuevo esquema informal, incluye de base a techo, a las Biozonas 1, 2 y 3. La Biozona 1, reconocida en el miembro inferior (Laguna Lillo) se caracteriza por el predominio de Gangamopteris por sobre Glossopteris, la aparición de Megistophyllum leanzai, y la presencia de helechos pecopterídeos de pínnulas pequeñas (ej., Asterotheca sp. 3). La Biozona 2 (equivalente a la biozona de Dizeugotheca waltonii), se reconoce por la presencia exclusiva de Annularia kurtzii, Dichotomopteris hirundinis, D. ovata, Glossopteris stricta y Eremopteris golondrinensis, por la aparición de Dizeugotheca waltonii, por la abundancia de las fructificaciones de glossopterídeas y por el reemplazo de las especies de Gangamopteris por las de Glossopteris, y caracteriza al miembro medio (Laguna Polina). La Biozona 3 (equivalente a la biozona de Asterotheca singeri), es reconocida por un claro empobrecimiento de la flora (respecto a la Biozona 2), por la presencia dominante de Glossopteris damudica, G. retifera, y Asterotheca golondrinensis, y la ausencia de Gangamopteris y Asterotheca andersonii. Esta última biozona caracterizaría al miembro superior (Dos Hermanos).

La presencia de cada taxón integrante de la flora de La Golondrina fue analizada y comparada para cada cuenca del Pérmico en Argentina (Tepuel-Genoa, Paganzo, San Rafael, Sierras Autrales, Malvinas), Brasil, India, Australia, Sudáfrica y la Antártida. Esta correlación permitió inferir una edad que abarca el lapso que va del Cisuraliano tardío al Lopingiano para las biozonas reconocidas en la Formación La Golondrina; la evidencia petrográfica de las areniscas que integran esta unidad refuerza dicha inferencia (Capítulo 5).

Por último, se utilizó la petrografía sedimentaria como método novedoso para el análisis de condiciones paleoambientales de la cuenca. El análisis de las areniscas medianas y gruesas de la Formación La Golondrina, reveló importantes datos respecto a la procedencia del aporte sedimentario en la Cuenca La Golondrina (Capítulo 6).

Las hipótesis testeadas confirmaron que: 
- La flora fósil de la Formación La Golondrina posee una diversidad mucho mayor a la previamente reconocida, acercándose a aquellas de Sudáfrica, Australia e India, y diferenciándose de sus afines sudamericanas (por ejemplo, Tepuel Genoa en Argentina, o Paraná, en Brasil).

El número de especies registradas hasta el momento para la formación oscilaba entre 45-50 taxones. A partir de este estudio, se confirma la presencia de 65 taxones hasta la fecha. Entre los numerosos nuevos hallazgos, se destacan varias tipos de fructificaciones de glossopterídeas, una de sphenophyllal, una licofita, y el primer registro para la formación de un grupo hasta el momento ausente, las coniferofitas. Asimismo, se presentaron por primera vez elementos florísticos provenientes del miembro inferior (Laguna Lillo), que permitieron revisar el esquema bioestratigráfico previamente propuesto para la Cuenca La Golondrina (Archangelsky y Cúneo, 1984), sobre la base de los elementos del miembro medio y superior únicamente.

- La mayor afinidad con floras de cuencas extra-sudamericanas estaría más relacionada a un sesgo de colección en las floras pérmicas sudamericanas que a una diferencia real en la diversidad.

El aumento en el número de fructificaciones de glossopterídeas reconocidas para la Formación La Golondrina es sin duda la causa de esta semejanza en diversidad con floras pérmicas extra-sudamericanas, de donde se conocen varias fructificaciones ya descriptas y asignadas. Muy posiblemente, la afinidad con cuencas sudamericanas podría aumentar a partir del posible hallazgo de fructificaciones de glossopterídeas en sedimentitas que actualmente exhiben registro de hojas de Glossoteridales (Cuenca Tepuel Genoa: Formaciones Río Genoa y Mojón de Hierro; Cuenca Paganzo: Fomaciones Arroyo Totoral, La Colina, Tasa Cuna y Bajo de Véliz; Cuenca Sierras Australes: Cuenca San Rafael: Formaciones El Imperial y Carapacha; Formación Bonete; Cuenca Malvinas: Formación Choiseul; Cuenca Paraná: Formaciones Río Bonito y Río Do Rasto -en Brasil- y 
Formación Melo -en Uruguay-), ya que su presencia parece ser dominante en las asociaciones fósiles donde las Glossopteridales constituyen un elemento importante.

- La edad de la Formación de La Golondrina abarca desde finales del Cisuraliano (Artisnkiano) al Lopingiano, esto evidenciado por el registro paleobotánico y apoyado por la evidencia aportada del análisis de cortes delgados de areniscas.

Si bien no se pudo acotar con mayor precisión la edad asignada a la Formación La Golondrina por distintos autores, se aportó otra evidencia que permite llegar a la misma conclusión. Los elementos florísticos hallados (principalmente las fructificaciones de glossopterídeas, y variaciones en la diversidad de especies en los tres miembros de la Formación) y el análisis petrográfico de las areniscas de los miembros Laguna Lillo y Laguna Polina, permitirían referir el Miembro Laguna Lillo al Artinskiano-Roadiano, el Miembro Laguna Polina al Wordiano-Wuchiapingiano y el Miembro Dos Hermanos al Changhsingiano (Lopingiano más tardío).

\section{2 - Líneas de investigación}

Ampliamente reconocida por todos los investigadores paleobotánicos como una flora muy diversa, la revisión de material de colección, así como de nuevos elementos, ha demostrado ser de gran utilidad para revelar que la flora de la Formación La Golondrina era mucho más diversa de lo que se creía. Sin duda, ninguna cuenca estará lo suficientemente prospectada o explorada, ni todos los fósiles colectados lo suficientemente analizados, estudiados o comprendidos como para creer que no hay razón para volver a revisarlos. Es por ello que aquí se propone no abandonar las investigaciones en el área, a través de prospecciones de zonas no exploradas, con la colección de nuevo material, pero con un enfoque más acotado, ya sea acotando el objetivo (estudio de un determinado 
grupo), por la aparición de un elemento novedoso, o por ser un elemento ya conocido pero que presenta una mejor preservación que pueda ayudar a dilucidar algunas de las descripciones incompletas y, por ende, afinar la asignación específica (ej., Sphenopteris sp II). Esto queda evidenciado a partir de la descripción de los primeros ejemplares paleobotánicos para el miembro inferior (Laguna Lillo). También, la revisión de colecciones es de suma importancia a la hora de rever los elementos de una determinada flora; a través de esta metodología, se hallaron varios ejemplares, que aumentaron considerablemente el número de especies conocida para La Golondrina.

La imposibilidad, hasta el momento, de hallar un área adecuada donde aflorara el miembro superior (Dos Hermanos) no permitió incrementar el número de ejemplares de su flora, y dejó pendiente además el muestreo de areniscas para su posterior análisis petrográfico.

Por ello, esta tesis plantea varias líneas de investigación, entre las que se proponen:

-Análisis paleoecológico de comunidades. El hallazgo de coniferofitas estaría indicando condiciones ambientales diferentes a las previamente propuestas en base a los demás taxones conocidos.

-Teoría de la Patagonia como un bloque alóctono. Muestreos más amplios y numerosos de areniscas para el análisis de cortes delgados provenientes de los distintos miembros aportaría datos que podrían ayudar a esclarecer el origen del bloque patagónico.

-Análisis filogenéticos/cladísticos. Aplicable especialmente al grupo de las glossopterídeas, dado que su número sigue aumentando en elementos fértiles y estériles. 


\section{- BIBLIOGRAFÍA -}

* Adendorff, R., 2005. A revision of the ovuliferous fructifications of glossopterids from the Permian of South Africa. Ph.D. Thesis, University of the Witwatersrand, Johannesburg, 421 pp.

* Adendorff, R., McLoughlin, S., Bamford, M.K., 2002. A new genus of ovuliferous glossopterid fructifications from South Africa. Palaeontologia Africana 38, 1-17.

* Amos, A.J., 1964. A review on the Carboniferous Marine Formations of Argentina. XXII International Congress of Geology, Proceedings 9, 53-72.

* Anderson, J.M., Anderson, H.M., 1985. Palaeoflora of southern Africa. Prodromus of South African megafloras: Devonian to Lower Cretaceous. Rotterdam: A.A. Balkema, 423 pp.

* Andreis, R.R., 2002. Cuenca La Golondrina (depósitos del rift pérmico y evento magmáticos triásicos). En: Halle, M.J., (Ed.), Geología y Recursos Naturales de Santa Cruz, Relatorio del $15^{\circ}$ Congreso Geológico Argentino (El Calafate), pp. 71-82.

- Andreis, R.R., Archangelsky, S., 1996. The Neo-Paleozoic Basins of southern South America. En: Moullade, M., Nairn, A.E.M., (Eds.), The Phanerozoic Geology of the World, The Paleozoic, B. Chapter 5, pp. 341-650. Elsevier, Amsterdam.

* Andreis, R.R., Archangelsky, S., González, C.R., López Gamundí, O., Sabattini, N., 1987. Cuenca Tepuel-Genoa. En: Archangelsky, S. (Ed.) El Sistema Carbonífero en la República Argentina. Academia Nacional de Ciencias, Córdoba, pp. 169-196.

* Arber, E.A.N., 1905a. Catalogue of the Fossil Plants of the Glossopteris Flora in the Department of Geology, British Museum (Natural History). Longmans and Co. and others, London, 255 pp. 8 pts.,

- Arber, E.A.N., 1905b. On the sporangium-like organs of Glossopteris browniana. Quaterly Journal of the Geological Society 61, 324-338.

* Archangelsky, A., 1999. Semillas del Paleozoico Superior de Argentina; su utilización bioestratigráfica. Ameghiniana 36, 465-476.

* Archangelsky, A., 2000. Estudio sobre semillas neopaleozoicas de Argentina. Boletín Academia Nacional Ciencias 64, 79-115.

* Archangelsky, S., 1957a. Las glossopterídeas del Bajo de La Leona (Santa Cruz). Revista de la Asociación Geológica Argentina 12, 135-164.

* Archangelsky, S., 1957b. Sobre la flora de Glossopteris del Bajo de La Leona, Santa Cruz, Patagonia. Ameghiniana 1, 42-43.

* Archangelsky, S., 1959a. Estudio geológico y paleontológico del Bajo de la Leona (Santa Cruz). Acta Geológica Lilloana 2 [1958], 5-133. 
* Archangelsky, S., 1959b. "Eremopteris golondrinensis". Nueva especie de la Serie La Golondrina, Bajo de La Leona. Santa Cruz. Acta Geológica Lilloana 2 [1958], 285-289.

* Archangelsky, S., 1979. Paleoecología del Paleozoico superior argentino sobre la base de sus plantas fósiles. Ameghiniana 15, 73-84.

* Archangelsky, S., 1960a. Lycopsida y Sphenopsida del Paleozoico superior de Chubut y Santa Cruz, Patagonia. Acta Geológica Lilloana 3, 21-36.

* Archangelsky, S., 1960b. "Chiropteris harrisii”, nueva especie de la Serie La Golondrina, Provincia de Santa Cruz. Acta Geológica Lilloana 3, 289-293.

* Archangelsky, S., 1990. Plant distribution in Gondwana. En: Taylor, T.N., Taylor E.L. (Eds.) Antarctic Paleobiology, pp. 102-117. Springer-Verlag.

* Archangelsky, S., 1992. Dictyopteridium Feistmantel (fructificaci6n pérmica de glossopteridales): primer registro argentino. VII Simposio Argentino de Paleobotánica y Palinologia. Publicación Especial de la Asociación Paleontológica Argentina 2, 19-22.

* Archangelsky, S., 2006. Dizeugotheca waltonii (Biozona de Intervalo de). En: Gutiérrez, P.R., Ottone, E.G., Japas, S.M., (Eds.), Léxico Estratigráfico de la Argentina. Volumen VII. Pérmico. Asociación Geológica Argentina, Serie B (Didáctica y Complementaria) 28, 108-109.

* Archangelsky, S., Arrondo, O.G., [1967] 1969. The Permian taphofloras of Argentina with some considerations about the presence of "northern" elements and their possible significations. En: Gondwana Stratigraphy, IUGS Symposium, pp. 71-89. Buenos Aires, Argentina.

* Archangelsky, S., Arrondo, O.G., 1973. Palaeophytología Kurtziana. III. 10. La tafoflora pérmica de la Sierra de Los Llanos, prov. de La Rioja. Ameghiniana 10, 201-228.

* Archangelsky, S., Bonetti, M., 1963. Fructificaciones de glossopterídeas del Pérmico del Bajo de la Leona, Provincia de Santa Cruz. Ameghiniana 3, 29-34.

* Archangelsky, S., Cúneo, N.R., 1984. Zonación del Pérmico continental argentino sobre la base de sus plantas fósiles. Memorias del III Congreso Latinoamericano de Paleontología, pp. 143-153. México.

* Archangelsky, S., Cúneo, N.R., 1987. Ferugliocladaceae, a new conifer Family from the Permian of Gondwana. Review of Paleobotany and Palynology 51, 3-30.

* Archangelsky, S., Cúneo, N.R., 2002. Floras del Paleozoico superior. Cuenca La Golondrina. En: Haller, M.J., (Ed.), Geología y Recursos Naturales de Santa Cruz, $15^{\circ}$ Congreso Geológico Argentino (El Calafate), Relatorio, pp. 401-405. Buenos Aires.

* Archangelsky, S., De la Sota, E., 1960. Contribución al conocimiento de las fílices pérmicas de la Patagonia extraandina. Acta Geológica Lilloana 3, 85-126.

* Archangelsky, S., Leguizamón, R., 1980. Elementos paleoflorísticos en el Carbónico Superior de la zona de Malanzán, Sierra de los Llanos, provincia de La Rioja. En: Actas del II Congreso Argentino de Paleontología y Bioestratigrafía y I Congreso Latinoamericano de Paleontología IV, 31-44. 
* Archangelsky, S., Azcuy, C.L., Wagner, R.H., 1981a. Three dwarf lycophytes from the Carboniferous of Argentina. Scripta Geologica 64, 1-35.

- Archangelsky, S., Archangelsky, A., Cúneo, R. 1981b. Algunos elementos paleoflorísticos de las Formaciones Piedra Shotel y Nueva Lubecka, Pérmico Inferior, Estancia La Casilda, Provincia de Chubut. Ameghiniana 18, 207-220.

* Archangelsky, S., Azcuy, C.L., Andreis, R.R., 1985. Cordillera and cratonic basins of Argentina. En: C. Martínez Díaz (Ed.), The Carboniferous of the World. IGCP Publications 20, pp. 180-226. Madrid, Spain.

* Archangelsky, S., Arrondo, O., Leguizamón, R.R., 1995. Floras Paleozoicas. Actas de la Academia Nacional de Ciencias 11, 85-125.

* Archangelsky, S., Jalfin, G.A, Cúneo, N.R., 1996a. Cuenca La Golondrina. En: Archangelsky, S., (Ed.), El Sistema Pérmico en la República Argentina y en la República Oriental del Uruguay, Academia Nacional de Ciencias, pp. 93-108. Córdoba.

* Archangelsky, S., Azcuy, C.L., Césari, S.N., González, C.R., Hünicken, M.A., Mazzoni, A., Sabattini, N., 1996b. Correlación y edad de las biozonas. En: Archangelsky, S., (Ed.), El Sistema Pérmico en la República Argentina y en la República Oriental del Uruguay, Academia Nacional de Ciencias, pp. 203226. Córdoba.

* Archangelsky, S., González, C., Cúneo, N.R., Sabattini, N, Césari, S.N., Aceñolaza, F., García, G., Buatois, L.A., Ottone, E., Mazzoni, A., Hünicken, M., Gutiérrez, P.R., 1996c. Paleontología, bioestratigrafía y paleoecología de las Cuencas Paganzo, Calingasta-Uspallata, Río Blanco y San Rafael. En: Archangelsky, S., (Ed.), El Sistema Pérmico en la República Argentina y en la República Oriental del Uruguay, Academia Nacional de Ciencias, pp. 177-201. Córdoba.

- Archangelsky, S., Césari, S.N., Cúneo, N.R., 1999. Revisión de Asterotheca golondrinensis Herbst, helecho pérmico de Patagonia, Argentina. Asociación Paleontológica Argentina, Publicación Especial 6, 23-26.

* Archangelsky, Césari, S.N., Cúneo, N.R., 2004. On some similar Patagonian and Indian Permian Ferns. En: Srivastava, P.C. (Ed.), Vistas in Palaeobotany and Plant Morphology: Evolutionary and Environmental Perspectives, Prof. D.D. Pant Memorial Volumen, pp. 71-81. U.P. Offset, Lucknow, India.

* Arrondo, O.G., 1967. Dizeugotheca branisae n. sp. Nueva fílice eusporangiada del Pérmico inferior, Bolivia. Revista del Museo de La Plata, Paleontología 5, 55-61.

* Arrondo, O.G., 1969. Estudio geológico y paleontológico en la zona de la Estancia La Juanita y alrededores, Provincia de Santa Cruz. Universidad Nacional de La Plata, Tesis de Doctorado, pp. 275 (inédita).

- Arrondo, O.G., 1972. Estudio geológico y paleontológico de la zona de Estancia La Juanita y alrededores, provincia de santa Cruz, Argentina. Revista del Museo de La Plata, Paleontología 43, 1-194. 
* Arrondo, O.G., Petriella, B., 1978. El género Lepidodendropsis Lutz del Carbónico inferior de Argentina. Ameghiniana 15, 440-444.

* Arrondo, O.G., Petriella, B., 1985. Bumbudendron millani (Arrondo et Petriella) n. comb., del CarbónicoPérmico de Argentina y Brasil. Ameghiniana 21, 169-171.

* Asama, K., (1967) 1969. Parallelism in Paleozoic plants between Gondwanaland and Cathaysia land. En: Gondwana Stratigraphy, IUGS Symposium, pp. 127-153. Buenos Aires, Argentina.

* Asama, K., 1970. Evolution and classification of Sphenophyllales in Cathaysia land. Bulletin of the National Science Museum of Tokyo 13, 291-317.

* Axelrod, D. I., 1966. A method for determining the altitudes of Tertiary floras. Palaeobotanist 14, 144177.

* Axelrod, D.I., 1981. Role of volcanism in climate and evolution. Geological Society of America Special Papers 185, 59.

* Azcuy, C.A., Caminos, R., 1987. Diastrofismo. En: Archangelsky, S. (Ed.) El Sistema Carbonífero en la República Argentina. Academia Nacional de Ciencias, Córdoba, pp. 239-252.

* Bajpai, U., 2001. Some remarks on the glossopterids and stratigraphical distribution of their fructifications during the Permian on Gondwana Supercontinent. Palaeobotanist 50, 287-293.

* Banerjee, M., 1968. On Scutum stowanum Plumstead, the fructification borne by Glossopteris decipiens Feistmantel from the Raniganj Stage of India and cuticular study of the fertile and vegetative leaves of $G$. decipiens Feistmantel. Bulletin of the Botanical Society of Bengal 22, 165-168.

* Banerjee, M., 1969. Senotheca murulidihensis, a new glossopteridean fructification from India associated with Glossopteris taeniopteroides Fesitmantel. J. Sen Memorial Volume. Botanical Society of Bengal, Calcutta, 359-368.

* Banerjee, M., 1973. Glossopteridean fructifications: 1. Dictyopteridium sporiferum Feistmantel. Bulletin of the Botanical Society of Bengal 27, 77-84.

* Banerjee, M., 1978. Genus Glossopteris Brongniart and its stratigraphic significance in the Palaeozoics of India. Part 1: a revisional study of some species of the genus Glossopteris. Bulletin of the Botanical Society of Bengal 32, 81-125.

* Banerjee, M., 1984. Fertile organs of the Glossopteris flora and their possible relationship in the line of evolution. En: Sharma, A.K., (Ed.), Proceedings of a symposium on evolutionary botany and biostratigraphy. A.K. Ghosh Commemoration Volume. New Delhi: Today and Tomorrows Printers and Publishers, pp. 29-59.

* Banerjee, M., Mitra, S., Dutta, S., 2009. On the occurrence of three species of Annularia Sternberg in the Early Permian Glossopteris flora of peninsular India. Review of Paleobotany and Palynology 153, 394407. 
* Barreda, V.D., Césari S.N., 1995. Glossopteridales y estructuras reproductivas asociadas en el Flanco Oriental de la Sierra de Los Llanos (Pérmico), Prov. de La Rioja. Argentina. VI Congreso Argentino de Paleontología y Bioestratigrafía, Actas, pp. 39-46. Trelew 1994.

* Basu, A., 1976. Petrology of Holocene fluvial sand derived from plutonic source rocks: Implications to paleoclimatic interpretation. Journal of Sedimentary Petrology 46, 694-709.

* Beeston, J.W., 1990. Cyclodendron leslii (Seward) Kräusel 1928 and associated palynomorphs in the Early Permian Reds Dome beds, Queensland, Australia. Alcheringa 14, 325-330.

* Bellosi, E.S., Jalfin, G.A., 1990. Cuencas neopaleozoicas de la Patagonia Extraandina e Islas Malvinas. En: Chebli, G., y Spalletti, L. (Eds.) Cuencas Sedimentarias Argentinas. Serie Correlación Geológica, pp. 379-393. San Miguel de Tucumán, Argentina.

* Benecke,A. K., 1976. Several new forms of Glossopteris fructifications from the Beaufort Daptocephalus-Zone (Upper Permian) of Natal, South Africa. Palaeontologia Africana 19, 97-125.

* Bernardes de Oliveira, M.E.C., 1978. Frutificações de pteridospermófitas eogondvânicas da camada Irapuá, Formação Rio Bonito, nos arredores de Criciúma, SC. En: Anais do Congresso Brasileiro de Geologia, 2, 986-1001.

* Bernardes de Oliveira, M.E.C., Carvhalo, R., 1981. Frutificações femeninas de Glossopterídeas da Formação Rio Bonito, Grupo Tubarãol, Estado de Santa Catarina, Brasil. En: Anais do Congresso Latino Americano de Paleontología I, 183-199.

* Bernardes de Oliveira, M.E.C., Ricardi-Branco, F., Rösler, O., 2000. As estruturas reprodutivas de Glossopterídeas na sucessão das tafofloras permianas da Bacia do Paraná, Brasil. Geociências 5, 62-68.

* Borrello, A.V., 1966. Paleontografía Bonaerense. Fascículo II. Plantas Fósiles. Comisión de Investigación Científica, La Plata.

* Boureau, E., 1964. Traité de Paléobotanique. III. Sphenophyta, Noeggerathiophyta.. Masson et Cie. Éditeurs, pp. 519. Paris.

* Boureau, E., 1967. Traité de Paléobotanique. II. Bryophyta, Psilophyta, Lycophyta. Masson et Cie. Éditeurs, pp. 845. Paris.

* Boureau, E., 1970. Traité de Paléobotanique. IV(I). Filicophyta. Masson et Cie. Éditeurs, pp. 519. Paris.

* Boureau, E., 1975. Traité de Paléobotanique. IV(II). Pteridophylla. Masson et Cie. Éditeurs, pp. 768. Paris.

* Brongniart, A., 1822. Sur la classification et la distribution des végétaux fossils en general, et sur ceux des terrains de sediment supérieur en particulier. Societé Philom., Bulletin, 25-28.

* Brongniart, A., 1828. Histoire des vegetaux fossiles ou recherches botaniques sur les vegetaux renfermes dans les diverses couches du globe. Paris 1, 1-136. 
* Buatois, L.A., Jalfin, G., Aceñolaza, F.G., 1997. Permian nonmarine invertebrates trace fossils from Southern Patagonia, Argentina: Ichnologic signatures of substrate consolidation and colonization sequences. Journal of Paleontology 71, 324-336.

* Bunbury, C.J.F., 1861. Notes on a collection of fossil plants from Nagpur, central India. Quaterly Journal of the Geological Society of London 17, 325-346.

* Cariglino, B., Gutiérrez, P.R., Manassero, M., 2009. Plumsteadia pedicellata sp. nov.: A new glossopterid fructification from the La Golondrina Formation (Guadalupian-Lopingian), Santa Cruz Province, Argentina. Review of Palaeobotany and Palynology 156, 329-336.

* Carrizo, M.A., Archangelsky, S., 2009. Una Pteridosperma fértil de la Formación La Golondrina (Pérmico), provincia de Santa Cruz, Argentina. Ameghiniana 46 (Resúmenes), 67.

* Cazzulo-Klepzig, M., 1978. Estudo da tafofloras do Membro Morro Pelado na sua localidade-tipo. Pesquisas 11, 225-303.

* Chaloner, W.G., Boureau, E., 1967. Lycophyta. En: Traité Paléobotanique. Tome II. Boureau, E. (Ed.), Masson et Cie. 435-802. Paris.

* Chaloner, W.G., Leistikow, K.U., Hill, A., 1979. Brasilodendron gen. nov. and B. pedroanum (Carruthers) nov. comb. a permian lycopod from Brasil. Review of Palaeobotany and Palynology 28, 117-136.

* Chandra, S., Rigby, J.F., 1983. The filicales from the Lower Gondwanas of Handappa, Orissa. Palaeobotanist 31, 143-147.

* Chandra, S., Srivastava, A.K., 1981. A new species of Arberia from the Lower Gondwana of South Rewa Gondwana Basin, India. Palaeobotanist 28, 40-45.

* Chandra, S., Surange, K.R., 1976. Studies of the reproductive organs of Glossopteris Part 1. Dictyopteridium feistmanteli sp. nov. attached on Glossopteris tenuinervis. Palaeontographica 156B, 87102.

* Chandra, S., Surange, K.R., 1977. Fertile bracts and scales of Glossopteris fructifications from the Lower Gondwana of India. Palaeobotanist 24, 195-201.

* Chandra, S., Surange, K.R., 1979. Revision of the Indian species of Glossopteris. Birbal Sahni Institute of Palaeobotany Monograph 2, pp. 291. Lucknow, India.

* Chebli, G.A., Gebhard, J., Menzel, M., 1976. Estratigrafía y magmatismo en la zona de la Estancia La Juanita y alrededores (Departamento de Deseado, provincia de Santa Cruz). Actas del VI Congreso Geológico Argentino 1, 357-373.

* Chumakov, N.M., Zharkov, M.A., (2002). Climate during Permian-Triassic biosphere reorganizations, Article 1: Climate of the Early Permian. Stratigraphy and geological Correlation 10, 586-602.

* Chumakov, N.M., Zharkov, M.A., (2002). Climate during Permian-Triassic biosphere reorganizations, Article 2: Climate of the Late Permian and Early Triassic: General inferences. Stratigraphy and geological Correlation 11, 361-375. 
* Compton, R.R., 1962. Manual of Field Geology. John Wiley \& Sons, New York, pp. 378.

* Conert, H.J., Schaarschmidt, F., 1970. Zur nomenklatur der paläozoichen Gattung Tristachya Lilpop 1937 (Sphenopsida). Taxon 19, 793-725.

* Criado Roque, P., 1953. Informes preliminaries del reconocimiento geológico zona Bahía Laura, territorio de Santa Cruz. Yacimientos Petrolíferos Fiscales, Buenos Aires (inédito).

* Crowley, T.J., Baum, S.K., 1992. Modeling late Paleozoic glaciation. Geology 20, 507-510.

* Cúneo, N.R., 1986. Ecología de las floras neopaleozoicas argentinas. En: Actas del IV Congreso Argentino de Paleontología y Bioestratigrafía 1, 195-204.

* Cúneo, N.R., 1987. Estudio geológico y paleontológico de los afloramientos meridionales de la Formación Río Genoa, Pérmico Inferior de Chubut, Argentina. Tesis de Doctorado (inédita), pp. 232. Universidad Nacional de Buenos Aires.

* Cúneo, N.R., 1996. Permian phytogeography in Gndwana. Palaeogeography, Palaeoclimatology, Palaeoecology 125, 75-124.

* Dana, J.D., 1849. Geology: Appendix L. En: Wilkes’ United States Exploring Expedition 1838-1842. C. Sherman, Philadephia, pp. 714-720.

* De Giusto, J.M., 1954. Informe preliminar reconocimiento geológico zona de Florida Negra, territorio de Santa Cruz. Yacimientos Petrolíferos Fiscales, Buenos Aires (inédito).

* Dickinson, W.R., Suczek, C.A., 1979. Plate tectonics and sandstone compositions. American Association of Petroleum Geologists Bulletin 63, 2164-2182.

* Dickinson, W.R., Beard, S.L., Brakenridge, G.R., Erjavec, J.L., Ferguson, R.C., Inman, K.F., Knepp, R.A., Lindberg, F.A., Ryberg, P.T., 1983. Provenance of North American Phanerozoic sandstones in relation to tectonic setting. Geological Society of America Bulletin 94, 222-235.

* Di Persia, C.A., 1955. Informe previo al levantamiento geológico en escala 1:100.000 de la zona norte del territorio de Santa Cruz al sur del Río Deseado. $2^{\circ}$ Campaña. Yacimientos Petrolíferos Fiscales, Buenos Aires (inédito).

* Di Persia, C.A., 1956. Informe previo al levantamiento geológico en escala 1:100.000 de la zona norte del territorio de Santa Cruz al sur del Río Deseado. $3^{\circ}$ Campaña. Yacimientos Petrolíferos Fiscales, Buenos Aires (inédito).

* Dolianiti, E., 1954a. A flora do Gondwana inferior em Santa Catarina. I. O gênero "Gangamopteris". Notas Preliminares e Estudos, División Geológica Minera Dependencia Nacional de Producción Minera $89,1-12$.

* Dolianiti, E., 1954b. A flora do Gondwana inferior em Santa Catarina. I. O gênero "Glossopteris". Notas Preliminares e Estudos, División Geológica Minera Dependencia Nacional de Producción Minera 60, 17. 
* Durango de Cabrera, J., 1990. Datos preliminares sobre la revisión del género Glossopteris en la República Argentina. En: Annual Meeting Working Group, Project 211-IGCP, Resúmenes p. 114.

* Escapa, I., Cúneo, R., 2006. Primer registro de Neocalamites (Halle) Vladimirovics en el Pérmico de Gondwana. Ameghiniana 43, 85-92.

* Espejo, I.S., López-Gamundí, O.R., 1994. Source versus depositional controls on sandstone composition in a foreland basin: The El Imperial Formation (Mid-Carboniferous-Lower Permian), San Rafael Basin, Western Argentina. Journal of Sedimentary Research 64, 8-16.

* Feistmantel, O., 1876. On some fossil plants from the Damuda Series in the Raniganj Coalfield. Journal of the Asiatic Society of Bengal 45, 329-382.

* Feistmantel, O., 1879. Paläeozoische und mesozoische Flora des östlichen Australien. Palaeontographica B 3, 130-195.

* Feistmantel, O., 1881. The fossil flora of the Gondwana System. The flora of the Talchir - Karharbari beds. Memoirs of the Geological Survey of India. Paleontologia Indica 12 (supplement), 49-64.

* Folk, R.L., Andrews, P.B., Lewis, D.W., 1970. Detrital sedimentary rock classification and nomenclature for use in New Zealand. Journal of Geology and Geophysics 13, 937-968.

* Frenguelli, J., 1942. Contribuciones al conocimiento de la flora del Gondwana Superior en la Argentina. X. Chiropteris barrealensis n. sp. Notas del Museo de La Plata 7, Paleontología 51, 341-353.

* Frenguelli, J., 1953. Las Pecopterídeas del Pérmico de Chubut. Notas del Museo de La Plata, Paleontología 16, 287-296.

* Gallego, J., Escapa, I., Cúneo, N.R., 2008. El par Glossopteris-Arberia en la Formación Río Genoa, Pérmico Inferior de Chubut, Argentina. En: V Simposio Argentino del Paleozoico Superior, Resúmenes, p. 19.

* Gastaldo, R.A., Adendorff, R., Bamford, M., Labandeira, C.C., Neveling, J., Sims, H., 2005. Taphonomic trends of macrofloral assemblages across the Permian-Triassic boundary, Karoo Basin, South Africa. Palaios 20, 479-497.

* Gee, C.T., 1989. Permian Glossopteris and Elatocladus megafossil floras from the English Coast, Eastern Ellsworth Land, Antarctica. Antarctic Science 1, 35-44.

* Girty, G.H., 1991. A note on the composition of plutoniclastic sand produced in different climatic belts. Journal of Sedimentary Petrology 61, 428-433.

* Godeas, M.C., 1985. Geología en el Bajo de La Leona y su mineralización asociada. Provincia de Santa Cruz. Revista de la Asociación Geológica Argentina 40, 262-277.

* Goeppert, H.R., 1864. Die fossile flora der Permischen Formation. PalaeontographicaB 12, 1-224.

* González, C.R., Díaz Saravia, P., 2010. Bimodal carácter of the Late Paleozoic glaciations in Argentina and bipolarity of climatic changes. Palaeogeography, Palaeoclimatology, Palaeoecology 298, 101-111. 
* Goswami, S., Das, M., Guru, B.C., 2006a. Permian biodiversity of Mahanadi Master Basin, Orissa, India and their environmental countenance. Acta Palaeobotanica 46, 101-118.

* Goswami, S., Singh, K.J., Chandra, S., 2006b. Palaeobotany of Gondwana basins of Orissa State, India: A bird's eye view. Journal of Asian Earth Sciences 28, 218-233.

* Goswami, S., Singh, K.J., Chandra, S., 2006c. Pteridophytes from the Lower Gondwana formations of the Ib River Colafield, Orissa and their diversity and distribution in the Permian of India. Journal of Asian Earth Sciences 28, 234-250.

* Gould, R.E., Delevoryas, T., 1977. The biology of Glossopteris: evidence from petrified seed-bearing and pollen-bearing organs. Alcheringa 1, 387-399.

* Guido, D.M., de Barrio, R.E., 2004. Laguna Dulce: Nuevo afloramiento del Complejo Río Deseado, Macizo del Deseado, provincia de Santa Cruz. Revista de la Asociación Geológica Argentina 59, 360363.

* Guido, D.M., Escayola, M.P., Schalamuk, I.B., 2004. The basement of the Deseado Massif at the Bahía Laura, Patagonia, Argentina: a proposal for its evolution. Journal of South American Earth Sciences 16, 567-577.

* Gutiérrez, P.R., Arrondo, O.G., 1994. Revisión de las licópsidas de la Argentina. 1. Archaeosigillaria Kidston y Frenguellia Arrondo, Césari \& Gutiérrez. Ameghiniana 31, 381-393.

* Gutiérrez, P.R., Césari, S.N., Limarino, C.O., 1986. Bumbudendron versiforme a new lycophyte species from the late Paleozoic of Argentina. Review of Palaeobotany and Palynology 36, 377-386.

* Gutiérrez, P.R., Ottone, E.G., Japas, S.M. (Eds.), 2006. Léxico Estratigráfico de la Argentina. Volumen VII. Pérmico. Asociación Geológica Argentina, Serie B (Didáctica y Complementaria) 28, 368 pp.

* Halle, T.H. 1908. Zur Kenntnis mesozoischen Equisetales Schnedens. Kungliga Svenska vetenskaps Akademie Handlingar 45, 1-15.

* Herbst, R., 1965. La flora fossil de la Formación Roca Blanca (provincia de Santa Cruz) con consideraciones geológicas y estratigráficas. Opera Lilloana 12, 101.

* Herbst, R., 1972. Nota sobre la Presencia de Lycopsidae Arboresente en el Pérmico (Serie Independencia) del Paraguay. Ameghiniana 9, 258-264.

* Herbst, R., 1978. Asterotheca golondrinensis n.sp. from the Lower Permian Golondrina Series of the Bajo de la Leona, Santa Cruz, Argentina. Palaeobotanist 25, 126-130.

* Herbst, R., 1986. Cyclodendron cf. leslii (Sew.) (Lycopodiopsidaceae, Lycopsidae) del Pérmico de Paraguay y Uruguay. FACENA 6, 33-43.

* Herbst, R., Gutiérrez, P.R., 1995. Cyclodendron andreisii nov. sp. (Lycopodiosidaceae, Lycophyta) del Pérmico Superior de Uruguay. Ameghiniana 32, 141-150.

* Herbst, R., Troncoso, A., Gnaedinger, S., 2001. Rochipteris nov. gen., hojas incertae sedis (=Chiropteris pro parte) del Triásico Superior de Argentina y Chile. Ameghiniana 38, 257-269. 
* Hetterscheid, W.L.A., Batenburg, L.H., 1984. Sphenophyllum miravilis Vetter and Bowmanites cupulatus sp. n. from the "Illinger Flözzone" ("Heusweiller Schichten", Lower Stephanian, Saar Basin, German Federal Republic). Review of Paleobotany and Palynology 40, 263-293.

* Hirmer, M., 1927. Handbuch der Paleobotanik. München.

* Holmes, W.B.K., 1974. On some fructifications of the glossopteridales from the Upper Permian of N.S.W. Proceedings of the Linnean Society of New South Wales 98, 131-141.

* Holmes, W.B.K., 2001. Equisetalean plant remains from the Early to Middle Triassic of New South Wales, Australia. Records of the Australian Museum 53, 9-20.

* Homovc, J.F., Constantini, L.A., 2001. Hydrocarbon exploration potential within intraplate shear-related depocenters, Deseado and San Julián basins, southern Argentina. American Association of Petroleum geologists, Bulletin 85, 1795-1816.

* Hota, R.N., Das, B.K., Sahoo, M., Maejima, W., 2011. Provenance variability during the Damuda sedimentation in the Talchir Gondwana Basin, India - A statistical assessment. International Journal of Geosciences 2, 120-137.

* Ianuzzi, R., 2010. The flora of Early Permian coal measures from the Paraná Basin in Brazil: A review. International Journal of Coal Geology 83, 229-247.

* Irving, E., 1983. Fragmentation and assembly of the continents, Mid-Carboniferous to Present. Geological Surveys 5, 299-333.

* Jalfin, G.A., 1987. Estratigrafia y paleogeografia de las Formaciones La Golondrina y La Juanita, Pérmico de la provincia de Santa Cruz y su relación con rocas de edad similar en las Islas Malvinas. Tesis de Doctorado (inédita). Universidad Nacional de Tucumán. San Miguel de Tucumán, Argentina.

* Jalfin, G.A., 1990. Grupo Tres Cerros. Denominación formal para las sedimentitas neopaleozoicas que conforman el relleno de la Cuenca La Golondrina, provincia de Santa Cruz, Argentina. En: Annual Meeting Working Group, Project 211-IGCP, Resúmenes pp. 36-39.

- Jalfin, G.A., Bellosi, E.S., 1984. Variaciones del sistema de planicies entrelazadas en el Pérmico del NE de Santa Cruz, Argentina. En: Annual Meeting Working Group, Project 211- IGCP, Resúmenes pp. 2425.

* Jalfin, G., Cúneo, R., Archangelsky, S., 1990. Paleoambientes, paleobotánica y bioestratigrafía de la Formación La Golondrina en la localidad Dos Hermanos, Pérmico superior, Santa Cruz, Argentina. En: Annual Meeting Working Group, Project 211-IGCP, Resúmenes pp. 18-20.

* Kay, S.M., Ramos, V.A., Mpodozis, C., Sruoaga, P., 1989. Late Paleozoic to Jurassic silicic magmatism at the Gondwana margin: Analogy to the Middle Proterozoic in North America? Geology 17, 324-328.

- Kerp, J.H.F., 1984. Aspects of Permian palaeobotany and Palynology. III. A new reconstruction of Lilpopia raciborskii (Lilpop) Conert et Schaarschmidt (Sphenopsida). Review of Paleobotany and Palynology 40, 237-261. 
* Kovâcs- Endrödy, É., 1979. A re-evaluation of the venation structure of Glossopteris. Annals of the Geological Survey of South Africa 12, 107-141.

* Kovâcs- Endrödy, É., 1984. Notes on the Glossopteris conspicua Feistmantel and on its assumed stratigraphic significance. Annals of the Geological Survey of South Africa 17, 69-85.

* Kräusel, R., 1928. Fossile Plfanzenreste aus der Karruformation Deutsch-Südwestafrikas. En: Kräusel, R, Range P., (Eds.), Beiträge zur Kenntniss der Karuformation Deutsch-Südwest-Afrikas. Beiträge zur geologischen Erforschung der deutschen Schutzgebiete 20, 17-54. Berlin.

* Kräusel, R., 1961. Lycopodiopsis derbyi Renault und einige ander Lycopodiales aus den GondwanaSchichten. PalaeontographicaB 100, 61-92.

* Krumbein, E.C., Sloss, L.L., 1955. Stratigraphy and sedimentation. San Francisco, Freeman \& Co., pp. 427.

* Kyle R.A., 1974. Plumsteadia ovata n. sp., a glossopterid fructification from south Victoria Land, Antarctica (note). New Zealand journal of geology and geophysics 17, 719-721.

* Lacey, W., 1978. A review of the Upper Permian Glossopteris flora in western Natal. Palaeobotanist 25, 185-189.

* Lacey, W., van Dijk, D.E., Gordon-Gray, K.D., 1974. New Permian Glossopteris flora from Natal. South African Journal of Science 70, 154-156.

* Lacey, W., van Dijk, D.E., Gordon-Gray, K.D., 1975. Fossil plants from the Upper Permian in the Mooi River district of Natal, South Africa. Annals of the Natal Museum 22, 349-420.

* Lakhanpal, R.N., Maheshwari, H.K., Awasthi, N., 1976. A catalogue of Indian fossil plants. Birbal Sahni Institute of Palaeobotany, pp. 318.

* Le Roux, S.F., 1976. On some “northern” elements in the lower Gondwana flora of Vereeniging. Palaeontographica Africana 13, 1-14.

* Lejal-Nicol, A., Bernardes de Oliveira, M.E.C., 1979. Sur une nouvelle spéce de Cyclodendron Kräusel 1928, du Permien Infèrieur de l'État de Santa Catarina au Brésil. 104 Congrès National des Sociétés savantes, Sciences, Comptes Rendus 1, 121-132. Bordeaux.

* Lele, K.M., 1976. Paleoclimatic implications of Gondwana flora. Geophytology 6, 207-229.

* Lemoigne,Y., Brown, J.T., 1980. Revision du genere Lycopodiopsis B. Renault, 1890. Geobios 13, 555577.

* Lesta, P.J., Ferrello, R., 1972. Región extraandina de Chubut y norte de Santa Cruz. En: Leanza, A.F. (Ed.) Geología Regional Argentina, 601-653. Academia Nacional de Ciencias. Córdoba, Argentina.

* Li, X., 1996. The mixed Permian Cathaysia-Gondwana flora. Palaeobotanist 35, 211-222.

* Limarino, C.O., Spalletti, L.A., 2006. Paleogeography of the Upper Paleozoic basins of southern South America: An overview. Journal of South American Earth Sciences 22: 134-155. 
* Limarino, C.O., Césari, S.N., López-Gamundí, O.R., 1996. Las fases climáticas del Paleozoico Superior del oeste Argentino: Su expresión estratigráfica y valor como herramienta de correlación. En: Actas del XIII Congreso Geológico Argentino y III Congreso de Exploración de Hidrocarburos 1, 495-509.

* Lindley, J., Hutton, W., 1832. The Fossil Flora of Great Britain or, figures and descriptions of the vegetable remains found in a fossil state in this country. James Ridgeway, Piccadilly, London, pp. 208.

* Lipiarski, I., 1972a. New data concerning the morphology of the fossil genus Lilpopia Conert et Schaarschmidt 1970 (=Tristachya Lilpop 1937). Acta Paleobotanica 13, 101-109.

* Lipiarski, I., 1972b. Lilpopia polonica Lipiarski from the Karniowice travertine (Lower Autunian) near Cracow, Poland. Acta Paleobotanica 13, 111-120.

* López-Gamundí, O.R., 2006. Permian plate margin volcanism and tuffs in adjacent basins of west Gondwana: Age constraints and common characteristics. Journal of South American Earth Sciences 22, 227-238.

* López-Gamundí, O.R., Limarino, C.O., Césari, S.N., 1992. Late Paleozoic paleoclimatology of central western Argentina. Palaeogeography, Palaeoclimatology, Palaeoecology 91, 305-329.

* López-Gamundí, O.R., Conaghan, P.J., Rossello, E.A., Cobbold, P.R., 1995. The Tunas Formation (Permian) in the Sierras Australes foldbelt, east central Argentina: evidence for syntectonic sedimentation in a foreland basin. Journal of South American Earth Sciences 8, 129-142.

* Mack, G.H., Jerzykiewicz, T., 1989. Detrital modes of sand and sandstone derived from andesitic rocks as paleoclimatic indicator. Sedimentary Geology 65, 35-44.

* Maheshwari, H.K., 1965. Studies in the Glossopteris Flora of India-22. On some species of the genus Glossopteris from the Raniganj Stage of the Raniganj Coalfield, Bengal. Palaeobotanist 13, 129-143.

* Maheshwari, H.K., 1968a. Gonophylloides nom. nov. Taxon 17, 238-239.

* Maheshwari, H.K., 1968b. Studies in the Glossopteris flora of India - 38. Remarks on Trizygia speciosa Royle with reference to the genus Sphenophyllum. Palaeobotanist 16, 283-287.

* Maheshwari, H.K., 1990. The glossopterid fructifications: an overview. En: Douglas J.G., Christophel, D.C., (Eds.), Proceedings of $3^{\text {rd }}$ IOP Conference, Melbourne 1988. International Organization of Palaeobotany Publ. 2, pp. 11-15.

* Maheshwari, H.K., 1974. Paleozoic Lycopsida and Sphenopsida. En: Surange, K.R., Lakhanpal, R.N., Bhardwaj, D.C. (eds.) Aspects and Appraisals of Indian Palaeobotany, pp. 54-61. Birbal Sahni Institute of Palaeobotany, Lucknow, India.

* Maheshwari, H.K, Bajpai, U., 2001. Phytostratigraphical succession in the Glossopteris flora of India. Revista Universidade Guaruhlos, Geociencias 4, 22-34.

* Mahr, A., 1868. Über Sphenophyllum thoni, eine neue Art aus dem Steinkohlengebirge von Ilmenau. Z. Dtsch. Geol. Gesch. 20 (1868), pp. 433-434. 
* Maithy, P.K., 1965. Studies in the Glossopteris flora of India - 20. Noeggerathiopsis and allies remains from the Karharbari beds, Giridih Colafield, India. Palaeobotanist 13, 94-100.

* Maithy, P.K., 1974a. A revision of the lower Gondwana Sphenopteris from India. Palaeobotanist 21, 7080.

* Maithy, P.K., 1974b. Dichotomopteris, a new type of fern frond from the lower Gondwana of India. Palaeobotanist 21, 365-367.

* Maithy, P.K., 1975. Some contribution to the knowledge of Indian lower Gondwana ferns. Palaeobotanist 22, 29-39.

* Maithy, P.K., 1977. Three new fern fronds from the Glossopteris flora of India. Palaeobotanist 24, 96101.

* McAllister Rees, P., Ziegler, A.M., Gibbs, M.T., Kutzbach, J.E., Behling, P.J., Rowley, D.B., 2002. Permian phytogeographic patterns and climate data/model comparisons. Journal of Geology 110, 1-31.

* McCLelland, J., 1850. Report of the Geological Survey of India for the season of 1848-1849. Military Orphan Press, Calcutta, pp. 52-57.

* McCoy, F., 1860. A commentary on “A communication made by the Rev. W. B. Clarke” \& C. Transaction of Royal Society, Victoria 5, 98.

* McLoughlin, S., 1990a. Late Permian glossopterid fructifications from the Bowen and Sydney Basins, eastern Australia. Geobios 23, 283-297.

* McLoughlin, S., 1990b. Some Permian glossopterid fructifications and leaves from the Bowen Basin, Queensland, Australia. Review of Palaeobotany and Palynology 62, 11-40.

* McLoughlin, S., 1992. Late Permian plant megafossils from the Bowen Basin, Queensland, Australia. Part I. Palaeontographica B228, 105-149.

* McLoughlin, S., 1993. Glossopterid megafossils in Permian Gondwanic non-marine biostratigraphy. En: Findlay, R. H., Unrug, R., Banks, M. R., Veevers, J. J., (Eds.), Gondwana Eight: Assembly, Evolution and Dispersal, A. A. Balkema, Rotterdam, Netherlands, pp. 253-264.

* McLoughlin, S., 1994a. Late Permian plant megafossils from the Bowen Basin, Queensland, Australia. Part II. Palaeontographica B231, 1-29.

* McLoughlin, S., 1994b. Late Permian plant megafossils from the Bowen Basin, Queensland, Australia. Part III. Palaeontographica B231, 31-62.

* McLoughlin, S., 1995. Bergiopteris and glossopterid fructifications from the Permian of Western Australia and Queensland. Alcheringa 19, 175-192.

* McLoughlin, S., 2001. The breakup history of Gondwana and its impact on pre-Cenozic floristic provincialism. Australian Journal of Botany 49, 271-300. 
* McLoughlin, S., Drinnan, A.N., 1996. Anatomically preserved Permian Noeggerathiopsis leaves from east Antarctica. Review of Paleobotany and Palynology 92, 207-227.

* McLoughlin, S, Drinnan, A.N., Lindström, S., 1997. Gondwanan floristic and sedimentological trends during the Permian-Triassic transition: new evidence from the Amery Group, northern Prince Charles Mountains, East Antarctica. Antarctic Science 9, 281-298.

* McLoughlin, S., Larsson, K., Lindström, S., 2005. Permian plant macrofossils from Fossilryggen. Vestfjella, Dronning Maud Land. Antarctic Science 17, 73-86.

* Melchor, R.N., Césari, S.N., 1997. Permian floras from Carapacha Basin, central Argentina. Description and importance. Geobios 30, 607-633.

* Menéndez, C.A., 1962. Hallazgo de una fructificación en la flora de Glossopteris de la Provincia de Buenos Aires (Lanceolatus bonaerensis sp.nov.). Consideraciones sobre la nomenclatura de fructificaciones de Glossopteris. Ameghiniana 2, 175- 182.

* Meyen, S.V., 1964. On the morphology, anatomy and nomenclature of leaves of the Angara-Gondwana genus Noeggerathiopsis. Dockl. Sovietic Geologie 9, 87-99.

* Meyen, S.V., (1967) 1969. New data on the relationships between Angara and Gondwana Late Paleozoic Floras. En: Gondwana Stratigraphy, IUGS Symposium, pp. 141-157. Buenos Aires, Argentina.

* Neish, PG., Drinnan, A.G., Cantrill, D.J., 1993. Structure and ontogeny of Vertebraria from silicified Permian sediments in East Antarctica. Review of Paleobotany and Palynology 79, 221-224.

* Palma, M.A., Ubaldón, M.C., 1988. Las sedimentitas gondwánicas de la Formación La Golondrina en la Estancia Dos Hermanos, Provincia de Santa Cruz. Revista de la Asociación Geológica Argentina 43: 388-403.

* Pankhurst, R.J., Rapela, C.W., Loske, W.P., Márquez, M, Fanning, C.M., 2003. Chronological study of the pre-Permian basement rocks of southern Patagonia. Journal of South American Earth Sciences 16, 27 44.

* Pankhurst, R.J., Rapela, C.W., Fanning, C.M., Márquez, M., 2006. Gondwanide continental collision and the origin of Patagonia. Earth Science Reviews 76, 235-257.

* Pant, D.D., 1958. The structure of some leaves and fructifications of the Glossopteris flora of Tanganyika. Bulletin of the British Museum (Natural History) Geology 3, 127-183.

- Pant, D.D., 1982. The Lower Gondwana gymnosperms and their relationships. Review of Palaeobotany and Palynology 37, 55-70.

* Pant, D.D., 1996. The biogeography of the late Paleozoic floras of India. Review of Paleobotany and Palynology 90, 79-98.

* Pant, D.D., Nautiyal, D.D., 1984. On the morphology and structure of Ottokaria zeilleri sp. nov.- a female fructification of Glossopteris. Palaeontographica B193, 127-152. 
* Panza, J.L., 1994. Hoja Geológica 4966-I/II Bahía Laura, escala 1:250000 (Santa Cruz). Dirección Nacional del Servicio Geológico, Boletín 214.

* Pezzuchi, H.D., 1978. Estudio geológico de la zona de Estancia Dos Hermanos, Estancia 25 de Marzo y adyacencias. Departamento Deseado. Provincia de Santa Cruz. Universidad Nacional de La Plata, Tesis de Doctorado, pp. 124 (inédita).

* Pfefferkorn, H.W., 1976. Pennsylvanian tree fern compressions Caulopteris, Megaphyton, and Artisophyton gen. nov. in Illinois. Illinois State Geological Survey Circular 492, 1-32.

* Pigg, K.B., Trivett, M.L., 1994. Evolution of the glossopterid gymnosperms from the Permian Gondwana. Journal of Plant Research 107, 461-477.

* Plumstead, E.P., 1952. Description of two new genera and six new species of fructitlcations home on Glossopteris leaves. Transactions and Proceedings of the Geological Society of South Africa 55, 281328.

* Plumstead, E.P., 1956a. Bisexual fructifications borne on Glossopteris leaves from South Africa. Palaeontographica B100, 1-25.

* Plumstead, E.P., 1956b. On Ottokaria, the fructification of Gangamopteris. Transactions and Proceedings of the Geological Society of South Africa 59, 211-236.

- Plumstead, E.P., 1958. Further fructifications of the Glossopteridae and a provisional classification based on them. Transactions and Proceedings of the Geological Society of South Africa 61, 51-76.

* Poulsen, C.J., Pollard, D., Montañez, I.P., Rowley, D., 2007. Late Paleozoic tropical climate response to Gondwanan deglaciation. Geology 35, 771-774.

* Powers, M. C., 1953. A new roundness scale for sedimentary particles. Journal of Sedimentary Petrology 23, 117-119.

* Powers, M.C., 1982. Comparison chart for estimating roundness and sphericity. AGI (@ 1982 American Geological Institute), Alexandria, Va., data sheet 18.1.

* Prevec, R., McLoughlin, S., Bamford, M., 2008. Novel double wing morphology revealed in a South African ovuliferous glossopterid fructification: Bifariala intermittens (Plumstead 1958) comb. nov. Review of Palaeobotany and Palynology 150, 22-36.

* Prevec, R., Labandeira, C.C., Neveling, J., Gastaldo, R.A., Looy, C.V., Bamford, M., 2009. Portrait of a Gondwanan ecosystem: A new late Permian fossil locality from KwaZulu-Natal, South Africa. Review of Palaeobotany and Palynology 156, 454-493.

* Prevec, R., Gastaldo, R.A., Neveling, J., Reid, S.B., Looy, C.V., 2010. An autochthonous glossopterid flora with latest Permian palynomorphs and its depositional setting in the Dicynodon Assemblage Zone of the southern Karoo Basin, South Africa. Palaeogeography, Palaeoclimatology, Palaeoecology 292, 391-408.

* Radczenko, G. P., 1955. Index-fossil od Upper Paleozoic flora of Sayan-Altai region. Atlas rukovod. Form iskop. Fauny I Flory Zap. Sibiri, 2, 42-153. 
* Ramos, V.A., 2008. Patagonia: A Paleozoic continent adrift? Journal of South American Sciences 26, 235-251.

* Ramos, V.A., Palma, M.A., 1996. Tectonismo y diastrofismo. Tectónica. En: Archangelsky, S., (Ed.), El Sistema Pérmico en la República Argentina y en la República Oriental del Uruguay, Academia Nacional de Ciencias, pp. 239-254. Córdoba.

* Rapela, C.W., Kay, S.M., 1988. Late Paleozoic to Recent magmatic evolution of northern Patagonia. Episodes 11, 175-182.

* Raymond, A., Parker, W.C., Parrish, J.T., 1985. Phytogeography and paleoclimate of the Early Carboniferous. En: Tiffney, B (Ed.) Geological factors and the evolution of plants, pp. 169-222. Yale University Press, New Haven, Connecticut.

* Rayner, R.J., 1985. The Permian lycopod Cyclodendron leslii from South Africa. Palaeontology 28, 111120.

* Retallack, G.J., Jahren, A.H., Sheldon, ND.,Chakrabarti, R., Metzger, C.A., Smith, R.M.H., 2005. The Permian-Triassic boundary in Antarctica. Antarctic Science 17, 1-17.

* Retallack, G.J., 1980. Middle Triassic megafossil plants and trace fossils from the Tank Gully, Canterbury, New Zealand. Journal of the Royal Society of New Zealand 10, 31-63.

* Rigby, J.F., [1962] 1963. On the collection of plants of Permian age from Baralaba, Queensland. Proceedings of the Linnean Society of New South Wales 87, 341-351.

* Rigby, J.F., 1969. The conservation of Plumsteadia Rigby 1963 over Cistella Plumstead 1958. Bolletim da Sociedade Brasileira de Geologia 17, 93.

- Rigby, J.F., 1971. A revision of some plants from the Permian of the Bowen Basin, Queensland. Geological Survey of Queensland Publications 349, 1-8.

- Rigby, J.F., 1972. On Arberia White, and some related Lower Gondwana female fructifications. Palaeontology 15, 108-120.

* Rigby, J.F., 1978. Permian glossopterid and other cycadopsid fructifications from Queensland. Geological Survey of Queensland Publications 367 41, 1-21.

* Rigby, J.F., Maheshwari, H, Schopf, J.M., 1980. Revision of Permian plants collected by J.D. Dana during 1839-1840 in Australia. Geological Survey of Queensland Publications 376, 1-25.

* Rohn, R., Rösler, O., 1986. Pteridófilas pecopteróides da Formação Rio do Rasto no Estado do Paraná e da Formação Estrada Nova no estado de São Paulo (Bacia do Paraná, Permiano Superior). Boletim IGUSP 17, 57-76.

* Rösler, O., 1978a. The Brazilian Eogondwanic floral succession. Bolletim IGUSP 9, 85-91.

* Rösler, O., 1978b. Novas ocorrência na Formação Rio do Rasto, Pemriano Superior, Estado do Paraná. Bolletim IGUSP 9, 127-132. 
* Rösler, O., Bernardes de Oliveira, M.E.C., Rohn, R., Peñaloza, A., 1994. Fructificação associada a Glossopteris na Formação Rio do Rasto, Estado de Paraná. En: Resumo da comunicaçöes da Reunião de Paleobotânicos e Palinólogos VIII, 67.

* Rothwell, G.W., Mapes, G., Hernández-Castillo, G., 2005. Hanskerpia gen. nov. and phylogenetic relationships among the most ancient conifers (Voltziales). Taxon 54, 733-750.

* Royer, D.L., 2006. $\mathrm{CO}_{2}$-forced climate thresholds during the Phanerozoic. Geochimica et Cosmochimica Acta 70, 5665-5675.

* Royle, J.F., 1833. Illustrations of the botany and other branches of natural history of the Hymalayan Mountains and of the flora of Cashmere, 2. W.H. Allen and Company, London, pp. 422.

* Ryberg, P.E., 2009. Reproductive diversity of Antarctic glossopterid seed-ferns. Review of Palaeobotany and Palynology 158, 167-179.

* Salvi, J., Jasper, A., Ricardi-Branco, F., Bernardes de Oliveira, M.E.C, Guerra-Sommer, M., 2008. Record of the genus Lycopodites in the Lower Permian of Paraná Basin, Brazil. Anais da Academia Brasileira de Ciências 80, 553-563.

* Schimper, W.P., 1869. Paléontologie Végétale. Texto en tres volúmenes y Atlas (1869-1874).

* Schopf, J.M., 1976. Morphologic interpretation of fertile structures in glossopterid gymnosperms. Review of Paleobotany and Palynology 21, 25-64.

* Scotese, C.R., McKerrow, W.S., 1990. Revised World maps and introduction. En: McKerrow, W.S., Scotese, C.R. (Eds.) Palaeozoic palaeogeography and biogeography. Geological Science Memoir 12, 121.

* Scotese, C.R., Boucot, A.J., McKerrow, W.S., 1999. Gondwanan palaeogeography and palaeoclimatology. Journal of South African Earth Sciences 28, 99-114.

* Seward, A.C., 1903. Fossil floras of Cape Colony. Annals South African Museum 4, 1-122.

* Seward, A.C., Leslie, T.N., 1908. Permo-Carboniferous plants from Vereeniging (Transvaal). Quaterly Journal of the Geological Society of London 64, 109-126.

* Shi, G.R., Waterhouse, J.B., McLoughlin, S., 2010. The Lopingian of Australasia: a review of biostratigraphy, correlations, palaeogeography and palaobiogeography. Geological Journal 45, $230-263$.

* Singh, S.M., 2000. Taxonomy and diversity of the genus Glossopteris. Palaeobotanist 49, 333-352.

* Singh, K.J., Goswami, S., Chandra, S., 2007. Occurrence of Cordaitales from the lower Gondwana sediments of Ib-River Coalfield, Orissa, India: An Indian scenario. Journal of Asian Earth Sciences 29, 666-684.

* Sommer, F.W., Trindade, N.M., 1966. Lycopodiales do Gondwana brasileiro. Ministério das Minas e Energia, Divisao de Geologia e Mineralogia, Boletim 230, 5-31. 
* Srivastava, A.K., 1978. Studies in the Glossopteris Flora of India 43. Some new plant fossils from the Lower Gondwana sediments of Auranga Coalfield, Bihar. Palaeobotanist 25, 486-493.

* Srivastava, A.K., 1992. Plant fossil assemblages from the Barakar Formation of Raniganj Coalfield, India. Palaeonotanist 24, 50-69.

* Srivastava, A.K., Agnihotri, D., 2010a. Morphological consequence of Gangamopteris McCoy in Glossopteris flora. Journal of Asian Earth Sciences 39, 760-769.

* Srivastava, A.K., Agnihotri, D., 2010b. Upper Permian plant fossil assemblage of Bijori Formation: A case study of Glossopteris flora beyond the limit of Raniganj Formation. Journal of the Geological Society of India 76, 47-62.

* Sternberg, G.K., 1825. Versuch einer geognostichen-botanischen Darstellung der flora der Vorwelt II (56), 1-80. Regensburg, Leipzig, Prague.

* Suero, T., Criado Roque, P., 1955. Descubrimiento del Paleozoico Superior al Oeste de Bahía Laura (territorio Nacional de Santa Cruz) y su importancia paleogeográfica. Notas del Museo de La Plata, Geología 18, 157-168.

* Surange, K.R., Chandra, S., 1973a. Dictyopteridium sporiferum Feistmantel - female cone from the Lower Gondwana of India. Palaeobotanist 20, 127-136.

* Surange, K.R., Chandra, S., 1973b. Denkania indica gen. et sp. nov., a glossopteridean fructification from the Lower Gondwana of India. Palaeobotanist 20, 264-268.

* Surange, K.R., Chandra, S., 1973c. Partha, a new type of female fructification from the Lower Gondwana of India. Palaeobotanist 20, 356.360.

* Surange, K.R., Chandra, S., 1974a. Fructifications of Glossopteridae from India. Palaeobotanist 21, 1-17.

* Surange, K.R., Chandra, S., 1974b. Lidgettonia mucronata sp. nov.: a female fructification from the Lower Gondwana of India. Palaeobotanist 21, 121-126.

* Surange, K.R., Chandra, S., 1974c. Some male fructifications of Glossopteridales. Palaeobotanist 21, 255-266.

* Surange, K. R., Chandra, S., 1975. Morphology of the gymnospermous fructifications of the Glossopteris flora and their relationships. Palaeontographica 149B, 153-180.

* Surange, K.R., Maheshwari, H.K., 1970. Some male and female fructifications of Glossopteridales from India. Palaeontographica 129B, 178-192.

* Suttner, L.J., Dutta, P.K., 1986. Alluvial sandstone composition and paleoclimate, I. Framework mineralogy. Journal of Sedimentary Petrology 56, 329-345.

* Suttner, L.J., Basu, A., Mack, G.H., 1981. Climate and the origin of quartz arenites. Journal of Sedimentary Petrology 51, 1235-1246. 
* Taylor, E.L., Taylor, T.N., 1992. Reproductive biology of the Permian Glossopteridales and their suggested relationship to flowering plants. Proceedings of the National Academy of Sciences USA 889, 11495-11497.

* Taylor, E.L., Taylor, T.N., Collinson, J.W., 1989a. Depositional setting and paleobotany of Permian and Triassic permineralized peat from the central Tansantarctic Mountains, Antarctica. International Journal of Coal Geology 12, 657-679.

* Taylor, T.N., Taylor, E.L., and Isbell, J.L., 1989b. Glossopterid organs from Mount Achernar, Antarctica. Antarctic Journal of the U.S. 24, 28-30

* Taylor, E.L., Taylor, T.N, Ryberg, P., 2007. Ovule-bearing reproductive organs of the glossopterid seed ferns from the Late Permian of the Beardmore Glacier region, Antarctica. $10^{\text {th }}$ International Symposium on Antarctic Earth Sciences: 1-4.

* Taylor, T.N., Taylor, E.L., Krings, M., 2009. Paleobotany - The biology and evolution of fossil plants. Second edition. Academic Press, 1230 pp.

* Thomas, H.H., 1958. Lidgettonia, a new type of fertile Glossopteris. Bulletin of the British Museum (Natural History) 3, 179-189.

* Thomas, B.A., 1977. Epidermal studies in the interpretation of Lepidophloios species. Paleontology 20, 273-293.

* Tucker, M.E., 2003. Sedimentary rocks in the field. John Wiley \& Sons, Ltd., pp. 234.

* Unger, F., 1850. Genera et species plantarum fossilium. Braumüller, Vienna, pp. 627.

* Viera, R., Pezzuchi, H., 1976. Presencia de sedimentitas pérmicas en contacto con rocas del "Complejo Metamórfico" de la Patagonia Extraandina, Estancia Dos Hermanos, provincia de Santa Cruz. Revista de la Asociación Geológica Argentina 31, 281-283.

* Vieira, C.E.L., Iannuzzi, R., Guerra-Sommer, M., Díaz-Martínez, E., Grader, G. W., 2004. Permian plants from the Chutani Formation (Titicaca Group, Northern Altiplano of Bolívia): genera Pecopteris and Asterotheca. Anais da Academia Brasileira de Ciências, 76, 1-12.

* Vieira, C.E.L., Ianuzzi, R, Guerra-Sommer, M., Cazzulo-Klepzig, M., 2005a. Revisão taxonómica de Dizeugotheca bortoluzzi Cazzulo-Klepzig. Boletim da Socidade Brasileira de Paleontología 49, 20.

* Vieira, C.E.L., Iannuzzi, R., Guerra-Sommer, M., Suarez-Soruco, R., 2005b. Pecopterídeas da Formação Copacabana (Permiano Inferior, Grupo Titicaca), Altiplano Boliviano. Boletim da Socidade Brasileira de Paleontología 49, 21.

* Vieira, C.E.L., Iannuzzi, R., Guerra-Sommer, M., 2007. Revisão de Pecopterídeas polimórficas do Neopaleozóico da América do Sul. Revista Brasileira de Paleontología 19, 107-116.

* Visser, J.N.J., 1995. Post-glacial Permian stratigraphy and geography of southern and central Africa: boundary conditions for climatic modelling. Palaeogeography, Palaeoclimatology, Palaeoecology 118, 213-243. 
* Visser, J.N.J., 1996. Controls on Early Permian shelf deglaciation in the Karoo Basin of South Africa. Palaeogeography, Palaeoclimatology, Palaeoecology 125, 129-139.

* Vladimirovicz, V.P.. 1958. Découverts des restes de Neocalamites avec les strobiles conservés. Doklady Adkademii Nauk S.S.S.R. 122, 695-698.

* Walkom, A.B., 1922. Palaeozoic floras of Queensland, part I. The flora of the Lower and Upper Bowen Series. Geological Survey of Queensland Publication 270, 1-65.

* Walkom, A.B., 1928. Notes on some additions to the Glossopteris flora in New South Wales. Proceedings of the Linnean Society of New South Wales 53, 555-564.

* Wang, J, Pfefferokorn, H.W., 2009. Nystromeiaceae, a new family of Permian gymnosperms from China with an unusual combination of features. Proceedings of the Royal Society 277B, 301-309.

* Wang, J., Pfefferkorn, H.W., Sun, B., Liu, L., 2003. Discovery of organic connection of Chiropteris Kurr and Nystroemia Halle from Early Permian of western Henan, China. Chinese Science Bulletin 48, 22482252.

* White, D., 1908. Report on the fossil flora of the coal measures of Brazil. Relatorio final Comisseo de Estudos das Minas de Carveo de Pedra do Brazil. Imprensa Nacional Rio de Janeiro 3, 336-617.

* White, M.E., 1964. Reproductive structures in Australian Upper Permian glossopteridae. Proceedings of the Linnean Society of New South Wales 88, 392-399.

* White, M.E., 1978. Reproductive structures of the Glossopteridales in the plant fossil collection of the Australian Museum. Records of the Australian Museum 31, 473-504.

* Wnuk, C., 1996. The development of floristic provinviality during the Middle and Late Paleozoic. Review of Paleobotany and Palynology 90, 5-40.

* Yemane, K., 1993. Contribution of Late Permian palaeogeography in maintaining a temperate climate in Gondwana. Nature 361, 51-54.

* Zeiller, R., 1896. Etude sur quelques plantes fossils en particulier Vertebraria et Glossopteris des environs de Johannesburg (Transvaal). Bulletin of the Geological Society of France 24, 349-378.

* Zeiller, R., 1902. Observations sur quelques plantes fossils des Lower Gondwanas. Memoirs of Geological Survey of India. Palaeontologica indica n.s. 2.

* Ziegler, A.M., 1990. Phytogeographic patterns and continental configurations during the Permian period. En: McKerrow, W.S., Scotese, C.R. (Eds.) Paleozoic Paleogeography and Biogeography. Geological Society of London Memoirs 12, 363-379. 


\begin{tabular}{|c|c|c|c|c|c|c|c|c|c|c|c|c|c|c|c|c|c|c|c|c|c|c|c|c|c|c|c|}
\hline \multirow{3}{*}{ CUENCA } & \multicolumn{13}{|c|}{ ARGENTINA } & \multirow{2}{*}{\multicolumn{2}{|c|}{$\begin{array}{c}\text { SudAm } \\
\text { Brasil }\end{array}$}} & \multicolumn{12}{|c|}{ Resto de Gondwana } \\
\hline & \multicolumn{3}{|c|}{ La Golondrina } & \multicolumn{2}{|c|}{$\begin{array}{l}\text { Tepuel } \\
\text { Genoa }\end{array}$} & \multicolumn{4}{|c|}{ Paganzo } & \multicolumn{2}{|c|}{$\begin{array}{c}\text { San } \\
\text { Rafael }\end{array}$} & \multirow{2}{*}{$\begin{array}{l}\text { Sa } \\
12\end{array}$} & \multirow{2}{*}{$\begin{array}{l}\mathbf{M} \\
13\end{array}$} & & & \multicolumn{3}{|c|}{ India } & \multicolumn{3}{|c|}{ Australia } & \multicolumn{3}{|c|}{ Sudafrica } & \multicolumn{3}{|c|}{ Antártida } \\
\hline & 1 & 2 & 3 & 4 & 5 & 6 & 7 & 8 & 9 & 10 & 11 & & & 14 & 15 & 16 & 17 & 18 & 19 & 20 & 21 & 22 & 23 & 24 & 25 & 26 & 27 \\
\hline ASTEROTHECA & & & & & & & $\mathrm{x}$ & & $\mathrm{x}$ & & & & & $\mathrm{x}$ & & & & & & & & $\mathrm{x}$ & & & & & \\
\hline Asterotheca $\mathrm{sp} 1$ & & $\mathrm{x}$ & & & & & & & & & & & & & & & & & & & & & & & & & \\
\hline Asterotheca $\mathrm{sp} 2$ & & $\mathrm{x}$ & & & & & & & & & & & & & & & & & & & & & & & & & \\
\hline Asterotheca sp 3 & $\mathrm{x}$ & $\mathrm{x}$ & & & & & & & & & & & & & & & & & & & & & & & & & \\
\hline A. anderssonii & & $\mathrm{x}$ & $\mathrm{x}$ & & $\mathrm{x}$ & & & & $\mathrm{x}$ & & & & & & & & & & & & & & & & & & \\
\hline A. golondrinensis & & $\mathrm{x}$ & $\mathrm{x}$ & $\mathrm{x}$ & & & & & & & & & & & & & & & & & & & & & & & \\
\hline A. piatnitzkyi & & $\mathrm{x}$ & & $\mathrm{x}$ & $\mathrm{x}$ & & & & & & & & & $\mathrm{x}$ & & & & & & & & & & & & & \\
\hline A. singeri & $\mathrm{x}$ & $\mathrm{x}$ & $\mathrm{x}$ & & & & & & & & & & & & & & & & & & & $\mathrm{x}$ & & & & & \\
\hline DIZEUGOTHECA & & & & & & & & & & & & & & & $\mathrm{x}$ & & & $\mathrm{x}$ & & & & & & & & & \\
\hline D. furcata & & $\mathrm{x}$ & & & & & & & & & & & & & & & & & & & & & & & & & \\
\hline D. neuburgiae & $\mathrm{x}$ & $\mathrm{x}$ & $\mathrm{x}$ & & & & & & & & & & & & & & & & & & & & & & & & \\
\hline D. waltonii & & $\mathrm{x}$ & $\mathrm{x}$ & & & & & & & & & & & & & & & & & & & & & & & & \\
\hline PECOPTERIS & & & & & & & & & $\mathrm{x}$ & & $\mathrm{x}$ & & & $\mathrm{x}$ & $\mathrm{x}$ & & & & & & & & & & & & \\
\hline$P . \mathrm{sp} \mathrm{A}$ & & $\mathrm{x}$ & & & & & & & & & & & & & & & & & & & & & & & & & \\
\hline$P$. sp I & & $\mathrm{x}$ & & & & & & & & & & & & & & & & & & & & & & & & & \\
\hline$P$. sp III & & $\mathrm{x}$ & & & & & & & & & & & & & & & & & & & & & & & & & \\
\hline
\end{tabular}




\begin{tabular}{|c|c|c|c|c|c|c|c|c|c|c|c|c|c|c|c|c|c|c|c|c|c|c|c|c|c|c|c|}
\hline & \multicolumn{3}{|c|}{ La Golondrina } & \multicolumn{2}{|c|}{$\begin{array}{l}\text { Tepuel } \\
\text { Genoa }\end{array}$} & \multicolumn{4}{|c|}{ Paganzo } & \multicolumn{2}{|c|}{$\begin{array}{c}\text { San } \\
\text { Rafael }\end{array}$} & \multirow{2}{*}{$\begin{array}{l}\text { Sa } \\
12\end{array}$} & \multirow{2}{*}{$\begin{array}{l}\mathbf{M} \\
13\end{array}$} & \multicolumn{2}{|c|}{ Brasil } & \multicolumn{3}{|c|}{ India } & \multicolumn{3}{|c|}{ Australia } & \multicolumn{3}{|c|}{ Sudafrica } & \multicolumn{3}{|c|}{ Antártida } \\
\hline & 1 & 2 & 3 & 4 & 5 & 6 & 7 & 8 & 9 & 10 & 11 & & & 14 & 15 & 16 & 17 & 18 & 19 & 20 & 21 & 22 & 23 & 24 & 25 & 26 & 27 \\
\hline$P$. sp IV & & $\mathrm{x}$ & & & & & & & & & & & & & & & & & & & & & & & & & \\
\hline Caulopteris sp. & & $\mathrm{x}$ & & & $\mathrm{x}$ & & & & & & & & & & & & & & & & & & & & & & \\
\hline DICHOTOMOPTERIS & & & & & & & & & & & & & & & & $\mathrm{x}$ & & & & & $\mathrm{x}$ & & & & & & \\
\hline D. hirundinis & & $\mathrm{x}$ & & & & & & & & & & & & & & & & & & & & & & & & & \\
\hline D. ovata & & $\mathrm{x}$ & & $\mathrm{x}$ & & & & & & & & & & & & & & & & & & & & & & & \\
\hline DAMUDOPTERIS & & & & & $\mathrm{x}$ & & $\mathrm{x}$ & & $\mathrm{x}$ & & & & & & & & & $\mathrm{x}$ & & & & & & & & & \\
\hline D. bengalensis & & $\mathrm{x}$ & & & $\mathrm{x}$ & & $\mathrm{x}$ & & $\mathrm{x}$ & & & & & & & & & $\mathrm{x}$ & & & & & & & & & \\
\hline SPHENOPTERIS & & & & & $\mathrm{x}$ & & $\mathrm{x}$ & & $\mathrm{x}$ & & $\mathrm{x}$ & & & $\mathrm{x}$ & & $\mathrm{x}$ & & $\mathrm{x}$ & & & & & & & & & \\
\hline Sphenopteris sp II & & $\mathrm{x}$ & & & & & $\mathrm{x}$ & & $\mathrm{x}$ & & & & & & & & & & & & $\mathrm{x}$ & & & & & & \\
\hline SPHENOPHYLLUM & & & & & $\mathrm{x}$ & $\mathrm{x}$ & & & & & & & & $\mathrm{x}$ & $\mathrm{x}$ & $\mathrm{x}$ & $\mathrm{x}$ & $\mathrm{x}$ & & & $\mathrm{x}$ & $\mathrm{x}$ & $\mathrm{x}$ & $\mathrm{x}$ & & & \\
\hline S. speciosum* & & $\mathrm{x}$ & $\mathrm{x}$ & & $\mathrm{x}$ & & & & & & & & & & $\mathrm{x}$ & $\mathrm{x}$ & $\mathrm{x}$ & $\mathrm{X}$ & & & $\mathrm{X}$ & $\mathrm{x}$ & $\mathrm{x}$ & $\mathrm{X}$ & & & \\
\hline S. thonii & $\mathrm{x}$ & $\mathrm{x}$ & $\mathrm{x}$ & & $\mathrm{x}$ & & & & & & & & & & & & & & & & & $\mathrm{x}$ & & & & & \\
\hline Lilpopia sp. & $\mathrm{x}$ & & & & & & & & & & & & & & & & & & & & & & & & & & \\
\hline ANNULARIA & & & & & & & & & & & & & & $\mathrm{x}$ & $\mathrm{x}$ & & $\mathrm{x}$ & & & & & $\mathrm{x}$ & $\mathrm{x}$ & $\mathrm{x}$ & & & \\
\hline A. kurtzii & & $\mathrm{x}$ & & & & & & & & & & & & & $\mathrm{x}$ & & & & & & & & & & & & \\
\hline Neocalamites sp. & & & $\mathrm{x}$ & & & & & & & & & & & & & & & & & & & & & & & & \\
\hline
\end{tabular}




\begin{tabular}{|c|c|c|c|c|c|c|c|c|c|c|c|c|c|c|c|c|c|c|c|c|c|c|c|c|c|c|c|}
\hline & \multicolumn{3}{|c|}{ La Golondrina } & \multicolumn{2}{|c|}{$\begin{array}{l}\text { Tepuel } \\
\text { Genoa }\end{array}$} & \multicolumn{4}{|c|}{ Paganzo } & \multicolumn{2}{|c|}{$\begin{array}{c}\text { San } \\
\text { Rafael }\end{array}$} & \multirow{2}{*}{$\begin{array}{l}\text { Sa } \\
12\end{array}$} & \multirow{2}{*}{$\begin{array}{l}\mathbf{M} \\
13\end{array}$} & \multicolumn{2}{|c|}{ Brasil } & \multicolumn{3}{|c|}{ India } & \multicolumn{3}{|c|}{ Australia } & \multicolumn{3}{|c|}{ Sudafrica } & \multicolumn{3}{|c|}{ Antártida } \\
\hline & 1 & 2 & 3 & 4 & 5 & 6 & 7 & 8 & 9 & 10 & 11 & & & 14 & 15 & 16 & 17 & 18 & 19 & 20 & 21 & 22 & 23 & 24 & 25 & 26 & 27 \\
\hline ?Phyllotheca sp. & & $\mathrm{x}$ & & & $\mathrm{x}$ & & $\mathrm{x}$ & $\mathrm{x}$ & & & $\mathrm{x}$ & $\mathrm{x}$ & $\mathrm{x}$ & $\mathrm{x}$ & $\mathrm{x}$ & & & $\mathrm{x}$ & & & $\mathrm{x}$ & & & $\mathrm{x}$ & & $\mathrm{x}$ & $\mathrm{x}$ \\
\hline Paraschizoneura sp. & & $\mathrm{x}$ & & & & & & & & & & & & & & & & & & & & & $\mathrm{x}$ & $\mathrm{x}$ & & & \\
\hline BUMBUDENDRON & & & & & $\mathrm{x}$ & & & & & & & & & & & & & & & & & & & & & & \\
\hline B. patagonicum & $\mathrm{x}$ & $\mathrm{x}$ & & & & & & & & & & & & & & & & & & & & & & & & & \\
\hline CYCLODENDRON & & & & & $\mathrm{x}$ & & & & & & & & & $\mathrm{x}$ & & $\mathrm{x}$ & $\mathrm{x}$ & $\mathrm{x}$ & & & $\mathrm{x}$ & $\mathrm{x}$ & & & & & \\
\hline C. golondrinensis & $\mathrm{x}$ & $\mathrm{x}$ & & & & & & & & & & & & & & & & & & & & & & & & & \\
\hline Licofita sp A & & $\mathrm{x}$ & & & & & & & & & & & & & & & & & & & & & & & & & \\
\hline Licofita sp B & & $\mathrm{x}$ & & & & & & & & & & & & & & & & & & & & & & & & & \\
\hline Eremopteris golondrinensis & & $\mathrm{x}$ & & & & & & & & & & & & & & & & & & & & & & & & & \\
\hline CORDAITES. (=Noegg)* & & & & $\mathrm{x}$ & $\mathrm{x}$ & $\mathrm{x}$ & $\mathrm{x}$ & $\mathrm{x}$ & $\mathrm{x}$ & & $\mathrm{x}$ & $\mathrm{x}$ & & $\mathrm{x}$ & $\mathrm{x}$ & $\mathrm{x}$ & & & & & $\mathrm{x}$ & & & $\mathrm{x}$ & & $\mathrm{x}$ & $\mathrm{x}$ \\
\hline Cordaites (Noegg.) hislopi & $\mathrm{x}$ & $\mathrm{x}$ & & & & $\mathrm{x}$ & $\mathrm{x}$ & $\mathrm{x}$ & $\mathrm{x}$ & & & $\mathrm{x}$ & & $\mathrm{x}$ & $\mathrm{x}$ & $\mathrm{x}$ & & & & & $\mathrm{x}$ & & & $\mathrm{x}$ & & $\mathrm{x}$ & $\mathrm{x}$ \\
\hline GLOSSOPTERIS & & & & $\mathrm{x}$ & $\mathrm{x}$ & $\mathrm{x}$ & $\mathrm{x}$ & $\mathrm{x}$ & $\mathrm{x}$ & $\mathrm{x}$ & $\mathrm{x}$ & $\mathrm{x}$ & $\mathrm{x}$ & $\mathrm{x}$ & $\mathrm{x}$ & $\mathrm{x}$ & $\mathrm{x}$ & $\mathrm{x}$ & $\mathrm{x}$ & $\mathrm{x}$ & $\mathrm{x}$ & $\mathrm{x}$ & $\mathrm{x}$ & $\mathrm{x}$ & $\mathrm{x}$ & $\mathrm{x}$ & $\mathrm{x}$ \\
\hline G. ampla & $\mathrm{x}$ & $\mathrm{x}$ & $\mathrm{x}$ & & & & & & & & & & & $\mathrm{x}$ & & $\mathrm{x}$ & $\mathrm{x}$ & $\mathrm{x}$ & & & $\mathrm{x}$ & $\mathrm{x}$ & $\mathrm{x}$ & $\mathrm{x}$ & $\mathrm{x}$ & & \\
\hline G. argentina & & $\mathrm{x}$ & $\mathrm{x}$ & & & & & & & & $\mathrm{x}$ & & & & & & & & & & & & & & & & \\
\hline G. browniana & $\mathrm{x}$ & $\mathrm{x}$ & $\mathrm{x}$ & & & $\mathrm{x}$ & & & & & $\mathrm{x}$ & $\mathrm{x}$ & $\mathrm{x}$ & $\mathrm{x}$ & $\mathrm{x}$ & $\mathrm{x}$ & $\mathrm{x}$ & $\mathrm{x}$ & & & $\mathrm{x}$ & $\mathrm{x}$ & $\mathrm{x}$ & $\mathrm{x}$ & & & \\
\hline G. consp. var. patagonica* & $\mathrm{x}$ & $\mathrm{x}$ & $\mathrm{x}$ & & & & & & & & & & & & & $\mathrm{x}$ & $\mathrm{x}$ & $\mathrm{X}$ & & & & $\mathrm{x}$ & & & & & \\
\hline
\end{tabular}




\begin{tabular}{|c|c|c|c|c|c|c|c|c|c|c|c|c|c|c|c|c|c|c|c|c|c|c|c|c|c|c|c|}
\hline & \multicolumn{3}{|c|}{ La Golondrina } & \multicolumn{2}{|c|}{$\begin{array}{l}\text { Tepuel } \\
\text { Genoa }\end{array}$} & \multicolumn{4}{|c|}{ Paganzo } & \multicolumn{2}{|c|}{$\begin{array}{c}\text { San } \\
\text { Rafael }\end{array}$} & \multirow{2}{*}{$\begin{array}{l}\text { Sa } \\
12\end{array}$} & \multirow{2}{*}{$\begin{array}{l}\mathbf{M} \\
13\end{array}$} & \multicolumn{2}{|c|}{ Brasil } & \multicolumn{3}{|c|}{ India } & \multicolumn{3}{|c|}{ Australia } & \multicolumn{3}{|c|}{ Sudafrica } & \multicolumn{3}{|c|}{ Antártida } \\
\hline & 1 & 2 & 3 & 4 & 5 & 6 & 7 & 8 & 9 & 10 & 11 & & & 14 & 15 & 16 & 17 & 18 & 19 & 20 & 21 & 22 & 23 & 24 & 25 & 26 & 27 \\
\hline G. damudica & & $x$ & $\mathrm{x}$ & & & & & & & & $x$ & & $\mathrm{x}$ & & & $\mathrm{x}$ & $\mathrm{x}$ & $\mathrm{x}$ & & & $\mathrm{x}$ & $\mathrm{x}$ & $\mathrm{x}$ & & & & \\
\hline G. indica & & $\mathrm{x}$ & $\mathrm{x}$ & & & & & & & & & $\mathrm{x}$ & $\mathrm{x}$ & $\mathrm{x}$ & & $\mathrm{x}$ & $\mathrm{x}$ & $\mathrm{x}$ & & & $\mathrm{x}$ & $\mathrm{x}$ & $\mathrm{x}$ & $\mathrm{x}$ & & & $\mathrm{x}$ \\
\hline G. retifera & & $\mathrm{x}$ & $\mathrm{x}$ & & & & & & & & & & & & & $\mathrm{x}$ & $\mathrm{x}$ & $\mathrm{x}$ & & & & $\mathrm{x}$ & & $\mathrm{x}$ & & & \\
\hline G. stipanicicii & $\mathrm{x}$ & $\mathrm{x}$ & & & & & & & & & & & & & & & & & & & $\mathrm{x}$ & & & & & & \\
\hline G. stricta & & $\mathrm{x}$ & & & & & & & & & & & & & $\mathrm{x}$ & $\mathrm{x}$ & $\mathrm{x}$ & $\mathrm{x}$ & & & & $\mathrm{x}$ & & & & & \\
\hline GANGAMOPTERIS & & & & & $\mathrm{x}$ & $\mathrm{x}$ & $\mathrm{x}$ & $\mathrm{x}$ & $\mathrm{x}$ & $\mathrm{x}$ & $x$ & $\mathrm{x}$ & & $x$ & & $\mathrm{X}$ & $\mathrm{x}$ & $?$ & $\mathrm{x}$ & & & $\mathrm{x}$ & & & & $\mathrm{x}$ & \\
\hline G. angustifolia & $\mathrm{x}$ & $\mathrm{x}$ & & & & & & & $\mathrm{x}$ & & & $\mathrm{x}$ & & $\mathrm{x}$ & & $\mathrm{x}$ & & & & & & & & & & $\mathrm{x}$ & \\
\hline G. castellanosii & $\mathrm{x}$ & $\mathrm{x}$ & & & & & & & & & & & & & & & & & & & & & & & & & \\
\hline G. mosesii & $\mathrm{x}$ & $\mathrm{x}$ & & & $\mathrm{x}$ & & & & & & & & & $\mathrm{x}$ & & & & & & & & & & & & & \\
\hline G. obovata & $\mathrm{x}$ & $\mathrm{x}$ & & & $x$ & $\mathrm{x}$ & $\mathrm{x}$ & $\mathrm{x}$ & $\mathrm{x}$ & $\mathrm{x}$ & $x$ & $\mathrm{x}$ & & $x$ & & $\mathrm{x}$ & & & & & $\mathrm{x}$ & $\mathrm{x}$ & & & & $\mathrm{x}$ & \\
\hline PALAEOVITTARIA & & & & & & & & & & & & & & & & $\mathrm{X}$ & $\mathrm{x}$ & $\mathrm{x}$ & & & & $\mathrm{x}$ & & & & $\mathrm{x}$ & \\
\hline P. kurtzii & & $\mathrm{x}$ & & & & & & & & & & & & & & & & & & & & & & & & & \\
\hline Vertebraria sp. & & $\mathrm{x}$ & & & & & & & & & & & $\mathrm{x}$ & & & $\mathrm{x}$ & $\mathrm{x}$ & $\mathrm{x}$ & & & $\mathrm{x}$ & & & $\mathrm{x}$ & & $\mathrm{x}$ & $\mathrm{x}$ \\
\hline Bifariala $\mathrm{cf}$. B. intermittens & & $x$ & & & & & & & & & & & & & & & & & & & & $\mathrm{x}$ & & & & & \\
\hline DICTYOPTERIDIUM & & & & & & & & & & & $\mathrm{x}$ & & & & & & & $\mathrm{x}$ & & & $\mathrm{x}$ & & & $\mathrm{x}$ & & & $\mathrm{x}$ \\
\hline D. costatum & & $\mathrm{x}$ & & & & & & & & & & & & & & & & & & & $\mathrm{x}$ & & & & & & \\
\hline
\end{tabular}




\begin{tabular}{|c|c|c|c|c|c|c|c|c|c|c|c|c|c|c|c|c|c|c|c|c|c|c|c|c|c|c|c|}
\hline & \multicolumn{3}{|c|}{ La Golondrina } & \multicolumn{2}{|c|}{$\begin{array}{l}\text { Tepuel } \\
\text { Genoa }\end{array}$} & \multicolumn{4}{|c|}{ Paganzo } & \multicolumn{2}{|c|}{$\begin{array}{c}\text { San } \\
\text { Rafael }\end{array}$} & \multirow{2}{*}{$\begin{array}{l}\text { Sa } \\
12\end{array}$} & \multirow{2}{*}{$\begin{array}{c}\mathbf{M} \\
13\end{array}$} & \multicolumn{2}{|c|}{ Brasil } & \multicolumn{3}{|c|}{ India } & \multicolumn{3}{|c|}{ Australia } & \multicolumn{3}{|c|}{ Sudafrica } & \multicolumn{3}{|c|}{ Antártida } \\
\hline & 1 & 2 & 3 & 4 & 5 & 6 & 7 & 8 & 9 & 10 & 11 & & & 14 & 15 & 16 & 17 & 18 & 19 & 20 & 21 & 22 & 23 & 24 & 25 & 26 & 27 \\
\hline D. natalensis & & $\mathrm{x}$ & & & & & & & & & & & & & & & & & & & & & & $\mathrm{x}$ & & & \\
\hline D. sporiferum & & $\mathrm{x}$ & & & & & & & & & $\mathrm{x}$ & & & & & & & $\mathrm{x}$ & & & $\mathrm{x}$ & & & $\mathrm{x}$ & & & \\
\hline GONOPHYLLOIDES & & & & & $?$ & & & & & & & & & & & $\mathrm{x}$ & & & $\mathrm{x}$ & & & $\mathrm{x}$ & & & & ? & \\
\hline G. semnes & & $\mathrm{x}$ & & & & & & & & & & & & & & & & & $\mathrm{x}$ & & & & & & & & \\
\hline Ottokaria sp. & & $\mathrm{x}$ & & & & & $\mathrm{x}$ & & & & & $\mathrm{x}$ & & & & $\mathrm{X}$ & & $\mathrm{x}$ & $\mathrm{X}$ & & $\mathrm{x}$ & $\mathrm{X}$ & & & & $\mathrm{x}$ & \\
\hline PLUMSTEADIA & & & & & & & & & & & & $\mathrm{x}$ & & $\mathrm{x}$ & & $\mathrm{x}$ & & $\mathrm{x}$ & $\mathrm{x}$ & & $\mathrm{x}$ & $\mathrm{x}$ & $\mathrm{x}$ & $\mathrm{x}$ & & $\mathrm{x}$ & $\mathrm{x}$ \\
\hline P. pedicellata & & $\mathrm{x}$ & & & & & & & & & & & & & & & & & & & & & & & & & \\
\hline SCUTUM & & & & & & & & & & & & & & $\mathrm{x}$ & & $\mathrm{x}$ & $\mathrm{x}$ & $\mathrm{x}$ & $\mathrm{x}$ & & $\mathrm{x}$ & $\mathrm{x}$ & & $\mathrm{x}$ & & & \\
\hline Scutum cf. S. elongatum & & $\mathrm{x}$ & & & & & & & & & & & & & & & & $\mathrm{x}$ & & & & & & & & & \\
\hline Senotheca sp. & & $\mathrm{x}$ & & & & & & & & & & & & & & & & $\mathrm{x}$ & & & $\mathrm{x}$ & & & & & & $\mathrm{x}$ \\
\hline LIDGETTONIA & & & & & & & & & & & & & & & & & & $\mathrm{x}$ & & & $\mathrm{x}$ & & $?$ & $\mathrm{x}$ & & & \\
\hline L. africana & & $\mathrm{x}$ & & & & & & & & & & & & & & & & & & & & & & $\mathrm{x}$ & & & \\
\hline Escamas tipo A & & $\mathrm{x}$ & & & & & & & & & & & & & & & & & & & & & & & & & \\
\hline Escamas tipo B & & $\mathrm{x}$ & & & & & & & & & & & & & & & & & & & & & & & & & \\
\hline Escamas tipo $\mathrm{C}$ & & $\mathrm{x}$ & & & & & & & & & & & & & & & & & & & & & & & & & \\
\hline ? Arberia sp. & & $\mathrm{x}$ & & & $\mathrm{x}$ & & $\mathrm{x}$ & & & & & & & $\mathrm{x}$ & & $\mathrm{x}$ & & & $\mathrm{x}$ & & ? & $\mathrm{x}$ & & & & & \\
\hline
\end{tabular}




\begin{tabular}{|c|c|c|c|c|c|c|c|c|c|c|c|c|c|c|c|c|c|c|c|c|c|c|c|c|c|c|c|}
\hline & \multicolumn{3}{|c|}{ La Golondrina } & \multicolumn{2}{|c|}{$\begin{array}{l}\text { Tepuel } \\
\text { Genoa }\end{array}$} & \multicolumn{4}{|c|}{ Paganzo } & \multicolumn{2}{|c|}{$\begin{array}{c}\text { San } \\
\text { Rafael }\end{array}$} & \multirow{2}{*}{$\begin{array}{l}\text { Sa } \\
12\end{array}$} & \multirow{2}{*}{$\begin{array}{l}\mathbf{M} \\
13\end{array}$} & \multicolumn{2}{|c|}{ Brasil } & \multicolumn{3}{|c|}{ India } & \multicolumn{3}{|c|}{ Australia } & \multicolumn{3}{|c|}{ Sudafrica } & \multicolumn{3}{|c|}{ Antártida } \\
\hline & 1 & 2 & 3 & 4 & 5 & 6 & 7 & 8 & 9 & 10 & 11 & & & 14 & 15 & 16 & 17 & 18 & 19 & 20 & 21 & 22 & 23 & 24 & 25 & 26 & 27 \\
\hline Coniferofitas & & $\mathrm{x}$ & & $\mathrm{x}$ & $\mathrm{x}$ & $\mathrm{x}$ & $\mathrm{x}$ & $\mathrm{x}$ & $\mathrm{x}$ & & & $\mathrm{x}$ & & $\mathrm{x}$ & & & & & & & & & & & & & \\
\hline SAMAROPSIS & & & & & $\mathrm{x}$ & $\mathrm{x}$ & & & $\mathrm{x}$ & $\mathrm{x}$ & & & & $\mathrm{x}$ & & & & & & & & & & & & & \\
\hline S. golondrinensis & & $\mathrm{x}$ & & & & & & & & & & & & & & & & & & & & & & & & & \\
\hline Megistophyllum leanzai & $\mathrm{x}$ & $\mathrm{x}$ & & & & & & & & & & & & & & & & & & & & & & & & & \\
\hline CHIROPTERIS & & & & & & & & & & & & & & $\mathrm{x}$ & & & & & & & & & & & & & \\
\hline C. harrisii & & $\mathrm{x}$ & & & & & & & & & & & & & & & & & & & & & & & & & \\
\hline
\end{tabular}




\section{ANEXO I}

Sa: Sierras Australes.

M: Malvinas.

1 - Miembro inferior Laguna Lillo.

2 - Miembro medio Laguna Polina.

3 - Miembro superior Dos Hermanos.

4 - Fm. Mojón de Hierro (Pm. Inf).

5 - Fm. Río Genoa (Pm. Inf).

6 - Fm. Bajo de Véliz (Pm. Inf).

7 - Fm. Arroyo Totoral (Pm. Inf).

8 - Fm. La Colina (Pm. Med-Inf).
9 - Fm. Tasa Cuna (Pm. Inf).

10 - Fm. El Imperial (Pm. Inf).

11 - Fm. Carapacha (Pm. Sup).

12 - Fm. Bonete (Pm. Inf).

13 - Fm. Bahía Choiseul (Pm. Inf).

14 - Fm. Río Bonito (Pm. Inf).

15 - Fm. Río do Rasto (Pm. Sup).

16-18 - Pérmico inferior, medio, superior.

19-21 - Pérmico inferior, medio, superior.

22-24 - Pérmico inferior, medio, superior.

25-27 - Pérmico inferior, medio, superior.

x: Taxón registrado.

X: Taxón registrado con mayor predominancia.

?: Taxón registrado con dudas.

* Notas: por cuestiones de conveniencia, se consideran indistintamente:

Sphenophyllum speciosum $\rightarrow$ Trizygia speciosa (ver discusión en 5.6)

Glossopteris conspicua var. patagonica $\rightarrow$ Glossopteris conspicua (por ser una variedad, se considera su presencia a nivel especie)

El registro de Paraschizoneura en Sudáfrica está aquí representado por Schizoneura africana según Anderson y Anderson (1985). 


\section{$\underline{\text { ANEXO II }}$}

Para el conteo de taxones en común entre las distintas cuencas, se consideraron los siguientes géneros:

Asterotheca

Dizeugotheca

Pecopteris

Caulopteris

Dichotomopteris

Damudopteris

Sphenopteris

Sphenophyllum

Lilpopia

Annularia

Neocalamites

Paraschizoneura

Phyllotheca

Bumbudendron

Cyclodendron

Eremopteris
Cordaites (=Noeggerathiopsis)

Glossopteris

Gangamopteris

Palaeovittaria

Vertebraria

Dictyopteridium

Gonophylloides

Ottokaria

Plumsteadia

Scutum

Senotheca

Lidgettonia

Arberia

Samaropsis

Megistophyllum

Chiropteris

Fueron excluídos aquellos taxones con nomenclatura abierta, como ser Licofita sp. A y B, etc.

Para el conteo de especies, se consideraron todas aquellas especies registradas en la Formación La Golondrina, excluyendo los taxones que no pudieron ser asignados a nivel específico (sp.), por ejemplo:

Asterotheca sp. 1

Asterotheca sp. 2

Asterotheca sp. 3
Pecopteris sp. A

Pecopteris sp. I

Pecopteris sp. III 
Pecopteris sp. IV

Sphenopteris sp. II

Licófita sp. A
Licófita sp. B

Coníferas

Las especies asignadas "cf." fueron consideradas como de la especie a la cual fueron conferidas en el conteo general. 


\section{$\underline{\text { ANEXO III }}$}

(Propiedades microscópicas de las areniscas analizadas)

\begin{tabular}{|c|c|c|c|c|c|}
\hline & $\%$ MATRIZ & REDONDEZ & ESFERICIDAD & SELECCIÓN & $\begin{array}{l}* \text { TAMAÑO DE } \\
\text { GRANO }(\varnothing)\end{array}$ \\
\hline $\mathrm{P} 4$ & $80 \%$ c, $20 \% \mathrm{~m}$ & subredondeado & subprismático & $\begin{array}{l}\text { moderadamente } \\
\text { seleccionado }\end{array}$ & $2-3$ \\
\hline $\mathrm{P} 3$ & $90 \% \mathrm{c}, 10 \% \mathrm{~m}$ & subanguloso & subprismático & $\begin{array}{c}\text { moderadamente } \\
\text { seleccionado }\end{array}$ & $-0,5-[0,5-1,5]-2$ \\
\hline P9 & $80 \% \mathrm{c}, 20 \% \mathrm{~m}$ & $\begin{array}{l}\text { subredondeado a } \\
\text { subanguloso }\end{array}$ & subdiscoidal & pobremente seleccionado & $-0,5-[2-3]-3$ \\
\hline P8 & $90 \% \mathrm{c}, 10 \% \mathrm{~m}$ & anguloso & $\begin{array}{l}\text { subdiscoidal a } \\
\text { esférico }\end{array}$ & pobremente seleccionado & $0-[1,5-2,5]-2,5$ \\
\hline P7 & $80 \% \mathrm{c}, 20 \% \mathrm{~m}$ & anguloso & $\begin{array}{l}\text { subprismático a } \\
\text { redondeado }\end{array}$ & $\begin{array}{c}\text { muy pobremente } \\
\text { seleccionado }\end{array}$ & $-1-[0,5-2]-2,5$ \\
\hline P6 & $90 \% \mathrm{c}, 10 \% \mathrm{~m}$ & $\begin{array}{l}\text { subanguloso a } \\
\text { subredondeado }\end{array}$ & subprismático & pobremente seleccionado & $1,5-[2-3]-4$ \\
\hline $\mathrm{P} 2$ & $90 \% \mathrm{c}, 10 \% \mathrm{~m}$ & subredondeado & subprismático & bien seleccionado & $0,5-[1-2]-2,5$ \\
\hline P5 & $90 \% \mathrm{c}, 10 \% \mathrm{~m}$ & subanguloso & subprismático & bien seleccionado & $2-[2-3]-3,5$ \\
\hline P13 & $90 \% \mathrm{c}, 10 \% \mathrm{~m}$ & $\begin{array}{c}\text { anguloso a } \\
\text { subanguloso }\end{array}$ & subprismático & pobremente seleccionado & $0-[1-2]-2,5$ \\
\hline $\mathrm{P} 12$ & $80 \% \mathrm{c}, 20 \% \mathrm{~m}$ & subanguloso & $\begin{array}{c}\text { esférico a } \\
\text { subprismático }\end{array}$ & pobremente seleccionado & $0,5-[1,5-3]-3,5$ \\
\hline P9 & $80 \% \mathrm{c}, 20 \% \mathrm{~m}$ & anguloso & subdiscoidal & pobremente seleccionado & $-0,5-[0,5-1,5]-2,5$ \\
\hline P8 & $80 \%$ c, $20 \% \mathrm{~m}$ & subanguloso & subdiscoidal & pobremente seleccionado & $-1-[0-1]-3$ \\
\hline P5 & $90 \% \mathrm{c}, 10 \% \mathrm{~m}$ & $\begin{array}{l}\text { subredondeado a } \\
\text { subanguloso }\end{array}$ & subdiscoidal & pobremente seleccionado & $-0,5-[-0,5-1]-3.5$ \\
\hline $\mathrm{P} 4$ & $90 \% \mathrm{c}, 10 \% \mathrm{~m}$ & subanguloso & $\begin{array}{l}\text { subdiscoidal a } \\
\text { subprismático }\end{array}$ & pobremente seleccionado & $0,5-[0,5-1,5]-3$ \\
\hline P3 & $80 \%$ c, $20 \% \mathrm{~m}$ & subanguloso & subdiscoidal & pobremente seleccionado & $0,5-[1-2]-2$ \\
\hline $\mathrm{P} 2$ & $80 \% \mathrm{c}, 20 \% \mathrm{~m}$ & $\begin{array}{l}\text { subredondeado a } \\
\text { subanguloso }\end{array}$ & subdiscoidal & $\begin{array}{l}\text { moderadadamente } \\
\text { seleccionado }\end{array}$ & $0,5-[1-2]-2,5$ \\
\hline
\end{tabular}

c: clastos

m: matriz

*Tamaño de grano en escala Phi $(\varnothing)$, indicando: máximo-[moda]-mínimo 